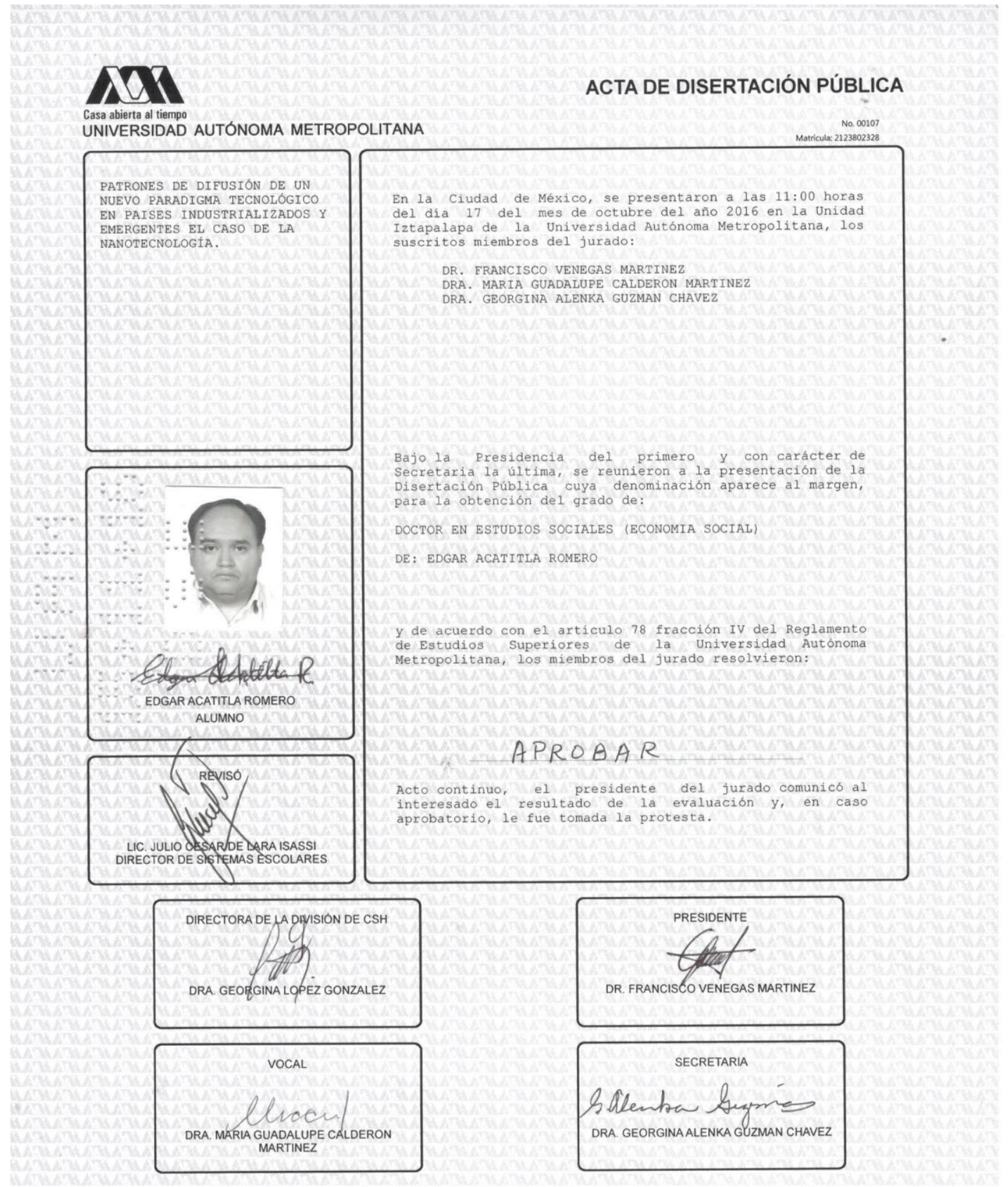




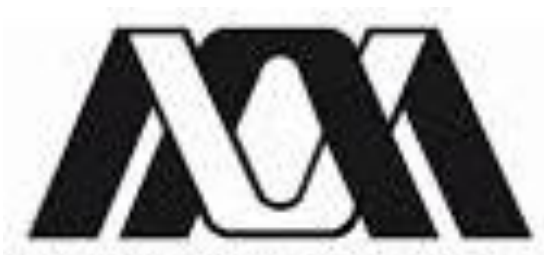

Casa abierta al tiempo

Universidad Autónoma Metropolitana

Unidad Iztapalapa

División de Ciencias Sociales y Humanidades

\section{Patrones de difusión de un nuevo paradigma tecnológico en países industrializados y emergentes. El caso de la nanotecnología}

Tesis que presenta:

EDGAR ACATITLA RoMERo

Para optar por el grado de Doctor en Estudios Sociales Línea Economía Social

Directora: Dra. Alenka Guzmán Chávez Co-Directora: Dra. Flor Brown

México, D. F., octubre 17 de 2016. 
Con todo cariño para mis padres, en especial para mi papá, quien emprendió el viaje a la eternidad, sé que estaría orgulloso. Gracias por su comprensión, respeto y consejos. También para mis hermanos: Paulina, Ernesto y Gastón, Y para mis sobrinos Ernesto y Emmanuel. 


\section{AGRADECIMIENTOS}

Agradezco el apoyo, cariño y paciencia de mi familia y amigos, quienes me dedicaron su tiempo, su paciencia, sus ánimos y sus comentarios para ayudarme a cumplir con este objetivo. A cada uno de ellos, quienes nunca dudaron de mí, mi agradecimiento.

A mis compañeros del Programa quienes con sus comentarios, correcciones en el trabajo y conocimientos contribuyeron, coloquio tras coloquio, al desarrollo y conclusión de la presente investigación.

Agradezco a mi directora y a mi co-directora. A la Dra. Alenka Guzmán Chávez le agradezco el aceptarme bajo su dirección, por orientarme en el interesante tema de la innovación y los paradigmas tecnológicos con su dedicación, amplia experiencia y amplio conocimiento, por proporcionarme pacientemente todo lo necesario para llevar a cabo la investigación, por todo el tiempo dedicado al asesoramiento de mi investigación y por su valiosa dirección en esta tesis doctoral. A mi co-directora la Dra. Flor Brown, igualmente agradezco mucho su paciencia y valioso tiempo que dedicó a mi trabajo, por sus valiosos comentarios y enseñanzas en la no fácil modelización econométrica. A ambas les estoy profundamente agradecido.

Al Dr. Francisco Venegas agradezco la lectura paciente de mi trabajo, sus valiosos comentarios que contribuyeron a mejorar constantemente la investigación, su constante motivación y recomendaciones no solo para concluir el trabajo sino también para publicar los resultados obtenidos.

A la Dra. Guadalupe Calderón le agradezco el buen recibimiento de mi investigación así como su amable disposición y paciencia en la lectura de mi trabajo y por sus valiosos comentarios que ayudaron a mejorarlo hasta la última corrección.

Finalmente, agradezco al Consejo Nacional de Ciencia y Tecnología por su apoyo financiero en mi formación como investigador al proporcionarme la beca con la que tuve la oportunidad de realizar los estudios de doctorado. 


\title{
Patrones de difusión de un nuevo paradigma tecnológico en países industrializados y emergentes. El caso de la nanotecnología
}

\section{Resumen}

El propósito de la tesis doctoral es identificar los factores que determinan los patrones de difusión del nuevo paradigma de nanotecnología en países industrializados y emergentes. Se plantea como hipótesis que la mayor probabilidad de difusión y la velocidad de este nuevo paradigma se asocia con $\mathrm{I}+\mathrm{D}$, redes internacionales de investigación, tamaño de equipos de investigación, extensión de campos tecnológicos, stock de conocimientos científicos y tecnológicos, colaboración entre universidades-firmas y especialización tecnológica del país. Con base en patentes USPTO concedidas en nanotecnología se propone un modelo econométrico binomial negativo. Nuestros resultados confirman la hipótesis pero se encuentran diferentes patrones de innovación y difusión de las nanotecnologías entre países. Estados Unidos tiene el liderazgo y atrás están Japón, Corea del Sur y Alemania. Sin embargo, en China, Rusia, India y Brasil se advierte relativo potencial. Se propone un modelo para probar la hipótesis de convergencia condicional entre países en nanotecnología, encontrándose evidencia positiva.

\begin{abstract}
The main objective of this doctoral thesis is to identify the factors that determine patterns of diffusion of the new nanotechnology paradigm across industrialized and emerging countries. We set out as hypothesis that the greater probability of diffusion and speed of this new technological paradigm is associated with R\&D investments, research teams size, international research network, a huge technological fields spread, universities-firms collaboration, scientific and technological knowledge stock and countries technological specialisation. Based on USPTO patents granted in nanotechnology we propose a negative binomial econometric model. Our outcomes confirm the hypothesis but show different patterns of innovating and diffusing the nanotechnology paradigm across countries. United States has the lidership and behind Japan, South Korea and Germany. However, China, Russia, India and Brazil have a relative potential. These countries announce some relative potential. We propose an econometrical model to test the conditional convergence hypothesis across countries in nanotechnologies, finding a positive evidence.
\end{abstract}




\section{Índice}

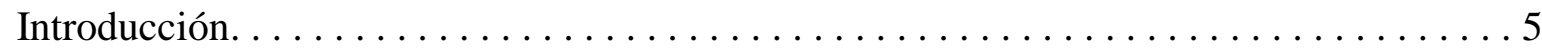

Capítulo 1. Enfoques teóricos de la difusión tecnológica. .....................10

1.1.El concepto de difusión. .....................................

1.2.Enfoques sobre difusión tecnológica. .............................20

1.3.Derechos de Propiedad Intelectual. . . . . . . . . . . . . . . . . . . . 48

1.4.Estudios empíricos sobre la difusión tecnológica. .................. 58

Capítulo 2. Naturaleza de la nanotecnología como nuevo paradigma tecnológico. . . . . 65

2.1. Características de otros paradigmas tecnológicos ocurridos en la historia. .........65

2.2. Características de la nanotecnología como nuevo paradigma tecnológico..........76

Capítulo 3. Patrones de difusión de un nuevo paradigma tecnológico: el caso de la nanotecnología........................................... 87

3.1. Datos y fuentes de información. ............................ 90

3.2. Análisis descriptivo de la difusión del NPN a nivel mundial con base en la población de

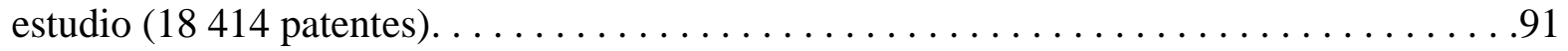

3.3. Diagnóstico de la difusión del NPN utilizando una muestra ( $\mathrm{n}=376$ patentes). . . . . 101

3.4. Propuesta de modelo econométrico. . . . . . . . . . . . . . . . . . . . . . . . . . 139

3.5. Estimación del modelo de conteo . . . . . . . . . . . . . . . . . . . . . . . . . 146

Capítulo 4. ¿Es posible la convergencia tecnológica y de innovación entre países en el nuevo paradigma de nanotecnología . .................................. 180

4.1. Brechas de innovación entre países en nanotecnología. . . . . . . . . . . . . 182

4.2. Convergencia y alcance en el NPN entre países....................... 185

4.3. Algunas sugerencias generales para los países industrializados y emergentes. . . . . 208

Conclusión...........................................216

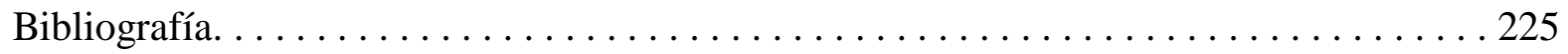




\section{Cuadros}

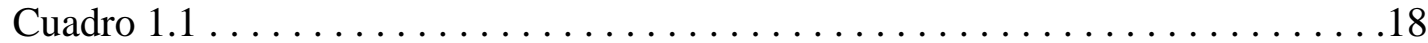

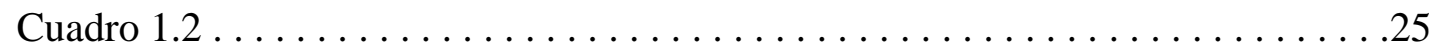

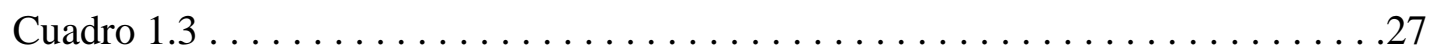

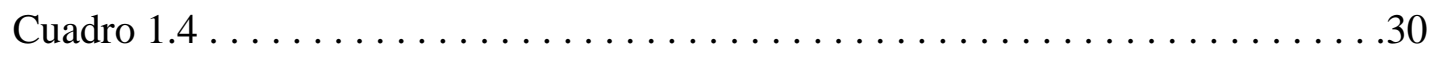

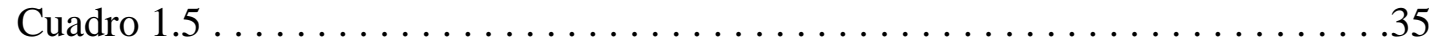

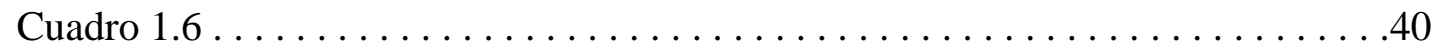

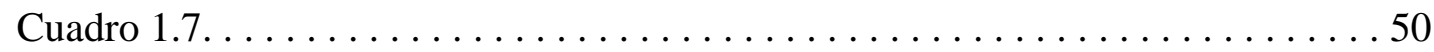

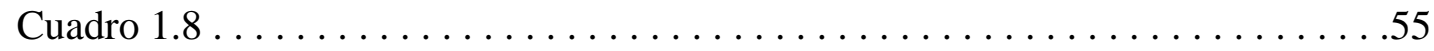

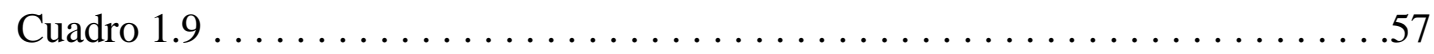

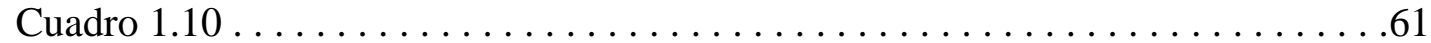

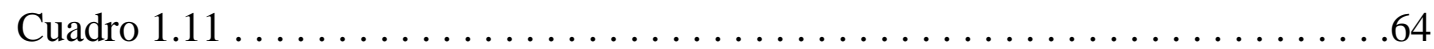

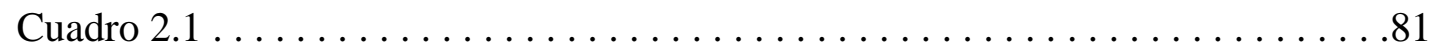

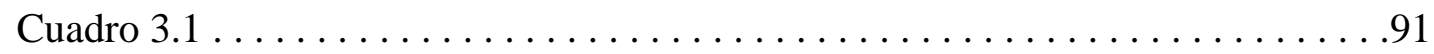

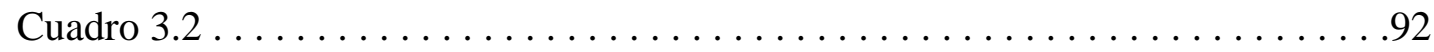

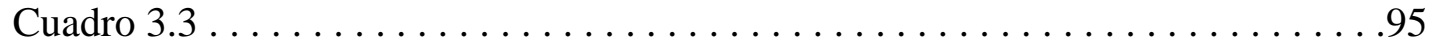

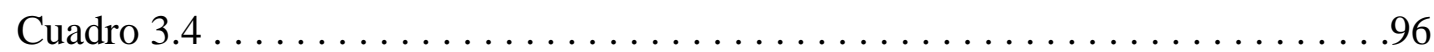

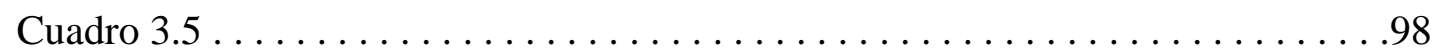

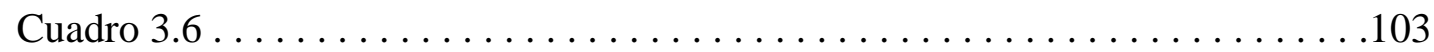

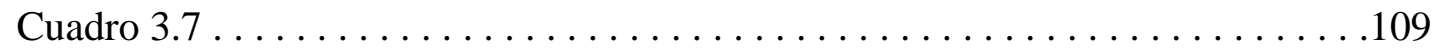

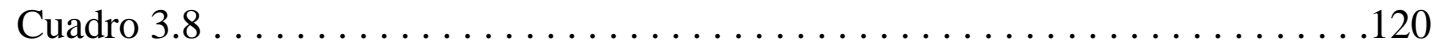

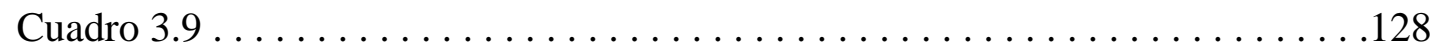

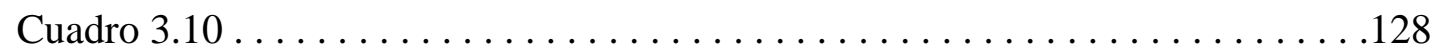

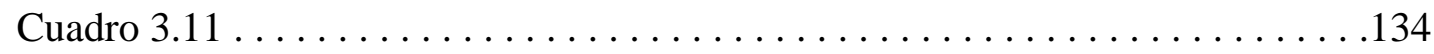

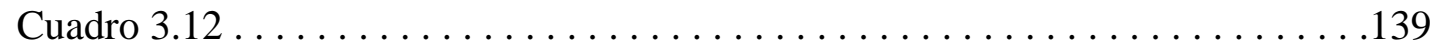

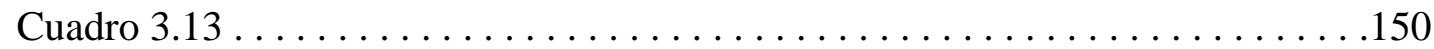

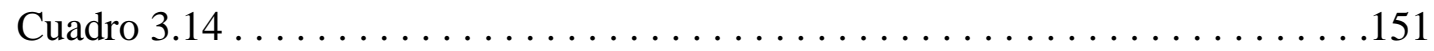

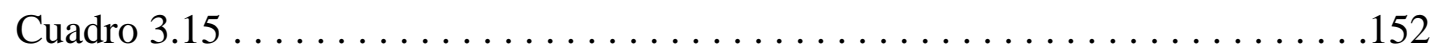

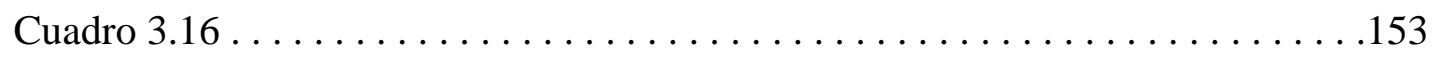

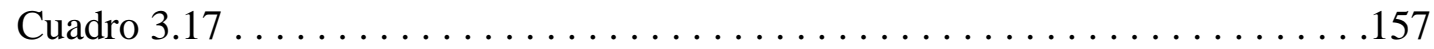

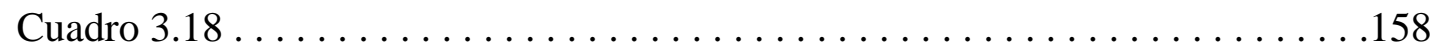

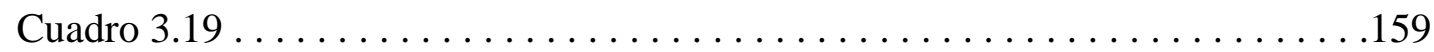

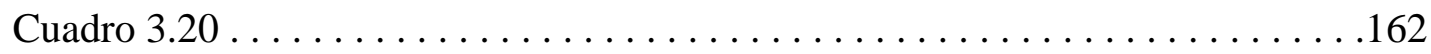

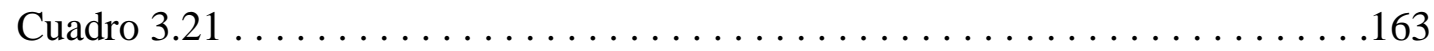

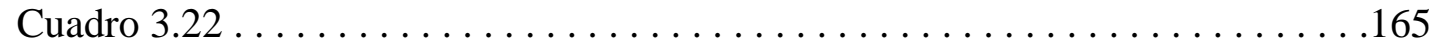

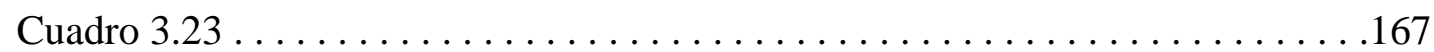

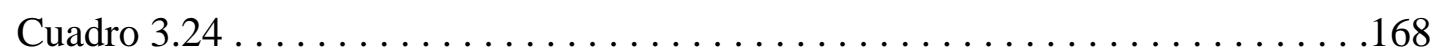

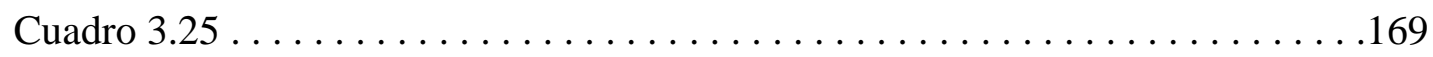

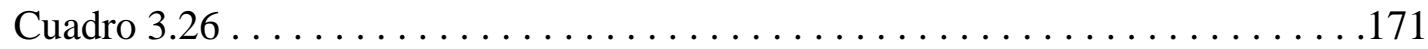

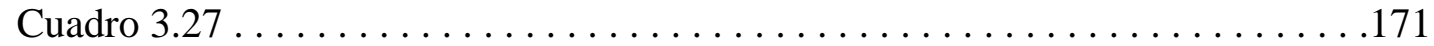

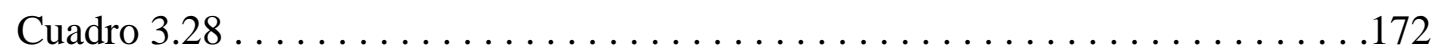

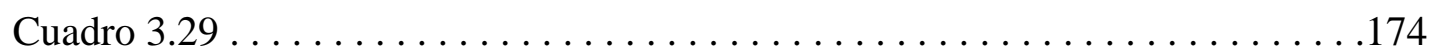

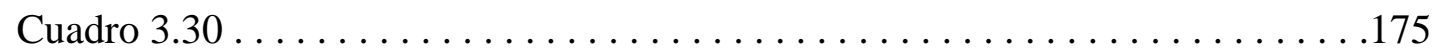

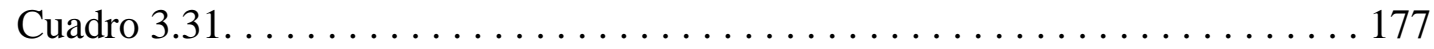

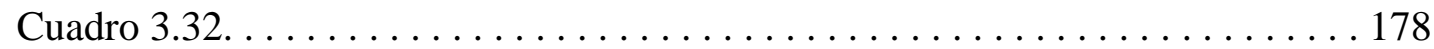




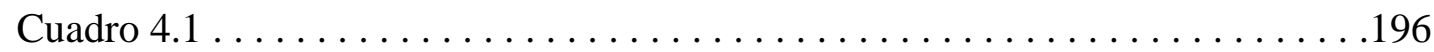

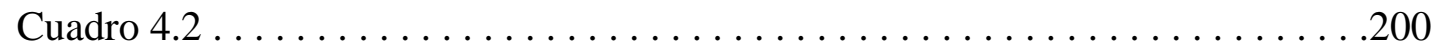

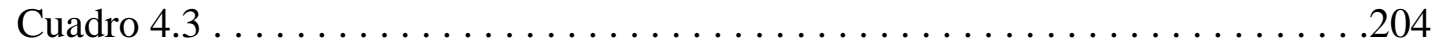

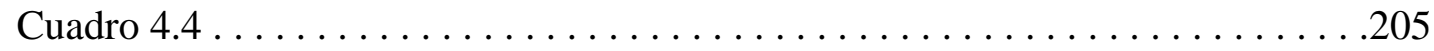

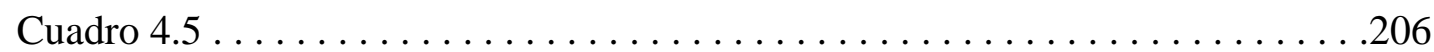

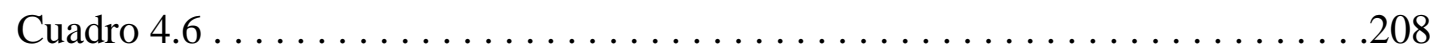

\section{Gráficas}

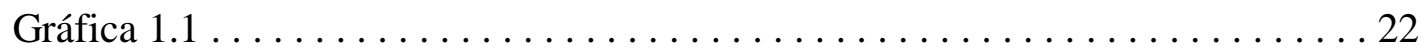

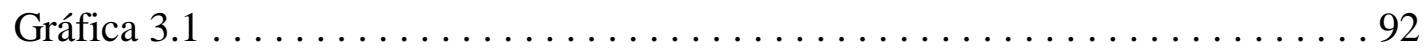

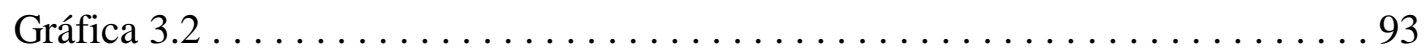

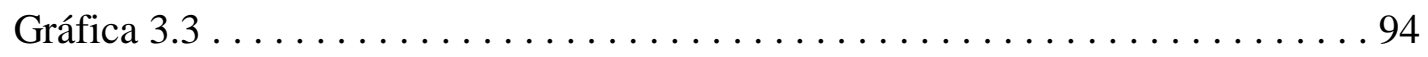

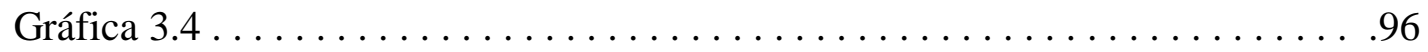

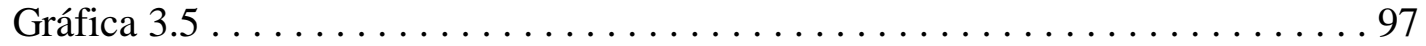

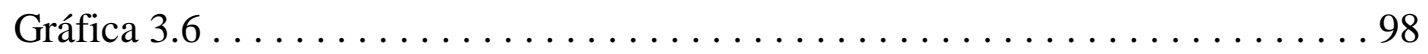

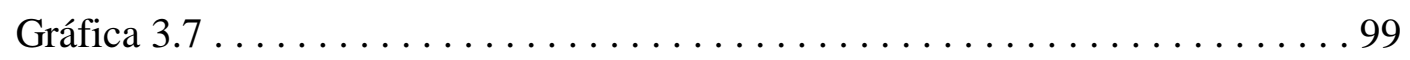

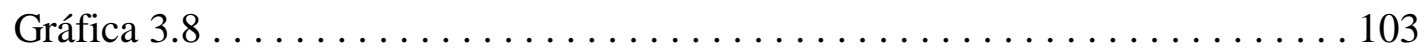

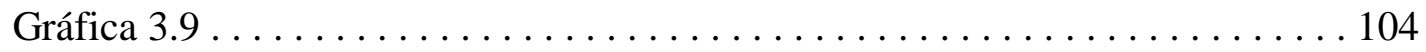

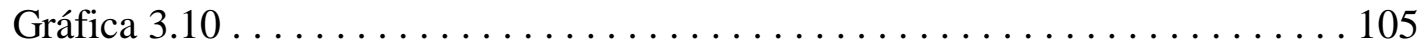

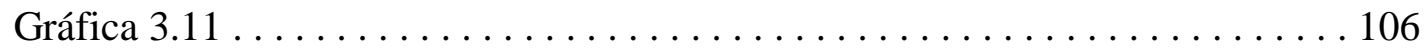

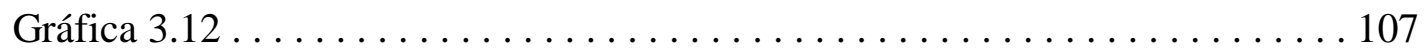

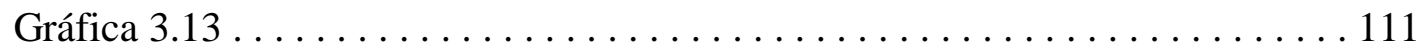

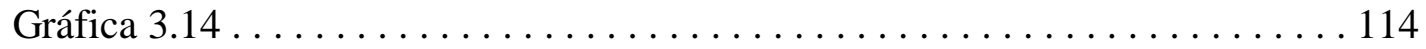

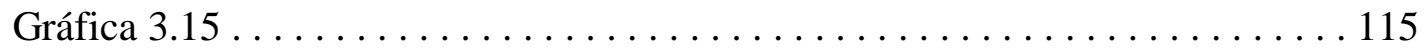

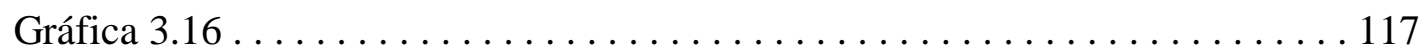

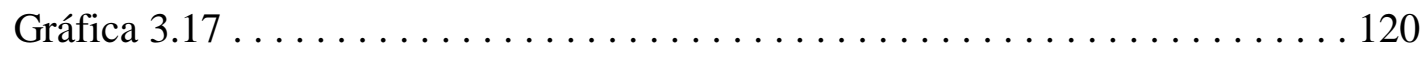

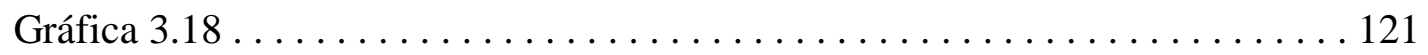

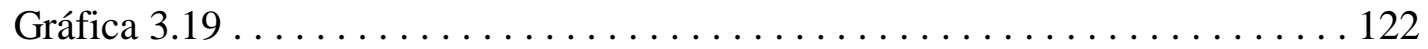

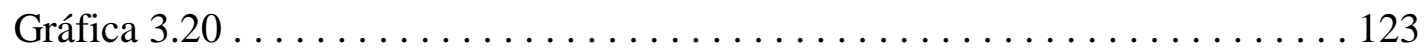

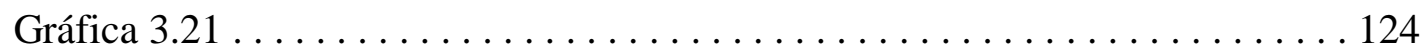

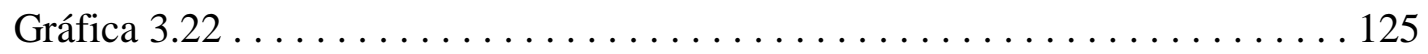

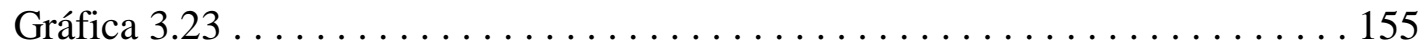

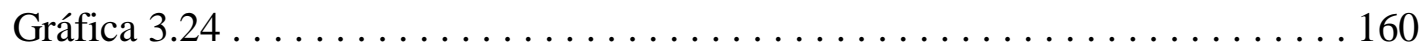

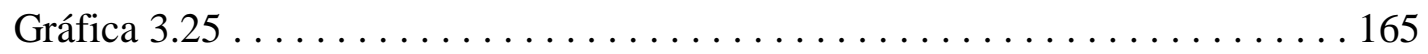

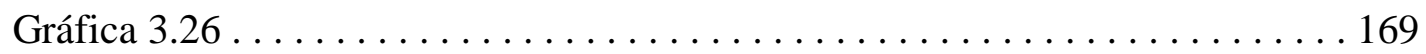

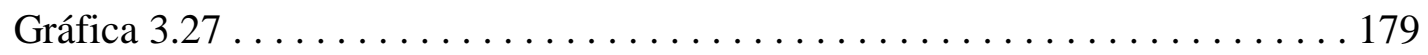

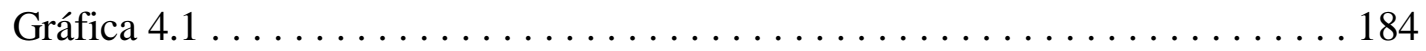

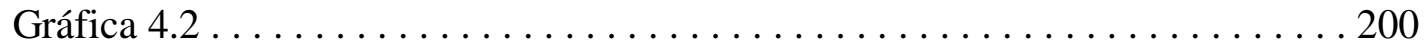




\section{Introducción}

El propósito de la presente investigación doctoral es explicar los diferentes patrones de difusión del nuevo paradigma tecnológico de nanotecnología (NPN) en países industrializados y emergentes en el marco conceptual de la teoría evolucionista ${ }^{1}$. En éste, el desarrollo económico se interpreta como el proceso de acumulación de capacidades tecnológicas y sociales en función del aprovechamiento de ventanas de oportunidad sucesivas y distintas. Las ventanas están dadas por la dinámica económica de los países industrializados y, en particular, por las revoluciones tecnológicas que ocurren en ellos aproximadamente cada medio siglo, las cuales, implican cambios radicales o trastornos en los sistemas de producción, en la productividad, en el consumo e, incluso, en el estilo de vida de la sociedad (Pérez, 2011). Así, la Era del vapor y los ferrocarriles, iniciada en Inglaterra y difundida hacia Europa y Estados Unidos a mediados del siglo XIX, asociada con el uso del hierro, el motor movido por vapor, el telégrafo y los grandes barcos y puertos; o la Era de la informática y las telecomunicaciones, iniciada en los Estados Unidos y difundida hacia Europa y Asia en el último cuarto del siglo $\mathrm{XX}$, asociada con el uso de computadoras, internet, correo electrónico, redes sociales y transporte físico de alta velocidad, son ejemplos de revoluciones tecnológicas que, al expandirse, produjeron trastornos económicos y sociales que delimitaron distintas épocas (Pérez, 2004). A su vez, estas revoluciones son el resultado de la convergencia que puede ocurrir en la difusión de nuevos paradigmas tecnológicos que, al interrelacionarse, constituyen nuevos y amplios sistemas que abarcan una gran cantidad de actividades productivas y de servicios.

Un paradigma tecnológico es el marco común bajo el cual se resuelven los problemas tecnológicos. De esta forma, la importancia de estudiar su difusión reside en el hecho de que, la nueva forma de resolución, podría impactar no solo en variables económicas tales como la productividad y el crecimiento económico de los países sino, además, en los ámbitos institucional, organizacional y cultural; es decir, en la forma de crecer de países o regiones al

\footnotetext{
${ }^{1}$ Teoría "evolucionista" se entiende en el sentido de Giovanni Dosi, es decir, como "una interpretación de los fenómenos económicos basada en la interacción de múltiples agentes heterogéneos - entre ellos, empresas e individuos -, quienes mediante la repetición de un sistema de prueba y error intentan continuamente explorar nuevas tecnologías, nuevas estrategias comportamentales, nuevas formas organizativas". (Dosi, 2009: 33).
} 
convergir con otros paradigmas y convertirse en una revolución tecnológica (Pérez, 2004 y 2009).

El estudio de este fenómeno dinámico es importante, ya que podría ayudar a explicar, desde esta perspectiva, por qué hay países emergentes que no logran cerrar las brechas de crecimiento y de tecnología, tales como los países de América Latina (CEPAL, 2012); o por qué algunos países sí han logrado hacerlo, por ejemplo, Japón después de la Segunda Guerra Mundial y, posteriormente, Corea del Sur (Pérez, 2001). A su vez, la comprensión de este problema puede aportar algo en el diseño de políticas que impulsen el desarrollo económico de los países.

En este contexto, una gran parte de los estudios sobre difusión tecnológica se han centrado en la revolución de las tecnologías de la información y comunicación (TIC). Sin embargo, algunos autores (Guzmán y Toledo, 2009; Hilbert y Cairó, 2008; Delgado, 2011; Takeuchi, 2011; OECD, 2013) prevén la emergencia de un nuevo paradigma tecnológico, la nanotecnología, que podría convergir con otros paradigmas y dar origen a la próxima revolución. De esta forma, cuando se manipula la materia a una escala de átomos y moléculas, emergen fenómenos y propiedades nuevas. Esto es el principio para crear materiales, aparatos y sistemas novedosos y poco costosos con propiedades únicas que permite extender su aplicación a una gama amplia de sectores que van desde la microelectrónica hasta la medicina; por ello, algunos autores hablan de "nanotecnologías" en vez de "nanotecnología" (Guzmán y Toledo, 2009; Delgado, 2011). Su continua y amplia difusión podría tener efectos importantes en el desarrollo de los países en el largo plazo. Por ello, resulta plausible estudiar los patrones que caracterizan su difusión a nivel de sectores tecnológicos y de países.

Así, se plantean las siguientes preguntas de investigación: ¿hacia qué sectores económicos y clases tecnológicas se difunde el NPN y cuál es su importancia económica en países industrializados y emergentes?; ¿Cuál es la probabilidad de que los países difundan y a mayor velocidad el NPN y qué factores son determinantes?; si existen brechas a nivel de actividad inventiva en este paradigma tecnológico ¿los países seguidores podrán alcanzar en algún momento a los países líderes y qué condiciones requieren para lograrlo?

De acuerdo con el marco teórico inscrito en el evolucionismo, sobre el primer problema se espera mostrar que el ámbito de la difusión de la nanotecnología es amplio y va desde los sectores tecnológicos maduros hasta los recientemente considerados nuevos paradigmas 
tecnológicos (TIC y biotecnología). En cuanto al segundo problema, se espera que la mayor probabilidad de difusión y velocidad del NPN se halle asociado a: investigación y desarrollo (I+D); redes internacionales de investigación; tamaño de equipos de investigación; extensión de campos tecnológicos; stock de conocimientos científicos y tecnológicos; colaboración entre universidades-firmas y especialización tecnológica del país. Por último, en cuanto al tercer problema, se espera que la convergencia tecnológica y de innovación en la nanotecnología entre países, en el largo plazo, esté condicionada por la existencia de tres conjuntos de factores reconocidos por algunos autores en las discusiones sobre crecimiento económico y convergencia entre países (Abramovitz, 1986; Rogers, 2003; Manca, 2009; Fagerberg et al., 2012): capacidades tecnológicas y de innovación en el sector, las capacidades de absorción tecnológica a nivel nacional y por las capacidades sociales del país.

Ahora bien, para verificar las hipótesis de trabajo, se requirió de información que capta los aspectos sistémicos de la interacción entre los distintos agentes que participan en la actividad inventiva en nanotecnología. Para ello, se construyeron bases de datos con información proveniente de distintas fuentes: Oficina de Marcas y Patentes de Estados Unidos (USPTO, por sus siglas en inglés) que proporciona la información contenida en cada una de las patentes asignadas en distintos campos tecnológicos. En particular, se tomó una población de estudio de 18414 patentes asignadas en el campo de nanotecnología, clase 977, entre 1974 y 2013. Con base en esta información, se tomaron muestras que se utilizaron como insumo para un modelo econométrico de conteo, el cual, se propuso para estudiar los patrones de difusión del NPN a nivel de sectores tecnológicos y de países. El aporte de esta metodología reside en aprovechar la riqueza de la información contenida en las patentes para hacer una caracterización de los patrones de difusión de un nuevo paradigma a nivel de actividad inventiva, así como para identificar las variables que los determinan. Esto podría representar un aporte en el análisis empírico de la difusión de los paradigmas tecnológicos en el marco de la teoría evolucionista.

La difusión del NPN se estudió en dos escalas: a nivel mundial, para identificar los patrones de difusión del nuevo conocimiento entre los principales sectores tecnológicos y los países que lo generan y difunden hacia el resto del mundo; a nivel de país, para identificar los factores que determinan los patrones de difusión en los países que mayores esfuerzos realizan en la actividad inventiva en este nuevo paradigma: Estados Unidos, Japón, Alemania y Corea 
del Sur. También se realizó un breve análisis de otro grupo de países industrializados (Taiwán, Francia y Canadá) que se identificó debajo del primer grupo en cuanto a los esfuerzos dedicados a nanotecnología. Así mismo, se ubicó un grupo de países emergentes (China, Rusia, India y Brasil), que muestran un importante potencial para desarrollar actividad inventiva en este paradigma.

Se construyó otra base de datos para analizar la posible convergencia entre países en el NPN a nivel de actividad inventiva, considerando indicadores tales como: el capital humano por país, medido con base en el número de investigadores en investigación y desarrollo (I+D) por millón de habitantes; el gasto en investigación y desarrollo por país como porcentaje del PIB, obtenido de los indicadores del Banco Mundial; el índice de desarrollo humano (IDH) por país, proporcionado por el Plan Nacional de Desarrollo de las Naciones Unidas (PNUD); el índice de competitividad global por país, el grado de tecnología por país, el grado de eficiencia de las instituciones públicas por país, el grado de absorción tecnológica de las firmas por país, el grado de estabilidad macroeconómica por país y el grado de corrupción por país, proporcionados en The Global Competitiveness Report del World Economic Forum. Con base en esta información, se propuso un modelo econométrico de corte transversal para estimar la posible convergencia entre países. Este modelo también aporta en el análisis empírico de la difusión de los paradigmas tecnológicos en términos de su posible convergencia.

De esta forma, en el capítulo 1 se expone, a manera de antecedente, un panorama breve sobre los estudios de fenómenos de difusión en física y biología, con el propósito de esclarecer primero el concepto de difusión en general y, posteriormente, el concepto de difusión tecnológica a través de los distintos enfoques teóricos que han abordado el tema en la economía. En el capítulo 2 se caracteriza, con base en un recorrido histórico, la naturaleza de la nanotecnología como un nuevo paradigma tecnológico bajo el marco conceptual de la teoría evolucionista. Para ello, se exponen primero las características de otros paradigmas y, después, se contrastan con las características de la nanotecnología. En el capítulo 3 se estudian los patrones de difusión de este nuevo paradigma a nivel de países y sectores tecnológicos con base en sus características acerca de su naturaleza y velocidad de difusión, señalando tendencias y perspectivas. En el capítulo 4 se presenta un análisis de la posible convergencia entre países líderes y seguidores en el NPN. Por último, se emiten algunas conclusiones generales de la investigación. 


\section{Capítulo 1}

\section{Enfoques teóricos de la difusión tecnológica}

El propósito del presente capítulo es proporcionar el marco teórico de la investigación, así como exponer los fundamentos de la metodología que se usará en los capítulos 3 y 4 para estimar la difusión de los paradigmas tecnológicos, al igual que su convergencia a través del uso de patentes y datos de patentes, en particular, el uso de citas hacia adelante. Así, en el apartado dedicado al tema de propiedad intelectual se presenta la discusión del sistema de patentes en dos sentidos: i) como factor que influye en la difusión de tecnología; y ii) como indicador para estimar el cambio tecnológico y su difusión. De esta forma, se expone primero el concepto de difusión en general y los distintos significados que adopta en aquellas áreas de la ciencia donde se iniciaron los estudios sobre fenómenos de difusión: física, biología y posteriormente economía ${ }^{2}$. Cabe señalar que el objetivo de realizar un recorrido en estas áreas de la ciencia no solo obedece a la idea de presentar los estudios que sirvieron de antecedente al análisis de la difusión tecnológica en economía sino, principalmente, para ubicar la importancia del objeto de estudio de la presente investigación. En cuanto al significado del concepto difusión tecnológica, cabe hacer notar que, a diferencia del concepto de difusión adoptado en otras áreas de la ciencia, en economía existe una variedad de definiciones proporcionadas por distintos autores ubicados en distintas vertientes teóricas, al igual que por distintas instituciones. Sin embargo, es posible distinguir dos conceptos asociados con dos grandes enfoques teóricos, referidos en la literatura sobre el tema como enfoque estándar (Vence, 1995) y enfoque evolucionista (Dosi, 1982 y Vence, 1995). Una vez que se presenta la discusión teórica sobre la difusión tecnológica, se adopta el enfoque evolucionista en función de las limitaciones que presenta el enfoque estándar en la explicación del cambio tecnológico y sus implicaciones en la economía y en la sociedad.

Ahora bien, en el marco conceptual del enfoque evolucionista se pone énfasis en el concepto de difusión de paradigmas tecnológicos debido a que permite explicar cambios

\footnotetext{
${ }^{2}$ Desde el punto de vista de la filosofía de la ciencia no se puede referir a la economía como un "área de la ciencia" en el mismo sentido que la física o la biología. Considerando esta observación y con sus debidas reservas, el análisis solo se avoca a resaltar el significado del término difusión en cada una de estas ciencias.
} 
tecnológicos de largo alcance con efectos que van más allá de la economía. Cabe señalar que un análisis de la importancia de la nanotecnología, más allá de los estudios sobre campos tecnológicos, requiere del concepto de difusión de paradigmas tecnológicos propuesto en el marco de este enfoque porque considera las posibles implicaciones sociales que resultan de la conformación de revoluciones tecnológicas que emergen de la difusión y convergencia de nuevos paradigmas tecnológicos. Sin embargo, no existe una metodología definida para estudiar empíricamente los patrones de difusión que pueden seguir éstos. En el presente trabajo se propone una metodología basada en datos de patentes, principalmente por dos motivos: i) las patentes son un reflejo, por lo menos en parte, de la actividad inventiva que se realiza en una economía, por lo que representan una fuente rica de información que puede ayudar para aproximarse en la comprensión de las posibles pautas que siguen los paradigmas tecnológicos; ii) porque el sistema de propiedad intelectual y, en particular, el sistema de patentes es un canal a través del cual se difunde el conocimiento tecnológico ofreciendo, a cambio, incentivos económicos que motivan la actividad inventiva. Así, se dedica un apartado para caracterizar los sistemas de patentes, al igual que los alcances y límites de la información que proporcionan las patentes en el estudio del cambio tecnológico y, específicamente, de la difusión tecnológica y sus posibles implicaciones en la economía y en la sociedad.

Este capítulo se organiza de la siguiente manera: en el primer apartado se discute el concepto de difusión en general; en el segundo apartado, se exponen los conceptos de difusión en física, biología y economía; en el tercer apartado, se presentan los enfoques sobre difusión tecnológica (estándar y evolucionista), después se discute el concepto de paradigma tecnológico, poniendo énfasis en su difusión, también se expone la hipótesis del catch-up tecnológico, luego se dedica un apartado para discutir la importancia de los sistemas de patentes y la información contenida en éstas y, por último, se revisan los trabajos empíricos sobre difusión de tecnología. 


\subsection{El concepto de difusión}

El término "difusión” adquiere en diversos contextos distintos significados que se usan para hacer referencia a una variedad de fenómenos; intentaremos revisar su relación de significado, por lo menos, en tres disciplinas: física, biología y economía. Desde un punto de vista histórico, los primeros estudios de fenómenos de difusión fueron realizados en la física, posteriormente en la biología y luego se extendieron a la economía. A continuación se revisarán las principales características de estos estudios en cada una de estas disciplinas.

\section{El concepto de difusión en física}

En física se estudia un conjunto de fenómenos conocidos como fenómenos de transporte (viscosidad, propagación del calor y difusión de masa). En particular, se le llama difusión al fenómeno donde hay transporte de materia (Skiba, 2009). En seguida se explica el significado de cada uno de ellos.

La viscosidad es la segunda magnitud más importante que caracteriza el comportamiento de los fluidos. La viscosidad relaciona el esfuerzo o tensión local en un fluido en movimiento con la velocidad de deformación de las partículas fluidas. Cuando un fluido se mueve con respecto a un sólido o cuando dos fluidos se mueven uno con respecto al otro, se origina una fuerza de fricción en la superficie de contacto en la dirección opuesta al movimiento. La viscosidad es una medida cuantitativa de la resistencia de un fluido. Concretamente, la viscosidad determina la velocidad de deformación del fluido cuando se le aplica un esfuerzo cortante dado. Por ejemplo, podemos movernos fácilmente a través del aire, que tiene una viscosidad muy baja. El movimiento es más difícil en el agua, con una viscosidad cincuenta veces mayor que la del aire, sin embargo, sería más difícil moverse en aceite SAE 30 (la norma SAE mide la viscosidad de aceites para motores de combustión interna), ya que es trescientas veces más viscoso que el agua. Así, cada fluido posee una propiedad que caracteriza su resistencia al movimiento o fluidez, la cual, se llama viscosidad. 
La viscosidad es una propiedad importante en el estudio de los flujos, ya que representa un factor para explicar por qué se genera la turbulencia. Se estudia con base en modelos matemáticos. Así, hay fluidos comunes como el agua, el aceite y el aire que presentan una relación lineal entre el esfuerzo aplicado y la velocidad de la deformación resultante, es decir:

$$
\tau \alpha \frac{\partial \theta}{\partial t}
$$

donde: $\tau$ representa el esfuerzo cortante en un plano; $\propto$ es la "constante de proporcionalidad"; $\partial \theta$ es el ángulo de deformación del fluido; y $\partial \mathrm{t}$ son los cambios en el tiempo. $\partial \theta / \partial \mathrm{t}$ es la velocidad a la que se mueve la superficie superior del fluido.

En el caso límite de variaciones infinitesimales, se obtiene una relación entre la velocidad de deformación y el gradiente de la velocidad:

$$
\frac{\partial \theta}{\partial t}=\frac{\partial u}{\partial y}
$$

donde: $\delta$ u es la velocidad a la que se mueve la superficie superior del fluido; y $\delta$ y es la velocidad a la que se mueve la superficie inferior del fluido.

La constante de proporcionalidad $\propto$ es el coeficiente de viscosidad $\mu$, de esta forma:

$$
\tau=\mu \frac{\partial \theta}{\partial t}=\mu \frac{\partial u}{\partial y}
$$

la cual, es la ley de viscosidad de Newton.

Lo más relevante es señalar que, en el estudio de la dinámica de fluidos, se pone atención en la velocidad de deformación del fluido y en la forma en cómo se distribuye esta velocidad. El aire, agua y petróleo siguen esta ley, sin embargo, existen muchos fluidos que no la siguen, por ejemplo, pinturas al óleo, pastas, jaleas, espumas, etcétera, en estos casos, se usa una ecuación generalizada de la anterior:

$$
\tau=k \frac{\partial u}{\partial y}^{n}
$$

Esta ecuación puede representar los siguientes casos: si $n$ es mayor que 1, entonces el fluido es dilatante, es decir, que la resistencia a la deformación en tal fluido aumenta al incrementar el esfuerzo cortante. Si $n$ es menor que 1, entonces el fluido es pseudo-plástico. La resistencia a la deformación disminuye al aumentar el esfuerzo. Por último, si $n$ es igual a 1 , entonces el fluido se comporta de acuerdo con la ley de viscosidad de Newton. 
En suma, el término viscosidad se usa en física en dos sentidos: para referirse a la propiedad de resistencia al movimiento que tienen los fluidos y como una medida cuantitativa de esta propiedad. Se estudia con base en la ley de viscosidad de Newton.

Otro fenómeno de transporte es la propagación del calor. Este fenómeno se estudia a través de la llamada "ecuación del calor", la cual, suponiendo que no hay fuentes de energía térmica y que las propiedades térmicas del material son constantes, tiene la siguiente forma:

$$
\frac{\partial u}{\partial t}=k \frac{\partial^{2} u}{\partial x^{2}}
$$

donde $u$ es la temperatura, $x$ es la unidad de área, $t$ representa el tiempo y $k$ es una constante que resulta de:

$$
k=\frac{K o}{c \rho}
$$

donde $K o$ es el "coeficiente de proporcionalidad" y mide la capacidad del material para conducir el calor y se le conoce como conductividad térmica; $c$ es el calor específico y está en función de la unidad de área y $\rho$ es la densidad de masa.

De esta forma, si la energía térmica está inicialmente concentrada en algún lugar, la ecuación del calor describirá cómo ésta se dispersa, es decir, cómo se difunde el calor. Es importante señalar que la ecuación del calor representa una ecuación diferencial en derivadas parciales, lo que significa que no solo describe la dinámica de la difusión térmica en el tiempo sino también en el espacio (Skiba, 2009 y Mijáilov, 1978).

Otro fenómeno de transporte es la difusión de masa y se define como: el proceso por el cual, la materia se propaga de una parte de una región en un sistema, a otra región del mismo (Cranck, 1964). Se produce, básicamente, por dos mecanismos: la difusión molecular o browniana y la difusión turbulenta. La difusión browniana es aquella en la cual las partículas suspendidas en un fluido experimentan un movimiento aleatorio producido por colisiones entre ellas (este fenómeno se conoce como movimiento browniano). La difusión turbulenta incluye procesos inducidos por agentes externos al fluido, los cuales, entregando energía de alguna forma al fluido, lo vuelven homogéneo, esto hace que en la difusión turbulenta las partículas se difundan más rápidamente que en la difusión browniana.

Ahora bien, como no todos los procesos de difusión ocurren a la misma velocidad, se define un número llamado coeficiente de difusión, usualmente denotado por $D$, que mide la velocidad de la difusión de una sustancia en otra. 
Las leyes que rigen los procesos de difusión de masa son: i) la ley de conservación de masa; y ii) la ley de Fick.

En general, se observa que en el estudio de estos fenómenos físicos de difusión se pone atención a la velocidad de difusión y a los factores que la determinan.

\section{El concepto de difusión en biología}

En biología el término "difusión” se usa en dos contextos: biología celular y epidemiología. En el primero, alude al proceso a través del cual se produce un flujo neto de moléculas a través de una membrana celular permeable, sin aporte externo de energía. En epidemiología "difusión" se entiende como el proceso de extensión de una enfermedad por contagio entre los elementos de una población (Esteva, 2002). Cabe señalar que este último significado inspiró a los estudios pioneros de difusión en economía y, en particular, de difusión tecnológica. Por este motivo, merece una explicación un poco más amplia.

Los primeros estudios de difusión de enfermedades por contagio se remontan al siglo XIX con Louis Pasteur (1822-1895), Robert Koch (1843-1910), entre otros. Los primeros intentos de modelación matemática fueron hechos por Daniel Bernoulli en 1760 y el primer estudio al respecto publicado por William Farr (1840). Sin embargo, fueron los trabajos de William O. Kermack y Anderson Grey McKendrick entre 1927 y 1939 los que dieron origen a la epidemiología matemática.

El modelo básico de Kermack y McKendrick (1927) divide a la población total en diferentes clases: S (susceptibles); I (infecciosos) y Z (eliminados). Para describir la dinámica de la enfermedad basta conocer el número de individuos de estas clases en el tiempo $t$, lo cual, se denota como $\mathrm{S}(\mathrm{t}), \mathrm{I}(\mathrm{t})$ y $\mathrm{Z}(\mathrm{t})$. Estos valores dependen del flujo de una clase epidemiológica a otra, para ello se supone lo siguiente:

i) La población a considerar es constante y de tamaño igual a $\mathrm{N}$

ii) La población es cerrada, es decir, no hay inmigración y emigración

iii) La población está homogéneamente mezclada

iv) El periodo de latencia desde el momento de la exposición hasta aquel en que el individuo comienza a ser infeccioso es lo suficientemente pequeño como para tomarlo 
en cuenta; es decir, un individuo susceptible que contrae la enfermedad se convierte inmediatamente en infeccioso

v) Los infecciosos abandonan su clase para formar parte de los eliminados a una tasa per cápita constante igual a $\gamma$.

El sistema de ecuaciones diferenciales ordinarias más simple del modelo de Kermack y McKendrick (1927) es de la siguiente forma:

$$
\begin{aligned}
& \frac{d S}{d t}=-\beta S I \\
& \frac{d I}{d t}=\beta S I-\gamma I \\
& \frac{d Z}{d t}=\gamma I
\end{aligned}
$$

donde: $\gamma$ y $\beta$ son parámetros sobre la velocidad de difusión de una enfermedad a través de contagios.

La caracterización global de las enfermedades depende de dos aspectos: el número reproductivo básico y el umbral. El primero, denotado comúnmente por $R o$, se define como el número promedio de infecciones secundarias producidas por un individuo durante su periodo infeccioso, y los umbrales son valores críticos de variables como el número reproductivo básico o la densidad de población susceptible.

Nuevamente, el estudio de difusión de enfermedades en una población dada se centra en los factores que afectan su velocidad de difusión ya que dicho conocimiento permite diseñar políticas de prevención y vacunación. Cabe señalar que el modelo de Kermack y McKendrick es la base para el estudio de la difusión de enfermedades en la actualidad (Esteva, 2002). El concepto de difusión en economía

El término "difusión" en economía se usa en el contexto específico del problema del cambio tecnológico y las implicaciones que éste tiene sobre el crecimiento y desarrollo económicos. Se halla asociado, por lo general, con otros dos términos: "invención" e "innovación". El 
encadenamiento de los tres términos describe el proceso que, en conjunto, representa el cambio tecnológico.

Joseph Schumpeter (1939) distinguió los significados de "invención” e "innovación”. La primera hace referencia al descubrimiento de ideas creativas en el contexto de la ciencia o del trabajo técnico. En cambio, la segunda se refiere a nuevas combinaciones productivas de materiales y procesos productivos y pueden ser sobre nuevos productos, nuevos métodos productivos, nuevas formas de organización, nuevas fuentes de materias primas y nuevos mercados. De acuerdo con Schumpeter (1939), se trata de una actividad realizada por los empresarios con el fin de colocar a la empresa en mejor situación de competencia. Por último, la "difusión tecnológica" se refiere, en general, al proceso de propagación de las invenciones e innovaciones tecnológicas. Así, este fenómeno se puede estudiar en dos niveles: a nivel de la actividad inventiva y a nivel de sus aplicaciones y usos comerciales (innovaciones).

A su vez, el concepto de difusión tecnológica adopta un significado específico dependiendo del enfoque teórico metodológico bajo el que se inscribe. En la literatura sobre el tema se reconocen dos grandes enfoques (Vence, 1995): el estándar o epidemiológico y el evolucionista.

La difusión tecnológica bajo el enfoque estándar o epidemiológico se caracteriza por tomar como modelo de referencia los estudios sobre difusión de enfermedades por contagio (de ahí que también se le conozca como epidemiológico) para estudiar la difusión de innovaciones tecnológicas a nivel de industrias (Vence, 1995). En este contexto, la difusión tecnológica se entiende como la propagación de innovaciones tecnológicas en el mercado a través de la imitación (Gomulka, 1990 y Vence, 1995). Cabe señalar que, al interior de este enfoque, la discusión reside sobre los factores que afectan la tasa de imitación. En cambio, bajo el enfoque evolucionista el concepto de "difusión" no hace referencia a difusión de innovaciones tecnológicas sino a "difusión de paradigmas tecnológicos", los cuales son el marco común bajo el cual se llevan a cabo las innovaciones tecnológicas. Se trata de un concepto más amplio donde intervienen no solo factores tecnológicos sino, económicos y sociales en la selección y difusión de un nuevo paradigma tecnológico.

Las diferencias y semejanzas del concepto de difusión en distintas disciplinas se presentan en el cuadro 1.1 . 
Cuadro 1.1. Significado del concepto difusión en distintos contextos

\begin{tabular}{|c|c|c|c|}
\hline Contexto & Significado & $\begin{array}{l}\text { Características } \\
\text { Comunes }\end{array}$ & Diferencias \\
\hline Física & $\begin{array}{l}\text { Forma parte del estudio de } \\
\text { fenómenos de transporte } \\
\text { (viscosidad, propagación del } \\
\text { calor y difusión de masa). En } \\
\text { particular, se le llama difusión } \\
\text { al fenómeno donde hay } \\
\text { transporte de materia (Skiba, } \\
\text { 2009). }\end{array}$ & \multirow{3}{*}{$\begin{array}{l}\text { Los estudios } \\
\text { sobre difusión } \\
\text { en distintas } \\
\text { disciplinas, } \\
\text { ponen énfasis } \\
\text { en estimar la } \\
\text { velocidad de } \\
\text { difusión y } \\
\text { explicar los } \\
\text { factores que } \\
\text { influyen en ésta. }\end{array}$} & \multirow{3}{*}{$\begin{array}{l}\text { En física y } \\
\text { biología, los } \\
\text { factores que } \\
\text { influyen en la } \\
\text { velocidad de } \\
\text { difusión están } \\
\text { regidos por } \\
\text { leyes precisas: } \\
\text { la de } \\
\text { conservación } \\
\text { de masa y la } \\
\text { ley de Fick. En } \\
\text { economía el } \\
\text { problema es } \\
\text { multifactorial. }\end{array}$} \\
\hline Biología & $\begin{array}{l}\text { Tiene dos usos: } \\
\text { *Biología celular. Se refiere al } \\
\text { proceso por el cual se produce } \\
\text { un flujo neto de moléculas a } \\
\text { través de una membrana } \\
\text { celular permeable, sin aporte } \\
\text { externo de energía. } \\
\text { *Epidemiología. Se entiende } \\
\text { como el proceso de extensión } \\
\text { de una enfermedad por } \\
\text { contagio entre los elementos } \\
\text { de una población (Esteva, } \\
\text { 2002). }\end{array}$ & & \\
\hline Economía & $\begin{array}{l}\text { Tiene dos usos: } \\
\text { *Enfoque estándar. Se } \\
\text { entiende como la propagación } \\
\text { de innovaciones tecnológicas } \\
\text { en el mercado, a través de } \\
\text { imitación (Vence, } 1995 \text { y } \\
\text { Gomulka, 1990). } \\
\text { *Enfoque evolucionista. Es la } \\
\text { propagación de paradigmas } \\
\text { tecnológicos, es decir, del } \\
\text { marco común bajo el cual se } \\
\text { llevan a cabo las innovaciones } \\
\text { tecnológicas. Intervienen } \\
\text { factores tecnológicos } \\
\text { socioeconómicos en } \\
\text { selección y difusión del } \\
\text { paradigma (Dosi, 1982). }\end{array}$ & & \\
\hline
\end{tabular}

Fuente: elaboración propia con base en Skiba (2009); Vence (1995); Gomulka (1990); Esteva (2002); Dosi (1982).

Como se observa en el Cuadro 1.1, aunque existen diferencias en el significado específico del término “difusión” según el contexto en el cual se usa, subyace un significado común entendido como proceso de propagación y divulgación. Otro aspecto común entre los 
diferentes significados de "difusión" es que los estudios sobre fenómenos de difusión en distintas disciplinas ponen énfasis no solo en estimar o medir la velocidad de difusión sino también en conocer los factores que influyen en dicha velocidad (Gomulka, 1990). En cuanto a sus diferencias, en física y biología se observa que los factores que influyen en la velocidad de difusión están regidos por leyes precisas: la ley de conservación de masa y la ley de Fick. En economía, sin embargo, se acepta que los factores que pueden influir en la velocidad de difusión de tecnología son diversos: tecnológicos, económicos y sociales.

Ahora bien, debido a que la discusión teórica sobre difusión tecnológica se ubica a nivel de los distintos enfoques teórico-metodológicos, en el siguiente apartado se desarrolla esta discusión. 


\subsection{Enfoques sobre difusión tecnológica}

La importancia que tiene el estudio del fenómeno de difusión tecnológica reside en los posibles efectos que puede tener en los niveles micro y macroeconómico. A nivel microeconómico su importancia radica en estimar los efectos de la adopción y propagación de innovaciones tecnológicas sobre los niveles de productividad de las firmas y el monto de ganancias. A nivel macroeconómico, la importancia radica en medir sus efectos sobre el crecimiento económico de un país así como el bienestar de su población. Esto ha llevado a distintos autores e instituciones económicas a definir el concepto de "difusión tecnológica". Por ejemplo Gomulka (1990), autor pionero en el estudio de este tema reconoce que el concepto de “difusión" se refiere a procesos de propagación en física, cuando se habla de partículas, de ideas o de patrones culturales en antropología, o de productos o métodos empleados en la manufactura cuando se habla de "difusión tecnológica” en economía (Gomulka, 1990). Este último concepto contrasta con la definición proporcionada por el Manual de Oslo donde se establece que: "Se entiende por difusión el modo mediante el cual las innovaciones se extienden a través de los circuitos comerciales, o cualquier otro, a los diferentes consumidores, países, regiones, sectores, mercados y empresas, después de su primera introducción" (Manual de Oslo, 2005: 24).

Se observa que, a diferencia de la definición proporcionada por Gomulka (1990), la del Manual de Oslo pone énfasis en los canales de difusión y en el espacio donde se lleva a cabo ésta. Sin embargo, entre ambas definiciones existen otras que se inscriben en discusiones de carácter teórico-metodológicas. Debido a que estas otras discusiones se ubican en el corazón de las teorías sobre el cambio tecnológico a través de dos grandes enfoques, el estándar y el evolucionista (Vence; 1995), se recuperan a continuación sus principales rasgos característicos. 


\section{La difusión tecnológica bajo el enfoque estándar}

El estudio de la difusión de innovaciones bajo el enfoque estándar o epidemiológico (por estar inspirado en los estudios sobre epidemias ya mencionados) se caracteriza por partir de los siguientes supuestos:

i) El número potencial de adoptantes es igual al total de la población (número total de empresas o industrias)

ii) Los conocimientos tecnológicos se difunden uniforme y homogéneamente;

iii) La propagación de innovaciones ocurre solamente por el contacto entre empresas o industrias

iv) Bajo los supuestos anteriores se plantean modelos matemáticos deterministas usados en el estudio de la difusión de enfermedades en una población dada, de ahí que a este enfoque se le conozca también como enfoque epidemiológico.

El modelo matemático más sencillo en el enfoque estándar es la ecuación logística:

$$
\frac{d x}{d t}=\beta x(1-x)
$$

donde: $x$ representa la cuota de mercado; $\beta$ es la velocidad de difusión de una innovación tecnológica; $(1-x)$ es la cuota de mercado que potencialmente puede adoptar la innovación; $t$ representa el tiempo.

La ecuación diferencial anterior tiene solución analítica y es de la forma:

$$
x t=\frac{1}{\left[1+e^{-\beta t-t 0}\right]}
$$

donde to representa el valor de la condición inicial.

Su dinámica a través del tiempo se muestra en la siguiente gráfica: 
Gráfica 1.1. Evolución de la cuota de mercado a través del tiempo para valores particulares de $\beta=0.30$ y $t=-20$ a 20 . Se trata de un comportamiento en forma de " $s$ " alargada simétrica.

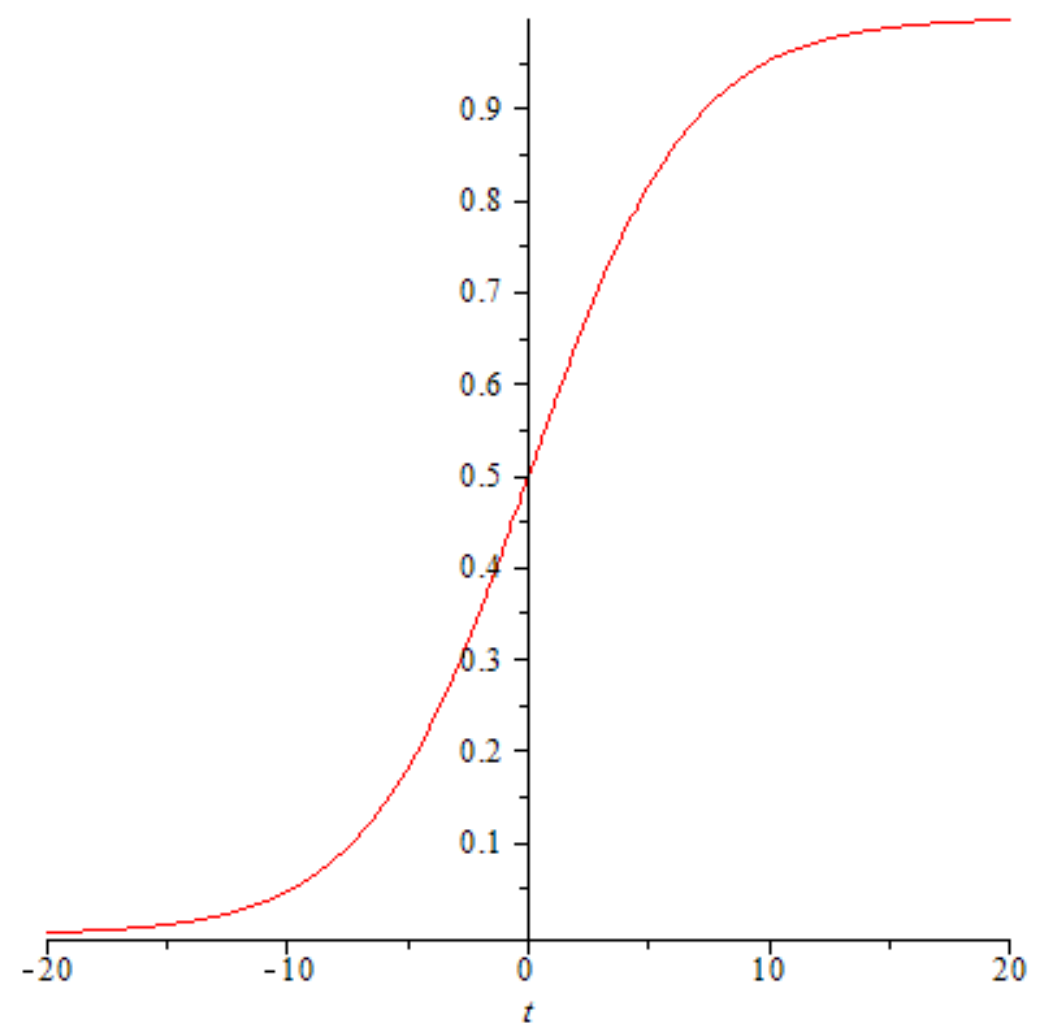

Fuente: elaboración propia con base en el programa de cómputo Matlab.

Los trabajos pioneros de Griliches (1957), Mansfield (1961) y Davies (1979) fundaron el enfoque estándar y, en sus trabajos, emplearon el modelo logístico.

En Griliches (1960), el autor se propuso explicar las diferencias entre las áreas en cuanto al patrón de difusión del maíz híbrido en el sector agrícola de Estados Unidos entre 1933 y 1958. Ya en un trabajo anterior, Griliches (1957) había demostrado que los datos se ajustaban bien al modelo logístico. En un estudio de 1960 se confirmó este resultado: "Casi en todas partes el desarrollo siguió una curva de crecimiento en forma de S" (Griliches, 1960: 197).

Debido a la evidencia mostrada por otros estudios que confirmaban el mismo patrón de difusión en medicamentos nuevos, uso de maquinaria y equipo, así como en el uso de 
productos nuevos en distintos sectores, Griliches (1960) sostuvo que el patrón del cambio técnico tiene forma de "S".

Este patrón que sigue la difusión de innovaciones tecnológicas, se puede resumir en tres parámetros: la fecha de inicio (origen), la velocidad relativa (pendiente) y el nivel final (tope). Así, la problemática fue planteada por Griliches (1960) de la siguiente forma: ¿qué determina las diferencias entre las áreas en cuanto al origen, la pendiente y el tope? En particular, sobre el maíz híbrido: ¿por qué algunas áreas se adelantaron a otras en la introducción del maíz híbrido?, ¿por qué el maíz híbrido se difundió más de prisa en algunas áreas que en otras?, ¿por qué algunas áreas alcanzaron mayores niveles de equilibrio que otras?

En cuanto al origen, señala Griliches que la fecha en que empezaron a producirse cantidades comerciales de los híbridos superiores en un área dada representó uno de los factores determinantes de su desarrollo. De esta forma, la condición inicial para que se llevara a cabo la difusión del maíz híbrido fue del 10\% de la superficie total sembrada, ya que en dicho nivel se contaba con maíz híbrido suficiente para fines comerciales. La velocidad de difusión de la innovación, en este caso el maíz híbrido, depende de los montos de ganancia que los agricultores esperan obtener por cambiar su producción hacia los híbridos.

Un resultado general de Griliches es que el maíz híbrido fue una innovación más rentable en áreas "buenas" que en las "malas". Por lo tanto, concluye que es posible que el cambio tecnológico tienda a acentuar las disparidades regionales en cuanto a los niveles de ingreso y las tasas de crecimiento.

En Mansfield (1961), el autor se planteó la siguiente pregunta: ¿con qué rapidez usarán otras empresas de la industria una innovación una vez que fue introducida por una empresa? Para responder esta pregunta, el autor se apoyó, al igual que Griliches, en el modelo logístico y después contrastó los resultados del modelo con la evidencia empírica de cuatro industrias y doce innovaciones en la economía de Estados Unidos correspondiente al periodo 1890-1958.

Estas industrias son las del carbón bituminoso, el hierro y el carbón, la fabricación de cerveza y los ferrocarriles. Las doce innovaciones son: horno de coque para subproductos, locomotoras diesel, recipientes de estaño, góndolas, retardador de carros, cargador móvil sin rieles, máquina perforadora continua, máquina cargadora de paleta, laminadora continua de banda ancha, control centralizado de tráfico, templado continuo y llenadora de botellas de alta velocidad. 
El modelo determinista usado por Mansfield descansa, básicamente, en la siguiente hipótesis: "Suponemos que la proporción de 'retrasados' en el momento $t$ que introduce la innovación en el momento $t+1$ es una función de 1) la proporción de empresas que ya la introdujeron en el momento $t, 2$ ) la rentabilidad de su instalación, 3) el monto de la inversión requerida por la instalación y 4) otras variables no especificadas" (Mansfield, 1961: 269).

Para verificar los resultados del modelo determinista, Mansfield (1961) trabajó con una versión estocástica, en la que la hipótesis básica fue la siguiente: "la probabilidad de que una empresa introduzca una técnica nueva es una función creciente de la proporción de empresas que ya la usan y de la rentabilidad de su uso, pero es una función decreciente del monto de la inversión requerida" (Mansfield, 1961:290).

Mansfield (1961) concluye que el modelo logístico, en su versión estocástica, parece funcionar bien al compararlo con los datos correspondientes de las doce innovaciones, y agrega que: "Como se esperaba, la tasa de imitación tendió a ser mayor en el caso de las innovaciones más rentables y que requerían inversiones relativamente pequeñas. Una ecuación de la forma pronosticada por el modelo puede explicar prácticamente el total de la variación observable entre las tasas de imitación” (Mansfield, 1961: 290).

Por último, Mansfield señala que estos resultados deben ser considerados como provisionales, ya que cuatro industrias y doce innovaciones no representan el total de las industrias y las innovaciones de la economía de Estados Unidos, no obstante, los resultados no dejan de ser importantes.

Otro modelo pionero bajo el enfoque estándar es el de Davies (1979), quien partiendo del modelo de Mansfield relajó algunos supuestos y obtuvo otros resultados. Principalmente, relajó el supuesto de que todas las firmas tienen la misma probabilidad para adoptar la innovación no solo en algún momento del tiempo sino a lo largo de él. Davies exploró otros factores que pueden modificar la probabilidad de adopción de las firmas, por ejemplo, el desarrollo profesional de los directivos o la existencia de instituciones financieras con sofisticada infraestructura, son factores que pueden afectar la velocidad de adopción de las innovaciones (Davies, 1979).

En el cuadro 1.2 se resumen las principales diferencias y semejanzas en cuanto al problema de investigación, los resultados y los indicadores usados por los autores pioneros del enfoque estándar. 


\section{Cuadro 1.2. Autores pioneros en el enfoque estándar o epidemiológico}

\begin{tabular}{|c|c|c|c|}
\hline Autor y año & Problema de investigación & Resultados & Indicadores \\
\hline $\begin{array}{l}\text { Griliches } \\
(1960)\end{array}$ & $\begin{array}{l}\text { ¿Qué determina las diferencias } \\
\text { entre las áreas en cuanto al } \\
\text { origen, la pendiente y el tope? }\end{array}$ & $\begin{array}{l}\text { Es posible que el cambio } \\
\text { tecnológico tienda a } \\
\text { acentuar las disparidades } \\
\text { regionales en cuanto a } \\
\text { los niveles de ingreso y } \\
\text { las tasas de crecimiento. }\end{array}$ & $\begin{array}{l}\text { Tasa de imitación y } \\
\text { montos de ganancias. }\end{array}$ \\
\hline $\begin{array}{l}\text { Mansfield } \\
\text { (1961) }\end{array}$ & $\begin{array}{l}\text { ¿Con qué rapidez usarán otras } \\
\text { empresas de la industria una } \\
\text { innovación? ¿Qué factores } \\
\text { determinan dicha rapidez? }\end{array}$ & $\begin{array}{l}\text { La probabilidad de que } \\
\text { una empresa introduzca } \\
\text { una técnica nueva es una } \\
\text { función creciente de la } \\
\text { proporción de empresas } \\
\text { que ya la usan y de la } \\
\text { rentabilidad de su uso, } \\
\text { pero es una función } \\
\text { decreciente del monto de } \\
\text { la inversión requerida. }\end{array}$ & Tasa de imitación. \\
\hline Davies (1979) & $\begin{array}{l}\text { ¿Qué otros factores no } \\
\text { considerados por Mansfield } \\
\text { pueden modificar la probabilidad } \\
\text { de las firmas? }\end{array}$ & $\begin{array}{l}\text { El desarrollo profesional } \\
\text { de los directivos e } \\
\text { instituciones financieras } \\
\text { afectan la velocidad de } \\
\text { difusión. }\end{array}$ & $\begin{array}{l}\text { Tasa de imitación, } \\
\text { Nivel de educación de } \\
\text { los directivos, } \\
\text { Infraestructura de } \\
\text { instituciones financieras. }\end{array}$ \\
\hline
\end{tabular}

Fuente: elaboración propia con base en Griliches (1960), Mansfield (1961) y Davies (1979).

La difusión tecnológica bajo el enfoque evolucionista

Otra forma de estudiar el fenómeno de la difusión tecnológica es bajo la vertiente teórica conocida como economía evolucionista. Los autores que se inscriben en esta vertiente, se centran en explicar que: "los cambios económicos y, dentro de éstos, el papel contemporáneo de la innovación tecnológica. Se plantea la búsqueda de una explicación endógena de la innovación, lo que implica una economía del cambio tecnológico" (Corona, 2010: 195).

Se trata de una teoría que tiene como principal objetivo explicar los cambios económicos. En este sentido, se puede afirmar que es una teoría económica dinámica, donde el fenómeno de la innovación tecnológica y su difusión juegan un papel esencial.

Cabe señalar que algunos conceptos centrales de la vertiente evolutiva tales como los de selección natural, evolución, diversidad, aprendizaje, comportamiento y paradigma, tienen sus fuentes en otras disciplinas como la filosofía, la física y la biología. No obstante, se 
recuperan de la economía los objetivos sociales planteados por los economistas clásicos: empleo y bienestar social. Entre las principales obras que caracterizan a la vertiente evolucionista del cambio tecnológico, se encuentran las de Nelson y Winter (1982), Freeman (1987), Dosi (1982), Pérez (1989 y 2004) y Pavitt (1984) (Corona; 2010). En particular, en Dosi (1982) se plantea la importancia de la difusión tecnológica entendida como difusión de paradigmas tecnológicos.

Sin embargo, antes de presentar una caracterización de los estudios sobre difusión tecnológica bajo el marco conceptual de la teoría evolucionista es conveniente exponer, brevemente y a manera de antecedentes, en qué consisten los enfoques sobre innovación tecnológica de los que emerge la vertiente evolucionista al considerar sus limitaciones.

\section{Antecedentes: enfoques sobre innovación tecnológica}

El propósito de este apartado no es hacer una revisión exhaustiva de los distintos enfoques sobre la innovación tecnológica en economía, lo cual escapa al objetivo principal de la presente investigación. Más bien, se trata de presentar algunos elementos conceptuales que ayuden a comprender, en primer lugar, el concepto de innovación tecnológica en el marco de la teoría evolucionista y, en segundo lugar, el concepto de difusión tecnológica en esta teoría. Así, en el marco de la discusión neoschumpeteriana que se llevó a cabo durante los años setenta y ochenta sobre el cambio tecnológico (Vence, 1995) se ubican, como antecedente, dos enfoques opuestos en la explicación de la innovación tecnológica: el primero conocido como DemandPull y el segundo como Technology-Push (Vence, 1995).

Los autores que se inscriben en el enfoque de Demand-Pull, sostienen la tesis de que las innovaciones son generadas por las necesidades de los consumidores. De acuerdo con Schmookler (1962), el autor fundador de este enfoque, el esfuerzo inventivo suele variar directamente con la producción de la clase de bienes que dicho esfuerzo trata de mejorar con la invención, tendiendo a quedar ligeramente atrás de la producción. Este patrón se explica por el hecho de que las variaciones de la invención son una consecuencia de las condiciones económicas con las que se correlaciona positivamente la producción, lo cual sugiere que, al aumentar la demanda, la producción aumenta, pero también aumentan los gastos en 
investigación y desarrollo (I+D), porque estos gastos siguen las variaciones de la demanda (Schmookler, 1962).

Por otra parte, los autores que se inscriben en el enfoque conocido como TechnologyPush, sostienen la idea de que el progreso científico y tecnológico da origen a las innovaciones. Mowery y Rosenberg (1979), después de haber hecho una revisión crítica sobre un conjunto de estudios (Myers y Marquis, 1969; Langrish, et al., 1972; Gibbons y Johnston, 1974, entre otros) que se ubican en el enfoque de Demand-Pull, concluyeron que ambos lados, demanda y oferta, tienen influencias cruciales en la comprensión de los procesos de innovación y lo que resulta criticable al enfoque de Demand-Pull es haberse preocupado exclusivamente por la demanda como principal fuerza de la innovación.

En este contexto de discusión surgió otro concepto de innovación tecnológica que, al mismo tiempo, dio origen a la teoría evolucionista. Dosi (1982 y 1984) concibe la actividad innovadora como resultado de la interacción entre factores que determinan la oferta y demanda de innovaciones. Se trata, a diferencia de los anteriores, de un enfoque sistémico y dinámico donde innovación y difusión interactúan como parte de un mismo proceso.

En el cuadro 1.3 se presentan, en forma resumida, las características de estos enfoques sobre innovación tecnológica.

\section{Cuadro 1.3. Enfoques teóricos sobre innovación en el marco de la discusión} neoschumpeteriana

\begin{tabular}{|l|l|l|}
\hline Enfoques & Autores la & $\begin{array}{l}\text { Factores que explican } \\
\text { innovación/Diferencias }\end{array}$ \\
\hline Demand-Pull & $\begin{array}{l}\text { Schmookler (1962); Myres and } \\
\text { Marquis (1969); Langrish, et. al., } \\
(1972) ; \text { Gibbons and Johnston } \\
(1974) .\end{array}$ & $\begin{array}{l}\text { Las innovaciones provienen de las } \\
\text { necesidades de los consumidores. }\end{array}$ \\
\hline $\begin{array}{l}\text { Technology-Push } \quad \text { paradigmas } \\
\text { trayectorias tecnológicas) }\end{array}$ & $\begin{array}{l}\text { Mowery y Rosenberg (1979); } \\
\text { Freeman, et. al., (1985). }\end{array}$ & $\begin{array}{l}\text { El progreso de ciencia-tecnología } \\
\text { da origen a las innovaciones. }\end{array}$ \\
\hline
\end{tabular}

Fuente: elaboración propia con base en Schmookler (1962); Myres y Marquis (1969); Langrish, et. al., (1972); Gibbons y Johnston (1974); Mowery y Rosenberg (1979); Freeman, et. al., (1985); Dosi (1982 y 1984). 
Ahora bien, la propuesta de Dosi (1984) parte de una crítica a los enfoques de DemandPull y Technology-Push sobre los factores que determinan el cambio tecnológico. La crítica general consiste en señalar que, ambas, muestran una incapacidad para dar cuenta de buena parte de los resultados obtenidos a partir de los análisis empíricos realizados sobre tecnologías y sectores concretos (Dosi, 1984).

Las críticas específicas al enfoque referido como Demand-Pull se centran, básicamente, en tres aspectos:

i) Suponen un concepto pasivo y mecánica reactividad del cambio técnico respecto a las necesidades expresadas en el mercado

ii) Incapacidad para definir el por qué y el cuándo de ciertos desarrollos tecnológicos en lugar de otros

iii) Ignoran los cambios que se registran en la capacidad inventiva con el paso del tiempo, sin guardar una relación directa con los cambios en el mercado.

Mientras que las críticas al enfoque conocido como Technology-Push se centran, principalmente, en dos aspectos:

i) Incorporan inadecuadamente la importancia de los factores económicos en la dirección del proceso de innovación

ii) Su esquema básico parte de una visión unidireccional de las relaciones cienciatecnología-producción, donde la ciencia es una fuerza exógena que actúa deus ex machina (Dosi, 1984).

Hay que señalar que la propuesta de Dosi (1982 y 1984) parte de un concepto amplio de tecnología: “un conjunto de elementos de conocimiento, directamente 'práctico' y 'teórico', know-how, métodos, procedimientos, experiencia de aciertos y errores y, por supuesto, aparatos físicos y equipos" (Dosi, 1984: 14).

Este concepto de tecnología, tiene implícitos varios supuestos:

i) Rechaza la idea de la tecnología como si fuese información (Arrow, 1974), inmediatamente aplicable y no apropiable 
ii) Incluye componentes inmateriales difíciles de captar con precisión e, incluso, conocimientos difícilmente codificables adquiridos por las personas y las organizaciones (conocimientos tácitos y específicos)

iii) La habilidad y experiencia de intentos pasados se combinan con los conocimientos y logros actuales

iv) Incorpora la percepción de un conjunto limitado de alternativas tecnológicas posibles y de sus desarrollos futuros

v) El supuesto anterior implica que la empresa (o país) no explora un stock de conocimientos libre sino que su proceso de búsqueda es de mejora y de diversificación a partir de su propia base de conocimientos, de tal forma que sus posibilidades dependen de lo que ha hecho en el pasado. En otras palabras, la tecnología también incluye los mecanismos de búsqueda y aprendizaje de los que dispone la empresa (o país) para la mejora de la eficiencia productiva y el desarrollo de nuevos productos y métodos de producción (innovaciones) (Vence, 1995).

En cuanto al concepto de difusión tecnológica, la teoría evolucionista parte de una crítica al enfoque estándar en los siguientes aspectos:

i) Crítica del indicador de difusión empleado: el número de utilizadores es un indicador burdo para dar cuenta de la tasa real de difusión por dos razones principales: a) se admite implícitamente que desde el momento en que una empresa introduce una innovación ésta pasa a ser su método exclusivo, pero lo que ocurre normalmente es que la nueva tecnología no desplaza totalmente a la vieja sino que "convive" con ella, por lo menos un tiempo; b) normalmente solo se consideran las grandes empresas, razón por la cual también tiende a sobreestimarse la tasa de difusión

ii) Crítica al análisis realizado en términos de equilibrio parcial. Privilegia los factores por el lado de la demanda de bienes de capital que pueden afectar la velocidad de difusión y menosprecia los factores por el lado de la oferta de bienes de capital, por ejemplo, la importancia que tiene el learning by doing 
iii) No puede determinarse a priori el campo de difusión. El espacio potencial de la difusión no está dado inicialmente, por esta razón el modelo no refleja la dinámica de expansión del espacio inicial de difusión

iv) Crítica global del modelo. El modelo estándar resulta un obstáculo epistemológico para el reconocimiento del carácter dinámico del proceso de difusión del cambio técnico y, por lo tanto, para la toma en cuenta del papel de la investigación técnica en el análisis de las modalidades mismas de la difusión (Vence, 1995)

Así, bajo esta teoría, los estudios de difusión tecnológica tienen que considerar las interacciones de feed-back entre innovación y difusión, las cuales, a su vez, se hallan inmersas en los contextos económico y social específicos. Como señala Vence (1995), en esta teoría: "La tecnología no es un dato que aparece definitivamente realizado en el momento en que nace, sino que se va desarrollando gradualmente al mismo tiempo que se difunde y, además, esa difusión no tiene lugar en un entorno banal y abstracto sino que tiene lugar en un entorno industrial, económico y social específico con el que mantiene un feed-back permanente" (Vence, 1995: 216).

El cuadro 1.4 presenta, en forma resumida, distintas definiciones del concepto de difusión tecnológica, propuestas por diferentes autores e instituciones.

Cuadro 1.4. Definiciones del concepto de difusión tecnológica en economía propuesto por distintos autores e instituciones

\begin{tabular}{|c|c|c|c|}
\hline $\begin{array}{l}\text { Autor o } \\
\text { institución }\end{array}$ & Definición & $\begin{array}{l}\text { Características } \\
\text { comunes }\end{array}$ & Diferencias \\
\hline Gomulka (1990) & $\begin{array}{l}\text { Se refiere a la propagación (en } \\
\text { el espacio o en el tiempo) de } \\
\text { un producto o método de } \\
\text { producción en la economía } \\
\text { (Gomulka, 1990). }\end{array}$ & \multirow{3}{*}{$\begin{array}{l}\text { * Las definiciones hacen } \\
\text { referencia a un } \\
\text { fenómeno de } \\
\text { propagación, en el } \\
\text { tiempo o en el espacio, } \\
\text { de conocimientos o } \\
\text { productos nuevos en la } \\
\text { economía. } \\
\text { *Énfasis en los factores } \\
\text { que afectan la velocidad } \\
\text { de difusión. }\end{array}$} & \multirow{3}{*}{$\begin{array}{l}\text { *Las definiciones están } \\
\text { dadas dependiendo el } \\
\text { nivel de la unidad de } \\
\text { análisis: firmas, sectores } \\
\text { económicos, países, } \\
\text { regiones. } \\
\text { *Las definiciones } \\
\text { también se distinguen } \\
\text { por la especificación de } \\
\text { lo que se difunde: } \\
\text { conocimientos } \\
\text { tecnológicos o nuevos } \\
\text { productos. } \\
\text { * Los factores que }\end{array}$} \\
\hline Rogers (2003) & $\begin{array}{l}\text { El conocimiento (entendido } \\
\text { como el conjunto de técnicas } \\
\text { y tecnologías usadas en la } \\
\text { producción de bienes y } \\
\text { servicios) no se difunde en } \\
\text { forma perfecta entre firmas y } \\
\text { países (Rogers, 2003). }\end{array}$ & & \\
\hline $\begin{array}{l}\text { Comín y Mestieri } \\
\text { (2013) }\end{array}$ & $\begin{array}{l}\text { La tecnología se difunde entre } \\
\text { los países y a largo plazo, con } \\
\text { rezagos en su adopción y } \\
\text { penetración, lo que explica en } \\
\text { gran medida la distribución }\end{array}$ & & \\
\hline
\end{tabular}




\begin{tabular}{|c|c|c|}
\hline & $\begin{array}{l}\text { del ingreso entre países ricos y } \\
\text { pobres (Comin y Mestieri, } \\
\text { 2013). }\end{array}$ & \multirow{4}{*}{$\begin{array}{l}\text { pueden afectar la } \\
\text { velocidad de difusión } \\
\text { son variados, tanto por el } \\
\text { lado de la demanda } \\
\text { como por el lado de la } \\
\text { oferta. }\end{array}$} \\
\hline Vence (1995) & $\begin{array}{l}\text { En el enfoque epidemiológico } \\
\text { la difusión tecnológica ocurre } \\
\text { por imitación y la velocidad } \\
\text { de difusión está determinada } \\
\text { por factores por el lado de la } \\
\text { demanda de bienes de capital } \\
\text { y no por el lado de la oferta } \\
\text { (Vence, 1995). }\end{array}$ & \\
\hline Dosi (1982) & $\begin{array}{l}\text { La difusión de tecnología bajo } \\
\text { un paradigma tecnológico, } \\
\text { considera los factores que } \\
\text { afectan su velocidad de } \\
\text { difusión tanto por el lado de la } \\
\text { demanda como por el lado de } \\
\text { la oferta de bienes de capital } \\
\text { (interacciones feed-back) } \\
\text { (Dosi, 1982). }\end{array}$ & \\
\hline $\begin{array}{l}\text { Manual de OSLO, } \\
\text { OECD (2005) }\end{array}$ & $\begin{array}{l}\text { Se entiende por difusión el } \\
\text { modo mediante el cual las } \\
\text { innovaciones se extienden a } \\
\text { través de los circuitos } \\
\text { comerciales, o cualquier otro, } \\
\text { a los diferentes consumidores, } \\
\text { países, regiones, sectores, } \\
\text { mercados y empresas, después } \\
\text { de su primera introducción } \\
\text { (Manual de OSLO, 2005). }\end{array}$ & \\
\hline
\end{tabular}

Fuente: elaboración propia con base en Gomulka (1990); Rogers (2003); Comín y Mestieri, (2013); Vence (1995); Dosi, (1982); Manual de OSLO (2005).

Considerando el debate a nivel teórico entre el enfoque estándar y el enfoque evolucionista, en la presente investigación se adopta el enfoque evolucionista y, por consiguiente, los conceptos de tecnología, innovación y difusión tecnológica propuestos por Dosi (1982 y 1984). Se asume que, en efecto, la innovación tecnológica es un proceso; es decir, un fenómeno social dinámico y, además, es no lineal, por ello, no puede ser explicado solamente por factores del lado de la demanda o del lado de la oferta de tecnología. También se asume que una explicación más integral de la difusión tecnológica debe considerar la interacción entre factores que provienen de ambos lados.

A su vez, estos conceptos se hallan relacionados con otros tres conceptos centrales en el enfoque evolucionista: paradigma tecnológico, trayectoria tecnológica y sistema nacional de innovación. Aunque otros autores como Mowery y Rosenberg (1998) logran identificar 
tecnologías propulsoras (propulsion technologies) bajo una perspectiva de historia económica para explicar el cambio tecnológico, no existe en su discurso la noción de paradigma tecnológico. Fue Dosi el primero en usar éste concepto entendido como el marco común bajo el cual se llevan a cabo las innovaciones tecnológicas. En sus palabras: “ un paradigma tecnológico se puede definir como un 'esquema' de solución de determinados problemas tecnoeconómicos basados en principios muy selectos derivados de las ciencias naturales, juntamente con reglas específicas orientadas a la adquisición de nuevos conocimientos y a salvaguardarlos, cuando sea posible, de una rápida difusión a los competidores" (Dosi, 1988: $277)^{3}$.

Dosi señala tres características importantes de los paradigmas tecnológicos: i) incorporan fuertes prescripciones acerca de las direcciones del cambio tecnológico que se debe buscar y aquél que se debe desdeñar; ii) tienen un fuerte poder de exclusión: los esfuerzos y la imaginación tecnológica de los ingenieros y las organizaciones que están en ellos se centran en direcciones bastante precisas que son "ciegas" respecto a otras posibilidades tecnológicas; iii) definen cierta idea de progreso.

Ahora bien, ¿de qué factores depende la selección de un nuevo paradigma tecnológico? Depende de un conjunto de variables físicas y socioeconómicas. Por un lado, todas las tecnologías están limitadas por las compensaciones básicas de las ciencias naturales, por ejemplo, las leyes de la física. Así, las características tecnológicas de un sistema pueden ser explicadas como un vector en el espacio n-dimensional, que está compuesto por una serie de parámetros $n$-lineales de propiedades físicas tales como espacio, tiempo y masa.

Una solución a un problema tecnológico puede darse a través de una combinación específica de estas propiedades en el sistema físico disponible, es decir, se puede utilizar material más pesado o más liviano, se puede hacer más grande o más pequeño, más rápido o más lento. Las innovaciones tecnológicas son, precisamente, los nuevos productos generados a partir de cambios en el abanico de parámetros.

\footnotetext{
${ }^{3}$ Cabe señalar que Dosi (1982) sugirió el concepto de paradigma tecnológico con base al de paradigma científico propuesto por Kuhn (1962) en el contexto de la historia de la ciencia. En su obra The Structure of Scientific Revolutions, Kuhn define paradigma científico como: "realizaciones científicas universalmente reconocidas que, durante cierto tiempo, proporcionan modelos de problemas y soluciones a una comunidad científica" (Kuhn, 1962: 13).
} 
Ahora bien, las innovaciones pueden ser de dos tipos: incrementales o radicales. Las primeras, son las mejoras continuas y sucesivas en la tecnología de procesos y productos que ocurren continuamente en las actividades industriales y de servicios. Estas no son, necesariamente, el producto de actividades deliberadas de investigación y desarrollo (I+D) dentro de la firma, sino el resultado de la actividad de los ingenieros de la planta y los trabajadores, o pueden ser propuestas de los consumidores y personas relacionadas con el proceso de innovación. Las innovaciones radicales comprenden la introducción de nuevos productos y procesos que modifican la trayectoria normal de una tecnología. No surgen en forma espontánea sino que son promovidas por gastos explícitos en I+D de los Estados nacionales y las empresas (Bramuglia, 2000).

Además de las limitaciones que impone el mundo físico, existen factores socioeconómicos que también son importantes en la selección de los problemas y las soluciones tecnológicas e influyen, por lo menos, en dos sentidos: en la dirección del proceso de resolución de problemas (naturaleza de la trayectoria tecnológica) y en la difusión de las innovaciones tecnológicas. Entre estos factores se pueden mencionar: a) los intereses económicos de las instituciones que promueven I+D; b) su historia tecnológica, sus campos de especialización, etcétera; c) variables institucionales como agencias públicas o militares. Estos tres factores influyen ex ante en la selección de trayectorias. En cuanto a la difusión de innovaciones tecnológicas influyen los siguientes factores: d) comercialización; e) rentabilidad y; f) capacidad de ahorrar costos.

De esta forma, una vez seleccionado un paradigma tecnológico se inicia un periodo de solución de problemas tecnológicos con base en éste, es decir, se abre un periodo de solución normal de los problemas tecnológicos al que se le conoce como trayectoria tecnológica. En palabras de Dosi una trayectoria tecnológica es: "el patrón de solución normal de los problemas dentro de un paradigma tecnológico" (Dosi, 1984: 15).

Destacan seis grandes características de las trayectorias tecnológicas:

i) Puede haber trayectorias más generales o más circunscritas y puede haber más poderosas o menos poderosas

ii) Hay generalmente complementariedades entre las diferentes formas de conocimiento, experiencia, destrezas, etcétera. Sin embargo, el desarrollo o no en una tecnología puede promover o impedir desarrollos en otras 
iii) Puede definirse como la frontera tecnológica de más alto nivel alcanzado por una senda tecnológica con respecto a las dimensiones tecnológicas y económicas relevantes

iv) El progreso en una trayectoria tecnológica es probable que tenga carácter acumulativo: la probabilidad de futuros avances está también relacionada con la posición que una empresa o un país ocupaba antes con respecto a la frontera tecnológica

v) Cuando una trayectoria es verdaderamente poderosa, es difícil cambiar por otra alternativa. Sin embargo, cuando es posible alguna comparabilidad, la frontera en la nueva trayectoria irá detrás de la vieja con respecto a alguna o todas las dimensiones comunes

vi) Es dudoso que sea posible comparar y valorar a priori la superioridad de una senda tecnológica sobre otra. Criterios objetivos solo pueden aplicarse a posteriori, definiendo un indicador adecuado (Dosi, 1984)

Como se observa, el concepto de trayectoria tecnológica alude, en general, a la idea de progreso tecnológico al resolverse los problemas tecnológicos planteados en el marco de un paradigma tecnológico.

No obstante, la emergencia, difusión y progreso de los paradigmas tecnológicos no podrían darse fuera del marco dado por los sistemas nacionales de innovación (SNI). Cabe señalar que no existe un concepto universal de SNI (Lundvall, 2004). Se trata de un concepto ex post, es decir, construido a partir de un conjunto de estudios empíricos, aunque puede funcionar como un concepto ex ante para aquellos países donde los agentes que participan en los procesos de innovación lo hacen de manera desarticulada. Esta es la razón por la que su definición varía entre los diferentes autores inscritos en la vertiente evolucionista. No obstante, lo común es que la mayoría de ellos, con base en estudios empíricos, caracterizan el rol que juegan los agentes (las instituciones educativas, científicas, las firmas y el gobierno) que participan en un SNI para llevar a cabo la innovación tecnológica y su difusión. A continuación se revisan algunas definiciones de este concepto. De acuerdo con Freeman, un SNI es: "la red de instituciones en los sectores público y privado cuyas actividades e interacciones inician, importan, modifican y difunden nuevas tecnologías" (Freeman; 1987: 1). 
Para Lundvall, se halla constituido por: "los elementos y relaciones que interactúan en la producción, difusión y uso de conocimientos nuevos y económicamente útiles (...) y se localizan dentro o en las fronteras de un Estado" (Lundvall; 1992: 2).

Otra definición de SNI, la proporciona Nelson como sigue: "El sistema de instituciones que sustentan la innovación tecnológica en un campo" (Nelson; 1992: 350).

En cambio, para Mowery el concepto de SNI hace referencia a sus componentes y procesos: “Típicamente, los sistemas 'nacionales' de innovación incluyen las instituciones, políticas, actores y procesos que afectan la creación de conocimiento, los procesos de innovación que llevan investigación en sus aplicaciones (ya sea para la venta o el despliegue de una innovación en un contexto de 'no mercado', como la defensa nacional), y los procesos e instituciones que influyen en la adopción de innovaciones” (Mowery, 2011: 2).

Mientras que Freeman (1987) y Nelson (1992) ponen énfasis en las instituciones, públicas y privadas, que sustentan la innovación tecnológica, Lundvall (1992) y Mowery (2011) resaltan la participación de los actores que participan en los SNI. Lo común en todos ellos es que la generación de nuevos conocimientos tecnológicos así como su difusión, dependen de los vínculos entre las instituciones o los actores que constituyen los SNI. En el cuadro 1.5 se presentan los aspectos comunes y diferencias de las definiciones de SNI de estos autores.

Cuadro 1.5. Definiciones del concepto de Sistema Nacional de Innovación (SNI), propuesto por diferentes autores. Aspectos comunes y diferencias

\begin{tabular}{|c|c|c|c|}
\hline Autor & Definición & Aspectos comunes & Diferencias \\
\hline Freeman (1987) & $\begin{array}{l}\text { “(..) la red de } \\
\text { instituciones en los } \\
\text { sectores público y privado } \\
\text { cuyas actividades e } \\
\text { interacciones inician, } \\
\text { importan, modifican y } \\
\text { difunden } \\
\text { tecnologías" } \\
\text { 1987: } 1) .\end{array}$ & $\begin{array}{l}\text { Pone énfasis en las } \\
\text { instituciones públicas } \\
\text { y privadas que } \\
\text { participan en la } \\
\text { innovación. En este } \\
\text { aspecto coincide con } \\
\text { los demás autores, } \\
\text { excepto con Lundvall } \\
(1992) \text {. }\end{array}$ & \\
\hline Lundvall (1992) & $\begin{array}{l}\text { “(...) los elementos y } \\
\text { relaciones que interactúan } \\
\text { en la producción, difusión } \\
\text { y uso de conocimientos } \\
\text { nuevos y económicamente } \\
\text { útiles }(\ldots) \text { y se localizan }\end{array}$ & & $\begin{array}{l}\text { Difiere de los demás } \\
\text { autores en cuanto a que } \\
\text { esta definición no pone } \\
\text { énfasis en las } \\
\text { instituciones, sino en los } \\
\text { agentes del SNI. }\end{array}$ \\
\hline
\end{tabular}




\begin{tabular}{|c|c|c|c|}
\hline & $\begin{array}{l}\text { dentro o en las fronteras de } \\
\text { un Estado" (Lundvall, } \\
\text { 1992: 2). }\end{array}$ & & $\begin{array}{l}\text { También difiere con las } \\
\text { otras definiciones, al } \\
\text { poner énfasis en la } \\
\text { difusión y uso de los } \\
\text { conocimientos nuevos. }\end{array}$ \\
\hline Nelson (1992) & $\begin{array}{l}\text { "El sistema de } \\
\text { instituciones que sustentan } \\
\text { la innovación tecnológica } \\
\text { en un campo" (Nelson, } \\
\text { 1992: 350). }\end{array}$ & $\begin{array}{l}\text { Resalta los aspectos } \\
\text { microeconómicos del } \\
\text { SNI, al poner énfasis } \\
\text { en la capacidad } \\
\text { innovadora de las } \\
\text { empresas de los países } \\
\text { en ciertos campos } \\
\text { tecnológicos. }\end{array}$ & \\
\hline Mowery (2011) & $\begin{array}{l}\text { "Típicamente, los sistemas } \\
\text { 'nacionales' de innovación } \\
\text { incluyen las instituciones, } \\
\text { políticas, actores y } \\
\text { procesos que afectan la } \\
\text { creación de conocimiento, } \\
\text { los procesos de innovación } \\
\text { que llevan investigación en } \\
\text { sus aplicaciones (ya sea } \\
\text { para la venta o el } \\
\text { despliegue de una } \\
\text { innovación en un contexto } \\
\text { de 'no mercado', como la } \\
\text { defensa nacional), y los } \\
\text { procesos e instituciones } \\
\text { que influyen en la } \\
\text { adopción de innovaciones" } \\
\text { (Mowery, 2011: 02). }\end{array}$ & & $\begin{array}{l}\text { Además de las } \\
\text { instituciones, } \\
\text { definición agrega las } \\
\text { políticas, actores y } \\
\text { procesos que participan } \\
\text { en la creación de nuevo } \\
\text { conocimiento. }\end{array}$ \\
\hline
\end{tabular}

Fuente: elaboración propia con base en Freeman (1987), Lundvall (1992), Nelson (1992) y Mowery (2011).

Con base en estas definiciones, se puede afirmar que el concepto de sistema nacional de innovación (SNI) se refiere, en general, al conjunto de agentes y relaciones institucionales que participan en el proceso de innovación. La base de un SNI son las empresas, centros de investigación y las universidades, quienes interactúan dentro de un marco institucional adecuado para la innovación y difusión. Un SNI se compone de relaciones entre elementos de diferentes ámbitos y su acción está ligada, directa o indirectamente, al núcleo de la I+D, dando origen al aprendizaje institucional e interactivo que, a su vez, determina la dirección y la velocidad de la difusión de nuevos conocimientos científicos y tecnológicos. En este sentido, de acuerdo con un estudio de la OCDE (2002) sobre los SNI: "La innovación y el progreso técnico son el resultado de un complejo conjunto de relaciones entre los actores que producen, distribuyen y aplican diversos tipos de conocimiento" (OCDE, 2002: 9). 
De esta forma, bajo el concepto de SNI, los procesos de innovación tecnológica aparecen como resultado de una compleja interacción entre diversos actores e instituciones. El cambio técnico no se produce como una secuencia perfectamente lineal, sino a través de circuitos de retroalimentación dentro de este sistema. Como se mencionó, en el centro del SNI están las empresas, es decir, la forma en cómo se organiza la producción y la innovación así como los canales por los que tienen acceso a fuentes externas de conocimiento. Estas fuentes podrían ser otras empresas, institutos de investigación públicos y privados, universidades o instituciones de transferencia a nivel regional, nacional o internacional. Así, como parte central del SNI, la empresa innovadora opera dentro de una compleja red de colaboraciones con otras empresas de la competencia e instituciones públicas y privadas, sobre la base de una serie de articulaciones y estrechos vínculos con proveedores y clientes (OCDE, 2002).

Ahora bien, a través de las interacciones que se establecen entre las firmas innovadoras, universidades, centros de investigación y gobierno, se establecen canales a través de los cuales fluye el conocimiento generado por estos actores (individuos y organizaciones) que componen el SNI. Si bien pueden surgir diversos canales a través de los cuales el conocimiento puede fluir entre los actores del SNI, la mayoría de las investigaciones sobre el tema ponen énfasis en el flujo de conocimiento a través de cuatro canales básicos: 1) las interacciones entre las empresas, el conocimiento fluye en este canal a través de las colaboraciones en I+D entre firmas y alianzas estratégicas, las cuales son cada vez más crecientes; 2) las interacciones entre empresas, universidades y laboratorios públicos de investigación, a través de este canal ocurre el mayor flujo de conocimiento en el SNI; 3) la difusión de conocimiento y tecnología a las empresas, es el tipo más tradicional de los flujos de conocimiento en los SNI a través de la compra de maquinaria y equipo que realizan las empresas, el flujo de conocimiento es lento y corre a través de años y las tasas de adopción varía de un sector a otro; 4) la movilidad del personal, en los estudios de difusión de tecnología se muestra que las habilidades y las capacidades de hacer redes por parte del personal es la clave para implementar y adaptar nueva tecnología (OCDE, 2002).

Como se mencionó, de estos cuatro canales donde se lleva a cabo el flujo de conocimiento en los SNI, tal vez el más importante ocurra a partir de las interacciones que se dan entre las organizaciones públicas y las privadas (OCDE, 2002). Por un lado, el componente público se compone, principalmente, de institutos de investigación públicos y universidades y, 
por otro lado, están las empresas privadas. La calidad de la infraestructura de la investigación pública y sus vínculos con la industria representa uno de los bienes nacionales más importantes para el apoyo de la innovación. Los institutos de investigación apoyados por el gobierno y las universidades son las actividades principales de investigación genérica y fuente de nuevos métodos, instrumentación y habilidades invaluables. Cada vez más, la investigación llevada a cabo en estos institutos está apoyada por las empresas que colaboran con el sector público en los proyectos de investigación tecnológicos, la contratación de investigación específica o el financiamiento personal a los investigadores (OCDE, 2002). Hay cuatro formas de medir los flujos de conocimiento entre las organizaciones públicas y privadas: a) articulación de las actividades de investigación, la cual se mide a través de las compensaciones que reciben los investigadores del sector público que dan servicio al sector privado (firmas); b) co-patentes y publicaciones, que se mide por el número de co-patentes o co-publicaciones desarrolladas por empresas en colaboración con una universidad o centro de investigación público; c) análisis de citas, el cual ayuda a evaluar el grado en que las empresas se basan en la información contenida en otras patentes o publicaciones de universidades e institutos de investigación; d) encuestas a empresas, las cuales revelan el grado en que las universidades e institutos de investigación públicos valoran sus actividades de innovación como fuentes de conocimiento útil (OCDE, 2002).

Por otra parte, considerando que los componentes de un sistema pueden relacionarse de distintas maneras (tipos de sistemas), de acuerdo con la teoría general de sistemas (Bertalanffy, 1968), los SNI pueden estar fuertemente o débilmente conectados (Albuquerque et al., 2011). Así, en países industrializados como Estados Unidos, Japón, Alemania o Corea del Sur, los vínculos entre universidades, centros de investigación público y privados y empresas son abundantes (Lundvall et al., 2009), lo que permite mayor intensidad en la invención, innovación y difusión de tecnología en todo el sistema económico. Mientras que en los países emergentes, los SNI se caracterizan por el hecho de que sus componentes presentan pocos vínculos haciendo lentos los procesos de invención, innovación y difusión, tal como ocurre en los países de América Latina (Albuquerque et al., 2011).

Ahora bien, la difusión de un paradigma tecnológico presenta distintos patrones espaciales y temporales y esto depende de la influencia que tengan los factores socioeconómicos ya mencionados. Es decir, depende de la forma en cómo se encuentren 
vinculados los actores que participan en los SNI. Por ejemplo, en los países industrializados los vínculos, a través de la política industrial, entre gobierno, universidades públicas, empresas y sistema financiero son abundantes, lo que facilita la difusión de un paradigma tecnológico; mientras que en los países emergentes, la desvinculación entre estos actores o la falta de coordinación entre ellos puede inhibir el proceso de difusión de un paradigma tecnológico y hacerlo lento.

Por ejemplo, Pérez (2009) identifica históricamente cinco paradigmas tecnológicos, caracterizados por un conjunto de industrias e innovaciones: 1) planta hiladora de algodón en Arkwright, Inglaterra, el insumo clave es el algodón en la industria textil; 2) máquina de vapor en la industria ferroviaria, el insumo clave es la energía generada con vapor; 3) la siderúrgica de alta eficiencia, el insumo clave es el acero; 4) el motor de combustión interna en la industria automotriz, el insumo clave es el petróleo; 5) el microprocesador de Intel en las TIC, los insumos son proporcionados por la microelectrónica, como los microchips. Señala cómo se difundieron los cinco paradigmas tecnológicos anteriores espacialmente a nivel de países, esto es, del país núcleo hacia otros países: el primero, se originó y difundió a toda Inglaterra; el segundo, se originó en Inglaterra y se difundió hacia Europa y Estados Unidos; el tercero, se originó en Estados Unidos y Alemania y se difundió a Europa; el cuarto, se originó en Estados Unidos y Alemania y se difundió a Europa; y el quinto paradigma tecnológico se originó en Estados Unidos y se difundió a Europa y Asia.

En cuanto a su difusión temporal, Pérez señala que las innovaciones radicales individuales a nivel meso describen un patrón en forma de $S$ que indica el grado de maduración y saturación del mercado al cual le llama trayectoria de innovación. Ésta se compone de cuatro fases: desarrollo inicial de nuevos productos e industrias; constelación completa (nuevas industrias, sistemas tecnológicos e infraestructura); plena expansión del potencial innovativo y de mercado; y madurez y saturación del mercado. En las trayectorias de innovación destacan dos características importantes: velocidad de difusión y direccionalidad. Ambas están condicionadas por la forma en que funcionan los SNI, por la forma en que los actores que participan en él interactúan y por el grado de vinculación entre ellos. De esta forma, se esperaría que en los países donde las interacciones entre los actores del SNI son más fuertes, es decir, en los sistemas más articulados, la velocidad de difusión de los paradigmas tecnológicos hacia otros sectores tecnológicos y hacia las actividades económicas sea mayor que en aquellos 
países donde el SNI está poco articulado, ya que no podría darse el flujo de conocimientos generados en el paradigma tecnológico hacia todos los actores que participan en él.

Por último, cabe señalar que el concepto de paradigma tecnológico propuesto por Dosi (1982 y 1984) ha sido extendido por otros autores de la vertiente evolucionista, principalmente por Freeman y Pérez (1988), y después Pérez (2004 y 2009), para explicar los cambios tecnológicos de gran magnitud, a nivel macro, y sus implicaciones sobre la economía, las instituciones y la cultura en el largo plazo. Para extender el concepto de paradigma tecnológico, proponen los términos de revolución tecnológica y paradigma tecno-económico. En el cuadro 1.6, se presenta la definición de estos conceptos así como sus semejanzas y diferencias.

Cuadro 1.6. Definiciones de los conceptos paradigma tecnológico, paradigma tecnoeconómico y revolución tecnológica

\begin{tabular}{|c|c|c|c|c|}
\hline Autores & Nombre & Definición & Semejanzas & Diferencias \\
\hline $\begin{array}{l}\text { Dosi } \\
(1982)\end{array}$ & $\begin{array}{l}\text { Paradigma } \\
\text { tecnológico }\end{array}$ & $\begin{array}{l}\text { Es un modelo y } \\
\text { parámetro de solución de } \\
\text { problemas tecnológicos } \\
\text { selectos, sobre la base de } \\
\text { principios derivados de } \\
\text { las ciencias naturales y } \\
\text { tecnologías específicas. }\end{array}$ & \multirow{3}{*}{$\begin{array}{l}\text { * Comparten la idea de } \\
\text { que un paradigma } \\
\text { tecnológico es el marco } \\
\text { común donde se resuelven } \\
\text { los problemas } \\
\text { tecnológicos. } \\
\text { * Intervienen factores } \\
\text { tecnológicos y } \\
\text { socioeconómicos en la } \\
\text { selección y difusión de un } \\
\text { nuevo paradigma } \\
\text { (tecnológico o tecno- } \\
\text { económico). } \\
\text { * Se difunden } \\
\text { describiendo una } \\
\text { trayectoria logística a } \\
\text { través del tiempo. }\end{array}$} & \multirow{3}{*}{$\begin{array}{l}\text { La principal } \\
\text { diferencia es de } \\
\text { magnitud. El } \\
\text { paradigma } \\
\text { tecnológico explica } \\
\text { el progreso } \\
\text { tecnológico a nivel } \\
\text { de ingenierías. El } \\
\text { concepto de } \\
\text { paradigma tecno- } \\
\text { económico explica } \\
\text { el progreso } \\
\text { tecnológico a nivel } \\
\text { macro tecnológico. } \\
\text { Y el concepto de } \\
\text { Revolución } \\
\text { tecnológica, se usa } \\
\text { para explicar } \\
\text { grandes oleadas de } \\
\text { desarrollo. }\end{array}$} \\
\hline $\begin{array}{l}\text { Freeman y } \\
\text { Pérez } \\
(1988)\end{array}$ & $\begin{array}{l}\text { Paradigma } \\
\text { tecno- } \\
\text { económico }\end{array}$ & $\begin{array}{l}\text { Es la práctica modelo } \\
\text { para el uso más efectivo } \\
\text { de las nuevas tecnologías } \\
\text { dentro y más allá de las } \\
\text { nuevas industrias. }\end{array}$ & & \\
\hline $\begin{array}{l}\text { Pérez } \\
(2009)\end{array}$ & $\begin{array}{l}\text { Revolución } \\
\text { tecnológica } \\
\text { (cambio de } \\
\text { paradigma } \\
\text { tecno- } \\
\text { económico) }\end{array}$ & $\begin{array}{l}\text { Es un conjunto de } \\
\text { avances radicales } \\
\text { interrelacionados, que } \\
\text { forman una constelación } \\
\text { mayor de tecnologías } \\
\text { interdependientes, es } \\
\text { decir, es un sistema de } \\
\text { sistemas (meta-sistema). }\end{array}$ & & \\
\hline
\end{tabular}

Fuente: elaboración propia con base en Dosi (1982); Freeman y Pérez (1988); Pérez (2009). 
De esta forma ¿qué es una revolución tecnológica? Pérez la define como un conjunto de avances radicales interrelacionados que forman una constelación mayor de tecnologías interdependientes; es decir, un cluster de clusters o un sistema de sistemas (meta-sistema). Por ejemplo, la revolución tecnológica de la información se compone de varios sistemas tecnológicos que se formaron alrededor de los microprocesadores: calculadoras, juegos, telecomunicaciones, internet, etcétera.

Lo que distingue a una revolución tecnológica de una colección aleatoria de sistemas tecnológicos y que justifica concebirla como tal, son dos características básicas:

i) Fuerza de las interconexiones tecnología-mercado; y

ii) La capacidad de transformar profundamente el resto de la economía (y también a la sociedad).

La segunda característica se halla asociada con el concepto de paradigma tecnoeconómico. Pérez lo define como la mejor práctica (práctica modelo) para el uso más efectivo de las nuevas tecnologías dentro y más allá de las nuevas industrias.

Por sus alcances económicos y sociales, una revolución tecnológica puede verse como una convulsión del potencial creativo de riqueza de la economía, abriendo un vasto espacio de oportunidades de innovación, proveyendo un nuevo conjunto de tecnologías genéricas asociadas, infraestructuras y principios organizacionales que pueden incrementar significativamente la eficiencia y la efectividad de todas las industrias y actividades (Pérez, 2009).

Sobre las diferencias que hay entre los conceptos de paradigma tecnológico y paradigma tecno-económico, Freeman y Pérez señalan que: "Usamos la expresión 'tecnoeconómico’ más que ‘paradigma tecnológico’ porque los cambios van más allá de trayectorias de ingeniería para productos específicos o tecnologías de proceso y afecta a la estructura de costos de los insumos y a las condiciones de producción y distribución por toda la economía" (Freeman y Pérez, 1988: 47).

Y en Pérez (2010) se aclara que un "paradigma tecno-económico" es: "un modelo de prácticas óptimas para la forma más efectiva de usar las nuevas tecnologías tanto en las industrias nuevas como en las otras. Mientras que los nuevos sectores se expanden para convertirse en los motores del crecimiento por largo tiempo, el paradigma tecno-económico 
que resulta de su uso sirve de guía para una gran reorganización y una elevación generalizada de la productividad en todas las industrias pre-existentes" (Pérez, 2010: 7).

Como se observa, la diferencia entre paradigma tecnológico y paradigma tecnoeconómico es de magnitud o alcance. Así, mientras que el paradigma tecnológico es el marco común que orienta la resolución de problemas tecnológicos a nivel de campo o sector tecnológico, el paradigma tecno-económico es el marco común que orienta las prácticas tecnológicas a un nivel de meta-sistema. Freeman y Pérez (1988) destacan el ajuste que se produce entre el cambio tecnológico y el resto de las instituciones y las estructuras sociales cuando un nuevo paradigma tecno-económico comienza a tener influencia.

En cuanto a la difusión de una revolución tecnológica y del paradigma tecnoeconómico que la acompaña (los efectos en la economía y en la sociedad), Pérez (2009) señala que también se cumple el patrón temporal en forma de $S$ que describe una trayectoria de innovación, pero en este caso, dado que incluye los efectos no solo en la economía sino también institucionales e incluso culturales, recibe el nombre de oleada de desarrollo.

Como señala Carlota Pérez: “Así, cada oleada representa un nuevo estadio en la profundización del capitalismo en la vida de la gente y en su expansión por todo el planeta [...] cada oleada amplía el grupo de países que conforman el centro avanzado del sistema y cada una extiende la penetración del capitalismo a otros rincones, dentro de cada país y de un país a otro" (Pérez, 2004: 46-47).

En cada oleada de desarrollo pueden abrirse ventanas de oportunidad para algunos países, lo cual les permitirá cerrar la brecha tecnológica que los separa de los países industrializados, tales son los casos de Corea del Sur o Taiwán, pero también puede alejar a otros países del desarrollo y abrir más la brecha, de ahí la importancia de comprender cómo se difunde un paradigma tecnológico.

En la presente investigación se asume el concepto de paradigma tecnológico propuesto por Dosi (1982), es decir, entendido como un modelo y parámetro de solución de problemas tecnológicos selectos sobre la base de principios derivados de las ciencias naturales y tecnologías específicas. Cabe señalar, además, que un paradigma tecnológico no es estático sino que se difunde a través del tiempo y del espacio. Se asume también que la difusión de un paradigma tecnológico ocurre como lo indica Dosi, es decir, que los factores que influyen en la velocidad de difusión del paradigma provienen tanto de la demanda como de la oferta de 
capital. Sin embargo, el nacimiento y difusión de los paradigmas tecnológicos ocurren en el marco de los SNI y, por ello, los patrones de difusión temporal y espacial dependerán de las formas en que ocurran las interacciones entre los actores que participan en ellos, es decir, la interacción entre firmas, universidades, centros de investigación públicos y privados y gobierno. Como los SNI pueden ser articulados o no articulados (Albuquerque et al., 2011), la dirección y velocidad de difusión de los paradigmas tecnológicos varía dependiendo de las características y articulación de los SNI donde se difunde el paradigma. Se esperaría que en aquellos SNI más articulados la velocidad de difusión de un paradigma tecnológico sea mayor, así como su amplitud hacia otros campos tecnológicos y hacia los sectores productivos. En cambio, en aquellos SNI poco articulados se espera que la velocidad de difusión de un paradigma tecnológico sea baja y que su difusión espacial no abarque muchos sectores tecnológicos y productivos, esto es, se espera encontrar sectores tecnológicos de enclave.

Por último, se considera que el estudio de la difusión de un nuevo paradigma tecnológico es una condición necesaria para el estudio de paradigmas tecno-económicos, es decir, para estudiar los cambios en la economía y en la sociedad que trae consigo la implementación de un nuevo paradigma tecnológico. A su vez, estos estudios podrían jugar un papel importante en el diseño de políticas de innovación, crecimiento económico y desarrollo de un país o una región.

\section{La hipótesis del catch-up tecnológico}

Una vez expuestos los enfoques sobre difusión de tecnología, es factible abordar el problema de cómo los países en desarrollo pueden cerrar la brecha tecnológica respecto de los países industrializados. A este problema se le conoce como catch-up tecnológico e involucra el estudio de la difusión internacional de tecnología. De esta forma, la respuesta tentativa general a este problema se le conoce como hipótesis del catch-up tecnológico. Ésta considera que, en el proceso de difusión internacional de tecnología, participan dos grupos de países: el líder, caracterizado por ser el creador de tecnología y el seguidor, que la capta, imita y la introduce en sus procesos productivos. Así, gracias al proceso de transferencia de tecnología se produce una reducción paulatina en la diferencia tecnológica existente entre ambos grupos de países. 
Esto implica que cuanto mayor sea la diferencia tecnológica entre el líder y el seguidor, gracias a la difusión de la tecnología internacionalmente disponible, mayores serán las mejoras potenciales que se podrán introducir en los procesos productivos del país seguidor y, como consecuencia de ello, más elevado será el crecimiento potencial de éste frente al país líder (Nelson y Phelps, 1966; Gomulka, 1971; Abramovitz, 1986 y 1989; Baumol, 1986; Abramovitz y David, 1996; Barro y Sala-i-Martin, 1997).

Desde el punto de vista de la política económica, resulta conveniente facilitar el proceso de difusión tecnológica eliminando cualquier traba o freno al proceso de catch-up tecnológico efectivo entre países líderes y países seguidores ya que, de lo contrario, se frenaría el progreso de los países más pobres y la convergencia entre las naciones. Los factores que pueden inhibir la difusión de tecnología son de tipo social, institucional, educativo o estructural.

Bajo el propósito de analizar las posibles consecuencias que tiene la hipótesis del catchup tecnológico sobre el crecimiento económico de los países, se modela matemáticamente primero esta hipótesis y, posteriormente, se introduce en los modelos de crecimiento de tipo neoclásico (por ejemplo, el modelo de Solow-Swan) de crecimiento endógeno y del neoestructuralismo cepalino.

No obstante que dichos modelos arrojan resultados a favor del rol que tiene el conocimiento tecnológico en el crecimiento económico, desde el punto de vista de la corriente principal (mainstream) se arguye que no hay suficiente evidencia empírica para probar esta importancia. De esta forma, en el marco de esta corriente teórica se plantea la hipótesis de que los flujos comerciales representan una buena aproximación de los flujos de conocimiento internacional y que, por ello, los flujos grandes de conocimiento que ocurren en economías de libre mercado agilizan el crecimiento económico de los países. Mark Rogers (2003) considera un concepto amplio de conocimiento, entendido como el conjunto de técnicas y tecnologías usadas en la producción de bienes y servicios y muestra evidencia empírica a favor de la tesis de que los países que son relativamente buenos para adquirir y difundir nuevos conocimientos muestran experiencia de crecimiento más rápido. En franca discusión con la vertiente teórica principal (mainstream), Rogers presenta evidencia empírica suficiente para sostener que el rol del conocimiento puede ser analizado y probado. Por lo tanto, usar el libre mercado como una aproximación a los flujos de conocimiento es necesariamente burdo y, debido a ello, la 
principal causa de los posibles engaños en los debates a nivel de política. En general, Rogers sostiene que el conocimiento no se difunde en forma perfecta entre firmas y países.

En el contexto de las hipótesis de crecimiento endógeno y el catch-up tecnológico, la discusión actual se centra sobre la forma en cómo factores de distinta naturaleza, como los institucionales, geográficos, históricos y económicos, influyen en la velocidad de la difusión internacional de tecnología.

Entre los textos más recientes se encuentran los siguientes: los trabajos de Keller (2001), Comin y Hobijn (2005), Spolaore y Wacziarg (2011) y Benhabib, Perla y Tonetti (2012). En el primer artículo, Keller estudia la difusión de tecnología entendida como tasa de cambio tecnológico en los países y cómo ésta incide en la distribución del ingreso a nivel mundial. Se trata de un trabajo sobre difusión internacional de la tecnología. El autor analiza la difusión a través de los canales de comercio internacional e inversión extranjera directa y usa como indicador de su análisis el gasto en I+D de los países. Concluye que la difusión internacional de la tecnología es un factor determinante del nivel de ingresos per cápita en el mundo.

El texto de Comin y Hobijn se centra en el estudio de los grupos de presión y cómo éstos pueden representar un obstáculo para la difusión de tecnología. Analizan los costos políticos que implica levantar barreras en el mercado de tecnología. Spolaore y Wacziarg analizan los obstáculos de largo plazo en la difusión internacional de las innovaciones tecnológicas. Así, se preguntan por la relación que hay entre la adopción de tecnologías y el grado de relación a largo plazo entre poblaciones de distintas generaciones. Usan como indicador la distancia genética con respecto a la frontera tecnológica mundial. Concluyen que las sociedades más alejadas de la frontera tecnológica tienden a enfrentar mayores costos de imitación.

Benhabib, Perla y Tonetti exploran la hipótesis de catch-up en los países de economías emergentes a través del análisis de la inversión en innovación e imitación en un modelo matemático propuesto por ellos. Llegan a la conclusión de que la inversión, no solo en innovación sino también en imitación, facilita la difusión de las innovaciones tecnológicas.

La importancia de estos trabajos reside en que la difusión de tecnología es vista como uno de los principales factores que explican el crecimiento económico a través de mecanismos endógenos. Sin embargo, la difusión tecnológica no es perfecta, como lo supone la corriente 
teórica principal (mainstream), ya que intervienen una serie de factores de distinta naturaleza: económicos, geográficos, institucionales e históricos.

Por último, otra forma de incorporar la hipótesis del catch-up tecnológico se inscribe en el neoestructuralismo de la Comisión Económica Para América Latina y el Caribe (CEPAL). Esta vertiente forma parte de la tradición heterodoxa en la teoría del crecimiento de largo plazo y retoma la perspectiva del estructuralismo latinoamericano de los fundadores de la CEPAL, en particular, de Raúl Prebisch (1949). Se argumenta a favor de la tesis de que las economías en desarrollo iniciaron sus procesos de industrialización cuando otros países habían acumulado ya capacidades tecnológicas sustanciales y, debido a que la difusión internacional de tecnología es lenta e irregular, emergió un sistema de tipo centro-periferia. De esta forma, los países de la periferia se mantienen a la zaga respecto de los países del centro, donde se producen nuevos sectores emergentes de bienes y servicios, de tal forma que su estructura productiva se diversifica. Empero, estas transformaciones alcanzan a sectores muy localizados (enclaves) de los países de la periferia. Como resultado, se mantienen altamente especializados en pocos sectores con baja productividad de sus trabajadores y actividades de subsistencia. Las dos estructuras, diversificada y homogénea (centro) versus especializada y heterogénea (periferia), emergen de la dinámica asimétrica capturada en el concepto de brecha tecnológica (Cimoli y Porcile, 2014).

A esta perspectiva estructuralista, se incorporan las ideas de la vertiente evolucionista sobre la dinámica de los paradigmas y revoluciones tecnológicas y las posibles ventanas de oportunidad que se pueden abrir para los países en desarrollo (Pérez, 2001; 2004 y 2011). Así, bajo esta perspectiva de desarrollo se sostiene que, a mayor brecha tecnológica, mayores serán las oportunidades para el aprendizaje relacionado con la imitación y los spillovers tecnológicos internacionales, de tal forma que los países de la periferia pueden ponerse al día. Es decir, que la brecha tecnológica ofrece la posibilidad a los países de la periferia, de que usen la tecnología externa existente para crear capacidades endógenas y reducir así las brechas de crecimiento y productividad respecto de los países del centro (Cimoli y Porcile, 2014).

Una vez presentada la discusión de la difusión tecnológica a nivel teórico, así como la perspectiva evolucionista que se sostiene en el presente trabajo de investigación, se discute a continuación la importancia que tiene el sistema de propiedad intelectual en el proceso de innovación en general y en la difusión tecnológica en particular, en dos sentidos: como 
sustento metodológico que hace posible medir y analizar el fenómeno de innovación tecnológica en su conjunto y, en particular, los procesos de difusión y, por otro lado, como un elemento que tiene influencia en ambos en la práctica. 


\subsection{Derechos de propiedad intelectual}

La propiedad intelectual protege a todas las creaciones intelectuales que son registradas, tanto las que tienen fines comerciales como las que tienen fines culturales. La propiedad intelectual se divide en dos categorías: i) la propiedad industrial, que incluye las patentes de invenciones, las marcas, los diseños industriales y las indicaciones geográficas; y ii) el derecho de autor, que incluye obras literarias, musicales, teatrales, arquitectónicas y artísticas en general (OMPI). En la práctica económica, los derechos de propiedad juegan un papel importante porque se hallan vinculados a una de las formas de obtener beneficios de las innovaciones tecnológicas por parte de las firmas.

Por otra parte, cabe mencionar que la innovación tecnológica es una de las actividades económicas más heterogéneas (Archibugi y Filippetti, 2010). Así, existe una diversidad de fuentes y métodos utilizados por las firmas para apropiarse de los beneficios provistos por las innovaciones. Tales métodos varían dependiendo de la industria, del mercado, de la economía e incluso del tiempo. Por ello, las firmas usan una combinación de estrategias jurídicas para apropiarse de los beneficios que se derivan de la innovación tecnológica: patentes, secreto industrial, diferenciación, etc., (Archibugi y Filippetti, 2010). Dependiendo de la posición de las firmas en el mercado nacional o internacional, elaboran sus estrategias con base en el sistema de derechos de propiedad intelectual (IPR, por sus siglas en inglés) o con base en los Acuerdos sobre los Aspectos de los derechos de propiedad intelectual relacionados con el comercio (TRIP, por sus siglas en inglés). En el siguiente apartado, se presentan las características de una de las estrategias usadas por las firmas para apropiarse de los beneficios derivados de la actividad inventiva, las patentes, como parte de los IPR. 


\section{Patentes}

Las patentes son instrumentos jurídicos que se usan en la vida económica (OCDE, 2009). Son documentos emitidos por una agencia gubernamental autorizada que otorga el derecho exclusivo de la producción o uso determinado de un nuevo dispositivo, aparato o proceso, en un número determinado de años (en la actualidad son veinte). Es un título jurídico que protege una invención. En el artículo 28 del Acuerdo sobre los aspectos de los derechos de propiedad intelectual relacionados con el comercio de la Organización Mundial del Comercio (OMC), se establece que:

Una patente le confiere a su titular los siguientes derechos exclusivos:

a) cuando la materia de la patente sea un producto, el de impedir que terceros, sin su consentimiento, realicen actos de: fabricación, uso, oferta para la venta, venta o importación para estos fines del producto objeto de la patente;

b) Cuando la materia de la patente sea un procedimiento, el de impedir que terceros, sin su consentimiento, realicen el acto de utilización del procedimiento y los actos de: uso, oferta para la venta, venta o importación para estos fines de, por lo menos, el producto obtenido directamente por medio de dicho procedimiento.

2. Los titulares de las patentes tendrán así mismo el derecho de cederlas o transferirlas por sucesión y de concertar contratos de licencia. (OMC, artículo 28 y citado en OCDE, 2009: 20).

Las patentes otorgan a su titular un conjunto de derechos de exclusividad sobre una invención (un producto o proceso nuevo, que supone un avance inventivo y es susceptible de aplicación industrial). Este conjunto de derechos otorga al titular de la patente una ventaja competitiva. Las patentes también pueden concederse bajo licencia o utilizarse para la creación o la financiación de una sociedad derivada o escindida. Por ello, los titulares pueden extraer valor de ellas, aun cuando ellos mismos no dispongan de capacidad de fabricación, por ejemplo, en el caso de las universidades. Como señala Calderón-Martínez (2014) al referirse a las universidades:

Los derechos de propiedad industrial no se consideran únicamente un documento legal sino que, en algunos casos, están presentes en aspectos que van desde el intercambio de conocimientos hasta la obtención de fondos para la investigación, la protección y la transferencia de resultados. Por ello, las patentes universitarias han generado un interés, tanto desde el punto de vista de la investigación académica como del de las políticas diseñadas para incentivar el cambio. (Calderón-Martínez, 2014: 38) 
Los inventores obtienen protección por distintas vías alternativas y optan en función de una u otra dependiendo de su estrategia de negocios nacional o mundial (OCDE, 2009). Puede ser por vía nacional, patentando en las oficinas nacionales de patentes; vía internacional, cuando los inventores hacen uso del procedimiento establecido en el Tratado de Cooperación en Materia de Patentes, PCT (por sus siglas en inglés), les permite proteger su invención en más de un país; por vía regional, para proteger sus inventos en oficinas regionales. Existen tres oficinas de patentes más grandes del mundo: la Oficina de Marcas y Patentes de Estados Unidos, USPTO (por sus siglas en inglés), la Oficina Europea de Patentes, EPO (por sus siglas en inglés), y la Oficina Japonesa de Patentes, JPO (por sus siglas en inglés). La USPTO y la JPO son nacionales, mientras que la EPO es regional-internacional. Si bien las primeras son oficinas nacionales, lo que significa que una patente concedida en la USPTO o en la JPO solo concede derechos en Estados Unidos o Japón, respectivamente, no significa que no tengan presencia internacional. Por el contrario, el tamaño de los mercados de tecnología de Estados Unidos y Japón, las hace representativas del mercado internacional.

Sin embargo, cabe señalar que el procedimiento para patentar en oficinas nacionales o internacionales varía, lo que influye en las decisiones que se puedan tomar, según la estrategia de negocios de los titulares. Por ejemplo, el examen en la EPO tiene dos fases, la búsqueda y el examen sustantivo, mientras que en los sistemas nacionales ante la JPO y la USPTO ambas fases se desarrollan conjuntamente. En el siguiente cuadro se presentan algunas de las diferencias y semejanzas entre estas tres oficinas de patentes.

Cuadro 1.7. Diferencias y semejanzas entre las tres oficinas de patentes más grandes del mundo

\begin{tabular}{|l|l|l|l|}
\hline Características & EPO de de & JPO & USPTO \\
\hline $\begin{array}{l}\text { La concesión de } \\
\text { patentes se basa en } \\
\text { presentación } \\
\text { presentación }\end{array}$ & $\begin{array}{l}\text { Prioridad de la invención } \\
\text { Duración de la patente }\end{array}$ & 20 años & 20 años \\
\hline Idioma de la solicitud & Inglés, Francés, Alemán & Japonés & Inglés \\
\hline Área cubierta & $\begin{array}{l}\text { Miembros del CPE y } \\
\text { países de "ampliación" }\end{array}$ & Japón & Estados Unidos \\
\hline Petición de examen & Sí, en 6 meses & Sí, en 3 años & No \\
\hline
\end{tabular}




\begin{tabular}{|l|l|l|l|}
\hline $\begin{array}{l}\text { Publicación de la la } \\
\text { solicitud }\end{array}$ & $\begin{array}{l}18 \text { meses después de la } \\
\text { fecha de prioridad }\end{array}$ & $\begin{array}{l}18 \text { meses después de la } \\
\text { fecha de prioridad }\end{array}$ & $\begin{array}{l}18 \text { meses después de la } \\
\text { fecha de prioridad }\end{array}$ \\
\hline $\begin{array}{l}\text { ¿Hay objetos excluidos } \\
\text { de la patentabilidad o } \\
\text { que no se consideren } \\
\text { invenciones? }\end{array}$ & Sí & Sí & Sí \\
\hline Sistema de oposición & Sí & Sí & Sí \\
\hline
\end{tabular}

Fuente: tomado de OCDE, 2009: 57.

Estas diferencias y semejanzas de los sistemas de patentes son consideradas en el uso de datos de patentes, ya que forma parte de la variabilidad intrínseca de esta información.

Aunque los sistemas de patentes presentan diferencias, tienen como propósito fomentar la invención y el progreso tecnológico facilitando un plazo temporal de exclusividad sobre la invención a cambio de su divulgación (OCDE, 2009). En este sentido, las patentes, como parte del sistema de derechos de propiedad intelectual, si bien pueden dar origen a situaciones de conflicto donde el beneficio privado se opone al beneficio público que resulta del uso de ciertos conocimientos (Moreno, 2009 y Flax, 2012), no deja de ser uno de los canales de difusión del nuevo conocimiento tecnológico no incorporado, es decir, es una de las vías a través de las cuales se difunde un nuevo paradigma tecnológico. Por este motivo, la información contenida en ellas da luz, al menos en parte, de las pautas de difusión que pueden seguir los nuevos paradigmas tecnológicos en los países industrializados y emergentes. En el siguiente apartado se discute el uso de datos de patentes en el análisis del cambio tecnológico y, en particular, en el estudio de la difusión tecnológica.

\section{Análisis del cambio tecnológico y datos de patentes}

El problema de cómo medir el cambio tecnológico ha sido tarea asumida por economistas, historiadores de la economía e historiadores de la tecnología (Basberg, 1987). En particular, el uso de patentes y estadísticas de patentes para medir el cambio tecnológico y sus implicaciones en la economía han fascinado a los economistas desde mitad del siglo XX, por lo menos (Basberg, 1987). Las cuestiones acerca de los factores del crecimiento económico, la tasa de cambio tecnológico, la posición competitiva de firmas y países, la dinámica de estructuras 
industriales y todo lo que gira en torno a la actividad inventiva, como la difusión del conocimiento tecnológico generado a través de ella, son algunas de las cuestiones de interés de los economistas (Griliches, 1998). Aunque existen otros métodos para abordar estas cuestiones, el uso de patentes se presenta atractivo dada su relación directa con la actividad inventiva y la información que contiene sobre otros factores que giran en torno a esta actividad. En general, las patentes incluyen la siguiente información: número de publicación, fecha de solicitud y fecha de asignación; nombre y dirección del o los inventores, nombre y dirección del solicitante o cesionario; título, resumen, descripción detallada de la misma, número de reivindicaciones, una serie de códigos que corresponden a grupos de la clasificación tecnológica, listado de referencias a otras patentes (citas hacia atrás) y patentes que la citan (citas hacia adelante) y citas de la literatura científica relevante para determinar la patentabilidad de la invención, entre otra información. Sin embargo, cabe señalar que el uso de esta metodología ha generado discusión entre los economistas debido a las limitaciones que presenta y la forma en que se ha usado.

En el marco de la discusión en economía sobre los factores que determinan la actividad inventiva destaca el trabajo de Schmookler (1952) no solo porque al proponer la tesis de que la oferta de tecnología depende, principalmente, de factores económicos, cuestionó la idea difundida y aceptada entre los economistas de que la tecnología es un factor exógeno a la economía sino, además, por usar una metodología basada en patentes y datos de patentes para sustentar empíricamente su tesis. El trabajo de Schmookler (1952) es pionero en este sentido e inició una metodología seguida por otros economistas que la han desarrollado desde entonces, tales como el grupo NBER (Griliches, Hall, Hausman, Jaffe, Pakes y Schankerman, entre otros), el grupo de Jale (Levin, Nelson, Klevorick, Reiss, Cohen, entre otros) sin contar a los seguidores de estos investigadores (Griliches, 1998). Todos ellos se han formulado cuestiones tales como: ¿se pueden usar las estadísticas de patentes? ¿Se pueden utilizar para interpretar tendencias de largo plazo de la economía? ¿El hecho de que las grandes empresas tienen una proporción por dólar menor, implica rendimientos decrecientes de este tipo de inversiones? ¿Se pueden usar estos datos para apoyar la conclusión de que las fuerzas de la demanda son factores que determinan con mayor fuerza el progreso tecnológico como lo pensaba Schmookler? (Griliches, 1998); ¿Las estadísticas de patentes son útiles para estudiar la difusión del conocimiento tecnológico?¿Se pueden usar las citas de patentes para analizar las 
pautas de difusión tecnológica? (Jaffe et al., 1993; Jaffe y Trajtenberg, 1999; Hall et al., 2001; Hu y Jaffe, 2003; Maurseth, 2005 y Gay et al., 2005).

Sobre la literatura que usa información de patentes, Basberg (1987) señala que se puede dividir en tres principales categorías: i) los estudios relacionados con la legislación en el uso de patentes; ii) los estudios sobre el sistema de patentes; iii) aquellos estudios que usan las estadísticas de patentes como indicador de la tecnología. A su vez, estos últimos pueden dividirse en tres grandes grupos: a) aquellos trabajos que abordan las relaciones entre cambio tecnológico y desarrollo económico; b) los estudios que analizan la difusión de la tecnología de un país a otro; c) aquellos que analizan los procesos de innovación en sí mismos, para valorar y evaluar el resultado de la actividad de investigación. En este último grupo de estudios se utilizan otros indicadores tales como el gasto en I+D y productividad, además de patentes.

Ahora bien, en aquellos trabajos que usan datos de patentes para estudiar las relaciones entre el cambio tecnológico y el desarrollo económico, aparece el siguiente problema: si bien el uso de patentes llama la atención por su relación con la actividad inventiva y disponibilidad (Griliches, 1998), la relación entre las patentes, las invenciones y las innovaciones no es sencilla. Así, si se consideran, en palabras de Basberg: "las relaciones entre invenciones, innovaciones y patentes, las cuales son producidas por ejemplo en un año en una firma, industria o país. Solamente algunas de estas invenciones son patentadas (...) Los datos de patentes contienen obviamente algunas innovaciones, a su vez éstas, contienen invenciones con algún valor comercial". (Basgerg: 1987: 133). Detrás de estas diferencias existen varios motivos por los cuales los inventos no se patentan: cuando un invento tiene potencial económico se prefiere usar el secreto en lugar de la patente; tampoco se patenta cuando se considera fácil la imitación (Basberg, 1987). En este sentido, las patentes representan un indicador de tecnología, es decir, una aproximación (proxy) para describir tendencias. Los datos de patentes son usados como un indicador de distintos aspectos del proceso de innovación: investigación, invención, desarrollo, producción y difusión.

Otros problemas que observa Griliches (1998) en estos trabajos tiene que ver con la clasificación y la variabilidad intrínseca. El primero es, básicamente, un problema técnico. La tasa de asignación y el rigor de la examinación varían mucho en los diferentes países y a través del tiempo. El segundo problema se refiere al hecho de que las patentes difieren enormemente en su clasificación económica y técnica. La variabilidad está fuertemente asociada con las 
diferencias en los procedimientos y recursos de las diversas oficinas de patentes lo que implica, por lo tanto, también diferencias en la calidad promedio de una patente asignada en los diferentes países y periodos (Griliches, 1998). Cuando se usen estos datos en el análisis del cambio tecnológico, será necesario tomar en cuenta estas limitaciones asociadas a la información de patentes. En este mismo sentido, Archibugi y Pianta (1996) señalan las siguientes desventajas en el uso de patentes y datos de patentes: i) no todas las invenciones son técnicamente patentables; ii) no todas las invenciones se patentan (el secreto industrial suele funcionar como una forma alternativa de protección a las innovaciones); iii) las empresas tienen una propensión distinta a patentar, dependiendo de su posición en los mercados nacional e internacional; iv) a pesar de la existencia de tratados internacionales sobre patentes entre los principales países industriales, cada oficina nacional de patentes tiene sus propias características institucionales.

A pesar de estos problemas en el uso de datos de patentes, Trajtenberg et al. (2006) reconocen que, sin lugar a dudas, el recurso más rico en cuanto a datos dentro del mundo de la innovación y el cambio tecnológico está constituido por patentes. También Basberg (1987) y Griliches (1998) coinciden en que existe todo un espectro de opciones entre el uso de la información contenida en las patentes individuales, grupos y clases de patentes y los datos de la actividad total de las patentes. Además, la elección de los datos puede ser en corte transversal o en series de tiempo. Pero la elección de los datos ya depende del propósito del análisis. La elección de datos en series de tiempo es confiable, ya que es posible reconstruir las series hacia atrás en, generalmente, periodos largos. Los datos de corte transversal son una herramienta útil en estudios comparativos, tanto a nivel de industrias como a nivel de países. Una conclusión importante de estos autores es que existe una relación fuerte entre las patentes y los gastos en $\mathrm{I}+\mathrm{D}$, por ello, las patentes pueden ser un buen indicador de la actividad inventiva (Griliches, 1998), sin perder de vista las limitaciones mencionadas. En este sentido, Archibugi y Pianta (1996) señalan que, en su calidad de indicador tecnológico, las patentes tienen una serie de ventajas: i) son un indicador apropiado para capturar la dimensión de propiedad y la dimensión competitiva del cambio tecnológico; ii) las solicitudes que se presentan son para aquellas invenciones cuyos beneficios, en promedio, se espera que sean mayores a sus costos; iii) las patentes proporcionan información no solo respecto de la tasa de la actividad inventiva, sino también, respecto de su dirección; iv) las estadísticas de patentes se 
encuentran disponibles en amplio número y para muy largos periodos de tiempo; las patentes son documentos públicos y, por ello, pueden ser un indicador de la difusión del conocimiento tecnológico. En el siguiente cuadro, se resumen las ventajas y desventajas que tiene el uso de datos de patentes en el estudio del cambio tecnológico.

\section{Cuadro 1.8. Ventajas y desventajas en el uso de datos de patentes para estudiar el cambio tecnológico y sus implicaciones en la economía}

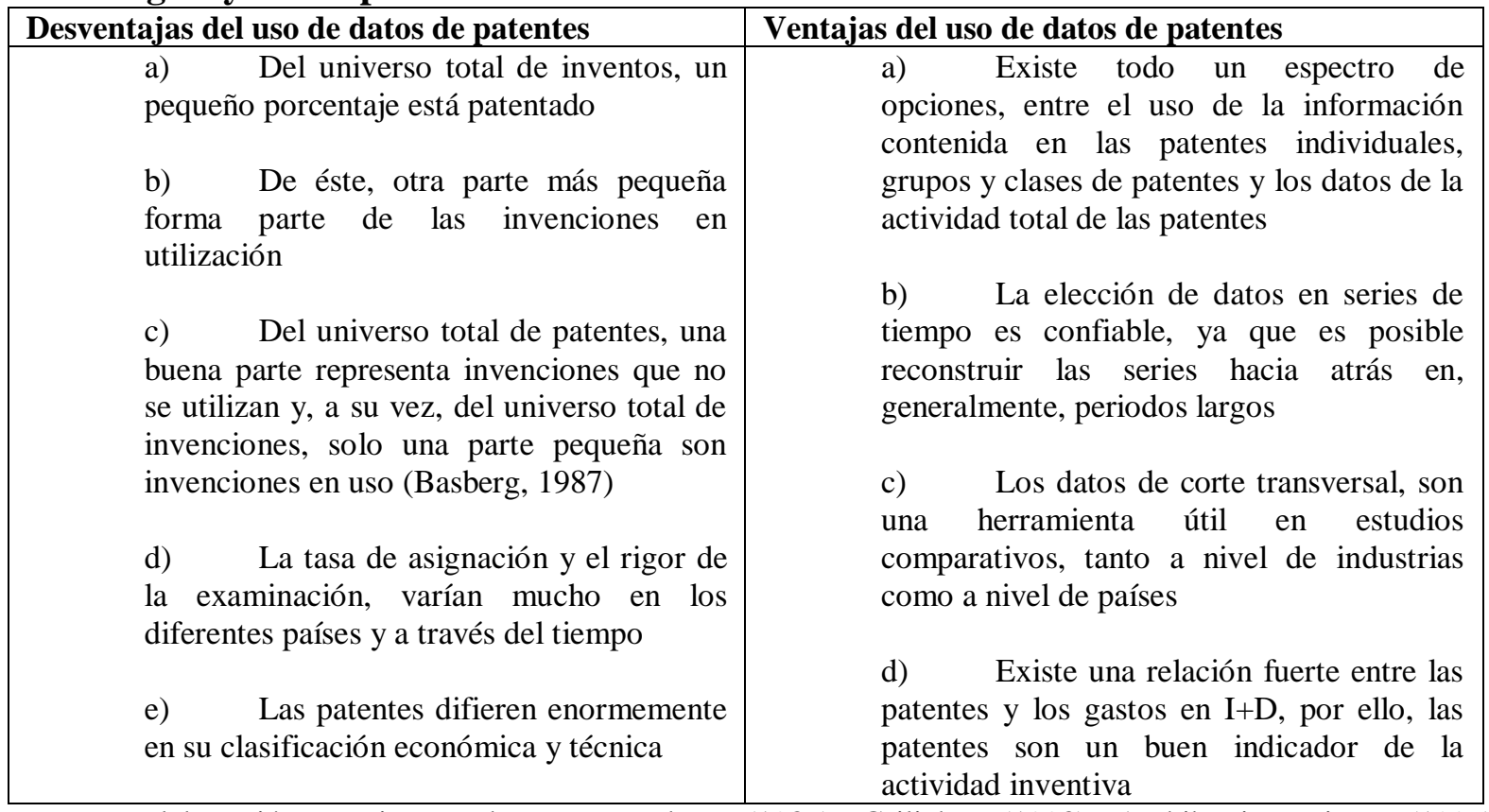

Fuente: elaboración propia con base en Basberg (1987), Griliches (1998), Archibugi y Pianta (1996) y Trajtenberg, et al. (2006).

Citas de patentes y difusión de conocimiento tecnológico

Como se mencionó, las patentes contienen información sobre citas de otras patentes (citas hacia atrás), citas recibidas de otras patentes (citas hacia adelante) y citas de artículos científicos. En conjunto, se usan para valorar la patentabilidad de la invención y definir la legitimidad de las reivindicaciones (claims) de una nueva solicitud de patente. Las citas hacia atrás hacen referencia al estado de la técnica, ya que indican los conocimientos previos a la invención (pueden ser un indicador del stock de conocimientos tecnológicos), también pueden ser utilizadas para justificar la falta de novedad de la invención citada. En conjunto, las citas 
son usadas como un indicador del valor tecnológico y comercial de la patente. Además, las citas indican las fronteras jurídicas de las reivindicaciones de la solicitud de patente en cuestión (OCDE, 2009).

En otro sentido, desde el punto de vista de la difusión del conocimiento (científico y tecnológico), las citas son un indicador que puede ayudar a estudiar los patrones de difusión. Así, las citas de artículos científicos que aparecen en las patentes pueden ser un indicador de los vínculos entre el sector académico y el inventivo. En particular, las citas de patentes hacia adelante, son un indicador de la difusión de conocimiento tecnológico ya que si una patente B cita a la patente A, significa que la primera representa una parte del conocimiento previo sobre el que avanza la patente B (OCDE; 2009), o dicho de otra forma, significa que el conocimiento tecnológico se difundió al pasar de la patente A a la patente $\mathrm{B}$.

Ahora bien, si se consideran las limitaciones que tienen los datos de patentes como indicador del cambio tecnológico ya mencionadas, se pueden reconocer las limitaciones de las citas hacia adelante como indicador de difusión de conocimiento tecnológico. En primer lugar, dado que las patentes solo reflejan una parte de la actividad inventiva, las citas de patentes también reflejan la difusión de solo una parte del conocimiento tecnológico generado a nivel industrial o de país. Además, las citas de patentes son un indicador del conocimiento tecnológico no incorporado todavía en bienes de consumo, maquinaria y equipo. Representa solo un canal de difusión de conocimiento tecnológico no incorporado, ya que existen otros canales tales como conferencias, movilidad de los inventores, asistencia técnica, etcétera.

No obstante estas limitaciones, el uso de citas de patentes hacia adelante en el estudio de la difusión y derramas del conocimiento tecnológico es cada vez mayor. Algunos autores que destacan en este tipo de análisis son: Jaffe et al. (1993); Jaffe y Trajtenberg (1996 y 1999); Hall et al. (2001); Hu y Jaffe (2003); Gay et al (2005); MacGarvie (2005); Maurseth (2005); MacGarvie (2006); Thompson (2006); Fisher (2009) y Montobbio y Sterzi (2010). Estos autores toman como fuentes de información las patentes registradas en la USPTO y en EPO y realizan análisis econométricos. Los trabajos estudian distintos aspectos de la derrama de conocimientos tecnológicos: difusión sectorial, medición de la difusión internacional, distancia geográfica y distancia tecnológica, así como sus efectos sobre la productividad y crecimiento a nivel sectorial, nacional y regional. 
Cabe señalar que, al interior de estos trabajos, se discuten y proponen mejoras en el uso de esta metodología, tal como se discute en el trabajo de Marco (2006), quien al estimar la probabilidad de las citas de patentes hacia adelante encuentra evidencia sobre la heterogeneidad (variabilidad) no observada. Este autor propone que la estimación de la probabilidad proporciona un medio para separar la calidad de la patente de la "inflación" de la cita. En el siguiente cuadro se presentan las ventajas y desventajas en el uso de citas de patentes en el estudio de la difusión del conocimiento tecnológico.

\section{Cuadro 1.9. Ventajas y desventajas del uso de citas de patentes en los estudios de difusión del conocimiento tecnológico}

\begin{tabular}{|c|c|}
\hline Desventajas del uso de citas de patentes & Ventajas del uso de citas de patentes \\
\hline $\begin{array}{l}\text { a) Las citas de patentes reflejan la } \\
\text { difusión de solo una parte del conocimiento } \\
\text { tecnológico generado a nivel industrial o de } \\
\text { país } \\
\text { b) Las citas de patentes son un } \\
\text { indicador del conocimiento tecnológico no } \\
\text { incorporado en bienes de consumo, } \\
\text { maquinaria y equipo } \\
\text { c) Representa solo un canal de } \\
\text { difusión de conocimiento tecnológico no } \\
\text { incorporado, ya que existen otros canales } \\
\text { tales como conferencias, movilidad de los } \\
\text { inventores, asistencia técnica, etc. }\end{array}$ & $\begin{array}{l}\text { a) Las citas de patentes hacia } \\
\text { adelante, son un indicador de la difusión de } \\
\text { conocimiento tecnológico ya que si una } \\
\text { patente B cita a la patente A, significa que } \\
\text { la primera representa una parte del } \\
\text { conocimiento previo sobre el que avanza la } \\
\text { patente B (OCDE, 2009) } \\
\text { b) Representa un canal de difusión de } \\
\text { conocimiento tecnológico no incorporado, } \\
\text { ya que existen otros canales tales como } \\
\text { conferencias, movilidad de los inventores, } \\
\text { asistencia técnica dearion de } \\
\text { c) cas citas de patentes permite } \\
\text { estudiar distintos aspectos de la derrama de } \\
\text { conocimientos tecnológicos: difusión } \\
\text { sectorial, medición de la difusión } \\
\text { internacional, distancia geográfica y } \\
\text { distancia tecnológica, así como sus efectos } \\
\text { sobre la productividad y crecimiento a nivel } \\
\text { sectorial, nacional y regional }\end{array}$ \\
\hline
\end{tabular}

Fuente: elaboración propia con base en OCDE (2009), Jaffe et al. (1993); Jaffe y Trajtenberg (1996 y 1999); Hall et al. (2001); Hu y Jaffe (2003); Gay et al (2005); MacGarvie (2005); Maurseth (2005); MacGarvie (2006); Thompson (2006); Fisher (2009) y Montobbio y Sterzi (2010).

Una vez expuesta la importancia que tiene el sistema de propiedad intelectual y, en particular, el sistema de patentes en el proceso de difusión tecnológica así como una fuente de información en los estudios de innovación y difusión de tecnología, se concluye este capítulo haciendo referencia a los diferentes estudios empíricos de la difusión de tecnología, con el propósito de ubicar entre ellos los estudios con base en citas de patentes ya referidos. 


\subsection{Estudios empíricos sobre la difusión tecnológica}

Los estudios empíricos de la difusión tecnológica se pueden clasificar en dos grandes grupos: los que analizan la difusión de tecnología no incorporada (disembodied) y los que analizan la difusión de tecnología incorporada en maquinaria y equipo (OCDE, 1992). La primera se caracteriza por el derrame de investigación y por la capacidad de absorción por parte de las empresas. Cabe señalar que la expresión “derrame de investigación” se refiere al conocimiento creado por una empresa que potencialmente puede llegar luego a manos de otras. La capacidad de absorción es la capacidad de una empresa de aprender a usar tecnología desarrollada por otra mediante un proceso que requiere de grandes inversiones, en particular de naturaleza intangible. Así, la I+D crea nuevos productos y aumenta la capacidad de las empresas de aprender a prever y seguir el curso de futuras invenciones (OCDE, 1992).

El conocimiento tecnológico incorporado se difunde al pasar de las industrias proveedoras de maquinaria y equipo a las industrias que requieren de éstos para producir otros bienes. Cabe señalar que los estudios de difusión tecnológica realizados en el marco del enfoque estándar se refieren a este tipo de conocimiento tecnológico. En los primeros apartados del presente capítulo se mencionaron las críticas que el enfoque evolucionista plantea al enfoque estándar y, en particular, a la modelación de la difusión tecnológica a través de la ecuación logística, resaltando que la velocidad de difusión solo es explicada con base en factores por el lado de la demanda de tecnología (costos de adopción de tecnología, beneficios esperados por el uso de innovaciones y beneficios obtenidos por otros agentes), pero deja de lado los factores de la oferta (heterogeneidad de los agentes, marco institucional, reglamentos y programas, artículos, conferencias, cursos, gasto en I+D tanto público como privado y aprendizaje por la práctica de los trabajadores). Por estas limitaciones metodológicas de los estudios de difusión de tecnología incorporada a maquinaria y equipo, no son considerados en el estudio de la difusión de paradigmas tecnológicos.

Los estudios empíricos que se ubican en el primer grupo, es decir, aquellos que analizan la difusión de tecnología no incorporada, captan aspectos sistémicos como las interacciones entre difusión e innovación y los factores socioeconómicos que los condicionan. Los estudios 
tienen como propósito general medir la capacidad de absorción de las empresas, las derramas de la investigación, así como los factores que subyacen a la eficacia y velocidad del proceso. Se reconoce también que la transmisión de conocimientos tecnológicos no incorporados se da a través de diversos canales: están contenidos en las descripciones de nuevos productos o procesos que se encuentran en publicaciones, catálogos y formularios para solicitar patentes; se difunden a través de conferencias y seminarios; a través de la movilidad del capital humano u otras formas de cooperación entre empresas. Estos diferentes canales de transmisión generan diferentes patrones de difusión con efectos sobre la productividad, la competitividad y los incentivos para la innovación (OCDE, 1992). Por ello, estos estudios son más acordes con el marco conceptual de la teoría evolucionista y, en particular, con el concepto de difusión de paradigmas tecnológicos.

A su vez, una parte importante de la literatura perteneciente a este primer grupo se refiere a la difusión de tecnología no incorporada organizada, es decir, aquella que ocurre cuando las empresas venden los derechos sobre cierta patente o emiten la licencia de una innovación. Debido a que las patentes, aún con sus limitaciones ya mencionadas, representan una fuente rica de información, existe un conjunto amplio de trabajos sobre difusión que toman como indicador las citas que se hacen sobre patentes. En el apartado anterior se mencionaron algunos autores que destacan en este tipo de análisis. A continuación se mencionan algunas de sus contribuciones en los análisis de difusión de tecnología.

Jaffe et al. (1993), usando datos de citas de patentes, comparan la localización geográfica del inventor (primer inventor) con el origen geográfico de la patente citada para medir el alcance de la difusión tecnológica dentro de E. U. En la misma línea de trabajo, Jaffe y Trajtenberg (1996) comparan la magnitud de los flujos tecnológicos a través de países. MacGarvie (2005) mide la difusión internacional de conocimientos tecnológicos y muestra que los efectos difusores se intensifican por la proximidad física y por compartir un idioma común. Globerman et al. (2000) estudian los canales de la difusión de conocimiento extranjero hacia Suecia, sus resultados muestran que las empresas multinacionales y pequeñas y medianas locales hacen más referencias a países con un gran stock de patentes y próximos a Suecia. MacGarvie (2006), usando citas de patentes de empresas francesas, descubrió que las invenciones de exportadores e importadores tienen más probabilidad de estar influenciadas por tecnología extranjera que las invenciones de empresas que no se comprometen en actividades 
de comercio internacional, lo cual, muestra evidencia de que las empresas que desarrollan actividad internacional aprenden de la tecnología extranjera.

En otro aspecto, Laursen y Meliciani (2002) muestran que los flujos de conocimiento tecnológico que ocurren entre sectores también aportan evidencia en torno a la proximidad tecnológica. Duguet y MacGarvie (2005) muestran que las citas, además de estar geográficamente concentradas, también están concentradas dentro de las mismas clases tecnológicas. Al respecto, Jaffe y Trajtenberg (1999) señalan que las patentes dentro de la misma clase tecnológica tienen mayor probabilidad de ser citadas que las patentes de distinta clase tecnológica. Gay et al. (2005) argumentan que una patente que es frecuentemente citada lo es más por patentes de otros campos tecnológicos, lo que indica que la patente citada tiene una difusión sectorial más amplia y, por lo tanto, mayor importancia tecnológica. Maurseth (2005) muestra que las patentes que reciben citas de campos tecnológicos diferentes tienen una tasa de supervivencia mayor que otras patentes, mientras que las patentes que reciben citas dentro del mismo campo tecnológico decaen antes en su uso.

Otros trabajos sobre proximidad geográfica y tecnológica como el de Fisher et al. (2009), analizan los patrones de difusión en dos niveles geográficos: a nivel regional y a nivel de país, usando la información proporcionada por la EPO y haciendo un seguimiento de las citas de patentes de las firmas con alta tecnología. El estudio muestra que la derrama de conocimientos no solo depende de la distancia geográfica sino también de la distancia tecnológica. Los flujos de conocimiento interregionales residen específicamente en la industria, es decir, está localizada, y ocurren más a menudo entre regiones ubicadas cerca en el espacio tecnológico. El estudio de Montobbio y Sterzi (2010) explora la importancia de la derrama de conocimiento internacional en los países de América Latina. A través de la información de citas de patentes proporcionadas por la USPTO, se estudia el impacto de la derrama de conocimientos a través de tres canales: la actividad de I+D en el extranjero, la derrama de és ta relacionada con citas de patentes y la derrama por los contactos cara a cara entre investigadores. Los resultados, con base en datos de Argentina, Brasil, Chile, Colombia y México, sugieren que la derrama internacional de conocimiento desde los países que conforman el Grupo de los cinco (G-5), fue un determinante significativo de la actividad inventiva durante el periodo 1988-2003. En particular, el stock de ideas producido en Estados 
Unidos tuvo un fuerte impacto sobre la actividad generadora de patentes internacional de los países de América Latina.

Los trabajos se enfocan en el estudio de dos dimensiones: la espacial y la sectorial. En la primera se resaltan la medición, el alcance y la comparación entre países de la difusión del conocimiento tecnológico. En la dimensión sectorial se pone énfasis en la dimensión, frecuencia de cita y tasa de supervivencia de las patentes a nivel de sector tecnológico. En el cuadro 1.10, se describen estas características de los estudios empíricos sobre difusión de conocimientos tecnológicos a través de análisis de citas de patentes, así como los autores representativos.

Cuadro 1.10. Características de estudios empíricos sobre difusión de tecnología con base en citas de patentes

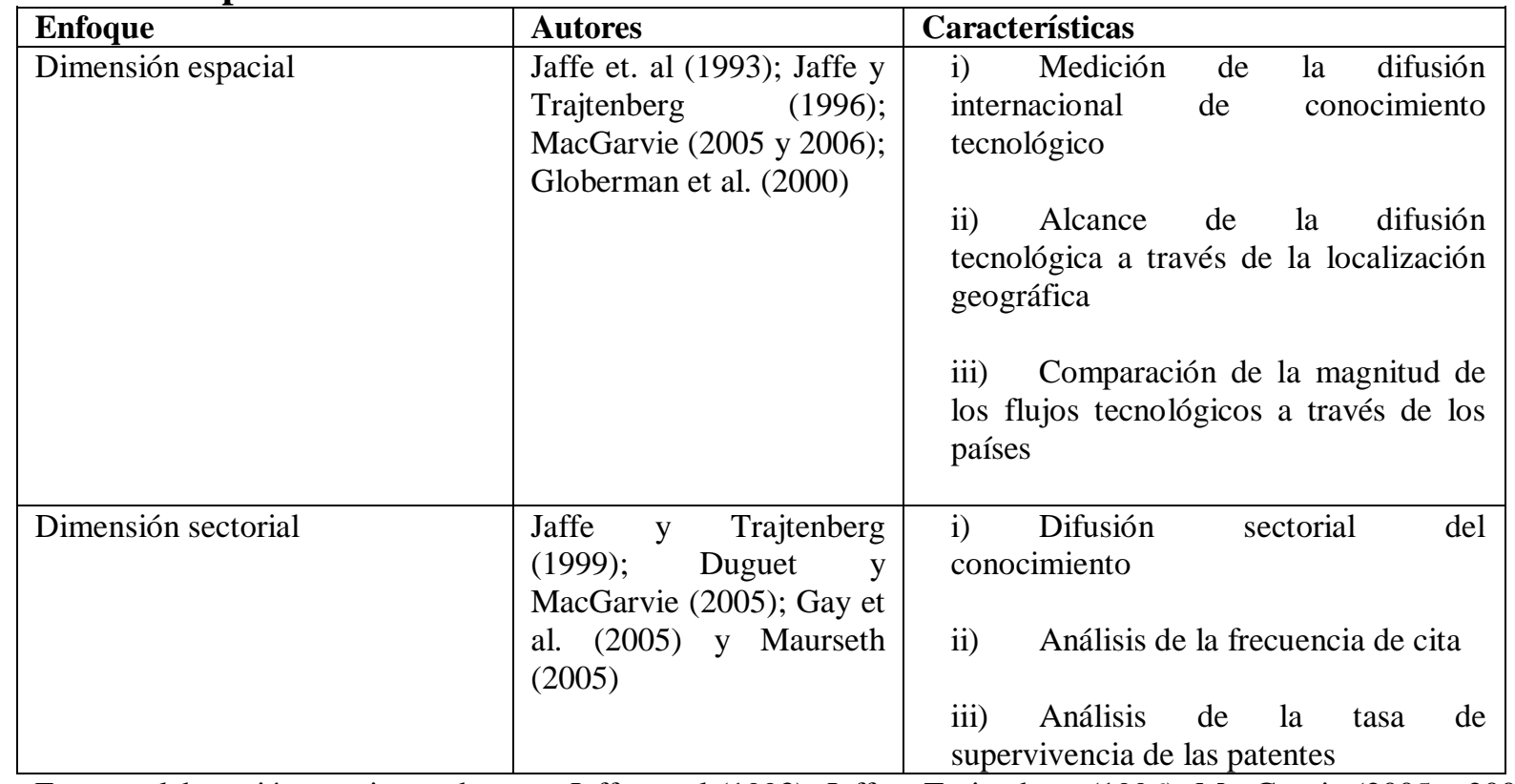

Fuente: elaboración propia con base en Jaffe et. al (1993); Jaffe y Trajtenberg (1996); MacGarvie (2005 y 2006); Globerman et al (2000); Jaffe y Trajtenberg (1999); Duguet y MacGarvie (2005); Gay et. al (2005) y Maurseth (2005).

Lo relevante de estos estudios sobre difusión de tecnología con base en citas de patentes es que pueden proporcionar información sobre la difusión de un nuevo paradigma tecnológico a nivel de actividad inventiva y sobre su configuración espacio-temporal, analizando los factores que influyen en su velocidad de difusión. Como se argumentó, la información contenida en las patentes puede ser una aproximación en el análisis de las características 
sistémicas asociadas a la innovación y difusión de tecnología en los sistemas nacionales o internacionales de innovación. Además, estudiar dichos elementos, permite aproximarse a la comprensión de los paradigmas tecnológicos en el marco de la teoría evolucionista (Dosi, 1982). Los estudios empíricos sobre trayectorias tecnológicas pueden complementar los estudios de difusión al enfocarse en la dirección o progreso del paradigma tecnológico (Dosi, 1982). Cabe señalar que el presente trabajo solo se enfoca en el estudio de los factores que explican las pautas de la difusión de paradigmas tecnológicos en el caso particular de la nanotecnología. No obstante, cabe mencionar las características que tienen los trabajos sobre trayectorias tecnológicas para comprender de qué manera pueden complementar los estudios de difusión de paradigmas tecnológicos.

De esta forma, en los análisis sobre trayectorias tecnológicas, una pregunta central es ¿cómo determinar los factores que condicionan el progreso tecnológico dentro de un paradigma tecnológico? En Hilbert y Cairó (2008) se establece que la planificación de las diversas soluciones tecnológicas, por lo general, está vinculada a su rendimiento en un área específica y en un momento determinado, y contempla varios factores. El primero de ellos tiene que ver con los índices de rendimiento seleccionados como variables para medir el progreso técnico. Esta medición se concentra en el diseño y funcionalidad del sistema o en su rendimiento e impacto.

Un segundo aspecto tiene que ver con el momento en que se va a medir el rendimiento. Se puede esperar que tecnologías específicas sigan un proceso de progreso continuo, combinado con procesos de progreso técnico discontinuos correspondientes a los cambios de paradigma. De esta forma, al graficar el rendimiento de las soluciones tecnológicas en el eje Y, y el tiempo en el eje $X$, se puede esperar un nivel considerable de dispersión, lo cual sugiere no solo cambios de paradigma sino también la intervención de factores socioeconómicos en algún momento.

En el caso específico de las TIC se distinguen cuatro subsistemas técnicos en los que se basa: interoperación, transmisión, procesamiento y almacenamiento de información. En un estudio previo, Hilbert y Cairó (2008) describieron las trayectorias tecnológicas para cada uno de estos subsistemas. Algunos datos interesantes son los siguientes: se observó un crecimiento exponencial de la capacidad de comunicación en el mundo. Así, en 1970 la capacidad instalada 
correspondía a unos 5.72 kibits ${ }^{4} /$ persona, en 1980 a unos 8.89 kibits/persona y en 1990 la capacidad instalada correspondía a unos 12.43 kibits/persona. Con la aparición de internet por banda ancha, este crecimiento ha sido explosivo. En 1995 cada habitante contó en promedio con 15.51 kibits/persona, en 2000 con 34.23 kibits/persona y en 2006 con 223.75 kibits/persona. En otras palabras, entre 1996 y 2006 la capacidad de intercambiar información se multiplicó por el factor 13 (Hilbert y Cairó, 2008).

En otros estudios sobre trayectorias tecnológicas se pone énfasis en la perspectiva de la empresa innovadora. Por ejemplo, en Jasso (2004) se propone analizar la trayectoria tecnológica de una empresa o industria como una forma de explicar su crecimiento o ciclo de vida. Para ello, se establecen algunos indicadores que se refieren a las fases del ciclo de vida de una empresa (1) innovadora, 2) madurez-estancamiento y 3) madurez-obsolescencia): participación de las innovaciones tecnológicas de un sector en el nivel internacional; participación sectorial en el mercado mundial y participación sectorial en la producción mundial. En Martínez et al. (2009) se intenta reconstruir la trayectoria productiva y tecnológica de General Motors Complejo Silao de 1995 a 2009. Los autores intentan rescatar las redes de colaboración que establecen con sus proveedores. Se apoyan en información recabada a través de entrevistas realizadas al equipo directivo y mandos medios de la empresa durante octubre y noviembre de 2008. En Solari y Padilla (2006) se elabora una propuesta para evaluar el desempeño y perspectivas de las empresas locales. Para ello, se propone considerar siete elementos clave: nivel del valor agregado, grado de engranamientos locales, combinaciones entre especialización y diversificación, grado de flexibilidad, trayectoria tecnológica, nivel de sustentabilidad local y papel frente a la acumulación de capital social local. Nótese que en este artículo la trayectoria tecnológica aparece como parte del análisis propuesto. En otro estudio, Alonso et al. (2000) plantean analizar la industria maquiladora de exportación en México bajo la siguiente pregunta central: ¿qué puede hacerse para potenciar los aspectos positivos y mitigar los negativos de la industria maquiladora? Los autores señalan la importancia que tiene comprender la trayectoria tecnológica y de aprendizaje de las empresas para dar respuesta a la pregunta. En el cuadro 1.11, se resumen las características de estudios empíricos sobre trayectorias tecnológicas.

\footnotetext{
${ }^{4}$ Unidad de medida que equivale a 1024 bits.
} 
Cuadro 1.11. Características de estudios empíricos sobre trayectorias tecnológicas

\begin{tabular}{|l|l|l|}
\hline Enfoque & Autores & Características \\
\hline Paradigmas tecnológicos & Hilbert y Cairó (2008) & $\begin{array}{l}\text { i) Índices de rendimiento como variable } \\
\text { para medir el progreso técnico } \\
\text { ii) Momento en que se mide el rendimiento }\end{array}$ \\
\hline Firmas & $\begin{array}{l}\text { Jasso (2004); Martínez } \\
\text { et. al (2009); Solari y } \\
\text { Padilla (2006); Alonso } \\
\text { et. al (2000). }\end{array}$ & $\begin{array}{l}\text { i) Explicación del ciclo de vida de } \\
\text { empresas o industrias a través de trayectorias } \\
\text { tecnológicas } \\
\text { ii) Uso de trayectorias tecnológicas para } \\
\text { evaluar el desempeño de empresas locales }\end{array}$ \\
& $\begin{array}{l}\text { Tii) Trayectoria tecnológica } \\
\text { trayectoria de aprendizaje de las firmas }\end{array}$ \\
\hline
\end{tabular}

Fuente: elaboración propia con base en Hilbert y Cairó (2008); Jasso (2004); Martínez et. al. (2009); Solari y Padilla (2006); Alonso et al (2000).

$\mathrm{Si}$ bien los estudios empíricos sobre trayectorias tecnológicas complementan los análisis sobre difusión de paradigmas tecnológicos en el marco de la teoría evolucionista, en el sentido de que permiten medir el progreso de los paradigmas, la presente investigación solo se enfoca, como ya se mencionó, en el análisis de los patrones de difusión de la nanotecnología como un paradigma tecnológico emergente. El estudio de su progreso queda como un problema abierto para una investigación posterior. De esta forma se adopta la metodología sustentada en la información contenida en las patentes, en particular, las asignadas en el campo tecnológico de nanotecnología. Como se argumentó, se trata de una metodología que permite medir, en forma aproximada, los patrones de difusión de los paradigmas tecnológicos a través de citas de patentes. En este sentido, esta metodología mide, aproximadamente, los flujos de los nuevos conocimientos tecnológicos a nivel de actividad inventiva. En forma específica, la metodología no recurre a modelos matemáticos y, en particular, al uso de la ecuación logística sino a modelos probabilísticos debido a que éstos permiten modelar un fenómeno que, por su naturaleza, es multifactorial. En particular, se recupera la metodología del conjunto de trabajos que utilizan modelos econométricos. 


\section{Capítulo 2}

\section{Naturaleza de la nanotecnología como nuevo paradigma tecnológico}

Una vez presentada la discusión, a nivel teórico, de la difusión tecnológica y la importancia que tiene el concepto de difusión de paradigmas tecnológicos en la explicación del cambio tecnológico y su impacto económico y social en el marco de la teoría evolucionista, en el presente capítulo se argumenta acerca de la naturaleza de la nanotecnología como un nuevo paradigma tecnológico (NPN). Para ello, se resaltan primero las características de otros paradigmas tecnológicos ocurridos en la historia $\mathrm{y}$, después, se contrastan con las características de la nanotecnología. Se mencionan algunas características comunes, así como sus diferencias frente a otros paradigmas, en particular, frente a las tecnologías de la información y la comunicación (TIC), con el propósito de mostrar que, debido a sus características peculiares, las abarca y las potencia, lo cual justifica la importancia del estudio de su difusión entre países. De esta forma, en el primer apartado se estudian las características de otros paradigmas tecnológicos ocurridos en la historia y en el segundo apartado se presentan, en forma detallada, las características del NPN.

\subsection{Características de otros paradigmas tecnológicos ocurridos en la historia}

Como se argumentó en el primer capítulo, la teoría evolucionista en economía explica el cambio tecnológico con base en un conjunto de conceptos. Así, la noción de paradigma tecnológico hace referencia al marco común de resolución de problemas tecnológicos en un sistema tecnológico (Dosi; 1982 y 1984). Sin embargo, cuando el paradigma tecnológico se difunde hacia otros campos tecnológicos y sectores de la economía a través de un conjunto de innovaciones radicales puede dar origen a una revolución tecnológica, la cual, va acompañada de un nuevo paradigma tecno-económico, es decir, de cambios que van más allá del ámbito económico, abarcando otras esferas como la institucional, organizacional y, en general, la forma de vida de la sociedad que vive la nouvelle ére. A su vez, la difusión de un paradigma 
tecno-económico genera una oleada de desarrollo (Pérez, 2004 y 2009). De ahí la importancia de estudiar los patrones de difusión de los nuevos paradigmas tecnológicos.

Por su dinámica, el despliegue de una revolución tecnológica se caracteriza por tener, al principio, una aceleración positiva $\mathrm{y}$, al transcurrir el tiempo, tiene una desaceleración hasta que se agota el despliegue. La trayectoria que describe este proceso tiene forma de $S$. Carlota Pérez (2004) caracteriza estas fases como periodos de instalación y despliegue, respectivamente. A su vez, cada una de estas fases se caracteriza por dos sub fases.

El periodo de instalación pasa por las fases de irrupción y de frenesí. En la primera, los nuevos productos y tecnologías, respaldados por el capital financiero, muestran su potencial futuro e incursionan poderosamente en un mundo aún moderado en lo fundamental por el paradigma anterior (Pérez, 2004). La fase de frenesí se caracteriza por el hecho de que, en general, el capital financiero se encarga de desarrollar intensivamente la nueva infraestructura y las nuevas tecnologías y, al final de esta fase, el nuevo paradigma tecno-económico se halla instalado en la economía y está listo para su despliegue. Surgen así tensiones estructurales y se inicia un intervalo de reacomodo, generalmente una recesión que sigue al colapso de la burbuja financiera donde se realizan los cambios institucionales necesarios para facilitar y dar forma al periodo de despliegue.

El periodo de despliegue pasa, a su vez, por dos fases: la de sinergia y la de madurez. En la primera, todas las condiciones favorecen la producción y el florecimiento total del nuevo paradigma. En la fase de madurez se introducen las últimas industrias, productos, tecnologías y mejoras, al mismo tiempo que en las principales industrias de la revolución tecnológica aparecen signos de disminución de oportunidades de inversión y estancamiento de mercados (Pérez, 2004).

A lo largo de la historia del capitalismo se identifican cinco revoluciones tecnológicas, desde la Revolución Industrial hasta hoy en día, cada una acompañada de su correspondiente paradigma tecno-económico. A su vez, cada revolución tecnológica se compone de un conjunto de paradigmas tecnológicos relacionados entre sí, constituyendo un meta sistema (Pérez; 2009). Cada uno de los paradigmas tecnológicos se caracterizan porque emergen de principios científicos y tecnológicos distintos; porque aparecen como un nuevo marco común bajo el cual se resuelven un conjunto de problemas tecnológicos selectos en forma distinta a las maneras hasta ese momento conocidas; porque se difunden hacia los distintos campos 
tecnológicos y sectores de la economía a través de distintos patrones espacio-temporales y porque usan un insumo barato en la solución de los problemas tecnológicos, lo cual, los hace atractivos en sentido comercial o económico.

La primera revolución tecnológica, conocida bajo el nombre popular de Revolución Industrial, se caracterizó por una serie de cambios económicos y sociales que modificaron radicalmente la forma de vida de Inglaterra a fines del siglo XVIII y principios del XIX. Ashton (1948) describe los cambios que experimentó Inglaterra respecto de la forma de vida correspondiente a la etapa previa:

Durante el breve lapso transcurrido entre el advenimiento de Jorge III y el de su hijo, Guillermo IV, cambió el aspecto de Inglaterra. Superficies que se habían cultivado, durante siglos, como campo abierto, o que permanecían en el abandono, como lugares de pastoreo común, fueron cercadas o valladas; las aldeas se convirtieron en populosas ciudades y los cañones de las chimeneas se elevaron hasta empequeñecer a las antiguas torres. Se hicieron caminos más rectos, fuertes y amplios que aquellas pobres vías de comunicación que corrompieron las buenas maneras de los viajeros en los días de Defoe. El mar del Norte y el de Irlanda, así como los tramos navegables de los ríos Mersey, Ouse, Trent, Severn, Támesis, Forth y Clyde, fueron unidos por hilos de agua tranquila. En el norte, se colocaron las primeras ferrovías para las nuevas locomotoras, y paquebotes de vapor comenzaron a funcionar en los estuarios y estrechos. (Ashton, 1948: 8)

La Revolución Industrial representó el paso de una economía basada en la agricultura y la fabricación de artesanías a otra basada en la industria y manufactura. A nivel social, los cambios se caracterizaron por un notable aumento de la población, frecuentes migraciones del campo a la ciudad, crecimiento de las zonas urbanas y suburbanas, así como un aumento de los sectores pobres.

Ahora bien, el paradigma tecnológico que se difundió para dar origen a esta revolución tecnológica consistió en la mecanización del trabajo, lo cual tuvo un considerable impacto sobre la economía basada en el trabajo manual que caracterizaba a la producción agrícola y artesanal previa. El origen de este paradigma tecnológico se ubica en la industria textil, en particular, en la industria algodonera. El problema técnico a resolver y que, al mismo tiempo, dio origen a este paradigma tecnológico fue el desequilibrio entre la eficiencia del hilado y la del tejido (Hobsbawm, 1977). Tres invenciones resolvieron el problema: "la spinning-jenny de la década de 1760 que permitía a un hilador a 'manos' hilar a la vez varias mechas; la waterframe de 1768 que utilizó la idea original de la spinning con una combinación de rodillos y 
husos; y la fusión de las dos anteriores, la mule de 1780, a la que se aplicó enseguida el vapor." (Hobsbawm; 1977: 58). La principal fuerza motriz fue el agua. Los telares eran relativamente sencillos y baratos, por lo que fue accesible para muchos pequeños productores, por lo cual se difundió a todo el país. Estas condiciones convirtieron a la industria textil en la industria clave del crecimiento económico de Inglaterra. Un rasgo característico de este paradigma tecnológico es que las innovaciones que se desarrollaron no fueron resultado de un fuerte vínculo entre el progreso científico y la industria, sino que fueron creadas por inventores individuales relacionados con ésta, lo cual se debió al hecho de que, por un lado, la ciencia se hallaba en transición hacia su sentido moderno y, por otro lado, porque su institucionalización era apenas incipiente:

La institucionalización empezó en las comunidades especializadas de las academias, que aparecieron en un principio en Italia: se distanciaron tanto de la ciencia aristotélica (gramática, retórica y lógica) como de otras instituciones (políticas, religiosas, filosóficas), que no compartían su interés exclusivo por "perfeccionar el conocimiento de las cosas naturales y de todas las artes útiles...mediante la experimentación", como se lee en el acta constitutiva de la Real Sociedad (Royal Society, 1662). (Salomon et al., 1996: 51).

De esta forma, la Revolución Industrial aumentó la cantidad de productos y disminuyó el tiempo en el que éstos se realizaban, dando paso a la producción en serie, ya que se simplificaron tareas complejas en varias operaciones básicas que puede realizar cualquier obrero sin necesidad de que sea mano de obra calificada y, de este modo, fue posible bajar los costos de producción y elevar la cantidad de unidades producidas. Estos cambios implicaron distintas formas de organización al interior de la fábrica y fuera de ella, es decir, tuvo implicaciones en los ámbitos institucional y organizacional que modificaron la forma de vida ya descrita por Ashton (1948).

La segunda revolución tecnológica se puede identificar como la era del vapor y los ferrocarriles. Esta época se caracterizó por el desarrollo de los transportes y algunas comunicaciones, sobre todo a nivel nacional y a lo largo de las líneas de ferrocarril, grandes puertos y veleros característicos de la época y observados en todo el mundo. Las nuevas industrias fueron las que produjeron las máquinas de vapor y maquinaria (hechas de hierro y alimentadas por carbón), minería de hierro y del carbón y las industrias productoras de los ferrocarriles (Pérez, 2009). El ferrocarril, como transporte fundamental que permitió la integración de los mercados, se desarrolló gracias al perfeccionamiento de máquinas movidas 
por energía generada por vapor de agua. Algunas implicaciones económicas fueron: mayor eficiencia de la producción y circulación de mercancías debido a la integración de los mercados; mayor eficiencia del sistema de transporte por tierra (ferrocarriles) y las telecomunicaciones (telégrafo); baja en el precio de los productos. Se inició, simultáneamente, en Inglaterra y los Estados Unidos. En cuanto al aspecto social, se caracterizó por el crecimiento acelerado de las ciudades, la desaparición de la sociedad estamental y predominio de la sociedad dividida en clases sociales y, también, por el surgimiento del movimiento obrero así como las formas de organización política a través de sindicatos y partidos (Ashton, 1948).

El paradigma tecnológico que se difundió y dio origen a esta revolución tecnológica se caracteriza por el uso de las máquinas térmicas, es decir, el nuevo paradigma tecnológico emergió con el uso de una nueva fuerza motriz que reemplazó el uso del agua como tal. Además, otro elemento importante que distingue a este paradigma tecnológico del anterior es un vínculo más fuerte entre progreso científico e industrial. Aunque primero se inventaron las máquinas térmicas, con sus diversas aplicaciones en la producción y los transportes, la comprensión científica de sus principios lograda por el ingeniero francés N. Sadi Carnot en 1824, afianzó y fortaleció los vínculos entre ciencia y producción en la segunda revolución tecnológica. De esta forma, las investigaciones de Carnot: "contienen el reconocimiento claro entre la equivalencia entre calor y trabajo así como la imposibilidad de construir una máquina de movimiento perpetuo, principio ahora conocido como la segunda ley de la termodinámica." (García-Colín, 2000: 18).

La realización y difusión de este paradigma tecnológico fueron posibles gracias a dos condiciones: uso de nuevos materiales (hierro y acero) y nuevas fuentes de energía (el carbón). Desde los primeros años del siglo XVIII la leña, que había sido hasta entonces el único combustible, se volvió escasa. En su lugar, el carbón mineral se impuso como la principal fuente de energía, debido a que era más abundante, más barato y poseía una mayor potencia calorífica. De esta forma, al emplearse el carbón como combustible para producir acero, los centros industriales se establecieron en las cercanías de las minas. Por otra parte, los aperos de labranza, las máquinas de todo tipo, raíles, puentes, etcétera, se construyeron con hierro. Así nació la industria siderúrgica moderna y el hierro se convirtió en el "pan de la industria”. Bajo estas condiciones, por ejemplo, la producción de las fundiciones inglesas se multiplicó por cien 
en un siglo, entre 1750 y 1850. La siderurgia sustituyó así al algodón como motor del crecimiento económico en Inglaterra (Derry y Trevor, 2006).

La tercera revolución tecnológica, se originó durante el último cuarto del siglo XIX y se le puede identificar como la era del acero, la electricidad y la ingeniería pesada. Se inició en Estados Unidos y Alemania y se caracterizó por la producción de acero barato (principal insumo); pleno desarrollo de la máquina de vapor para los buques de acero; inicio de la química pesada e ingeniería civil; aparecen las industrias de equipo eléctrico, cobre y cables; se inicia la industria de alimentos enlatados o embotellados, papel y embalaje. Esta época se caracterizó por la aparición de infraestructura de acero, por ejemplo, en buques rápidos de vapor; ferrocarriles transcontinentales (lo cual fue posible por el uso de rieles de acero y pernos baratos de tamaño normal); grandes puentes y túneles. Apareció el teléfono (sobre todo a nivel nacional) y redes eléctricas (para iluminación y uso industrial). En cuanto a los cambios organizacionales que implicó esta revolución tecnológica, se encuentran la aparición de estructuras gigantes; economías de escala de planta; integración vertical; energía distribuida por la industria (electricidad); la ciencia como una fuerza productiva; contabilidad de costos para el control y eficiencia; producción en gran escala para el mercado mundial (Pérez, 2009).

El paradigma tecnológico que se difundió en esta revolución tecnológica fue el uso del acero, es decir, de un material que desplazó el uso del hierro. Sin embargo, la difusión del uso del acero no hubiera sido posible sin la interacción con otros paradigmas tecnológicos emergentes como la electricidad y sin la potenciación de otros ya existentes como el uso de metales desarrollados por la industria siderúrgica. La interrelación de estos paradigmas tecnológicos también fue posible por la fuerte e intensa relación entre la ciencia y la industria a través del desarrollo de la ingeniería pesada. Como señala Pérez: "Las tecnologías y productos constituyentes de una revolución no son solamente aquellos que experimentan los mayores saltos. Con frecuencia la articulación de las tecnologías nuevas con algunas de las viejas es lo que genera el potencial revolucionario" (Pérez, 2004: 38). 
De esta forma, el material que permitió la difusión del paradigma tecnológico de las máquinas térmicas durante la segunda revolución tecnológica, el hierro, fue sustituido por el uso del acero 5 .

Estos avances potenciaron los progresos tecnológicos originados en la revolución tecnológica anterior, tales como el uso de las máquinas térmicas para mover motores, barcos, etcétera; además, el uso de la electricidad como nueva fuerza motriz se fue extendiendo en la industria. El uso comercial y doméstico de la electricidad modificó la organización al interior de la fábrica y, en general, la vida de los ciudadanos, ya que los días se hicieron más “extensos" y las noches más “cortas". Por último, una innovación que resultó del uso de la electricidad y que representó un cambio paradigmático en telecomunicaciones fue el teléfono. Como señalan Derry y Trevor (2006):

el crecimiento global de la red telefónica mundial en la primera mitad de este siglo (siglo XX) fue notable. Así, por ejemplo, Estados Unidos tenía 17 millones de teléfonos en 1934 y 32 millones en 1947; las cifras correspondientes para Gran Bretaña son 2 millones y 4 millones, mostrando una tasa de crecimiento comparable. El total mundial en 1934 era de unos 33 millones; en 1976 sería de 380 millones. (Derry y Trevor, 2006: 448).

La cuarta revolución tecnológica, se inició a principios del siglo XX en Estados Unidos y Alemania y se difundió hacia Europa. Se le identifica bajo el nombre popular de la era del petróleo, el automóvil y la producción en masa. La aparición del motor de combustión interna (modelo T) en Detroit, Michigan, Estados Unidos dio origen a ésta. Se caracteriza por la producción de automóviles en masa; petróleo y combustibles de petróleo baratos; inicio de la petroquímica (sintéticos); desarrollo de transportes a partir del motor de combustión interna (automóviles, tractores, aeroplanos, tanques de guerra); aparición de electrodomésticos (refrigeradores). En cuanto a infraestructura, se observan redes de carreteras, autopistas, puertos y aeropuertos; redes de petroductos; electricidad universal (industrial y doméstica); se inician las telecomunicaciones analógicas mundiales (teléfono, télex y telegrama). Los cambios organizacionales se vieron reflejados en la producción en masa (mercados masivos), economías de escala (volumen de producto y mercado); integración horizontal en las fábricas; estandarización de productos; energía intensiva (basada en petróleo); materiales sintéticos;

\footnotetext{
${ }^{5}$ La diferencia principal entre el hierro y el acero se halla en el porcentaje del carbono: el acero es hierro con un porcentaje de carbono de entre el $003 \%$ y el $1.075 \%$, a partir de este porcentaje se consideran otras aleaciones con hierro.
} 
especialización funcional (pirámides jerárquicas); centralización (aparición de centros metropolitanos); poderes nacionales, acuerdos mundiales y confrontaciones (Pérez, 2009).

El paradigma tecnológico que, al difundirse, dio origen a esta revolución tecnológica fue generado por un cambio en el sistema motriz que hasta ese momento había sido predominante: el motor de combustión externa (máquinas térmicas y eléctricas) fue sustituido por el motor de combustión interna, teniendo como principal combustible el petróleo. El funcionamiento del motor de combustión interna, como el motor Otto (en honor de su diseñador N. A. Otto), es el siguiente:

En una máquina de vapor, el fluido elástico que la impulsa se genera quemando combustible para calentar agua y convertirla en vapor en una caldera aparte; en el motor Otto, el combustible se quema dentro del motor y son los productos de la combustión los que proporcionan la fuerza motriz. (Derry y Trevor, 2006: 234).

Aunque fue en Estados Unidos de América donde este paradigma tecnológico se difundió en forma exitosa, después de que apareció por primera vez el motor de combustión interna (modelo T) en Detroit, Michigan, su origen es europeo. La invención se puede remontar a dos italianos: el padre Eugenio Barsanti, un sacerdote escolapio, y Felice Matteucci, ingeniero hidráulico y mecánico, que ya en 1853 habían detallado documentos de operación y construcción y patentes pendientes en varios países europeos como Gran Bretaña, Francia, Italia y Alemania. ${ }^{[}$Como señalan Mowery y Rosenberg (1998):

El motor de combustión interna, el cual, hizo posible el automóvil y los aeroplanos, a menudo es considerado como la contribución de la tecnología americana por excelencia en la primera mitad del siglo XX. Sin embargo, el desarrollo inicial del motor de gasolina fue casi logrado en Europa, dominado por inventores alemanes y franceses Carl Benz (un alemán que había operado el primer vehículo que se puso en marcha por un motor de combustión interna en 1885), Gottieb Daimler, Nikolaus Otto, Alphonse Beau de Rochas, Peugeot, Renault y otros. (Mowery y Rosenberg, 1998: 47).

Este es un claro ejemplo, de cómo las condiciones más adecuadas de un país, pueden ser aprovechadas para desarrollar y explotar los conocimientos generados en otros países (Mowery y Rosenberg, 1998). La mejora rápida del motor y la adopción en Estados Unidos ocurrió velozmente por la abundancia doméstica de los combustibles basada en los bajos costos del petróleo y la fuerza latente de la demanda debido a los bajos costos de los automotores y la transportación por aire entre centenares de personas dispersadas geográficamente en ese país. 
Su difusión en Estados Unidos también demostró la importancia creciente de los flujos intersectoriales de tecnología al interior de la economía. El motor de combustión interna fue utilizado en una amplia gama de productos, en los transportes y otros sectores, por ejemplo, en los implementos para las granjas, el tractor jugó un papel importante en la mecanización de la cosecha del algodón y, debido a ello, influyó en la migración de los granjeros hacia el sur. También los métodos de producción en masa que fueron perfeccionados por la industria automotriz fueron adoptados en otras industrias. En suma, el uso del motor de combustión interna y el desarrollo de las industrias del automóvil y de aeronaves, se convirtieron en impulsores importantes de la demanda, debido a los requerimientos de materiales y componentes (Mowery y Rosenberg, 1998).

Otro paradigma tecnológico que se difundió en esta revolución tecnológica ocurrió en la química y se le conoce como petroquímica ${ }^{6}$. La química orgánica dio un salto al pasar de un sistema basado en el carbón a otro sistema basado en el petróleo y gas natural (Mowery y Rosenberg, 1998).

Por último, la quinta revolución tecnológica inició a principios de los años setenta y se le conoce popularmente como la época de la información y las telecomunicaciones; se originó en los Estados Unidos y se difundió a Europa y Asia. Se caracteriza por nuevas infraestructuras como el mundo digital de las telecomunicaciones (cable, fibra óptica, radio y satélite); internet (mail electrónico); fuente múltiple, uso flexible, redes de electricidad, transporte físico multimodal de alta velocidad (por tierra, aire y agua). En cuanto a los cambios organizacionales que ha implicado la era de la información, destaca el quebrantamiento de las estructuras jerárquicas que caracterizaron a las organizaciones durante la revolución tecnológica anterior. De esta forma:

Hasta 1980 aproximadamente, la organización prevaleciente que servía como marco óptimo al despliegue de la revolución de la producción en masa era la pirámide jerárquica centralizada y compartimentada por funciones. Esta estructura fue aplicada en la economía por casi todas las corporaciones, pero también fue reproducida en cualquier otra organización que confrontara una tarea vasta y compleja como el gobierno, los hospitales, los sindicatos y los partidos políticos, en el mundo occidental y en el sistema soviético, en los países desarrollados y en los subdesarrollados. Con la llegada de las computadoras e internet, esas grandes pirámides se revelaron rígidas y difíciles de manejar. En su lugar, la estructura en redes descentralizadas y flexibles, con

\footnotetext{
${ }^{6}$ La petroquímica consiste en derivar productos del petróleo y gas natural.
} 
un núcleo estratégico y un sistema de comunicación rápido, mostró su capacidad para adecuarse a organizaciones mucho más grandes y complejas al igual que a organizaciones más pequeñas. (Pérez, 2004: 43 y 45).

El paradigma tecnológico que se difundió para dar origen a esta quinta revolución tecnológica se le conoce como paradigma digital. Una característica peculiar de los seres humanos consiste en el almacenamiento e intercambio permanente de información a través del lenguaje (en sus distintos tipos), arte y herramientas, de tal forma que es una característica esencial que lo distingue de otras especies (Hilbert y Cairó, 2008); para esta quinta revolución, las acciones socioeconómicas más importantes en la sociedad son la captación de información, su almacenamiento, su transmisión y su computación de la información. Así:

El surgimiento del paradigma digital se identifica con la introducción del microprocesador a inicios de los años setenta (Freeman y Louça, 2001). En este caso, el detonante del cambio consistió en una innovación con efectos sistémicos sobre una clase especial de proceso informático: el manejo de información con la ayuda de un circuito integrado de transistores sobre un único componente semiconductor. El paradigma científico que condujo a esta innovación era mucho más antiguo que el microprocesador y se caracterizaba por el uso del dígito binario, el bit, como método para codificar la información. (Hilbert y Cairó, 2008: 32)

Bajo este paradigma, se identifican 4 sistemas tecnológicos: interoperación, transmisión, procesamiento y almacenamiento de información (Hilbert y Cairó, 2008). Así, es posible identificar que en cuanto al procesamiento de información hubo un cambio de paradigma tecnológico que dio origen al paradigma digital: el paso de los tubos de vacío a los transistores, circuitos integrados y microprocesadores. Cabe señalar, que el escenario donde ocurrió este salto fue en la microelectrónica.

El transistor es un dispositivo electrónico semiconductor utilizado para producir una señal de salida en respuesta a otra señal de entrada y ${ }^{\square}$ cumple funciones de amplificador, oscilador, conmutador o rectificador. El dominio de este semiconductor y su difusión como nuevo paradigma tecnológico frente al uso de tubos de vacío, se debió al uso del silicio, el cual, era de bajo costo (Mowery y Rosenberg, 1998).

Posteriormente, en 1958 ocurrió otro avance importante al desarrollarse el primer circuito integrado, que alojaba seis transistores en un chip. Estos progresos significativos en la microelectrónica coincidieron con una serie de acontecimientos históricos relevantes que, a su vez, plantearon nuevos problemas tecnológicos, tal como ocurrió durante la Segunda Guerra 
Mundial. En efecto, ante el problema de codificar y decodificar información, así como de tener un control del sistema militar, los científicos se concentraron en desarrollar la computadora (tal fue el caso de Alan Turing, quien desarrolló el modelo teórico de la computadora conocido como Máquina de Turing) (Viso, 2008). Sin embargo, después de la Segunda Guerra Mundial, el uso de la computación digital no solo tenía demanda militar sino también civil, principalmente de los científicos. El conjunto de estas circunstancias, permitió la gestación de un meta sistema tecnológico que desembocó en la producción para el mercado de la primera computadora en 1971 en los Estados Unidos (Pérez, 2009).

La convergencia de los cuatro sistemas tecnológicos en los que se basa este paradigma tecnológico (interoperación, transmisión, procesamiento y almacenamiento de información) fue posible gracias a la idea de manejar la información en bits. Pero el desarrollo de la computadora potenció enormemente las posibilidades de la comunicación. Así, las diferencias en cuanto al potencial de comunicación y transmisión de cantidades de información entre el telégrafo y el internet es abismal (Hilbert y Cairó, 2008).

En suma, este recorrido histórico ha permitido no solo caracterizar las distintas revoluciones tecnológicas ocurridas desde la Revolución Industrial a la fecha, sino también identificar los principales paradigmas tecnológicos que, al difundirse, dieron origen a meta sistemas característicos de cada revolución tecnológica. También fue posible identificar algunos factores comunes que permiten la difusión de un nuevo paradigma tecnológico, tales como el uso de un insumo barato, por ejemplo: el carbón, el petróleo, el silicio, en la primera, tercera y quinta revolución tecnológicas, respectivamente. Así como las condiciones históricas (como las guerras mundiales) e institucionales de los países donde emerge y se difunde cada paradigma tecnológico. Los estudios sobre la difusión de un nuevo paradigma tecnológico son importantes, ya que caracterizar sus patrones de difusión puede ayudar a comprender la evolución no solo de un conjunto de tecnologías sino, sobre todo, a comprender sus posibles consecuencias para la economía y la sociedad lo cual, a su vez, resulta fundamental en la elaboración de políticas y toma de decisiones.

Aunque la mayoría de los estudios se centran en la evolución de la revolución tecnológica de las TIC y sus efectos en el crecimiento económico y social de los países por la importancia mencionada, se ha planteado la emergencia de otro paradigma tecnológico y su posible gestación como la próxima revolución tecnológica (Pérez, 2001; Hilbert y Cairó, 2008; 
Guzmán y Toledo, 2009). Así, a partir de la revolución científica de la mecánica cuántica se perfila un nuevo paradigma tecnológico conocido como nanotecnología o nanotecnologías, debido a la diversidad de sus aplicaciones en otros campos tecnológicos, incluyendo biotecnología y TIC. Si bien se encuentra en gestación, ha comenzado a mostrar su potencial y alcances en distintas áreas de la ciencia y sectores económicos. A continuación, se explora la naturaleza de la nanotecnología como nuevo paradigma tecnológico.

\subsection{Características de la nanotecnología como nuevo paradigma tecnológico}

El propósito de este apartado, es caracterizar a la nanotecnología como un paradigma tecnológico y contrastarlo con otros paradigmas con el objetivo de observar sus rasgos distintivos, ventajas y posibles riesgos.

Los orígenes de la nanotecnología se remontan a la conferencia que impartió el físico estadounidense Richard Feynman (Premio Nobel de Física, 1965) el 29 de diciembre de 1959, titulada There is plenty of room at the bottom (Hay mucho espacio en el fondo) en un congreso de la Sociedad Americana de Física en el Instituto de Tecnología de California. Feynman describió ahí, a nivel teórico: "que ninguna ley física evitaba que se pudiesen hacer cosas como miniaturizar las computadoras...y construir maquinaria con átomos y moléculas" (Takeuchi, 2011: 49). La conferencia de Feynman auguraba así el surgimiento de un nuevo paradigma tecnológico, sustentado en los avances de la física (teoría del átomo) y de la química (teoría molecular).

Norio Taniguchi, científico de la Universidad de Ciencia de Tokio, fue el primero en usar el término "nanotecnología" en 1974. La define así: "La nano-tecnología consiste principalmente en el procesado, separación, consolidación y deformación de materiales átomo por átomo, molécula por molécula" (Taniguchi, 1974: 18).

En la literatura reciente sobre nanotecnología (Poole y Owens, 2003; Guzmán y Toledo, 2009; Takeuchi, 2011; OECD, 2013) se define a la nanotecnología como el área de investigación (o campo tecnológico) donde convergen conocimientos que provienen de distintas disciplinas: física, química, biología, materiales científicos e ingeniería. En ella se: 
“estudia, diseña y fabrica materiales o sistemas a escalas nanoscópicas y les da alguna aplicación práctica. Sin embargo, en muchas ocasiones se denomina nanotecnología a la habilidad de controlar la materia átomo por átomo.” (Takeuchi, 2011: 15 y 16).

Cabe señalar que: “el prefijo 'nano’ proviene del latín nanus que significa 'enano’ y actualmente tiene la acepción de una milmillonésima parte. Así, un nanómetro (abreviado nm) es una milmillonésima parte (1/1000 000 000) de un metro.” (Takeuchi, 2011: 14). Así, cuando se habla de escalas nanoscópicas significa que el estudio, diseño y fabricación de materiales y sistemas ocurre en nanómetros (entre 1 y 100 nm).

Un primer rasgo característico de la nanotecnología como un nuevo paradigma tecnológico es, precisamente, que se deriva del progreso de la ciencia. La definición anterior de nanotecnología señala que convergen conocimientos que provienen de distintas disciplinas, lo cual es posible bajo el enfoque interdisciplinario, el cual, es una característica peculiar del progreso de la ciencia. Este enfoque representa un nuevo paradigma científico (Kuhn, 1962) y se puso en marcha a mitad del siglo XX en las ciencias que estudian la naturaleza: física, química, biología, principalmente. La nanotecnología es un producto del desarrollo de dicho paradigma científico ${ }^{7}$.

El enfoque y fundamentos de la nanotecnología, permite resolver problemas tecnológicos aún no resueltos bajo otros paradigmas tecnológicos. Por ejemplo, en electrónica (sector donde nació la nanotecnología), existe una restricción conocida como la "Ley de Moore", la cual señala que el número de transistores en un chip aumenta al doble aproximadamente cada dos años. Esto limita la posibilidad de crear dispositivos más pequeños y veloces. Sin embargo, una posibilidad es el uso del silicio "estirado", que aumenta la velocidad de los chips en $35 \%$ sin necesidad de hacer más pequeños los transistores. Otro ejemplo es el uso de nuevos materiales como las zeolitas como catalizadores más eficientes para ahorrar energía. Los nanotubos de carbono pueden usarse para mejorar la resistencia mecánica y térmica. Sustituiría el uso de fibras de carbón en, por ejemplo, la construcción de aviones. En medicina resolvería una variedad de problemas, por ejemplo: tratamiento de

\footnotetext{
${ }^{7}$ En cuanto a la física, la nanotecnología se fundamenta en los resultados de la mecánica cuántica a través de sus experimentos para comprender las leyes que gobiernan el mundo físico a nivel de partículas; de la química, se apoya en los desarrollos sobre enlaces, moléculas y compuestos; y en cuanto a la biología, se apoya en los estudios sobre el ADN (Takeuchi, 2011).
} 
tumores cancerígenos, combate de bacterias y virus, biosensores, uso de nanoporos para decodificar el ADN, nanogeles para curar neuronas, entre otras aplicaciones.

En este sentido, debido a su naturaleza, la nanotecnología como un paradigma tecnológico que resuelve los problemas tecnológicos a nivel de nano escala envuelve otros paradigmas tecnológicos como las TIC y biotecnología. Al respecto, señala Hilbert y Cairó (2008) que:

El paradigma digital está siendo cada vez más permeado por las tecnologías mediante las cuales se manipulan moléculas, como la nanotecnología, la biotecnología y la tecnología genética. Se cree que el paradigma molecular constituirá - la próxima onda larga socioeconómica de la humanidad, y que convertirá al paradigma digital en condición sine qua non para el progreso socioeconómico, de la misma manera que los anteriores paradigmas del motor de combustión interna en el transporte o la electricidad se han hecho indispensables para el desarrollo actual. (Hilbert y Cairó, 2008: xx)

Debido a que es una propiedad de los seres humanos la transmisión de información, incluso desde tiempos remotos, la nanotecnología no hará desaparecer o extinguir el paradigma de las TIC, más bien ésta pasará a formar parte de un conjunto de tecnologías básicas para el desarrollo económico y social futuro. Al mismo tiempo, al quedar envueltas por la nanotecnología, tendrá mejoras potenciales, pero ya no será el motor económico y social en la próxima oleada de desarrollo.

En cuanto a la biotecnología, paradigma tecnológico que se caracteriza por la manipulación de células vivas, la nanotecnología es un paradigma más amplio, ya que se utiliza para resolver problemas tecnológicos bajo una cierta escala de la materia (a nivel nano), independientemente de la naturaleza de la entidad o material de trabajo, mientras que la biotecnología se restringe solo a la manipulación de ciertas propiedades de células a escala molecular. De esta forma, el área conocida como nano biotecnología indica la manipulación y diseño de sistemas a nivel de nano escala pero con material vivo, lo que representa solo una aplicación particular, entre muchas, de la nanotecnología. Por ello, comprender los patrones de difusión de este nuevo paradigma tecnológico, resulta central en la gestación de la próxima revolución tecnológica.

Debido a las potencialidades mencionadas que muestra la nanotecnología para resolver problemas tecnológicos no resueltos por otros paradigmas tecnológicos en diversas áreas, la vuelve atractiva para los gobiernos y firmas de los países. De esta forma, en el ámbito 
internacional, el desarrollo de la nanotecnología es dominado por los Estados Unidos, Japón y Alemania, quienes aportan anualmente casi el 52\% de la inversión total mundial, equivalente a USD \$12 400000 000. De ésta, el 51\% corresponde a los gobiernos, el 43\% a las empresas y el 6\% a capital de riesgo. Destaca el crecimiento en la inversión gubernamental realizada en el mundo para el apoyo de la I+D en nanotecnología al pasar de USD \$432000 000 en 1997 a USD \$6 400000000 en 2006, es decir, casi 15 veces el monto originalmente considerado (CIMAV, 2008). ${ }^{8}$

En relación con el PIB, el país que mayor proporción destina a la investigación y desarrollo de la nanotecnología es Corea del Sur (\$350 por cada millón de dólares del PIB), seguido por Japón (\$250), Estados Unidos (\$90) y la Unión Europea (\$86) (Roco, 2005).

La mayor proporción de la inversión en I+D se destina a los sectores académico e industrial. Así, en 2007 Estados Unidos destinó el 65\% al sector académico y 10\% al sector industrial; Alemania lo hizo con $45 \%$ y $30 \%$ respectivamente y Corea del Sur con $20 \%$ al sector académico y $60 \%$ al sector industrial (CIMAV, 2008).

Estos montos de inversión destinados a la nanotecnología por parte de gobiernos y empresas se ven reflejados en una intensa actividad inventiva (18 467 patentes en 2013 publicadas en el campo de nanotecnología en la USPTO). Por países, Estados Unidos de América, Japón y Alemania ocuparon el 43\%, 17\% y10\% del total de patentes registradas en este campo en 2009.

Estos indicadores son generales, sin embargo, muestran el interés que tienen los gobiernos y empresarios de los países mencionados por invertir en la actividad inventiva generada en dicho campo. Además, indica la presencia de factores económicos en la selección y difusión de este paradigma tecnológico, tal como lo señala Dosi (1982 y 1984).

Esencialmente se identifican cuatro campos de la nanotecnología en los cuales confluyen distintas disciplinas científicas y tecnologías encontrando diversos sectores de aplicación: i) nanometrología/nanoanálisis; ii) la nanobiotecnología/ nanomedicina; iii) nanomateriales/ nanoquímica/ nanoelectrónica y iv) nano-óptica. A su vez, cada uno de estos campos está asociado con diversos sectores de aplicación, en orden correspondiente: i) tecnologías de la energía y del medio ambiente, tecnologías de la medición; ii) ciencias de la

\footnotetext{
${ }^{8}$ Salvo cualquier aclaración en el cuerpo del texto, los montos se expresan en dólares estadounidenses.
} 
vida, tecnologías médicas, farmacéuticas, procedimientos cosméticos; iii) Industria química, industria textil, industria alimentaria, bienes durables del hogar y equipos deportivos; iv) tecnologías de la información y comunicación; v) industria automotriz (Guzmán y Toledo, 2009).

Además, sus aplicaciones están ocurriendo en áreas estratégicas: gobierno, industria y milicia. Esto la convierte en un área estratégica para la competencia industrial, militar y espacial de las próximas décadas (Guzmán y Toledo, 2009).

En suma, la nanotecnología como un paradigma tecnológico se puede definir como un nuevo marco de resolución de problemas tecnológicos no resueltos aún por otros paradigmas tecnológicos (incluyendo al paradigma de las TIC). Se distingue de otros paradigmas tecnológicos por algo peculiar: los problemas se resuelven a través del diseño y fabricación de dispositivos o sistemas a nivel de nanoescala. Convergen distintas disciplinas (física, química, biología e ingeniería) bajo un nuevo paradigma científico: la interdisciplina. Funciona con base en un nuevo principio tecnológico: las propiedades de los materiales a nivel nanométrico son distintas de las propiedades de los sistemas macroscópicos. Define su propia unidad de medida (el nanómetro) y tiene su propio instrumento: el microscopio potente (microscopio de efecto túnel), para diseñar y crear dispositivos y sistemas a nivel de nanoescala. Por último, existen factores económicos (significativos esfuerzos en I+D por parte de gobiernos y empresas de los países).

La primera característica que distingue a la nanotecnología de los paradigmas tecnológicos anteriores es que la solución de problemas tecnológicos ocurre a un nivel muy pequeño de la materia (nanoescala), mientras que en los otros paradigmas ocurre a nivel macroscópico. Esta diferencia de escala supone otra distinción en cuanto a los fundamentos científicos que la sustentan, mientras que los anteriores paradigmas se apoyan en los avances de la física que estudia el mundo macroscópico, como las leyes de la mecánica clásica, por ejemplo, en el paradigma de la mecanización del proceso de producción que predominó en la Revolución Industrial, o el uso de máquinas térmicas en la era de vapor y los ferrocarriles, o el uso intensivo de información a través de las computadoras en el paradigma de las TIC, en el paradigma de nanotecnología, los fundamentos científicos provienen de la mecánica cuántica. En este sentido, hay un salto cualitativo respecto de los otros paradigmas. Sin embargo, desde el punto de vista del desarrollo de la ciencia, la nanotecnología es resultado de la continuidad 
en la ciencia desarrollada en paradigmas tecnológicos anteriores, por ejemplo, los avances de la física, la química y la biología, ocurrieron durante la era del petróleo, el automóvil y la producción en masa y en lo que va de las TIC. De hecho, la nanotecnología emerge de un sector específico del paradigma de las TIC: la microelectrónica. Sin embargo, por el potencial que muestra para resolver problemas tecnológicos en distintos campos, la nanotecnología abarca prácticamente todos los sectores tecnológicos, incluyendo aquellos sectores propios del paradigma de las TIC al que, incluso, potencia tal como se mencionó arriba. Así:

Por su naturaleza multidisciplinaria, la nanotecnología puede ser utilizada en muchos campos relacionados con la información y la comunicación. No solamente nació con la ambición de escribir la Enciclopedia Británica en la cabeza de un alfiler, sino con el interés de mejorar los microprocesadores, pero está en pleno proceso de impulsar a las TIC hacia una nueva fase de su desarrollo. (Hilbert y Cairó, 2008: 123).

Nuevamente, el país núcleo donde emerge el nuevo paradigma tecnológico de la nanotecnología es Estados Unidos, manteniendo el liderazgo tecnológico desde la era del vapor y los ferrocarriles aunque, cabe señalar, que generalmente aparece como parte de un pequeño grupo (cluster) de países innovadores. Por último, se observa una tendencia a largo plazo sobre la actividad inventiva: ésta es producto de una relación ciencia-tecnología cada vez más fuerte. Las diferencias entre el paradigma de la nanotecnología y los otros paradigmas tecnológicos se presentan en el cuadro 2.1 .

Cuadro 2.1. Características de los principales paradigmas tecnológicos que han tenido un impacto económico y social

\begin{tabular}{|c|c|c|c|c|c|c|}
\hline $\begin{array}{l}\text { Nombre del } \\
\text { paradigma }\end{array}$ & $\begin{array}{l}\text { Característica } \\
\mathrm{s} \text { generales }\end{array}$ & $\begin{array}{l}\text { Nueva } \\
\text { solución de } \\
\text { problemas }\end{array}$ & Eficiencia & \begin{tabular}{lr}
\multicolumn{2}{l}{ Industria, } \\
país y año \\
donde & se \\
inició & \\
\end{tabular} & $\begin{array}{l}\text { Expansi } \\
\text { ón }\end{array}$ & $\begin{array}{l}\text { Repercusion } \\
\text { es en el } \\
\text { ámbito } \\
\text { social }\end{array}$ \\
\hline $\begin{array}{l}\text { Revolución } \\
\text { Industrial }\end{array}$ & $\begin{array}{l}\text { La } \\
\text { mecanización } \\
\text { del proceso de } \\
\text { producción, el } \\
\text { trabajo } \\
\text { artesanal fue } \\
\text { reemplazado } \\
\text { por la industria } \\
\text { (Pérez, 2009). }\end{array}$ & $\begin{array}{l}\text { Se soluciona } \\
\text { el problema } \\
\text { de } \\
\text { productividad } \\
\text {, a través de } \\
\text { la } \\
\text { mecanización } \\
\text { del trabajo y } \\
\text { no a través } \\
\text { del aumento } \\
\text { del número de } \\
\text { trabajadores. }\end{array}$ & $\begin{array}{l}\text { Aumento } \\
\text { significativo de } \\
\text { la productividad } \\
\text { del trabajo } \\
\text { (Pérez, 2009). }\end{array}$ & $\begin{array}{l}\text { Textil. } \\
\text { Hilandería } \\
\text { de algodón } \\
\text { de Arkwright } \\
\text { en Cromford, } \\
\text { Inglaterra, } \\
1771 .\end{array}$ & $\begin{array}{l}\text { De } \\
\text { Cromfor } \\
\text { d a toda } \\
\text { Inglaterr } \\
\text { a. }\end{array}$ & $\begin{array}{l}\text { Cambios } \\
\text { institucionale } \\
\text { s (por } \\
\text { ejemplo, la } \\
\text { ley de de } \\
\text { cercado de } \\
\text { los campos). } \\
\text { Aumento de } \\
\text { la } \\
\text { producción } \\
\text { agrícola. } \\
\text { Migración de }\end{array}$ \\
\hline
\end{tabular}




\begin{tabular}{|c|c|c|c|c|c|c|}
\hline & & $\begin{array}{l}\text { Se solucionó } \\
\text { un problema } \\
\text { de } \\
\text { comunicación } \\
\text { y transportes, } \\
\text { a través de } \\
\text { máquinas } \\
\text { movidas con } \\
\text { la fuerza del } \\
\text { agua y la } \\
\text { apertura de } \\
\text { canales (redes } \\
\text { locales) } \\
\text { (Pérez, 2009). }\end{array}$ & & & & $\begin{array}{l}\text { la población } \\
\text { del campo a } \\
\text { la ciudad. } \\
\text { Revolución } \\
\text { demográfica } \\
\text { (alta } \\
\text { natalidad, } \\
\text { baja } \\
\text { mortalidad) } \\
\text { (Ashton, } \\
\text { 1948). }\end{array}$ \\
\hline $\begin{array}{l}\text { Era del vapor y } \\
\text { los ferrocarriles }\end{array}$ & $\begin{array}{l}\text { Desarrollo de } \\
\text { maquinaria, } \\
\text { cuya fuente de } \\
\text { energía es el } \\
\text { vapor (Pérez, } \\
2009 \text { ). }\end{array}$ & $\begin{array}{l}\text { Se soluciona } \\
\text { el problema } \\
\text { de integrar los } \\
\text { mercados } \\
\text { locales en uno } \\
\text { nacional. } \\
\text { Aparece la } \\
\text { industria que } \\
\text { abastece la } \\
\text { demanda de } \\
\text { maquinaria y } \\
\text { equipo } \\
\text { (Pérez, 2009). }\end{array}$ & $\begin{array}{l}\text { Se hace más } \\
\text { eficiente la } \\
\text { producción } \\
\text { circulación de } \\
\text { mercancías } \\
\text { debido a la } \\
\text { integración de } \\
\text { los mercados } \\
\text { (Pérez, 2009). } \\
\text { Se hace más } \\
\text { eficiente el } \\
\text { sistema de } \\
\text { transporte por } \\
\text { tierra } \\
\text { (ferrocarriles) y } \\
\text { las } \\
\text { telecomunicaci } \\
\text { ones (telégrafo) } \\
\text { (Pérez, 2009). } \\
\text { Baja el precio } \\
\text { de } \\
\text { productos. }\end{array}$ & $\begin{array}{l}\text { Transportes } \\
\text { (ferrocarriles } \\
\text { ). Motor a } \\
\text { vapor Rocket } \\
\text { para el } \\
\text { ferrocarril } \\
\text { Liverpool- } \\
\text { Manchester. } \\
\text { Inglaterra, } \\
\text { 1829. } \\
\text { Energía y } \\
\text { Metalurgia. }\end{array}$ & $\begin{array}{l}\text { Europa } \\
\text { y E.U.A. }\end{array}$ & $\begin{array}{l}\text { La economía } \\
\text { industrial } \\
\text { sustituyó a la } \\
\text { agrícola. } \\
\text { Crecimiento } \\
\text { acelerado de } \\
\text { las ciudades. } \\
\text { Desaparece } \\
\text { la sociedad } \\
\text { estamental y } \\
\text { predomina la } \\
\text { sociedad } \\
\text { dividida en } \\
\text { clases } \\
\text { sociales. } \\
\text { Surgen } \\
\text { sindicatos y } \\
\text { partidos } \\
\text { políticos. }\end{array}$ \\
\hline $\begin{array}{l}\text { Era del acero, } \\
\text { la electricidad } \\
\text { y la ingeniería } \\
\text { pesada }\end{array}$ & $\begin{array}{l}\text { Producción de } \\
\text { acero barato. } \\
\text { Desarrollo } \\
\text { pleno de la } \\
\text { máquina de } \\
\text { vapor. Aparece } \\
\text { la industria de } \\
\text { equipo } \\
\text { eléctrico. Se } \\
\text { inicia la } \\
\text { ingeniería } \\
\text { pesada para } \\
\text { crear obras de } \\
\text { infraestructura } \\
\text { de acero } \\
\text { (Pérez, 2009). }\end{array}$ & $\begin{array}{l}\text { Se resuelve } \\
\text { un problema } \\
\text { de energía } \\
\text { usando una } \\
\text { nueva fuente } \\
\text { de energía, la } \\
\text { electricidad } \\
\text { (Pérez, 2009). }\end{array}$ & 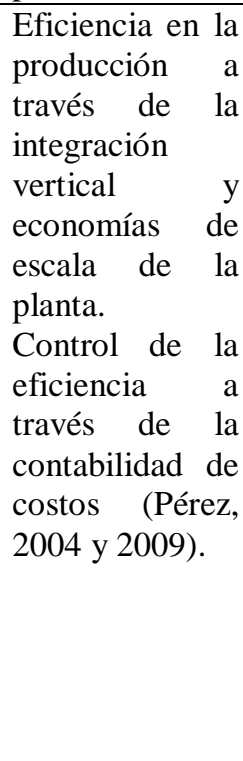 & $\begin{array}{l}\text { Acero. } \\
\text { Acería } \\
\text { Bessemer de } \\
\text { Carnegie, } \\
\text { Pennsylvania } \\
\quad \text { Estados } \\
\text { Unidos, } \\
1875 .\end{array}$ & $\begin{array}{l}\text { Inglaterr } \\
\text { a, } \\
\text { E.U.A. y } \\
\text { Alemani } \\
\text { a. }\end{array}$ & $\begin{array}{l}\text { Fuerte } \\
\text { vinculación } \\
\text { entre la } \\
\text { actividad } \\
\text { científica y el } \\
\text { sector } \\
\text { productivo. } \\
\text { Globalizació } \\
\text { n de la } \\
\text { economía, } \\
\text { redes } \\
\text { mundiales e } \\
\text { imperios. } \\
\text { Gran } \\
\text { importancia } \\
\text { del capital } \\
\text { financiero. } \\
\text { Gestación de } \\
\text { revoluciones }\end{array}$ \\
\hline
\end{tabular}




\begin{tabular}{|c|c|c|c|c|c|c|}
\hline & & & & & & $\begin{array}{l}\text { sociales } \\
\text { (revolución } \\
\text { Rusa) (Pérez, } \\
\text { 2009). }\end{array}$ \\
\hline $\begin{array}{lr}\text { Era } & \text { del } \\
\text { petróleo, } & \text { el } \\
\text { automóvil y } & \text { la } \\
\text { producción } & \text { en } \\
\text { masa } & \end{array}$ & $\begin{array}{l}\text { Aumento de la } \\
\text { potencia de las } \\
\text { máquinas, con } \\
\text { el motor de } \\
\text { combustión } \\
\text { interna. El } \\
\text { principal } \\
\text { insumo es el } \\
\text { petróleo (Pérez, } \\
\text { 2009). }\end{array}$ & $\begin{array}{l}\text { Se resuelve el } \\
\text { problema de } \\
\text { mejorar la } \\
\text { potencia de } \\
\text { las máquinas } \\
\text { a través del } \\
\text { motor de } \\
\text { combustión } \\
\text { interna } \\
\text { (Pérez, 2009). }\end{array}$ & 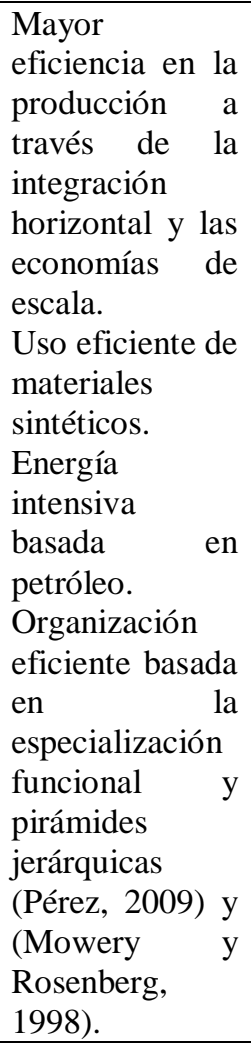 & $\begin{array}{l}\text { Automotriz. } \\
\text { Modelo T de } \\
\text { la planta } \\
\text { Ford } \\
\text { (Detroit, } \\
\text { Michigan). } \\
\text { Estados } \\
\text { Unidos, } \\
1908 .\end{array}$ & $\begin{array}{l}\text { De } \\
\text { E.U.A. } \\
\text { hacia } \\
\text { Europa } \\
\text { y Asia. }\end{array}$ & $\begin{array}{l}\text { Centros } \\
\text { metropolitan } \\
\text { os y } \\
\text { suburbanizac } \\
\text { ión. } \\
\text { Poderes } \\
\text { nacionales, } \\
\text { acuerdos } \\
\text { mundiales y } \\
\text { confrontacio } \\
\text { nes (Pérez, } \\
\text { 2004 y } \\
2009 \text { ). }\end{array}$ \\
\hline $\begin{array}{lr}\text { Era de la } \\
\text { informática } \\
\text { las } \\
\text { telecomunicaci } \\
\text { ones }\end{array}$ & $\begin{array}{l}\text { Uso intensivo } \\
\text { de la } \\
\text { información } \\
\text { basada en } \\
\text { microelectrónic } \\
\text { a. Nuevas } \\
\text { infraestructuras } \\
\text { en } \\
\text { telecomunicaci } \\
\text { ones (cable, } \\
\text { fibra óptica, } \\
\text { radio yá y } \\
\text { satélite); } \\
\text { internet (Pérez, } \\
\text { 2009). }\end{array}$ & $\begin{array}{l}\text { Se resuelve el } \\
\text { problema de } \\
\text { almacenamie } \\
\text { nto y } \\
\text { procesamient } \\
\text { o de grandes } \\
\text { cantidades de } \\
\text { información. } \\
\text { Resuelve } \\
\text { problemas de } \\
\text { comunicación } \\
\text { a gran } \\
\text { distancia y en } \\
\text { forma } \\
\text { instantánea } \\
\text { (Pérez, 2009) } \\
\text { y (CEPAL, } \\
\text { 2008). }\end{array}$ & $\begin{array}{l}\text { Eficiencia en el } \\
\text { almacenamient } \\
\text { o y } \\
\text { procesamiento } \\
\text { de información. } \\
\text { Eficiencia en } \\
\text { telecomunicaci } \\
\text { ones. }\end{array}$ & $\begin{array}{l}\text { Anuncio del } \\
\text { microprocesa } \\
\text { dor Intel en } \\
\text { Santa Clara, } \\
\text { California, } \\
\text { Estados } \\
\text { Unidos, } \\
1971 .\end{array}$ & $\begin{array}{l}\text { De } \\
\text { E.U.A. } \\
\text { hacia } \\
\text { Europa } \\
\text { y Asia. }\end{array}$ & $\begin{array}{l}\text { Integración } \\
\text { descentraliza } \\
\text { da. } \\
\text { Conocimient } \\
\text { o como } \\
\text { capital (valor } \\
\text { agregado } \\
\text { intangible). } \\
\text { Segmentació } \\
\text { n de de } \\
\text { mercados. } \\
\text { Interacción } \\
\text { entre lo } \\
\text { global y lo } \\
\text { local. } \\
\text { Cooperación } \\
\text { hacia el } \\
\text { interior y } \\
\text { hacia el } \\
\text { exterior. } \\
\text { Redes } \\
\text { Sociales. } \\
\text { Comunicació } \\
\text { n global } \\
\text { instantánea }\end{array}$ \\
\hline
\end{tabular}




\begin{tabular}{|c|c|c|c|c|c|c|}
\hline & & & & & & $\begin{array}{l}\text { (Pérez, 2009) } \\
\text { y (CEPAL, } \\
2008) .\end{array}$ \\
\hline $\begin{array}{l}\text { Era de la } \\
\text { nanotecnología } \\
\text {, biotecnología } \\
\text { y nuevos } \\
\text { materiales } \\
\text { (Pérez, 2006) }\end{array}$ & $\begin{array}{l}\text { Estudio, } \\
\text { diseño, } \\
\text { fabricación y } \\
\text { perfección de } \\
\text { materiales o } \\
\text { sistemas a nivel } \\
\text { de nanoescala } \\
(1 / 1000 \quad 000 \\
000 \text { de un } \\
\text { metro) y } \\
\text { tratamientos de } \\
\text { materiales } \\
\text { orgánicos } \\
\text { inorgánicos por } \\
\text { sistemas } \\
\text { biológicos para } \\
\text { producir bienes } \\
\text { y servicios } \\
\text { (Poole and } \\
\text { Owens, 2003), } \\
\text { (Delgado, } \\
\text { 2007) } \\
\text { (Finardi, 2013). }\end{array}$ & $\begin{array}{l}\text { Se soluciona } \\
\text { el problema } \\
\text { de controlar } \\
\text { propiedades } \\
\text { fundamentale } \\
\text { s de los } \\
\text { materiales, } \\
\text { tales como } \\
\text { magneto- } \\
\text { resistencia } \\
\text { gigante. Uso } \\
\text { de materiales } \\
\text { compuestos, } \\
\text { reacciones } \\
\text { químicas, } \\
\text { liberación } \\
\text { controlada de } \\
\text { medicamento } \\
\text { s y } \\
\text { almacenamie } \\
\text { nto } \\
\text { energía. } \\
\text { Dispositivos } \\
\text { que contienen } \\
\text { mayor } \\
\text { densidad de } \\
\text { componentes } \\
\text { (mejores } \\
\text { biodegradicos } \\
\text { dispositivos } \\
\text { electrónicos, } \\
\text { circuitos más } \\
\text { pequeños y } \\
\text { más rápidos, } \\
\text { funciones } \\
\text { más desables } \\
\text { sofisticadas y } \\
\text { gran } \\
\text { reducción de } \\
\text { la potencia } \\
\text { consumida). } \\
\text { Tratamiento } \\
\text { de enfermedades } \\
\text { mejorados, } \\
\text { blimentos }\end{array}$ & $\begin{array}{l}\text { Mayor } \\
\text { eficiencia en el } \\
\text { uso de las } \\
\text { propiedades de } \\
\text { materiales y en } \\
\text { el tratamiento } \\
\text { de materiales } \\
\text { orgánicos e } \\
\text { inorgánicos. } \\
\text { Mayor } \\
\text { eficiencia en la } \\
\text { reducción de } \\
\text { contaminantes. } \\
\text { En general, } \\
\text { mayor } \\
\text { eficiencia en el } \\
\text { uso de recursos } \\
\text { naturales. } \\
\text { Potenciación de } \\
\text { las TICs (Poole } \\
\text { y Owens, } \\
\text { 2003), } \\
\text { (Delgado, } \\
\text { 2007) } \\
\text { (Takeuchi, } \\
\text { 2011). }\end{array}$ & $\begin{array}{l}\text { En 1974, el } \\
\text { japonés } \\
\text { Norio } \\
\text { Taniguchi } \\
\text { mostró la } \\
\text { posibilidad } \\
\text { de } \\
\text { fabricación a } \\
\text { nivel de } \\
\text { nanoescala y } \\
\text { acuñó el } \\
\text { término } \\
\text { nanotecnolo } \\
\text { gía. } \\
\text { En 1976, } \\
\text { Herbert } \\
\text { Boyer } \\
\text { Robert } \\
\text { Swanson } \\
\text { fundan } \\
\text { Genentech, } \\
\text { Inc., } \\
\text { primera la } \\
\text { compañía } \\
\text { biotecnológi } \\
\text { ca en E.U.A. } \\
\text { (Tutor et al, } \\
\text { 2011). }\end{array}$ & $\begin{array}{l}\text { De } \\
\text { Estados } \\
\text { Unidos } \\
\text { y Japón } \\
\text { hacia } \\
\text { Europa } \\
\text { y todo el } \\
\text { mundo. }\end{array}$ & $\begin{array}{l}\text { Altas } \\
\text { expectativas } \\
\text { económicas } \\
\text { y nuevas } \\
\text { oportunidade } \\
\text { s de } \\
\text { crecimiento } \\
\text { para } \\
\text { empresas y } \\
\text { países. } \\
\text { Sectores } \\
\text { estratégicos: } \\
\text { milicia, } \\
\text { gobierno y } \\
\text { seguridad. } \\
\text { Cierto temor } \\
\text { entre } \\
\text { sectores de la } \\
\text { población } \\
\text { por el uso de } \\
\text { productos } \\
\text { que } \\
\text { contienen } \\
\text { nanomaterial } \\
\text { es o que han } \\
\text { sido } \\
\text { modificados } \\
\text { a nivel } \\
\text { atómico } \\
\text { molecular } \\
\text { (OCDE, } \\
\text { 2013). }\end{array}$ \\
\hline
\end{tabular}




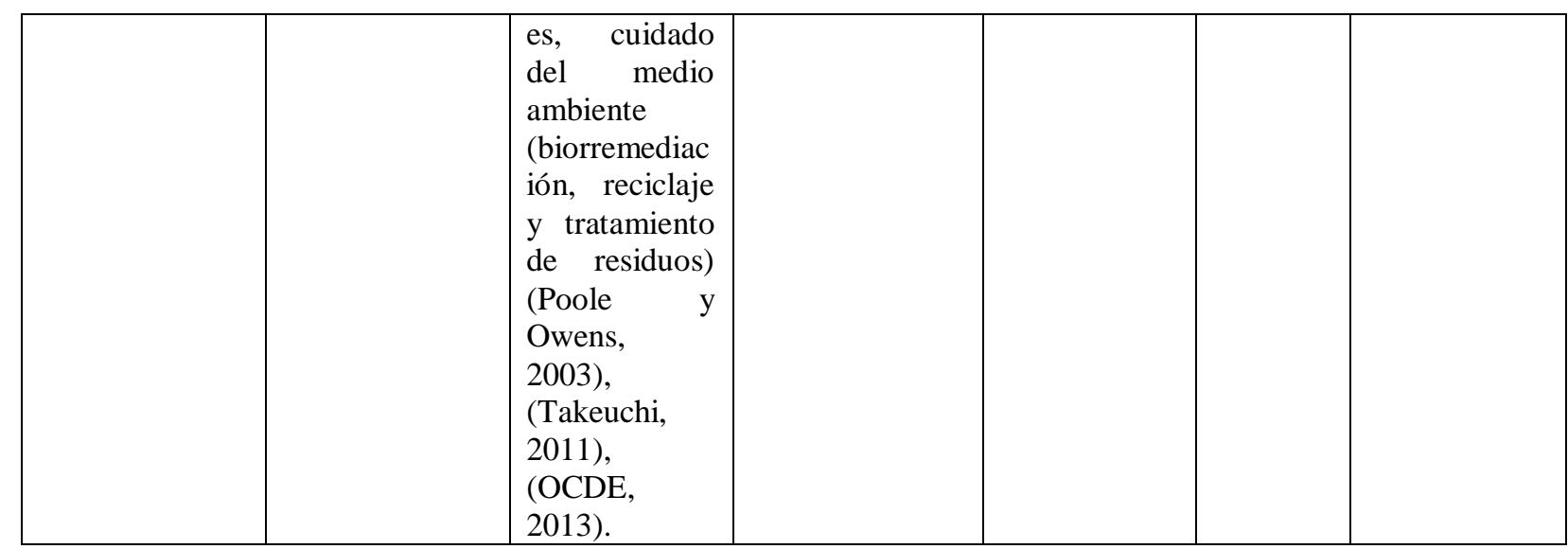

Fuente: elaboración propia con base en Pérez (2004 y 2009), Mowery y Rosenberg (1998), Hilbert y Cairó (2008), Ashton (1948), Poole y Owens (2003), Takeuchi (2011), OCDE (2013), Finardi (2013), Delgado (2007) y Tutor et al (2011).

En este capítulo, se presentó un recorrido histórico de las diferentes revoluciones tecnológicas ocurridas en la historia de acuerdo con el marco conceptual de la teoría evolucionista. Dicho recorrido, permitió observar las condiciones y las tendencias en la gestación de una revolución tecnológica como resultado de la difusión y convergencia de diversos paradigmas tecnológicos al conformar meta-sistemas, los cuales, tienen consecuencias económicas, sociales y organizacionales al difundirse (paradigmas tecnoeconómicos). En este panorama, se destacó la relevancia que tienen los estudios de difusión de paradigmas tecnológicos en el desarrollo económico de los países: a través de estos estudios, es posible observar las tendencias de evolución de un paradigma tecnológico y su posible convergencia con otros paradigmas para formar meta-sistemas. Por otro lado, se caracterizó a la nanotecnología como un nuevo paradigma tecnológico y se distinguieron también las características del nuevo paradigma tecnológico de nanotecnología (NPN) frente a otros paradigmas tecnológicos $\mathrm{y}$, en particular, frente al paradigma digital que dio origen a la revolución tecnológica de las TIC. Así, con base en el análisis anterior, se prevé que el NPN al difundirse y convergir con otros paradigmas tecnológicos tales como biolotecnología, materiales y el paradigma digital, podría dar origen a la próxima revolución tecnológica, la cual, estaría sustentada en el paradigma molecular. 
De esta forma, dado que la importancia de estudiar la difusión del NPN reside en la posibilidad de convergir con otros paradigmas y conformar un meta-sistema, en el siguiente capítulo se estudia su difusión. 


\section{Capítulo 3}

\section{Patrones de difusión de un nuevo paradigma tecnológico: el caso de la nanotecnología}

El propósito del presente capítulo es describir los patrones o pautas de difusión tecnológica de un nuevo paradigma tecnológico, en particular, el caso de la nanotecnología en países industrializados y emergentes, así como identificar los factores que los determinan. El estudio toma como base la información contenida en las patentes asignadas a residentes y no residentes en la Oficina de Marcas y Patentes de Estados Unidos (USPTO) en el campo tecnológico de nanotecnología (clase 977) en el periodo 1974-2013.

En el capítulo 2, se enfatizó la importancia que tienen los estudios de la difusión de paradigmas tecnológicos en el marco de la teoría evolucionista, en tanto que proveen información acerca de sus tendencias hacia la convergencia con otros paradigmas y de la posible emergencia de un meta-sistema que de origen a una nueva revolución tecnológica. Sin embargo, en este marco conceptual no existe una metodología propia para llevar a cabo estos estudios porque se asumen los resultados de los estudios que intentan integrar los procesos de innovación y de difusión.

Específicamente, se propone una metodología para contrastar con la evidencia empírica las siguientes hipótesis: i) se espera mostrar que el ámbito de la difusión de la nanotecnología es amplio y va desde los sectores tecnológicos maduros hasta los recientemente considerados nuevos paradigmas tecnológicos (TIC y biotecnología); ii) se espera mostrar que la mayor probabilidad de difusión y velocidad del nuevo paradigma tecnológico de nanotecnología (NPN), sea para aquellos países que invierten más en investigación y desarrollo (I+D), redes internacionales de investigación, tamaño de equipos de investigación, extensión de campos tecnológicos, stock de conocimientos científicos y tecnológicos, colaboración entre universidades-firmas y especialización tecnológica del país. En el siguiente apartado, se expone la metodología propuesta para contrastar empíricamente estas hipótesis. 


\section{Metodología propuesta}

La metodología consiste en tomar como principal fuente de información y unidad de análisis a las patentes asignadas en el campo tecnológico de nanotecnología. Considerando la discusión presentada en el primer capítulo sobre los alcances y límites del uso de datos de patentes en los estudios empíricos del cambio tecnológico, se puede afirmar que si bien las patentes representan solo una parte de la actividad inventiva total que se lleva a cabo en una economía, proporciona información que, en general, resulta confiable para estudiar el cambio tecnológico a través de series de tiempo o análisis de corte transversal (Basberg, 1987; Griliches, 1998; Calderón-Martínez, 2014). Ahora bien, un dato contenido en la información que contienen las patentes son las citas que reciben las patentes de otras patentes (citas hacia adelante). Este dato se usa para estimar el valor de la patente o como un indicador del flujo de conocimientos de una patente hacia patentes sucesivas (OCDE y OEPM, 2009). Así, en esta propuesta se considera como una variable proxy de la difusión del NPN el número de citas que recibe una patente. Dado que las patentes asignadas tienen posibilidades comerciales, el flujo de conocimientos medido a través del número de citas que reciben las patentes asignadas en nanotecnología también considera la potencialidad de que este nuevo paradigma tecnológico se difunda a través del mercado en forma de productos con conocimiento tecnológico incorporado.

De esta forma, la idea de medir el flujo de conocimientos tecnológicos a través de citas de patentes es sencilla: si una patente $P_{2}$ cita a la patente $P_{1}$ puede ser indicativo de que existe un flujo de conocimiento de la patente $P_{1}$ hacia la patente $P_{2}$ (Hall et al., 2001). La información procedente de las citas de patentes resulta útil como medida de difusión tecnológica porque puede ser usada para determinar la influencia de invenciones anteriores a través del tiempo y del espacio (países y sectores tecnológicos). Sin embargo, una limitación que tiene el uso de citas de patentes como indicador de flujos de conocimiento tecnológico es que no contempla los flujos de conocimiento que ocurren en aquellas actividades donde no se patenta (Verspagen, 2000). Aun así, las citas de patentes representan un indicador relevante sobre la difusión de tecnología y, por ello, se propone como una variable proxy de la difusión de un nuevo paradigma tecnológico a nivel de actividad inventiva. 
De manera específica, se estima la velocidad de difusión de los nuevos conocimientos en nanotecnología, usando como variable proxy el rezago de cita (lag time) propuesto por Gay et al. (2005), que consiste en medir, tomando como unidad de tiempo los años, la diferencia entre la fecha de asignación de una patente y la fecha de publicación de la patente que la cita por primera vez. La propuesta de Gay tiene la ventaja de que no considera el rezago de cita promedio, medida usada por otros investigadores, lo cual podría influir en el valor del parámetro de la velocidad de difusión. Cabe señalar que, bajo el propósito de medir el flujo de nuevos conocimientos, podría usarse la fecha de publicación de la patente citada en lugar de la fecha de asignación como lo hace Gay; sin embargo, se considera esta última opción porque las patentes asignadas tienen mayor posibilidad de uso comercial y, por lo tanto, mayores posibilidades de difusión como conocimiento tecnológico incorporado, lo que forma parte también de la difusión de un nuevo paradigma tecnológico así como de sus posibilidades de convergencia con otros paradigmas y de formar un meta-sistema y dar origen a una revolución tecnológica.

Ahora bien, dada la importancia que tiene Estados Unidos como uno de los principales países innovadores en el mundo y, considerando el tamaño del mercado de tecnología que representa este país (por lo que puede ser considerado como una muestra representativa del mercado de tecnología a nivel mundial), se toman como fuente de información las patentes sobre nanotecnología (clase 977) registradas en la USPTO de 1974 a 2013. Además, como se mostró en el primer capítulo, un problema que guarda relación con la variabilidad intrínseca de los datos de patentes tiene que ver con los distintos criterios que usan las distintas oficinas de patentes. Para evitar este problema, se toman las patentes asignadas en nanotecnología solo de la USPTO, de esta forma se reduce la magnitud de este problema y es posible realizar inferencia estadística (Marco, 2006).

Una vez definida la base de datos, se presenta una descripción de la configuración del flujo de conocimientos tecnológicos generados a nivel de actividad inventiva por el NPN, por sectores tecnológicos y por países, a través de un análisis estadístico con el propósito de describir su distribución y, posteriormente, se complementa este análisis con un modelo econométrico de conteo para identificar los posibles factores que dieron origen a dicha difusión en cada país. El modelo econométrico de conteo que se propone incluye dos modalidades: el modelo Poisson, que permite estimar la probabilidad promedio de que ocurra el flujo de 
conocimiento (medido a través del número de citas de patentes hacia adelante) ante un cambio en una unidad de las variables explicativas. Sin embargo, tiene algunas restricciones que no siempre son satisfechas por la naturaleza de los datos analizados, tales como el supuesto de equidispersión, es decir, el supuesto de que la variable dependiente se distribuye de acuerdo con la distribución de Poisson, lo que implica que la media y la varianza son iguales. Esto generalmente no se cumple. Ante este problema, se estima la segunda modalidad: el modelo binomial negativo. Más adelante, en la sección que corresponde a la especificación del modelo, se explican estas limitaciones con más detalle.

\subsection{Datos y fuentes de información}

Con base en la información proporcionada por la USPTO, se realizó una búsqueda de patentes asignadas en el campo tecnológico de nanotecnología con base en el método propuesto por Guzmán y Toledo (2009). El método de búsqueda consiste en llevar a cabo ésta por clase tecnológica, en este caso, la clase 977 para inventores residentes y no residentes de 1974 a 2013. La base de datos de patentes en esta clase, de acuerdo con la USPTO, corresponde a:

i) Nanoestructura y composiciones químicas de nanoestructura

ii) Componentes informáticos que incluye al menos una nanoestructura

iii) Algoritmos matemáticos (para modelar configuraciones o propiedades de nanoestructura)

iv) Métodos o aparatos para hacer, detectar, analizar o tratar nanoestructuras

v) Usos particulares específicos de nanoestructura (Guzmán y Toledo, 2009).

Además, esta búsqueda se puede complementar asociando la clase 977 a otras clases particulares, por ejemplo, las asociadas a la biotecnología: CCL/977/800 (Guzmán y Toledo, 2009). La ventaja de usar este método reside en que evita sobreestimar la información, como podría ocurrir usando otros métodos, por ejemplo el propuesto por Huang et al. (2003), quienes realizaron su búsqueda formando un query utilizando la palabra nano.

Después de realizar la búsqueda de patentes siguiendo el método propuesto por Guzmán y Toledo (2009) se obtuvieron un total de 18414 patentes asignadas a residentes y no 
residentes de Estados Unidos entre 1974 y 2013. Con base en esta información se presenta, en el apartado siguiente, un análisis descriptivo de la difusión de la nanotecnología como un nuevo paradigma tecnológico, a nivel mundial, usando la población de estudio seleccionada.

\subsection{Análisis descriptivo de la difusión del NPN a nivel mundial con base en la población de estudio (18 414 patentes)}

En general, los países que se caracterizan por destinar más recursos económicos (como porcentaje del PIB) y esfuerzos en investigación y desarrollo (I+D) (datos promedio entre 2000 y 2011) son Finlandia (3.5\%), Japón (3.2\%), Corea del Sur (3\%), Alemania (2.62\%), Estados Unidos (2.6\%) y Francia $(2.17 \%)$, de acuerdo con la información proporcionada por los indicadores económicos del Banco Mundial. A su vez, los países que más invierten en el campo tecnológico de nanotecnología son Estados Unidos, Japón, Alemania, quienes aportan anualmente más del $50 \%$ de la inversión total mundial, y Corea del Sur, que mayor proporción destina a la investigación y desarrollo de la nanotecnología, como se explicó en el capítulo 2. En el cuadro 3.1 aparece la información del gasto en I+D como porcentaje del PIB desglosada en los años 2000, 2005 y 2011.

Cuadro 3.1. Gasto en I+D como porcentaje del PIB, por países, en los años 2000, 2005 y 2011

\begin{tabular}{|l|l|l|l|}
\hline Países / años & $\mathbf{2 0 0 0}$ & $\mathbf{2 0 0 5}$ & $\mathbf{2 0 1 1}$ \\
\hline Finlandia & 3.35 & 3.48 & 3.80 \\
\hline Japón & 3 & 3.31 & 3.30 \\
\hline Corea del Sur & 2.4 & 2.7 & 3.8 \\
\hline $\begin{array}{l}\text { Estados Unidos de } \\
\text { América }\end{array}$ & 2.61 & 2.49 & 2.67 \\
\hline Alemania & 2.47 & 2.51 & 2.89 \\
\hline Francia & 2.15 & 2.11 & 2.25 \\
\hline
\end{tabular}

Fuente: elaboración propia con base en Indicadores Económicos del Banco Mundial y Eustat.

La información contenida en el cuadro 3.1, se complementa con el comportamiento que describe la gráfica 3.1, que representa el gasto en I+D (como porcentaje del PIB) de un conjunto de países industrializados y emergentes entre el año 2000 y 2012. Cabe resaltar que el grupo de países que más esfuerzos realizan en I+D en nanotecnología (Estados Unidos, Japón, 
Corea del Sur y Alemania) se separan claramente de un grupo de países emergentes (Brasil, China y México), lo que indica la relevancia que tiene la innovación en los países industrializados, en contraste con los países emergentes.

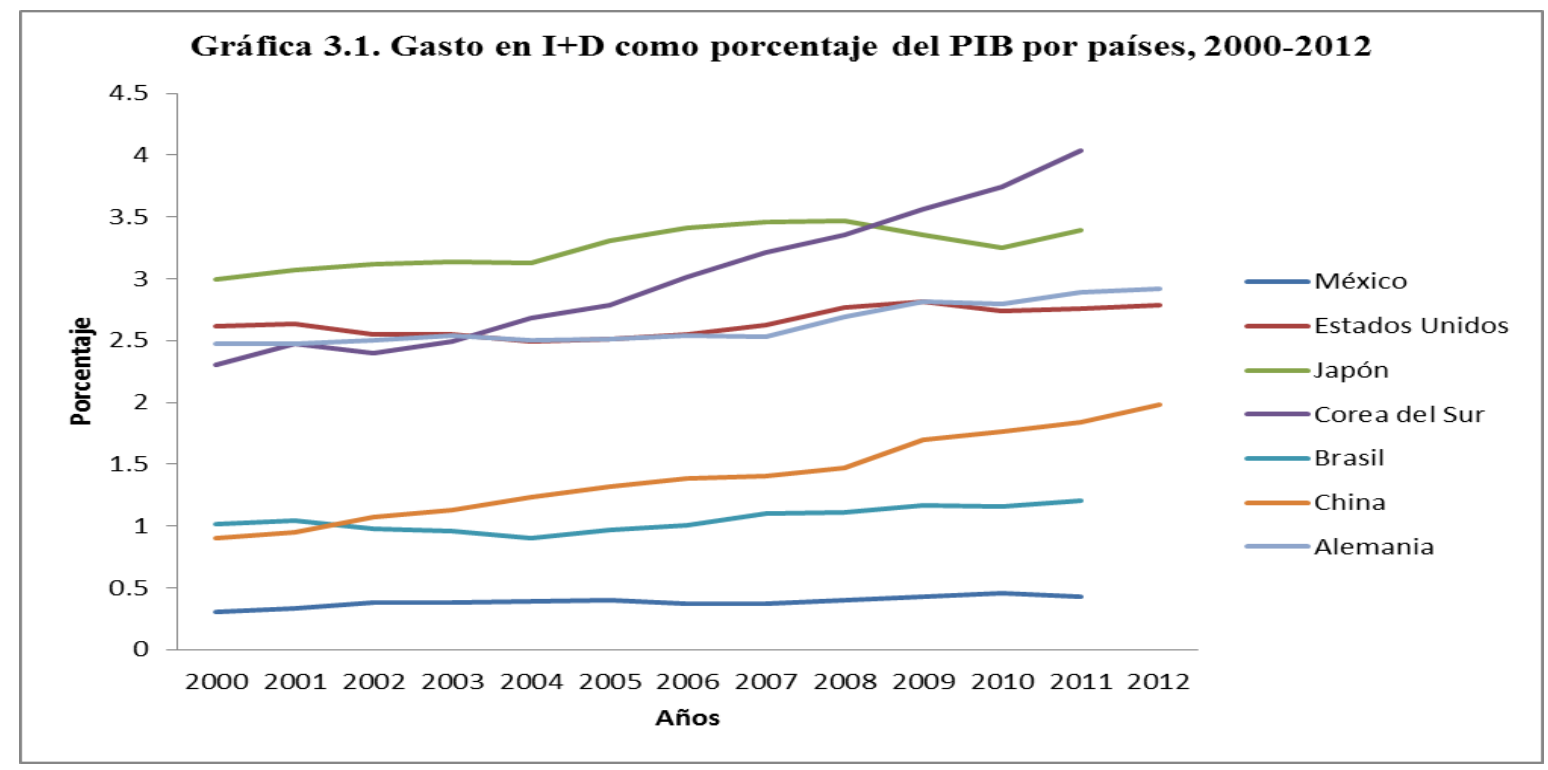

Fuente: elaboración propia con base en Indicadores Económicos del Banco Mundial

Estos esfuerzos que realizan los gobiernos y las firmas se ven reflejados en la intensidad de la capacidad inventiva en este campo. Una forma aproximada (proxy) de captar esta intensidad es observar cómo crece el número de patentes concedidas en nanotecnología. En el cuadro 3.2 se observa el número de patentes concedidas en nanotecnología, clase CCL/977/700-863 en la USPTO, de 1975 a 2013.

Cuadro 3.2. Número de patentes concedidas en nanotecnología, clase CCL/977/700-863, 1975-2013 (USPTO). Datos acumulados en periodos de 5 años.

\begin{tabular}{|c|c|}
\hline Años & Número de patentes \\
\hline 1975 & 2 \\
\hline 1980 & 17 \\
\hline 1985 & 63 \\
\hline 1990 & 283 \\
\hline 1995 & 1460 \\
\hline 2000 & 4221 \\
\hline
\end{tabular}




\begin{tabular}{|c|c|}
\hline 2005 & 8752 \\
\hline 2010 & 13688 \\
\hline $2013 *$ & 18414 \\
\hline
\end{tabular}

Fuente: elaboración propia con base en información tomada de USPTO, 1975-2013. *La información de 2013 es hasta septiembre.

La tendencia de los datos sugiere que, en esta fase, la difusión del nuevo paradigma tecnológico es altamente creciente. Esta tendencia se confirma con el comportamiento que muestra la gráfica 3.2 que se observa a continuación.

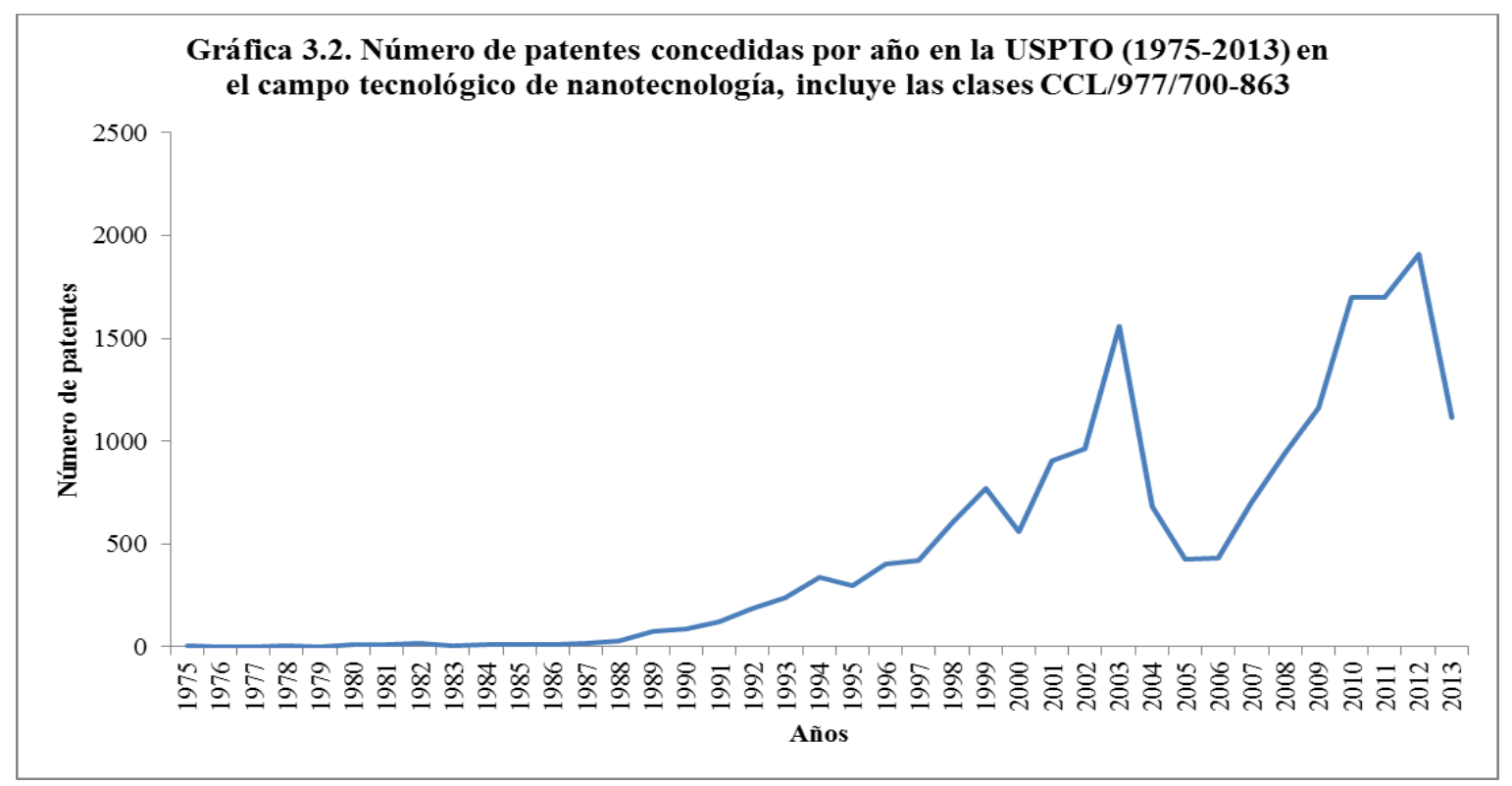

Fuente: elaboración propia con base en datos proporcionados por la USPTO.

La gráfica 3.2, muestra la evolución de la actividad inventiva generada en el marco del NPN. Dicha actividad, medida a través del número de patentes asignadas en este campo tecnológico año por año, muestra en forma aproximada la difusión del nuevo paradigma tecnológico a través del tiempo y a nivel mundial. En general, se observa que los datos describen un patrón de difusión que se asemeja a la fase inicial del patrón señalado por Pérez (2009), es decir, en forma de $S$. Al inicio del paradigma la actividad inventiva es lenta, lo que podría reflejar la desconfianza de los actores que participan en el proceso de innovación: inventores, instituciones públicas y empresas. En la gráfica se observa esta primera etapa con 
un crecimiento raquítico, casi nulo, entre 1975 (dos patentes) y 1986 (cinco patentes). Es decir, la actividad inventiva en nanotecnología fue relativamente escasa en un periodo de 12 años, con una tasa de crecimiento promedio anual de 7.9\%. El comportamiento en este periodo, si bien puede reflejar parte de la situación económica mundial, también sugiere la fase de instalación de este nuevo paradigma. No obstante, a partir de 1987, la actividad inventiva muestra un crecimiento importante: de 8 patentes en 1987 pasó a 1,254 patentes en 2012, es decir, una tasa de crecimiento promedio anual de $21.4 \%$. Esta variabilidad puede reflejar incertidumbre en la actividad inventiva, propia de la emergencia de un paradigma tecnológico. Sin embargo, aunque con altibajos, de 1987 a 2013 se observa que el crecimiento de la actividad inventiva en nanotecnología ha sido importante, ya que la tasa de crecimiento promedio anual correspondiente a todo el periodo (1975-2013) es de $17.4 \%$.

En cuanto a la tasa de crecimiento anual se observa que, de 1980 a 1990, la actividad inventiva en nanotecnología fue volátil, alcanzando tasas de entre $-71.4 \%$ en 1983 hasta $162.1 \%$ en 1989, lo cual, sugiere elevada incertidumbre en dicho periodo. Sin embargo, a partir de 1990, se observan tasas de crecimiento entre $11.8 \%$ en 1990 y $62.6 \%$ en 2003 , lo que sugiere que a partir de 1990 la actividad inventiva bajo este paradigma tecnológico fue más estable en relación con el periodo previo. En la gráfica 3.3, se observa dicho comportamiento.

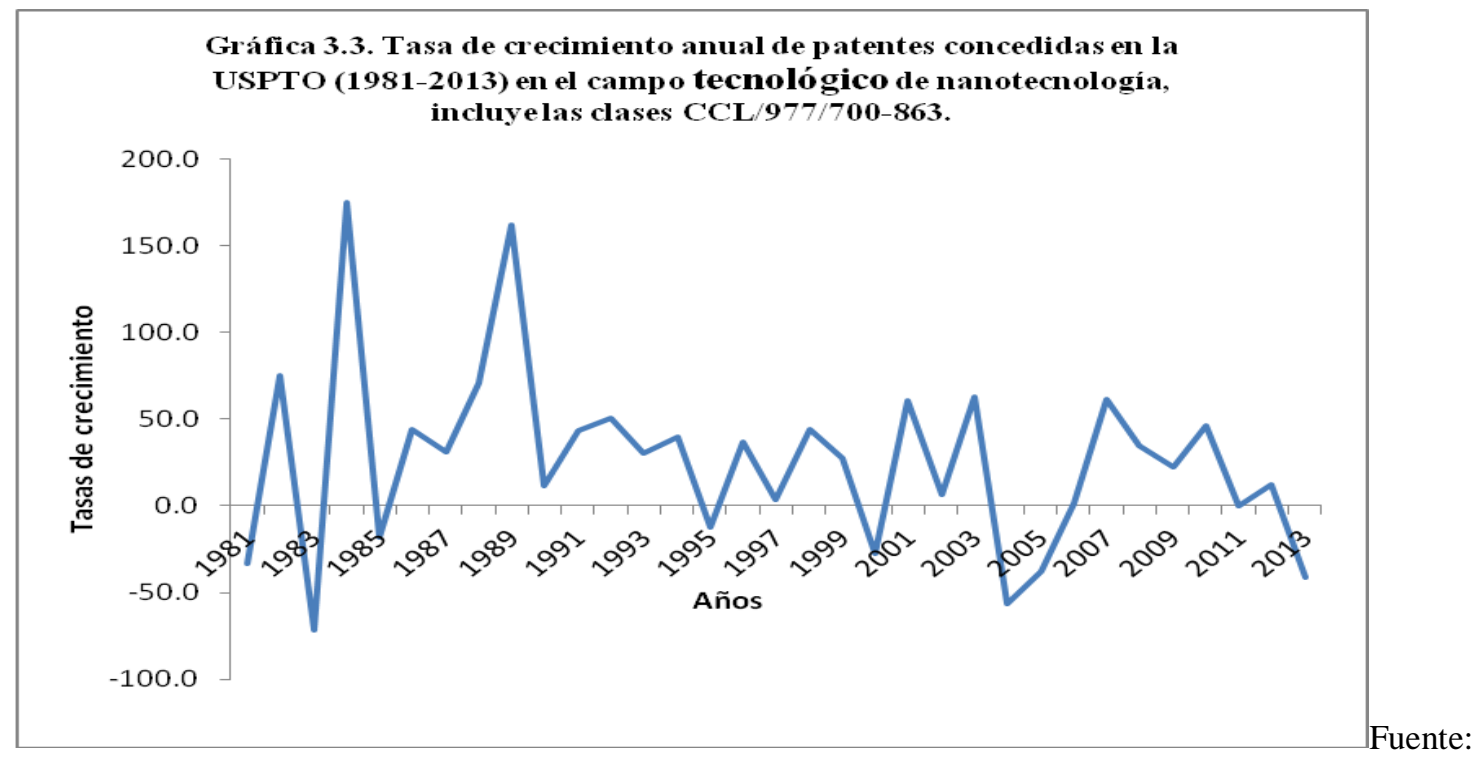

elaboración propia con base en información proporcionada por la USPTO. 
Ahora bien, una descripción informativa de cualquier conjunto de datos, está dada por la frecuencia de repetición o arreglo distribucional de las observaciones en el conjunto (Canavos, 1988). Al dividir el periodo de estudio, 1975-2013, en clases de cinco años, se obtienen 8 clases, lo cual, satisface la condición mínima para observar la distribución de los datos: "Si existe una cantidad sustancial de datos, el número de clases debe encontrarse entre ocho y doce y, generalmente, no existirán más de 15 clases” (Canavos, 1988: 4).

Al registrar el número de patentes en cada intervalo, se obtiene la frecuencia de clase y al estimar el cociente de una frecuencia de clase con respecto al número combinado de observaciones en todas las clases, se obtiene la frecuencia relativa de cada clase. En el cuadro 3.3, se observan los resultados.

Cuadro 3.3. Frecuencia de clase y frecuencia relativa de las patentes concedidas en la USPTO, en el campo tecnológico de nanotecnología, 1975-2013

\begin{tabular}{|l|l|l|}
\hline Sub periodos (clases) & $\begin{array}{l}\text { Número de patentes en cada } \\
\text { clase (frecuencia de clase) }\end{array}$ & Frecuencia relativa \\
\hline $\mathbf{1 9 7 5 - 1 9 7 9}$ & 5 & 0.0003 \\
\hline $\mathbf{1 9 8 0 - 1 9 8 4}$ & 49 & 0.0027 \\
\hline $\mathbf{1 9 8 5 - 1 9 9 0}$ & 229 & 0.0124 \\
\hline $\mathbf{1 9 9 1 - 1 9 9 5}$ & 1177 & 0.0639 \\
\hline $\mathbf{1 9 9 6 - 2 0 0 0}$ & 2761 & 0.1499 \\
\hline $\mathbf{2 0 0 1 - 2 0 0 5}$ & 4531 & 0.2461 \\
\hline $\mathbf{2 0 0 6 - 2 0 1 0}$ & 4936 & 0.2681 \\
\hline $\mathbf{2 0 1 1 - 2 0 1 5}$ & 4726 & 0.2567 \\
\hline Total & 18,414 & 1 \\
\hline
\end{tabular}

Fuente: elaboración propia con base en USPTO, 1975-2013, clase 977.

En el cuadro 3.3 se observa que el número de patentes en cada clase tiene una tendencia creciente a excepción del último intervalo, lo cual se explica por el hecho de que los datos que caen en la última clase solo consideran el número de patentes concedidas entre 2011 y 2013, lo que obedece al método utilizado para organizar los datos. En cuanto a la tendencia creciente del número de patentes en cada clase, significa que en cada periodo de cinco años sucesivo después del periodo inicial, 1975-1979, el número de patentes concedidas en nanotecnología es mayor. En otras palabras, que en cada periodo de cinco años la actividad inventiva en el campo de nanotecnología es más intensa que en el periodo anterior. En términos porcentuales (frecuencia relativa) se observa la misma tendencia. En la gráfica de frecuencia relativa (3.4) se 
presenta este comportamiento. Este resultado confirma nuevamente la tendencia creciente de la actividad inventiva bajo el paradigma tecnológico de la nanotecnología a nivel de actividad inventiva.

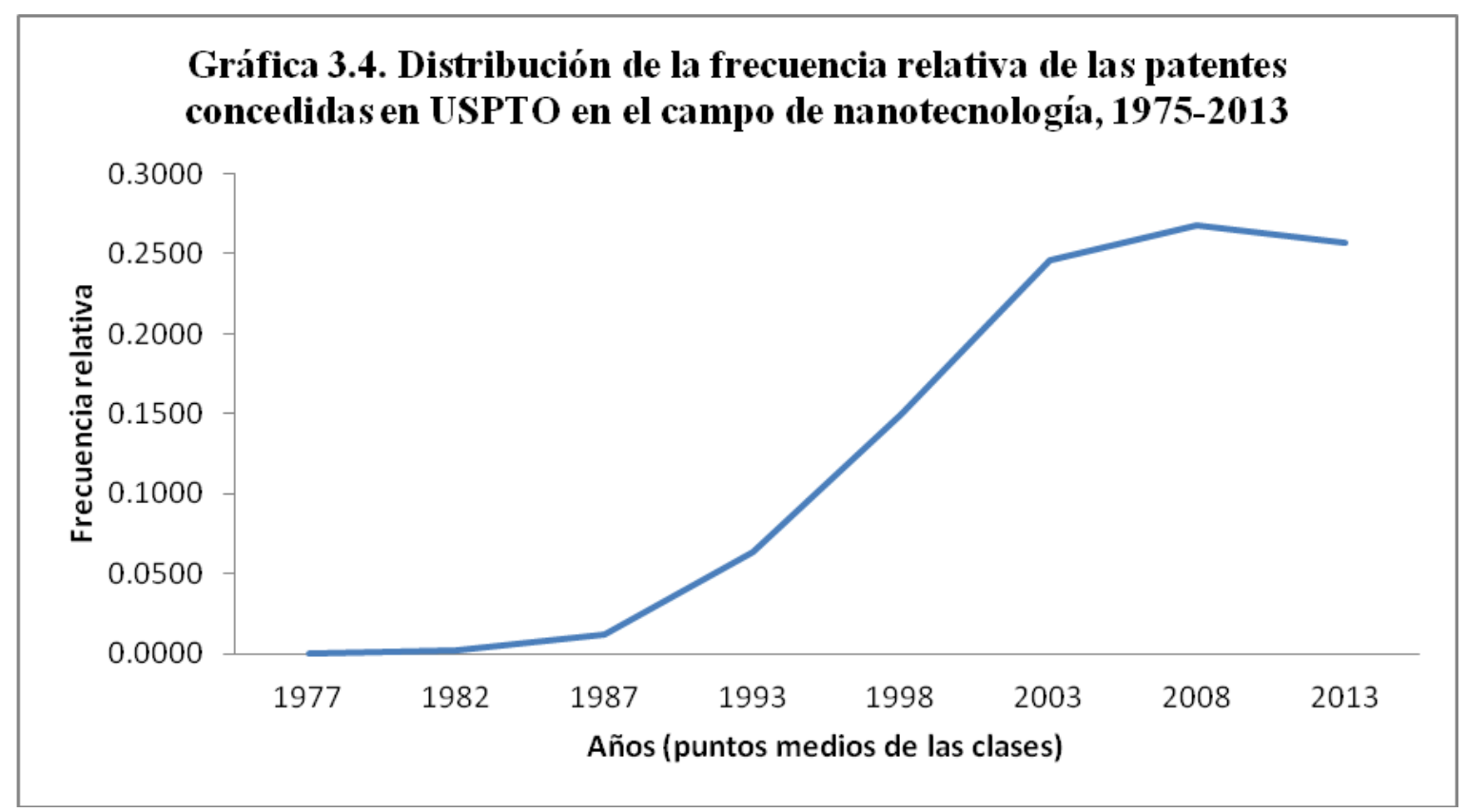

Fuente: elaboración propia con base en USPTO, 1975-2013, clase 977.

Ahora bien, si las patentes se agrupan por clases tecnológicas se obtendrá una distribución cualitativa de los datos. De esta forma, siguiendo una primera clasificación propuesta por Guzmán y Toledo (2009), se puede calcular la distribución de patentes concedidas en USPTO a residentes y no residentes en el campo de nanotecnología entre 1975 y 2013. El siguiente cuadro muestra esta distribución:

Cuadro 3.4. Distribución de patentes concedidas en USPTO a residentes y no residentes en el área de nanotecnología (número de patentes total hasta 2013)

\begin{tabular}{|l|l|l|}
\hline Clases tecnológicas & Número de patentes & Proporción \\
\hline Nanoestructuras & 6601 & 37.84 \\
\hline Biotecnología & 6245 & 35.8 \\
\hline Química & 4596 & 26.35 \\
\hline
\end{tabular}


Fuente: elaboración propia con base en USPTO clases Química: 977/900-93; Biotecnología: 977/800-890; y Nanoestructuras: 977/700-799.

Los resultados obtenidos muestran que la mayor parte de la actividad inventiva en nanotecnología está concentrada en la clase de Nanoestructura (37.84\%); mientras que Biotecnología ocupa el segundo lugar en importancia con 35.8\% y Química el tercer lugar con $26.35 \%$. En la siguiente gráfica de pastel se pueden visualizar estas proporciones.

Gráfica 3.5. Distribución de patentes concedidas en USPTO a residentes y no residentes en el área de nanotecnología (número total de patentes hasta 2013)

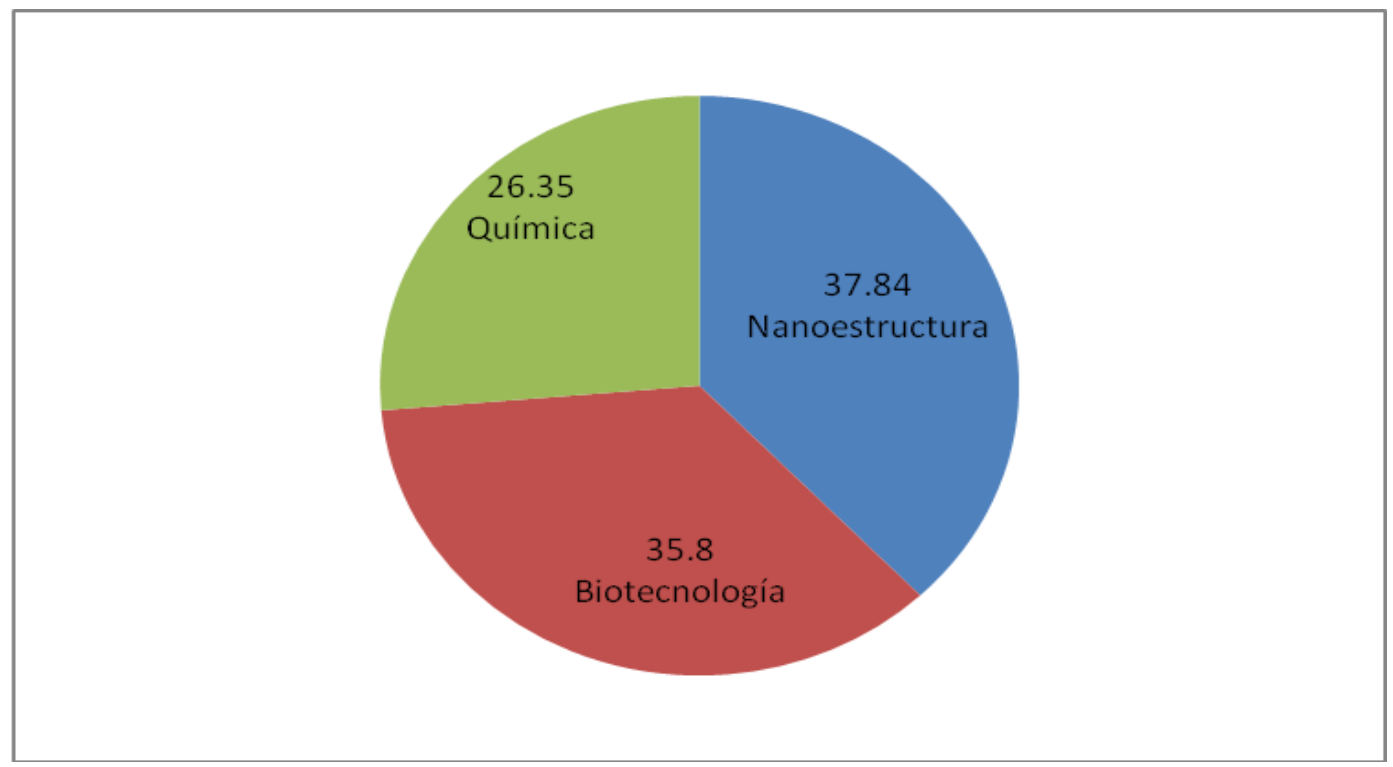

Fuente: elaboración propia con base en USPTO clases Química: 977/900-93; Biotecnología: 977/800890; y Nanoestructuras: 977/700-799.

La distribución que se observa es casi equitativa. Sin embargo, al comparar estos datos con los correspondientes a la distribución del número de patentes por clases tecnológicas en 1980, la distribución era marcadamente desigual. En el cuadro 3.5, se presentan estos datos.

Cuadro 3.5. Distribución de patentes concedidas en USPTO a residentes y no residentes en el área de nanotecnología (número de patentes total hasta 1980) 


\begin{tabular}{|l|l|l|}
\hline Nanoestructuras & 11 & 67 \\
\hline Biotecnología & 4 & 22 \\
\hline Química & 2 & 11 \\
\hline Total & 17 & 100 \\
\hline
\end{tabular}

Fuente: elaboración propia con base en USPTO clases Química: 977/900-93; Biotecnología: 977/800-890; y Nanoestructuras: 977/700-799.

Si bien los datos correspondientes a 1980 tienen la misma estructura en cuanto a la concentración, es decir, la clase de nanoestructura concentra el mayor número de patentes, seguido de la clase de biotecnología y, por último, química como se observa en los datos correspondientes a 2013, la diferencia reside en el grado de concentración. Como se observa en el gráfico 3.6, nanoestructura concentró el 67\%, biotecnología el 22\% y química el $11 \%$.

Gráfica 3.6. Distribución de patentes concedidas en USPTO a residentes y no residentes en el área de nanotecnología (número total de patentes hasta 1980)

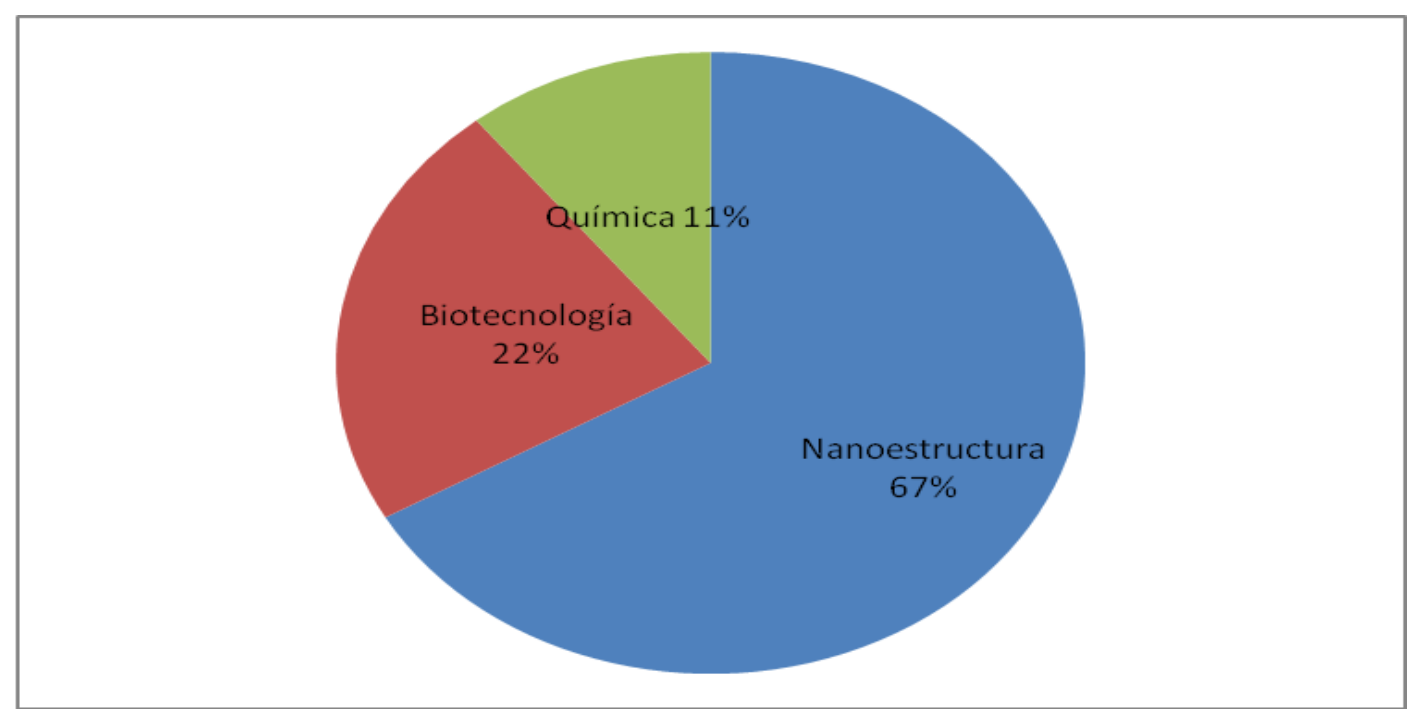

Fuente: elaboración propia con base en USPTO clases Química: 977/900-93; Biotecnología: 977/800890; y Nanoestructuras: 977/700-799.

Mientras que en 1980 la diferencia entre nanoestructura y biotecnología era de 45\%, entre nanoestructura y química de 56\% y entre biotecnología y química de 11\%, en 2013 la diferencia es de $2.04 \%, 11.49 \%$ y de $9.45 \%$, respectivamente; lo que sugiere que la actividad inventiva en biotecnología y química ha crecido a mayor velocidad que la actividad inventiva 
en nanoestructura, clase tecnológica donde se originó este nuevo paradigma tecnológico. Esto último se confirma cuando se grafica la evolución de la actividad inventiva a través del tiempo por clase tecnológica y al comparar sus tasas de crecimiento promedio anual.

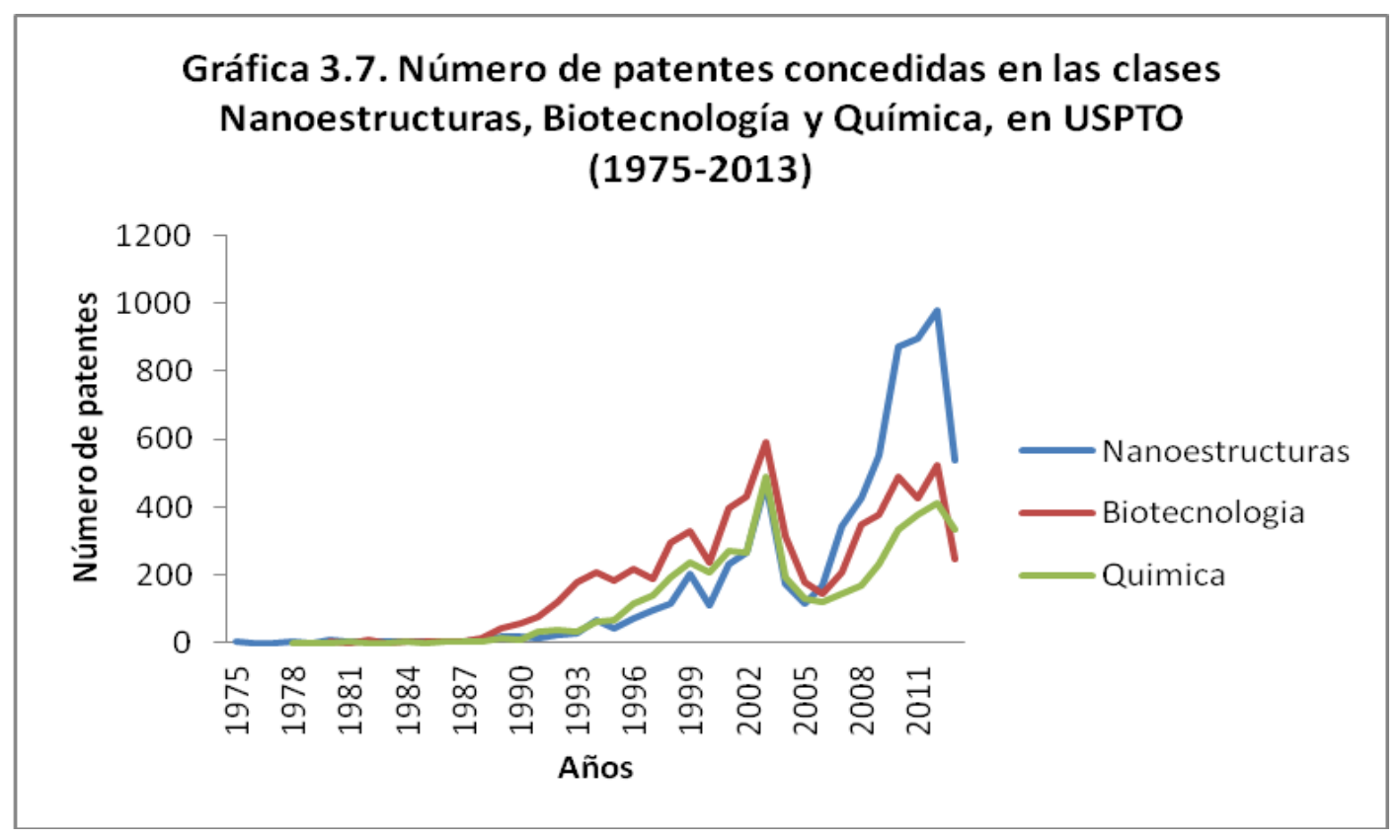

Fuente: elaboración propia con base en datos proporcionados por la USPTO.

En la gráfica 3.7 se observa que, entre 1990 y 2006, biotecnología y química tuvieron un crecimiento considerable, ya que el número de patentes en cada una de estas clases fue mayor que el número de patentes en la clase de nanoestructura. Sin embargo, a partir de 2007, nanoestructura se colocó, nuevamente, en primer lugar, seguido de biotecnología y química. En cuanto a la tasa de crecimiento promedio anual se confirma el crecimiento acelerado de la actividad inventiva en biotecnología y química, ya que registraron una tasa de $12.9 \%$ y $17.5 \%$ respectivamente, comparada con una tasa de $15.4 \%$ correspondiente a nanoestructura. Cabe señalar que química registró una tasa de crecimiento promedio anual superior no solo a nanoestructura sino, también, superior a la tasa correspondiente a todo el campo de nanotecnología (17.4\%), entre 1975 y 2013.

En cuanto a la concentración y dispersión de los datos, el valor promedio del número de patentes concedidas en cada una de las clases tecnológicas fue de 6138 en el periodo de estudio considerado. Así, mientras que nanoestructura y biotecnología registraron una 
actividad inventiva superior al promedio (6 894 y 6868 patentes, respectivamente), química registró 4642 patentes concedidas, es decir, 1496 patentes menos que el número promedio. Esto indica que, aunque el ritmo de crecimiento de la actividad inventiva en química fue superior a nanoestructura y biotecnología, en valores absolutos generó no solo un número menor de patentes que éstas sino, también, menor que el número promedio generado en cada clase tecnológica.

El análisis descriptivo previo a nivel mundial del NPN muestra que, a nivel de actividad inventiva, se ha difundido en tres grandes campos tecnológicos, principalmente: nanoestructura, donde tuvo su origen, biotecnología y química entre 1975 y 2013 . A su vez, la actividad inventiva en cada uno de estos grandes campos ha sido distinta, lo que sugiere distintos ritmos de difusión al interior de estas clases.

En este apartado, se puede concluir que, a nivel mundial, el NPN se difunde a nivel de actividad inventiva en forma volátil pero creciente, entre 1975 y 2013. También se puede conjeturar que, por clases tecnológicas, el paradigma se difunde a velocidades distintas, aunque mantiene cualitativamente la misma estructura: nanoestructura, biotecnología y química. Cabe señalar que la cantidad de datos seleccionados en el tamaño de la población (18 414 patentes) dificultan la realización de un análisis más fino, por ejemplo, por países y otras variables contenidas en la información que proporcionan las patentes, por lo que se propuso trabajar con una muestra seleccionada aleatoriamente con base en el método de inferencia estadística:

Una buena muestra es aquella que refleja las características esenciales de la población de la cual se obtuvo. En estadística, el objetivo de las técnicas de muestreo es asegurar que cada observación en la población tiene una oportunidad igual e independiente de ser incluida en la muestra. Tales procesos de muestreo conducen a una muestra aleatoria. Las observaciones de la muestra aleatoria se usan para calcular ciertas características de la muestra denominadas estadísticas. Las estadísticas se usan como base para hacer inferencias acerca de ciertas características de la población, que reciben el nombre de parámetros. (Canavos, 1988: 1).

A continuación, se presenta un análisis de la difusión de la nanotecnología, definiendo una muestra de 376 patentes asignadas en el campo tecnológico de nanotecnología en la USPTO, lo que permitió realizar un análisis descriptivo más detallado sobre la difusión de este nuevo paradigma tecnológico. 


\subsection{Diagnóstico de la difusión del NPN utilizando una muestra (n=376 patentes)}

\section{Obtención de la muestra}

Con base en la población de 18414 patentes se obtuvo una muestra de 376 usando el método de muestreo aleatorio simple para obtener una muestra representativa a partir de una población finita (Anderson et al., 2008). El tamaño de la muestra se obtuvo a través de la siguiente expresión:

$$
n=\frac{Z_{\alpha}^{2} N p q}{i^{2} N-1+Z_{\alpha}^{2} p q}
$$

Correspondiente a poblaciones finitas y conocidas, donde:

$N$, es el tamaño de la población considerada (18 414 patentes en este caso).

$Z$, es el valor correspondiente a la distribución de Gauss:

$$
Z_{\alpha=0.05}=1.96
$$

$p$, es la prevalencia esperada del parámetro a evaluar. Cuando se desconoce (por la falta de estudios que den cuenta de su valor) se puede asumir que:

$$
p=0.5
$$

$q$, está dado por:

$$
q=1-p
$$

$i$, es el error que se prevé cometer. En este caso es del 5\%, por lo cual:

$$
i=0.05
$$

Realizando los cálculos se obtiene que n = 17687.6868 / 47.0004, por lo tanto:

$$
n=376.33
$$

Redondeando el valor anterior:

$$
n=376 \text { patentes. }
$$

Una vez definido el tamaño de la muestra, se realizó la selección aleatoria de los datos usando la hoja de cálculo de Excel, siguiendo los siguientes pasos:

i) En la primera columna se enumera cada uno de los datos disponibles en la población, de 1 hasta 18,414 
ii) En una columna aparte, se genera una lista con el número de datos necesarios para la muestra, en este caso del 1 al 376

iii) En la columna siguiente se generan los números aleatorios por medio de la formula "aleatorio.entre". En este caso se escribe la fórmula de la siguiente manera:

$=$ ALEATORIO.ENTRE $(1,18414)$

iv) Obtenido el primer número aleatorio, se genera una cantidad mayor de número aleatorios a los que se requiere en la muestra. Lo anterior debido que es posible que se repitan más de uno de los número aleatorios generados por el programa y será necesario eliminarlos;

v) Una vez eliminados los números aleatorios que se repiten, se procede a extraer de la población todos y cada uno de los 376 datos de acuerdo con los número aleatorios obtenidos.

En la siguiente sección se presenta el análisis descriptivo de la difusión de la nanotecnología, usando esta muestra.

\section{Evolución del NPN a nivel mundial}

Las patentes pertenecientes a la muestra de tamaño $n=376$, abarcan un periodo entre 1983 y 2013. El siguiente cuadro muestra el comportamiento del número acumulado por año, descrito a través de sub periodos de cinco años. Esto proporciona una idea sobre el crecimiento de este nuevo paradigma tecnológico, a través de la expansión de la actividad inventiva en este campo tecnológico en el tiempo.

Cuadro 3.6. Número de patentes concedidas en nanotecnología, clase CCL/977/700-863, 1983-2013 (USPTO), utilizando una muestra de $n=376$ patentes

\begin{tabular}{|l|l|}
\hline Años & Número de patentes \\
\hline 1983 & 1 \\
\hline 1988 & 1 \\
\hline 1993 & 14 \\
\hline 1998 & 50 \\
\hline 2003 & 148 \\
\hline
\end{tabular}




\begin{tabular}{|l|l|}
\hline 2008 & 221 \\
\hline 2013 & 376 \\
\hline
\end{tabular}

Fuente: elaboración propia con base en la muestra de tamaño $n=376$ patentes.

La gráfica 3.8 describe el comportamiento de estos datos.

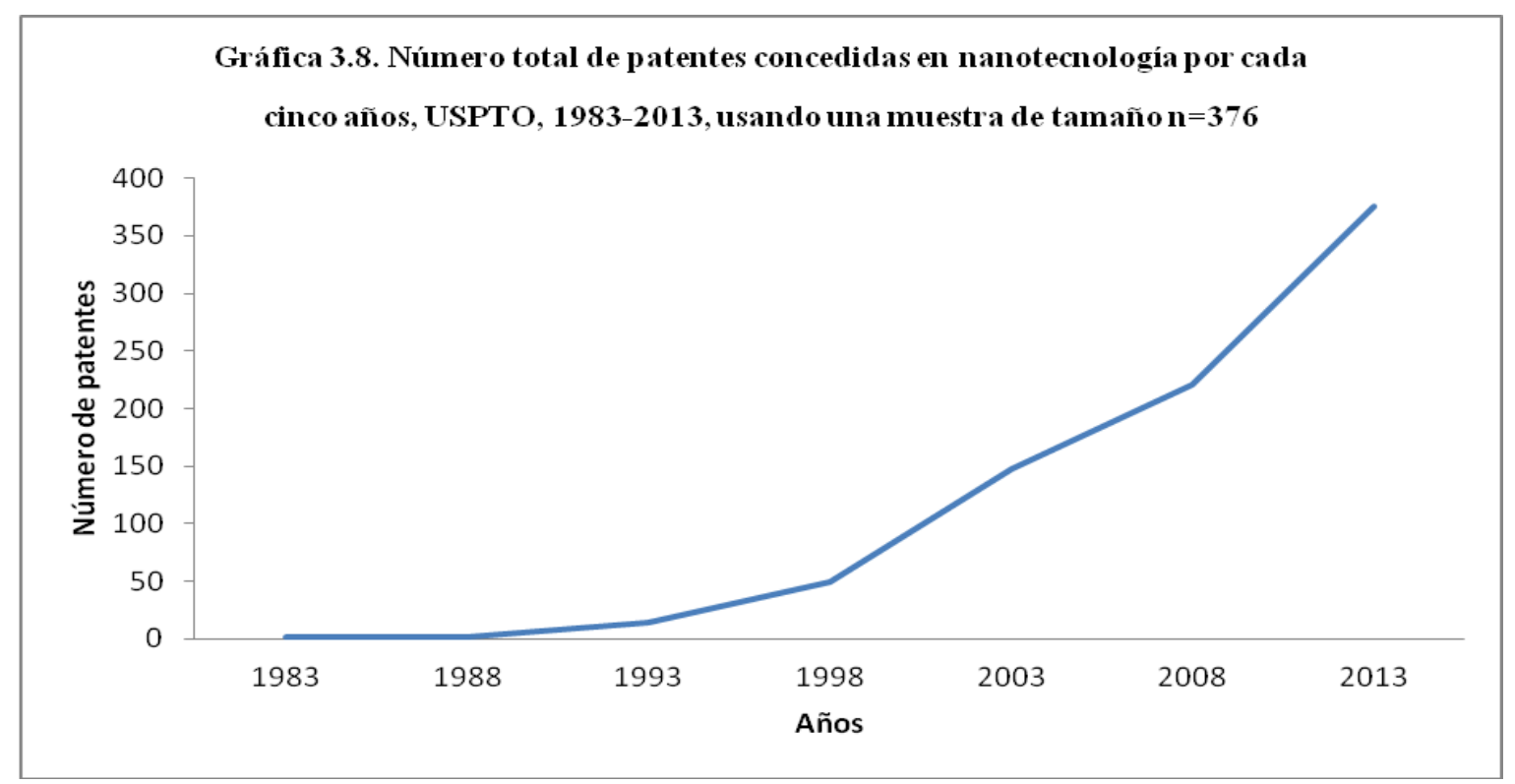

Fuente: elaboración propia con base en muestra de tamaño n=376 patentes.

Se confirma un patrón de difusión semejante al que se observa con los datos correspondientes a toda la población ( $\mathrm{N}=18414$ patentes). Al inicio, la actividad inventiva en el campo de nanotecnología es lento: entre 1983 y 1988 el número de patentes concedidas que forman parte de la muestra es 1 , lo que sugiere, nuevamente, que el crecimiento al inicio del nuevo paradigma tecnológico es lento, posiblemente porque refleje incertidumbre. Sin embargo, conforme transcurre el tiempo, el número de patentes acumulado aumenta hasta cubrir las 376 en 2013.

La siguiente gráfica describe el comportamiento del número de patentes solicitadas y concedidas a través del tiempo para los datos correspondientes a la muestra. 


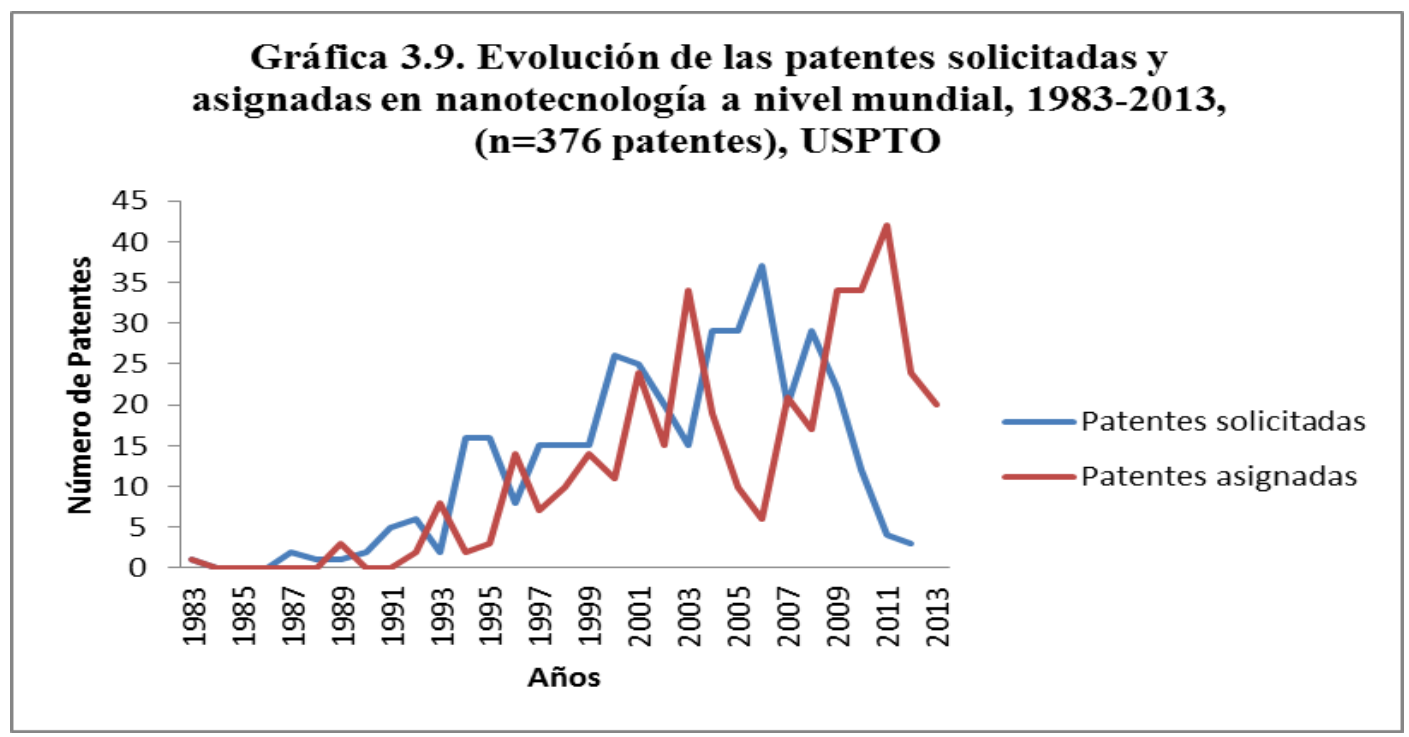

Fuente: elaboración propia con base en muestra de tamaño $n=376$ patentes.

La línea de color azul indica el comportamiento de las patentes solicitadas mientras que la línea de color rojo indica el número de patentes asignadas. Se observa que ambas muestran un comportamiento creciente, aunque con volatilidad. Así, la tasa de crecimiento promedio anual de las patentes solicitadas entre 1983 y 2013 fue de 9.28\%, mientras que la tasa de crecimiento promedio anual correspondiente al número de patentes concedidas durante el mismo periodo fue de $13.42 \%$. Dado que una tasa de crecimiento puede ser vista como un valor proxy de la velocidad, significa que la velocidad de difusión de la actividad inventiva en el campo tecnológico de nanotecnología, medido a través del número de patentes solicitadas, fue de 9.28 entre 1983 y 2013. Sin embargo, fue menor en comparación con la velocidad de difusión medido a través del número de patentes asignadas (13.42). La brecha indica el desfase temporal entre la fecha de solicitud y la fecha de asignación de las patentes en este campo. Se observa que, en general, la línea correspondiente al número de patentes solicitadas se ubica por encima de la línea correspondiente al número de patentes asignadas, sin embargo, esto se invierte en el año 2011, observándose una ligera caída entre 2011 y 2013.

Ahora bien, en cuanto a la volatilidad que muestran los datos se observa que, tanto para el número de patentes solicitadas como concedidas, al inicio la variabilidad es alta y, conforme pasa el tiempo, disminuye y se “estabiliza". En la gráfica 3.10, se describe este comportamiento. 


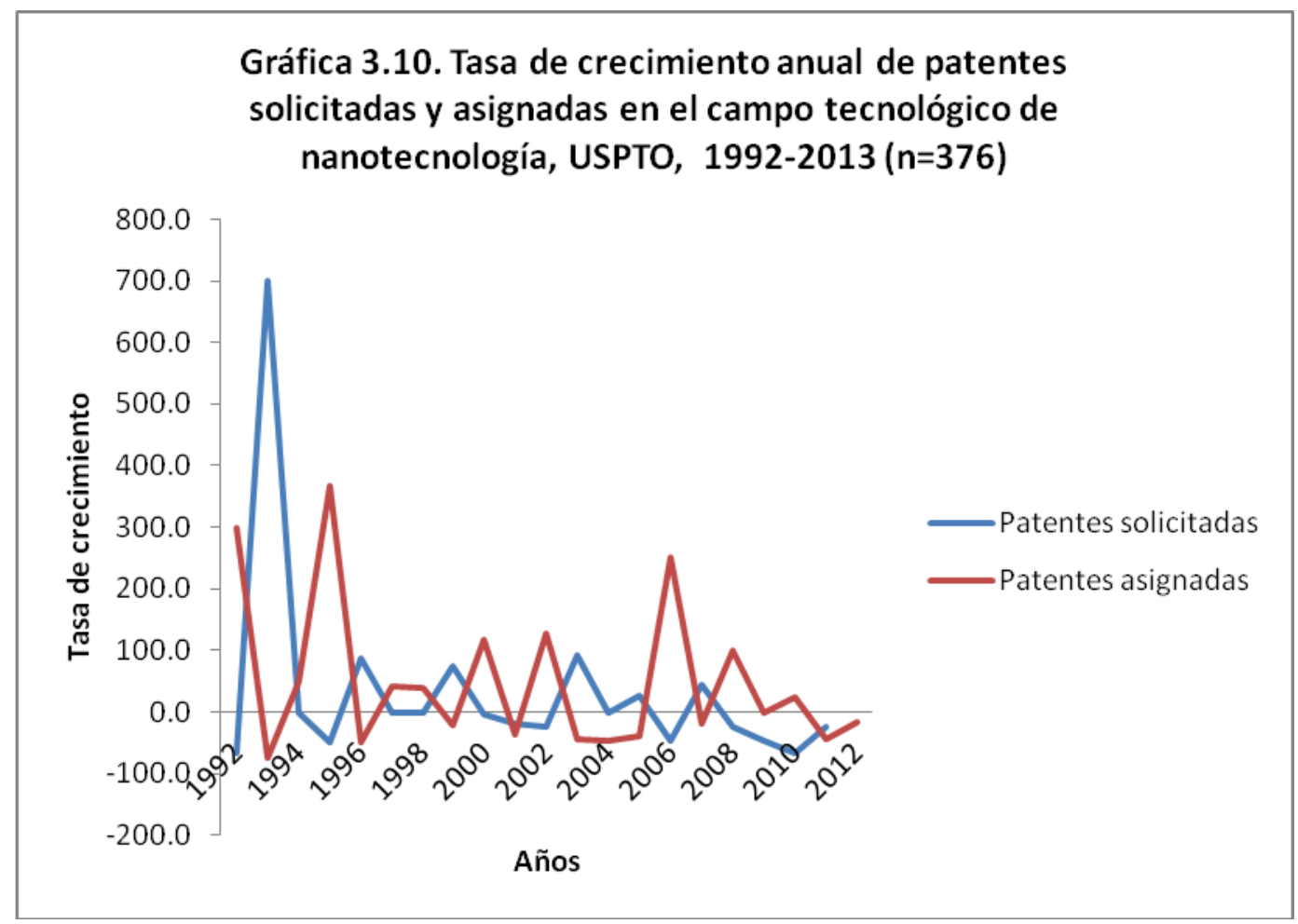

Fuente: elaboración propia con base en una muestra de tamaño n=376 patentes.

Cabe señalar que este patrón de comportamiento también se observa en los datos correspondientes a toda la población ( $\mathrm{N}=18414$ patentes) descrito en la gráfica 3.3 , lo que sugiere que la muestra de estudio es confiable, porque permite inferir las características de la población en su conjunto. En cuanto al fenómeno estudiado, la volatilidad que se observa al inicio del proceso (entre 1991 y 1996) puede sugerir que el comienzo de un nuevo paradigma tecnológico va acompañado de un grado mayor de incertidumbre, por lo cual, los cambios en la velocidad de difusión de la actividad inventiva son más bruscos al inicio; conforme pasa el tiempo y el paradigma se difunde, los cambios en la velocidad de difusión de la actividad inventiva disminuyen, lo que podría indicar una disminución en el grado de incertidumbre, al mismo tiempo en que abarca la actividad inventiva en otras clases y sectores tecnológicos. 
Difusión en clases y sectores tecnológicos de la nanotecnología a nivel mundial

Otro rasgo característico de la difusión de un nuevo paradigma tecnológico es su amplitud en clases y sectores tecnológicos. Así, de acuerdo con Guzmán y Toledo (2009), una clasificación básica considera las clases tecnológicas donde ocurre la mayor actividad inventiva en el campo de nanotecnología. Estas clases son, principalmente: nanoestructura, biotecnología y química. De acuerdo con los datos de la muestra ( $\mathrm{n}=376$ patentes), la participación de la actividad inventiva en estas tres clases principales, entre 1983 y 2013, es la que se observa en la Gráfica 3.11 .

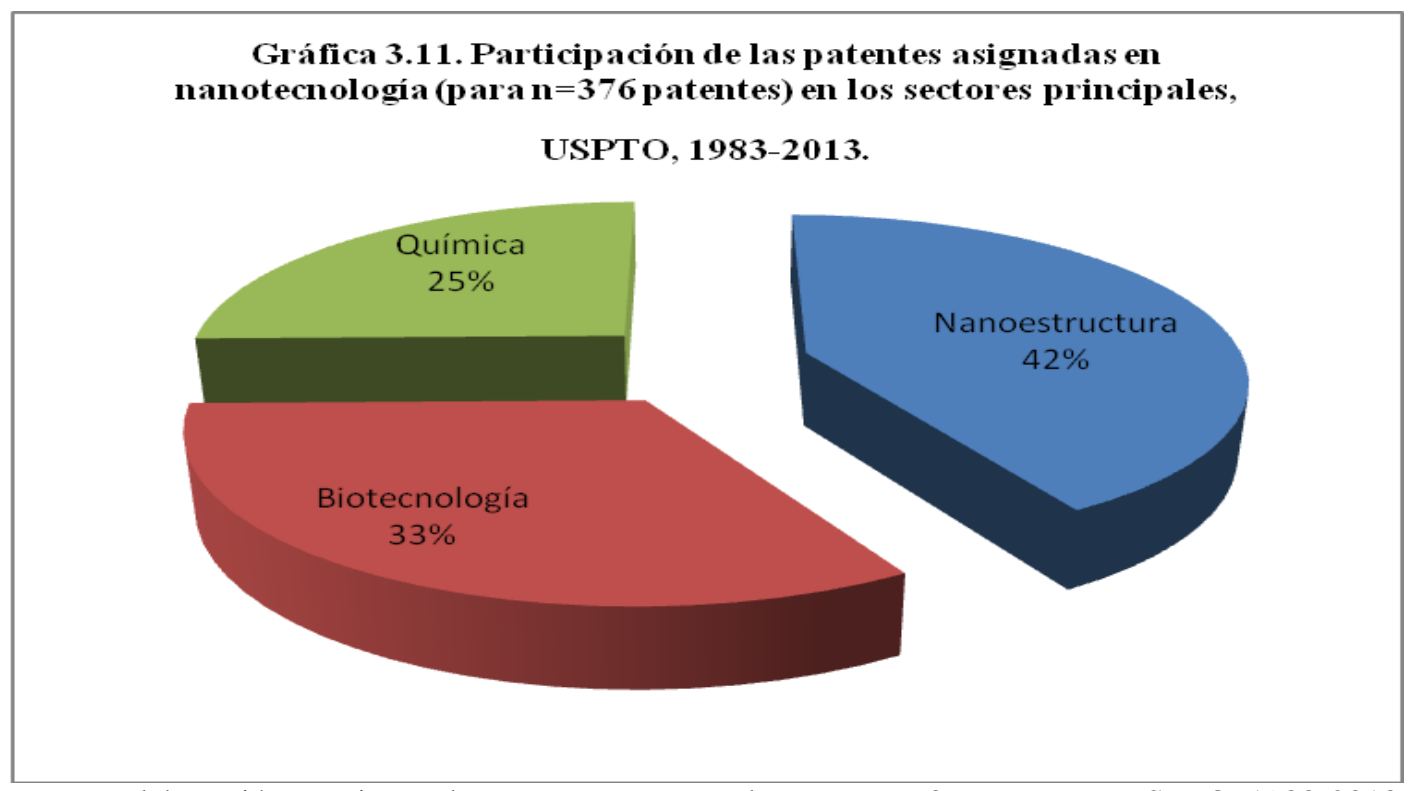

Fuente: elaboración propia con base en una muestra de tamaño n=376 patentes, USPTO, 1983-2013.

Como se observa en la Gráfica 3.11, la principal actividad inventiva en el campo de nanotecnología se ubica en el sector de nanoestructura con $42 \%$ de las patentes concedidas entre 1983 y 2013. Le sigue en importancia biotecnología, con una participación del 33\% y, por último, química con el 25\%. Cabe mencionar, que la tendencia de la distribución coincide con la distribución obtenida a partir de los datos poblacionales, es decir, con las 18414 patentes usadas en la descripción general en el apartado 3.3, donde las patentes asignadas en nanoestructura representan el $37.84 \%$, en biotecnología el $35.8 \%$ y en química el $26.35 \%$, en el periodo 1974-2013. 
Al usar la clasificación propuesta por Jaffe y Trajtenberg (2002) que incluye una gama de sectores tecnológicos, se observa la siguiente distribución.

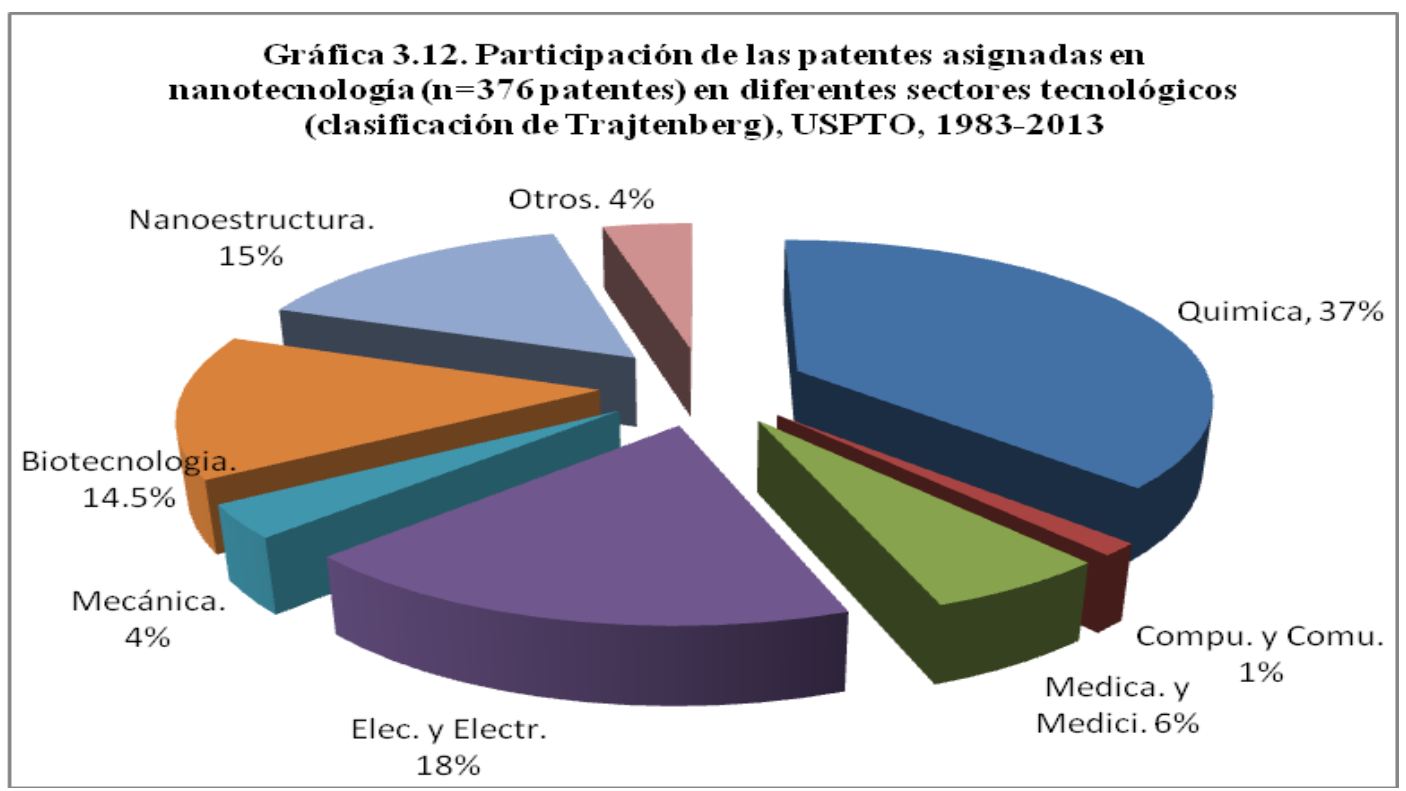

Fuente: elaboración propia con base en muestra de tamaño n=376 patentes, USPTO, 1983-2013.

El principal sector donde se lleva a cabo la actividad inventiva en nanotecnología es química, con un $37 \%$ de las patentes; en segundo lugar, se ubica eléctrica y electrónica con un $18 \%$, le siguen nanoestructura y biotecnología con un $15 \%$ y $14.5 \%$, respectivamente. Lo importante de esta clasificación es que permite observar la amplitud que tienen las patentes asignadas en nanotecnología, hacia otros sectores tecnológicos, por ejemplo, mecánica (4\%), medicamentos y medicina $(6 \%)$ y computación y comunicaciones $(1 \%)$. La distribución de la actividad inventiva en nanotecnología hacia otros sectores tecnológicos confirma otro de los rasgos característicos de un nuevo paradigma tecnológico: la amplitud de sus aplicaciones y sus grandes posibilidades de uso comercial en diferentes sectores de la industria (Dosi, 1982).

Otra forma de describir la amplitud (y el valor) que tienen las patentes concedidas en nanotecnología en otros sectores tecnológicos, es usando el índice de generalidad tecnológica propuesto por Trajtenberg et al. (1997) (IGT). Se expresa de la siguiente forma:

$$
I G T=1-{ }_{j}^{n_{1}} S_{i j}^{2}
$$

donde: $S_{i j}^{2} \quad$ denota el porcentaje de citas al cuadrado que recibe una patente $i$ que pertenece a la clase $j$, dentro del grupo $n l$ de clases de patentes. 
De esta forma, si la suma del porcentaje de citas al cuadrado que recibe una patente $i$ que pertenece a la clase $j$, dentro del grupo $n l$ de clases de patentes es igual o cercano a 0 , entonces el IGT será igual a 1 o cercano a 1, lo cual significa que la patente tiene un amplio impacto en otros sectores tecnológicos. Por el contrario, si la suma del porcentaje de citas al cuadrado que recibe una patente $i$ que pertenece a la clase $j$, dentro del grupo $n l$ de clases de patentes es igual a 1 o cercano a 1 , entonces el IGT tendrá un valor cercano a 0 , lo cual significa que la patente no tiene un amplio impacto en otros sectores tecnológicos.

Al realizar el cálculo del IGT en las patentes de la muestra y clasificándolas en las tres clases principales (nanoestructura, biotecnología y química) se obtuvieron los valores promedio del IGT que se observan en el siguiente cuadro.

Cuadro 3.7. Índice de generalidad tecnológica (IGT) promedio de las patentes asignadas en nanotecnología, con base en la muestra de tamaño $n=376$ patentes, USPTO

\begin{tabular}{|l|l|}
\hline Sectores tecnológicos & IGT promedio \\
\hline Nanoestructura & 0.39 \\
\hline Biotecnología & 0.4 \\
\hline Química & 0.33 \\
\hline
\end{tabular}

Fuente: elaboración propia con base en muestra de tamaño $\mathrm{n}=376$ patentes, USPTO.

Se observa en el cuadro 3.7 que el valor promedio del IGT más alto corresponde a las patentes asignadas en biotecnología con 0.4. Dado que: si el valor del IGT es cercano a 1, significa que las patentes tienen un amplio impacto o, en caso contrario, si el valor del IGT es cercano a 0 , significa que las patentes no tienen un amplio impacto, entonces un valor de 0.4 , puede interpretarse como patentes medianamente concentradas en un sector tecnológico o, dicho de otra manera, patentes con impacto medio sobre otros sectores tecnológicos. Lo mismo puede decirse de las patentes asignadas en nanoestructura. Sin embargo, en el caso de las patentes asignadas en química donde el valor numérico del IGT es más cercano a 0, es decir, 0.33, se puede afirmar que las patentes tienen menor impacto en otros sectores tecnológicos que las patentes asignadas en nanoestructura o biotecnología. Esto significa que las patentes asignadas en química se hallan ligeramente más concentradas en un solo sector tecnológico que las patentes asignadas en nanoestructura y biotecnología.

Sin embargo, existen algunas patentes que presentan un valor del IGT cercano a 1, es decir, que tienen un alto impacto sobre la actividad inventiva de otros sectores tecnológicos. 
Por ejemplo, la patente número 6203983 asignada en química presenta un valor del IGT de 0.71, lo que implica un impacto alto en otros sectores tecnológicos como eléctrica y electrónica, medicamentos y medicina y computación. Es una patente de Estados Unidos solicitada el 16 junio de 1998 y concedida a Affymetrix, Inc. el 20 de marzo de 2001. Fue realizada por un equipo de cuatro inventores: F. Quate Calvin (Stanford, California); O. Trulson Mark (San José, California); R. Manales Scott (Santa Bárbara, California); Jonathan E. Forman (San José, California). Tiene 13 reivindicaciones (claims). La invención consiste en proporcionar un método para utilizar dispositivos micromecánicos, tales como los sensores para la detección de interacciones químicas entre bio-polímeros de origen natural y parejas de unión no idénticos. El método es útil si las reacciones se producen a través de fuerzas electrostáticas o de otras fuerzas. El estrés inducido, calor o cambio en la masa se detecta cuando una pareja de unión se coloca sobre un voladizo para una posible reacción con moléculas de analito (es decir, una pareja de unión no idénticos). El método es particularmente útil en la determinación de la hibridación de $\mathrm{ADN}$, también puede ser útil en la detección de la interacción en cualquier ensayo químico. Estas características en su conjunto confirman por qué resultó con un $I G T$ elevado.

Existen otras patentes que centralizan su actividad inventiva en un solo sector tecnológico, por ejemplo, la patente número 7655934 asignada en el sector de nanoestructura se concentra solo en eléctrica y electrónica, por lo cual tiene un valor del IGT de 0. Es una patente de Estados Unidos solicitada el 28 de junio de 2006 y concedida a Virgin Island Microsystems, Inc. el 2 de febrero de 2010. Fue realizada por un equipo de dos inventores: Jonathan Gorrell (Gainesville, FL); y Henry Davis (Ash Fork, AZ). Tiene quince reivindicaciones (claims). La invención consiste en un dispositivo emisor de luz; es un producto que incluye una pluralidad de ultra pequeñas estructuras resonantes, cada una construida y adaptada para emitir radiación electromagnética (EMR) a una longitud de onda particular, cuando un haz de partículas cargadas pasa cerca. Es un mecanismo construido y adaptado para combinar datos de una fuente de datos con la EMR emitida por, al menos, una de las ultra pequeñas estructuras resonantes. Las aplicaciones de la invención describen varias estructuras que emiten radiaciones electromagnéticas (EMR). La longitud de onda/frecuencia de la EMR emitida puede ser controlada o puede depender de la estructura utilizada. Una estructura de emisión de luz puede ser (o puede ser incorporada en) cualquier tipo de luz o 
lámpara, incluyendo habitaciones o áreas de trabajo, por ejemplo: la iluminación del escritorio, la iluminación del vehículo y similares. Estas características del invento confirman por qué su amplitud no es tan amplia.

La patente número 6203983 y la número 7655934 representan valores extremos del $I G T$, pero entre ambos límites se encuentran muchas patentes con una ampliación media. El promedio de las variaciones del IGT de cada una de las patentes se resume en el cuadro anterior.

El análisis descriptivo anterior sobre el impacto del NPN sobre otros campos tecnológicos confirma la tendencia señalada en el segundo capítulo sobre el potencial que muestra la nanotecnología para envolver a otros paradigmas tecnológicos, en particular, al de las tecnologías de la información y la comunicación (TIC), tal como lo muestra el impacto sobre campos tecnológicos como nanoestructura, eléctrica y electrónica y computación, los cuales se hallan directamente ligados al paradigma tecnológico de las TIC (Hilbert, 2008).

Así, se espera que el paradigma de las TIC, al estar envuelto por el paradigma de la nanotecnología, no va a desaparecer, por el contrario, se convertirá en un paradigma fundamental para el progreso económico futuro de los países, tal como ocurrió con otros paradigmas tecnológicos como el sustentado en la combustión interna (Pérez, 2004).

\section{Difusión espacial del NPN}

En cuanto a la difusión espacial, la gráfica 3.13 muestra que los principales países donde se llevan a cabo mayores esfuerzos en la actividad inventiva en nanotecnología son Estados Unidos $^{9}(63 \%)$, Japón (10\%), Corea del Sur (7\%) y Alemania (4\%), seguidos por países tales como Taiwán (3\%), Canadá (3\%) y Francia (2\%). Con mucho menor peso, pero con potencial importante, aparecen algunos países emergentes tales como China e India, los cuales forman parte de los BRIC (Brasil, Rusia, India y China) ${ }^{10}$.

\footnotetext{
${ }^{9}$ El liderazgo de Estados Unidos a nivel mundial en nanotecnología lo confirman otros estudios, tales como los de la OCDE (OCDE, 2007 y OCDE, 2013) quienes toman la información que proporcionan otras oficinas de patentes como la Oficina de Marcas y Patentes Europea (EPO).

${ }^{10}$ Grupo de países emergentes que han mostrado un notable crecimiento en, por lo menos, los últimos diez años. En 2011 se agregó Sudáfrica por lo que en algunos estudios se hace referencia a los BRICS. En el presente 


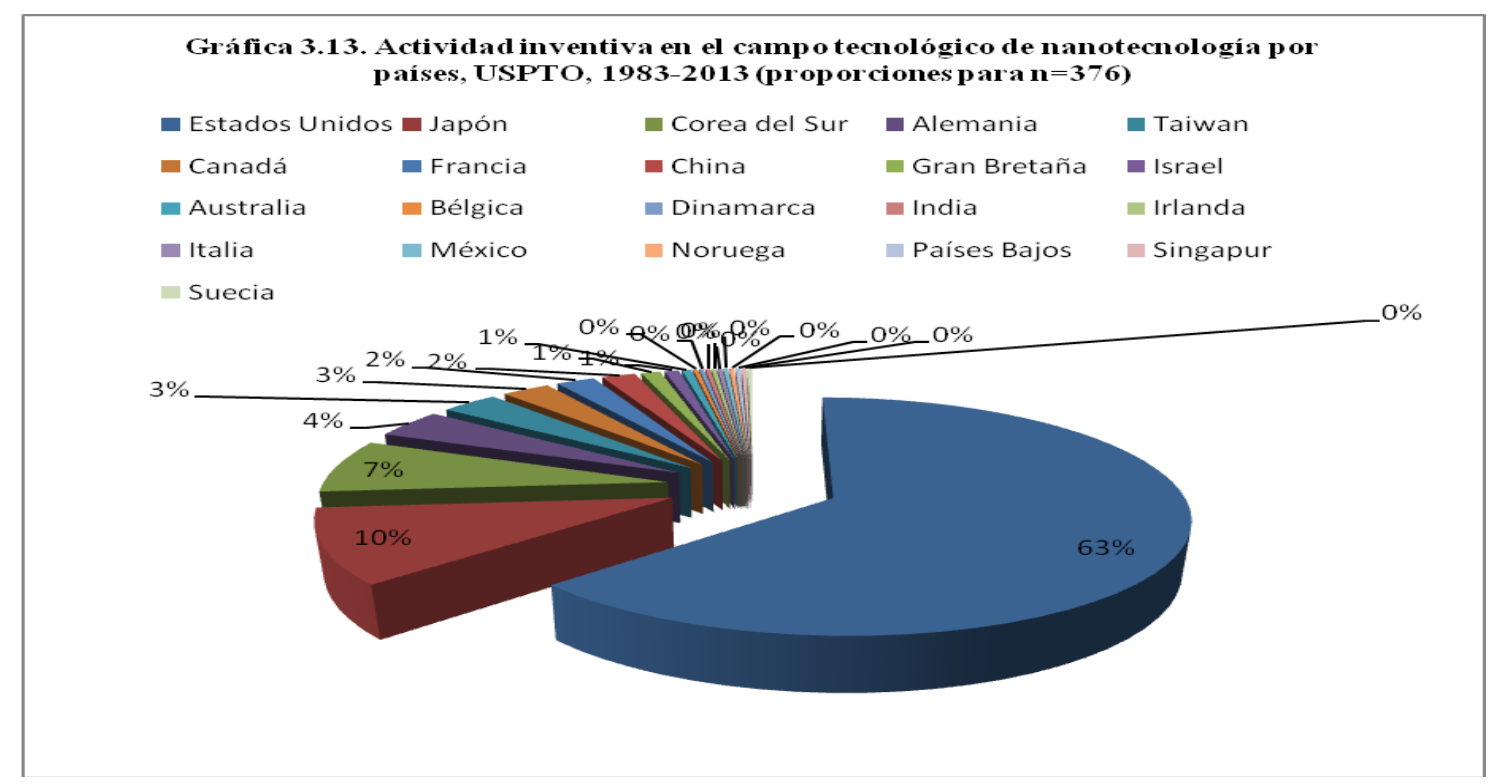

Fuente: elaboración propia con base en una muestra de tamaño n=376 patentes tomadas de USPTO, 1983-2013.

Estos resultados coinciden, en general, con los obtenidos por Guzmán y Toledo (2009), quienes analizaron una base de datos de patentes tomadas de la USPTO en el periodo 19802008 y obtuvieron la siguiente distribución por países: Estados Unidos de América (60\%), Japón (18.6\%), países europeos (7.8\%) y Corea del Sur (2.8\%). Sin embargo, la diferencia reside en que estos autores englobaron a los países europeos en un mismo rubro mientras que, en el presente estudio, se toman por separado, lo cual permite ubicar con mayor precisión qué países europeos se ubican en la vanguardia en nanotecnología: Alemania (4\%), Francia (2\%) y Gran Bretaña (2\%). El grupo de países principales en la generación de la actividad inventiva en el campo de nanotecnología confirma que países industrializados como Estados Unidos, Japón y Alemania, siguen ubicándose en la vanguardia en cuanto a la gestación y desarrollo de nuevos paradigmas tecnológicos, por lo menos desde el paradigma tecnológico de las TIC, a partir de la segunda mitad del siglo XX (Mowery y Rosenberg, 1998).

Se confirma la tendencia que muestra la dinámica que siguen los nuevos paradigmas tecnológicos: una vez que se gesta un paradigma tecnológico en alguno de los países industrializados se difunde hacia otros países industrializados o emergentes (Pérez; 2004). Los países que mayores esfuerzos realizan en la actividad inventiva en nanotecnología son Estados

estudio, se usará BRIC excluyendo a Sudáfrica debido a que su actividad inventiva en nanotecnología es menos significativa en relación con Rusia, China, India y Brasil. 
Unidos, Japón, Corea del Sur y Alemania, por lo que es conveniente analizar las pautas de difusión de este nuevo paradigma tecnológico en estos países por dos motivos: i) para comprender los factores que determinan su difusión hacia otros países; ii) porque estos países cuentan con mayor actividad inventiva en nanotecnología medida en número de patentes, lo que permite estimar el modelo de difusión de conocimiento tecnológico propuesto. A continuación se expone el análisis de estos países.

Actividad inventiva y difusión de los países industrializados que mayores esfuerzos realizan en el NPN (Estados Unidos, Japón, Corea del Sur y Alemania)

Una vez descrita la difusión sectorial y geográfica de la nanotecnología a nivel mundial, con base en la muestra, se puede realizar un diagnóstico sobre los canales de difusión, dados por las interacciones entre los agentes que forman parte del sistema nacional de innovación (SNI) de los países que más esfuerzos realizan en actividades de I+D en nanotecnología: Estados Unidos, Japón, Corea del Sur y Alemania.

Como se mencionó en el primer capítulo de la presente investigación, los canales por donde fluye el conocimiento en un sistema nacional de innovación (SNI) son principalmente cuatro: a) interacciones entre empresas; b) interacciones entre empresas, universidades y laboratorios públicos de investigación; c) difusión de conocimientos y tecnología a las empresas; d) movilidad de personal (Albuquerque et al., 2011). Sin embargo, es b el principal canal de flujo de conocimiento. A su vez, existen 4 formas para medir el conocimiento que fluye a través de este canal: i) articulación de las actividades de investigación; ii) co-patentes y publicaciones; iii) análisis de citas; iv) encuestas a empresas.

Ahora bien, otra información que proporcionan las patentes tiene que ver con la frecuencia en que una patente cita a otras patentes (citas hacia atrás) y con la frecuencia en que una patente es citada por otras (citas hacia adelante). Es decir, con los flujos de conocimiento que ocurren a partir de las interacciones entre empresas, universidades y laboratorios públicos de investigación en un SNI. Así, las citas hacia atrás reflejan el grado de novedad de la invención así como los patrones de transmisión de conocimiento. Las citas hacia adelante sugieren el impacto que puede tener una patente sobre otras (OCDE y OEPM, 2009 y OCDE, 
2013), aunque también se usan para estimar la difusión del conocimiento tecnológico, ya que las citas involucran la interacción entre empresas y universidades. En general, el análisis de citas de patentes puede ayudar a comprender los patrones de difusión de un nuevo paradigma tecnológico. De esta forma, en cuanto a las citas hacia atrás, se observa que el número total de citas hechas por las 376 patentes correspondientes a la muestra fue de 6551 durante el periodo 1983-2013. En promedio, cada patente cita a 17.4 patentes, lo que sugiere no solo el grado de novedad de las invenciones realizadas en el campo tecnológico de nanotecnología sino también los flujos de conocimiento que ocurren a partir de las interacciones entre los agentes del sector público y privado de los SNI de los países. Por ejemplo, la patente que registró mayor número de citas hechas a otras patentes fue la número 7655934, se ubica en el campo tecnológico de química con 311 citas y fue asignada a inventores de Estados Unidos en 2010. En el extremo, hay 14 patentes que no registran citas de otras patentes y se ubican en los campos tecnológicos de biotecnología (3 patentes), química (5 patentes) y nanoestructura (6 patentes). Por un lado, este ejemplo sugiere que, en el primer caso, los flujos de conocimiento que ocurrieron entre los agentes del SNI de Estados Unidos que participaron en la generación del nuevo conocimiento reconocido en dicha patente, son mayores que los que ocurrieron entre los agentes del SNI donde se llevó a cabo la actividad inventiva de las 14 patentes que no registraron citas de otras patentes. Al mismo tiempo sugiere que las interacciones entre los agentes del SNI en el primer caso son mayores que en el segundo. Por otro lado, también sugiere que, en el primer caso, se requirió de un stock de conocimiento tecnológico mayor que en el segundo caso para generar el nuevo conocimiento. Esto pudo haber ocurrido por la naturaleza del conocimiento patentado, por lo que el carácter acumulativo del conocimiento tecnológico es diferente en ambos casos: “el número de citas que se hacen (y se reciben) por patente varía considerablemente en función del campo tecnológico o de la madurez de la tecnología." (OCDE, 2009: 127). Por otra parte, puede deberse también al tipo de invención patentada, ya que una invención radical puede tener pocas citas hacia atrás o muchas citas hacia adelante.

El grupo de países industrializados de estudio (Estados Unidos, Japón, Corea del Sur y Alemania) suman en conjunto 5600 citas hacia atrás, lo que representa el $85.4 \%$ del número total de citas hacia atrás, realizadas por las 376 patentes pertenecientes a los diferentes países. Esto sugiere que este grupo de países no solo produce la mayor cantidad de patentes solicitadas y concedidas en nanotecnología sino que, además, dicha actividad inventiva se sustenta en un 
amplio stock de conocimiento tecnológico acumulado. Además, significa que las interacciones que ocurren entre los agentes que participan en los SNI de estos países, así como el flujo de conocimiento que ocurre por este canal, son mayores. Esto puede explicarse, en gran medida, debido a que los SNI de estos países se caracterizan por ser articulados (Albuquerque et al., 2011).

Además, cabe señalar que el $97.6 \%$ de las citas hacia atrás realizadas por las 320 patentes generadas por estos países pertenecen a patentes de Estados Unidos y el 79.2\% respecto del total de citas hacia atrás realizadas por las 376 patentes de la muestra. Asimismo, el número de citas hacia atrás realizadas por patentes promedio de Estados Unidos es de 21.8\%, lo cual es ampliamente superior al número de citas hacia atrás promedio correspondientes a las 376 patentes de la muestra, que fue de 17.42 citas hacia atrás por patente. Los demás países registran un valor promedio de citas hacia atrás por patente muy por debajo del promedio total: Japón (7.25), Corea del Sur (0.6), Alemania (7.4). Estos datos sugieren que la actividad inventiva en nanotecnología se halla sustentada en el stock de conocimiento tecnológico acumulado en este campo (ver gráfica 3.14).

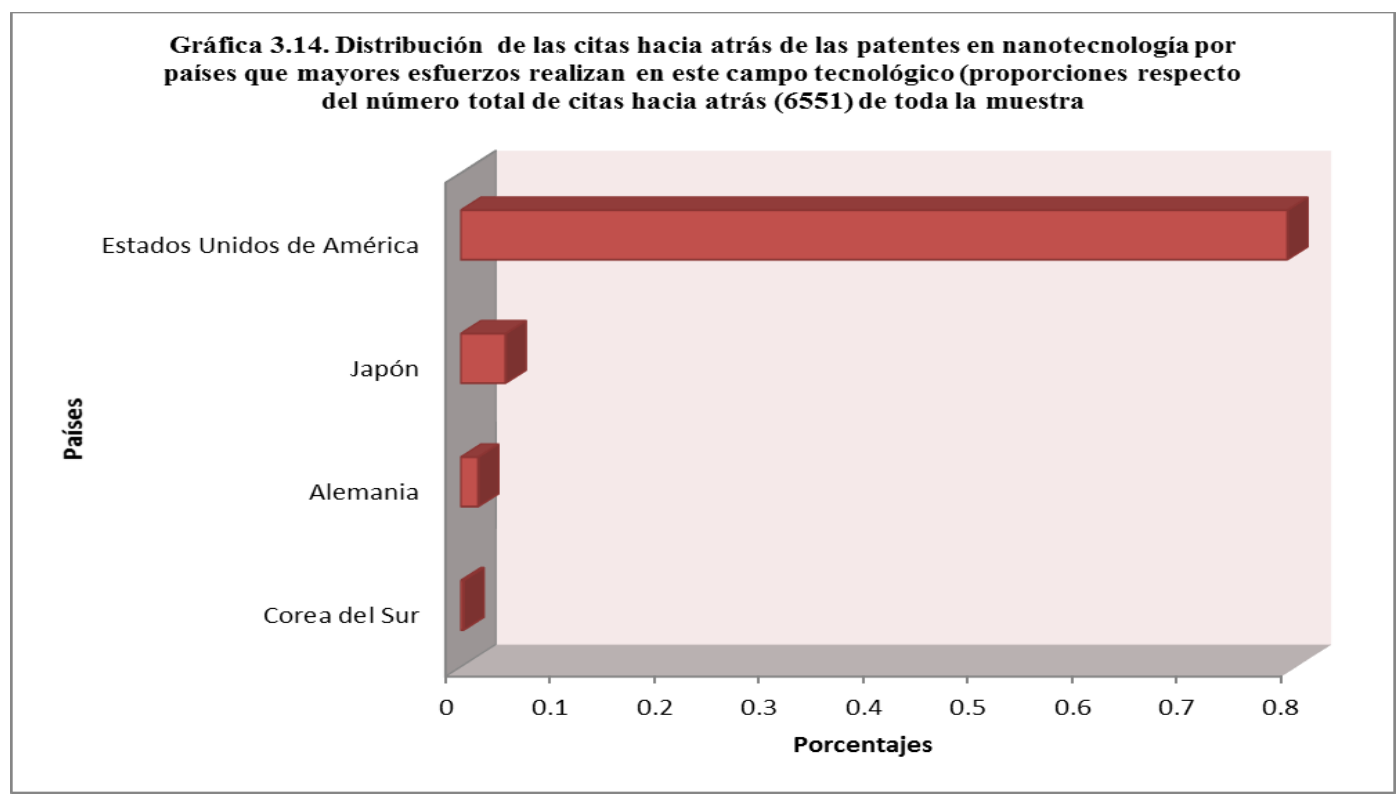

Fuente: elaboración propia con base en la muestra de tamaño $n=376$ patentes, USPTO.

En cuanto a las citas hacia adelante (forwards citations), si bien son tomadas como un indicador que refleja la importancia tecnológica de una patente para el desarrollo de 
tecnologías posteriores, así como un indicador del valor económico de las patentes (OCDE, 2009; Jaffe y Trajtenberg, 1996; Hall et al., 2001 y Harhoff et al., 2003), también son usadas en los estudios sobre difusión de conocimiento tecnológico (Gay et al., 2005). De esta forma, si la patente A es citada por la patente B y, a su vez, la patente B citada por la C, indica que hubo un flujo de conocimiento que pasó de la patente A a la B y de ésta a la C. Con base en esta idea y mediante un análisis descriptivo de los datos sobre citas recibidas (citas hacia adelante) en las 376 patentes de la muestra, se hallaron los siguientes resultados. Las 376 patentes de la muestra correspondientes a diferentes países recibieron un total de 4628 citas (citas hacia adelante) y, en promedio, cada una de las patentes recibió 12.3 citas, lo que indica el impacto promedio que tiene una patente sobre la generación de nueva tecnología, en particular, en este campo tecnológico.

Ahora bien, al hacer el análisis por países, se encontró que de las 4628 citas, 3894 fueron recibidas por patentes correspondientes al conjunto de países que más esfuerzos realizan en el campo de nanotecnología (Estados Unidos, Japón, Corea del Sur y Alemania), lo que representa el $84.1 \%$ del total. Esto se explica simplemente por el hecho de que estos países son los que más patentan en este campo tecnológico, por lo que cada patente tiene mayor probabilidad de ser citada que las patentes correspondientes a los demás países. En la siguiente gráfica, se muestran estas proporciones.

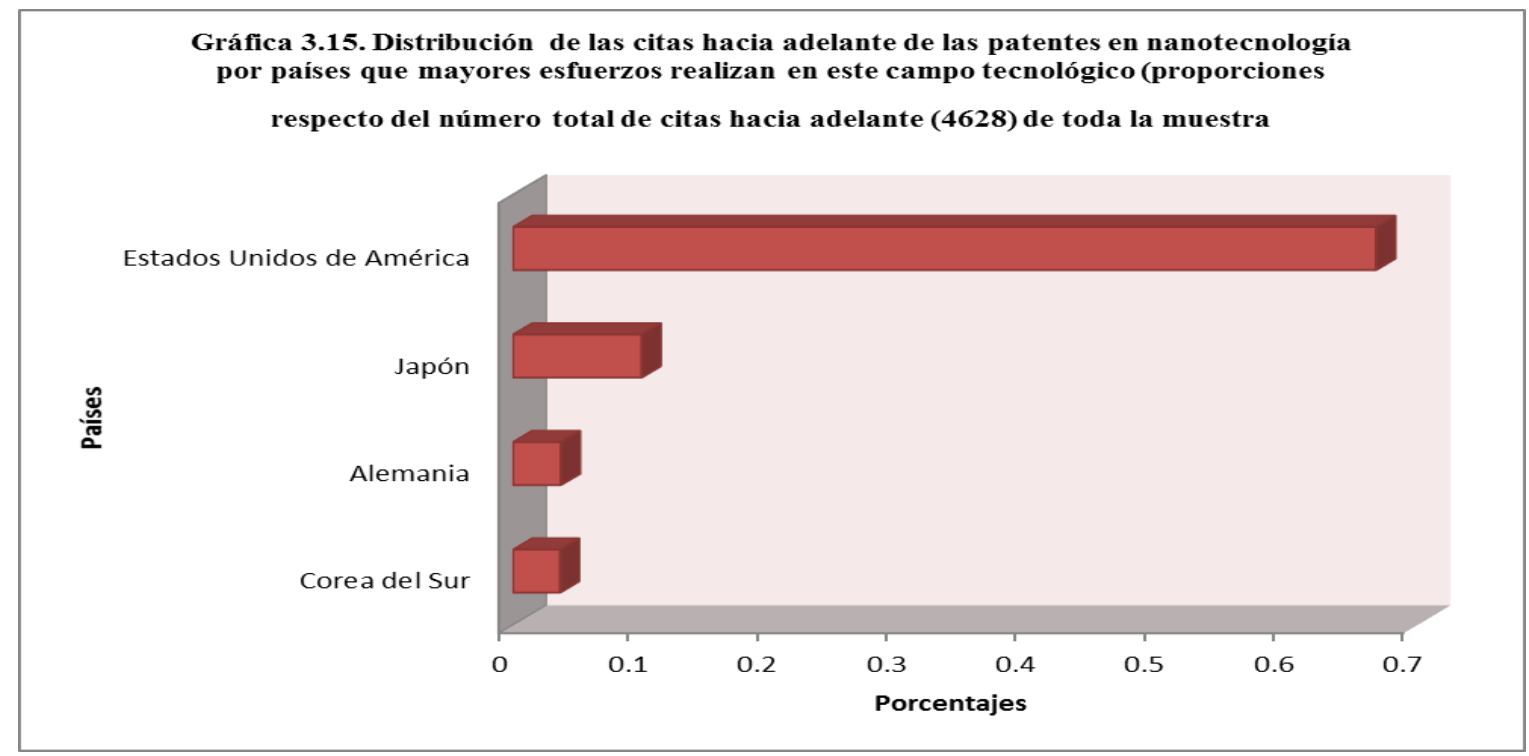

Fuente: elaboración propia con base en la muestra de tamaño $n=376$ patentes, USPTO. 
En promedio, cada una de las patentes correspondientes a este grupo de países recibe 10.5 citas, lo cual se aproxima al promedio total (12.3 citas por patente). A su vez, de estas 3 894 citas recibidas por este conjunto de países, 3092 corresponden a patentes de Estados Unidos (238 patentes), lo que representa el 79\% del total de citas recibidas por este conjunto de países y el $66.8 \%$ del total de citas recibidas por las 376 patentes de la muestra. Nuevamente, la mayor proporción de citas que reciben las patentes de Estados Unidos se explican por el hecho de que es el país que más patenta en nanotecnología a nivel mundial (este resultado está sustentado también por los estudios de la OCDE: OCDE, 2007 y OCDE, 2013 con base en información de la EPO). Por ello, sus patentes tienen mayor probabilidad de ser citadas por otras patentes.

Cabe señalar también que, considerando los sectores tecnológicos, en el caso de Estados Unidos, 1350 citas fueron recibidas por patentes que pertenecen al sector tecnológico de nanoestructura (94 patentes), lo que representa el $43.6 \%$ del número total de citas recibidas por las patentes correspondientes a este conjunto de países, y el $29.1 \%$ del total de citas recibidas por las 376 patentes de la muestra. Esto sugiere la importancia que tiene el SNI en Estados Unidos en la generación y difusión de nueva tecnología, en particular, en el NPN. Específicamente, indica que la difusión a nivel mundial del nuevo conocimiento en este paradigma tecnológico está generada, principalmente, por el sector de nanoestructura (véase gráfica 3.16).

En el caso de las patentes de Japón (39), recibieron 461 citas, lo que representa el $11.8 \%$ del número total de citas recibidas por las patentes correspondientes a este conjunto de países. En promedio, cada patente de Japón recibe 8.4 citas, es decir, por debajo del promedio de citas que reciben cada una de las 376 patentes de la muestra (12.3 citas por patente). A su vez, de estas 461 citas recibidas, 332 pertenecen a patentes que se ubican en el sector de biotecnología, lo que representa el $72 \%$ de las citas recibidas por patentes de Japón y el $8.5 \%$ del total de citas recibidas por las patentes pertenecientes a este conjunto de países. En promedio, cada una de las patentes que se ubican en este sector reciben 15.8 citas (por encima de las 12.3 citas que reciben en promedio cada una de las 376 patentes de la muestra), en comparación con 6.6 y 11.5 citas que reciben, en promedio, las patentes que se ubican en nanoestructura y química, respectivamente. Esto sugiere que, en Japón, el sector principal en la 
difusión de este nuevo paradigma tecnológico a nivel mundial es el de biotecnología. En la gráfica 3.16, se presentan los sectores tecnológicos con mayor número de citas hacia adelante promedio, por países (ver gráfica 3.16).

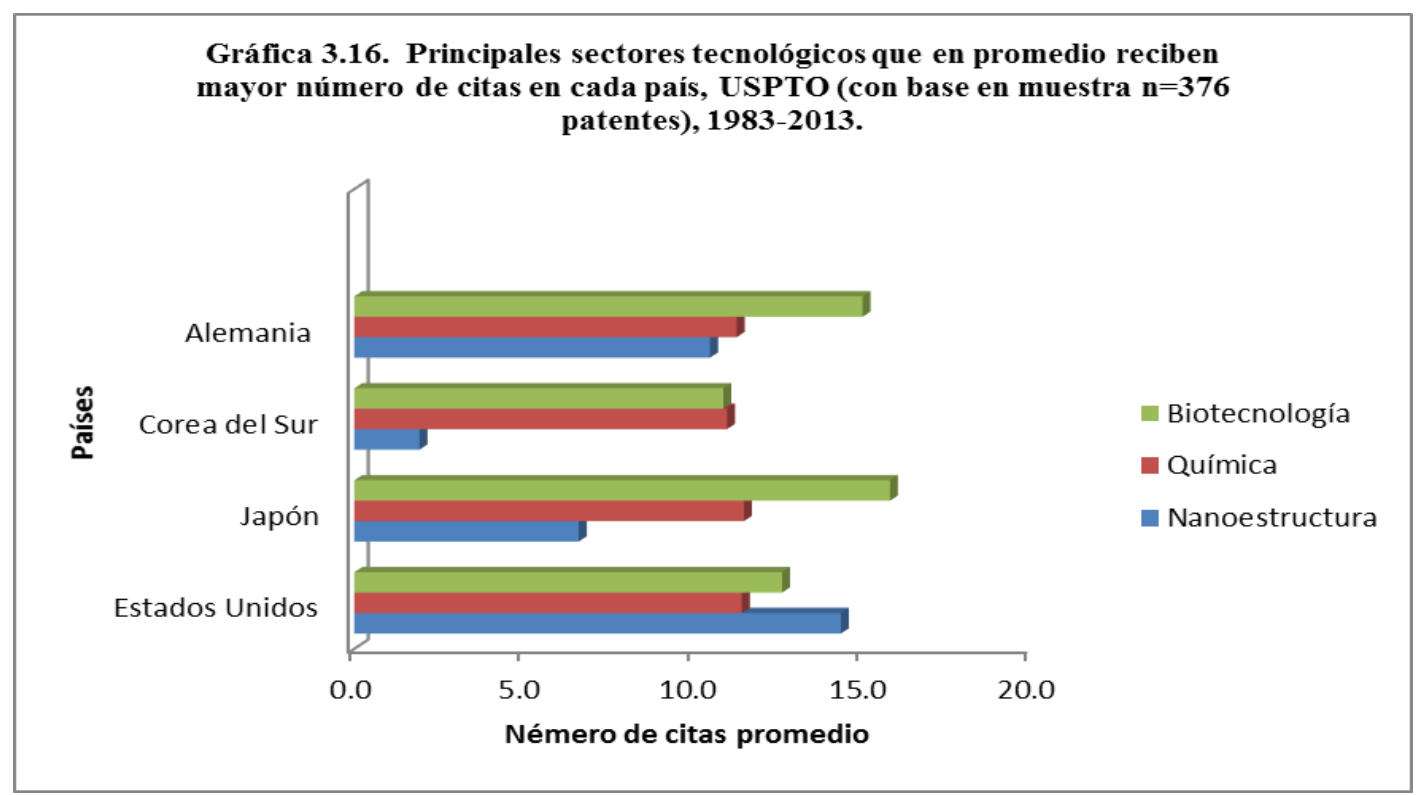

Fuente: elaboración propia con base en muestra de tamaño n=376 patentes, USPTO.

Las 28 patentes correspondientes a Corea del Sur representan el 7\% de las 376 patentes de la muestra, éstas recibieron un total de 169 citas que representan el $4.3 \%$ del número total de citas recibidas por las patentes pertenecientes a este conjunto de países promotores de nanotecnología, y el 3.6\% del total de citas recibidas por las 376 patentes de la muestra. A su vez, de estas 169 citas, 98 se ubican en patentes que pertenecen al campo de biotecnología, lo que representa el 58\%. Sin embargo, en promedio, las patentes que reciben más citas (11 citas) se ubican en el sector de química, seguido por las patentes que se ubican en biotecnología, las cuales reciben 10.8 citas en promedio. No obstante, ambas están por debajo del promedio de citas que reciben cada una de las patentes de la muestra, es decir, 12.3 citas. Este diagnóstico sugiere que, Corea del Sur, difunde NPN hacia el mundo a través de dos sectores tecnológicos: química y biotecnología (ver gráfica 3.16).

En cuanto a las 15 patentes correspondientes a Alemania, representan el $4 \%$ del total de patentes de la muestra (376 patentes). Estas patentes recibieron 172 citas que representan el $4.4 \%$ del número total de citas recibidas por las patentes del conjunto promotor de países en 
nanotecnología y el $3.7 \%$ del número total de citas recibidas por las 376 patentes de la muestra. De estas 172 citas hacia adelante, 73 corresponden a patentes que se ubican en el sector tecnológico de química, seguido de 63 citas que corresponden a patentes que se ubican en nanoestructura, lo que representa el $46 \%$ y el $36.6 \%$ de las 172 citas recibidas por las patentes de Alemania, respectivamente. Sin embargo, aunque las patentes ubicadas en biotecnología solo recibieron 30 citas, muestran el promedio de citas recibidas más alto (15 citas), seguido de las patentes que se ubican en química (11.2 citas) y las patentes que se ubican en nanoestructura (10.5 citas). Este panorama sugiere que, en el caso de Alemania, hay dos sectores principales en la difusión de este nuevo paradigma tecnológico a nivel mundial: biotecnología y química (véase gráfica 3.16).

El diagnóstico anterior muestra algunas tendencias de especialización sectorial por países que se resumen en el cuadro 3.8 .

Cuadro 3.8. Algunas tendencias de especialización sectorial de la actividad inventiva en el NPN, con base en una muestra de tamaño $n=376$ patentes, tomadas de la USPTO, 19832013

\begin{tabular}{|l|l|l|}
\hline País & $\begin{array}{l}\text { Principal(es) Sector(es) } \\
\text { tecnológico(s) }\end{array}$ & $\begin{array}{l}\text { Número promedio de citas } \\
\text { recibidas (citas hacia adelante) }\end{array}$ \\
\hline Estados Unidos de América & Nanoestructura & 14.3 \\
\hline Japón & Biotecnología & 15.8 \\
\hline Corea del Sur & Química y Biotecnología & 11 y 10.8 respectivamente \\
\hline Alemania & Biotecnología y Química & 15 y 11.2 , respectivamente \\
\hline
\end{tabular}

Fuente: elaboración propia con base en muestra de tamaño $\mathrm{n}=376$ patentes tomadas de USPTO.

Velocidad de difusión (lag time) por países y sectores tecnológicos

En cuanto a la velocidad de difusión por países, existe un parámetro proxy que mide el tiempo que transcurre entre al año de concesión de una patente y el primer año en que la patente es citada por primera vez por otra patente (lag time), propuesto por Gay et al. (2005). Esta medida no es el rezago medio, utilizado comúnmente en los estudios sobre difusión. Dado que las patentes no son citadas inmediatamente después de su concesión, es decir, que hay un desfase entre el año de la concesión de la patente y la primera cita que reciben, el uso del rezago medio 
podría influir en la tasa de citas recibidas por patente, debido a que se calcula con todas la citas recibidas. La estimación propuesta por Gay- evita este problema estadístico. Este parámetro se interpreta en el sentido de que a menor valor, mayor velocidad de difusión, porque el conocimiento contenido en la patente tarda menos tiempo en difundirse; y a mayor valor del lag time, la velocidad de difusión es menor, debido a que el conocimiento tecnológico tarda más tiempo en difundirse (Gay et al., 2005).

De esta forma, al realizar el cálculo de este parámetro proxy de velocidad de difusión en las 376 patentes de la muestra, se obtuvieron algunos resultados interesantes. Por ejemplo, que el lag time promedio correspondiente a las patentes de la muestra entre 1983 y 2013 es de 1.53 años, es decir que, en promedio, una patente que pertenece al campo tecnológico de nanotecnología tarda 1.53 años en ser citada por otra patente. En un estudio realizado por Gay et al. (2005), se estimó el lag time para patentes asignadas en la USPTO a inventores franceses y británicos entre 1969 y 1998, y se obtuvo que: "En promedio, una patente es citada por primera vez casi 4 años después de su año de concesión (nuestra media es más alta que la reportada por Trajtenberg, 1990), pero muchas de las patentes (20\%) se citan por primera vez dentro de los dos años de su concesión.” (Gay et al., 2005: 343). Si bien los resultados del presente estudio no son comparables con los de Gay et al. (2005), en tanto que se trata de muestras distintas y periodos distintos, el valor del lag time estimado ofrece una idea aproximada de la velocidad de difusión en el campo de nanotecnología.

Al estimar el lag time en cada uno de los países pertenecientes al grupo de países que mayores esfuerzos realizan en la generación y difusión de la nanotecnología a nivel mundial (Estados Unidos, Japón, Corea del Sur y Alemania) se hallaron los siguientes resultados. En promedio, las patentes que pertenecen a Estados Unidos son citadas después de 1.5 años, lo cual coincide con el promedio del conjunto de patentes de la muestra ( $n=376$ patentes). A su vez, el sector tecnológico donde el lag time resultó ser más pequeño, es decir, donde el nuevo conocimiento tecnológico se difunde a mayor velocidad, es nanoestructura con un valor de 1.38 años. Llama la atención que este dato está por debajo del promedio correspondiente a las patentes de la muestra (1.53 años). Así, en cuanto a la velocidad de difusión de este nuevo paradigma tecnológico, el sector más importante en Estados Unidos es nanoestructura (ver gráfica 3.17). 


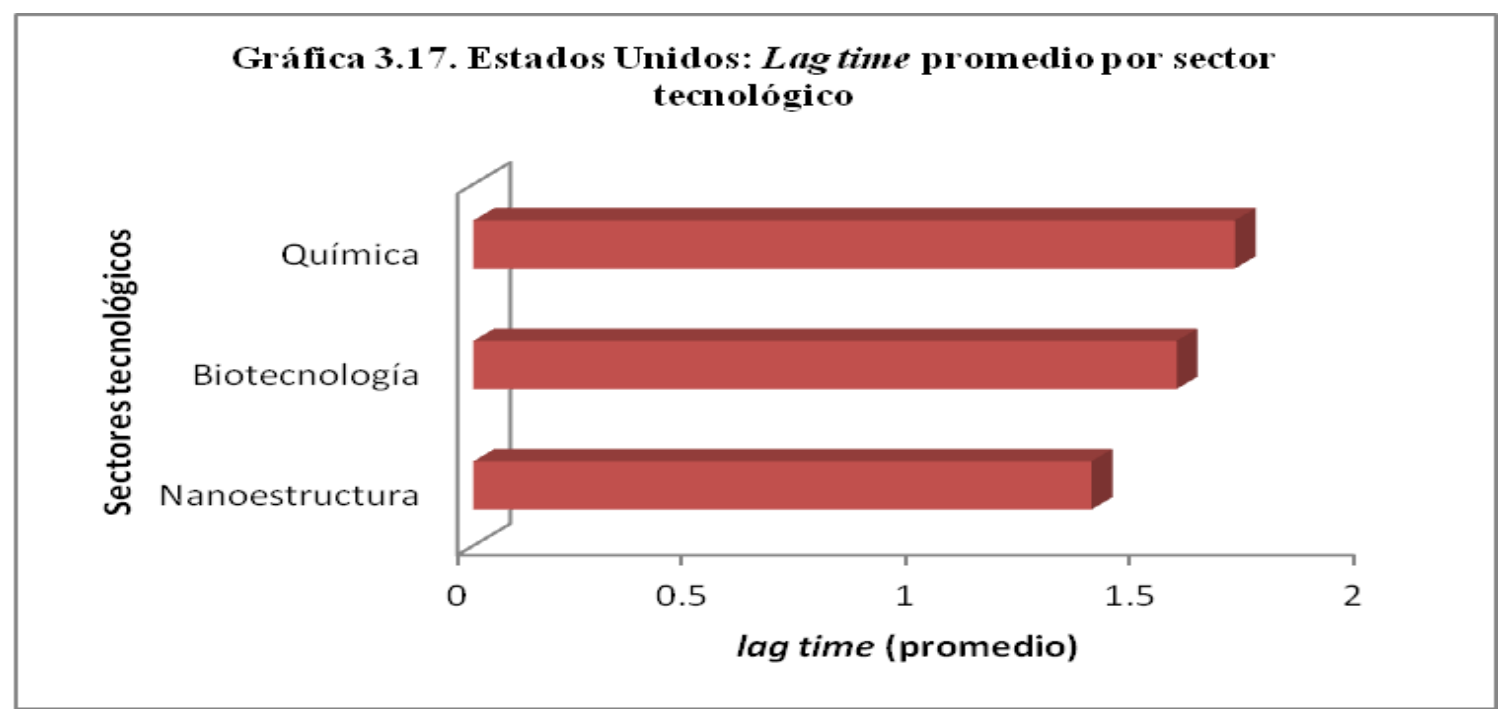

Fuente: elaboración propia con base en muestra de tamaño $n=376$ patentes, USPTO.

En el caso de Japón, el lag time estimado fue de 1.94 años esto significa que, en promedio, una patente de Japón concedida en el campo tecnológico de nanotecnología tarda 1.94 años en ser citada por primera vez. La velocidad de difusión en este país es menor, en promedio, que la velocidad de difusión de cualquier patente que pertenezca a la muestra, y también menor que la velocidad de difusión de las patentes que pertenecen a Estados Unidos. Cabe precisar que las patentes que se difunden con mayor velocidad son las que se ubican en el sector tecnológico de nanoestructura con un lag time de 1.6 años en promedio. Valor que sigue siendo elevado en relación con el lag time estimado para el conjunto de patentes de la muestra, así como respecto del lag time estimado para las patentes de Estados Unidos. En la siguiente gráfica, se presentan los valores promedio de este parámetro, por sectores tecnológicos, de Japón. 


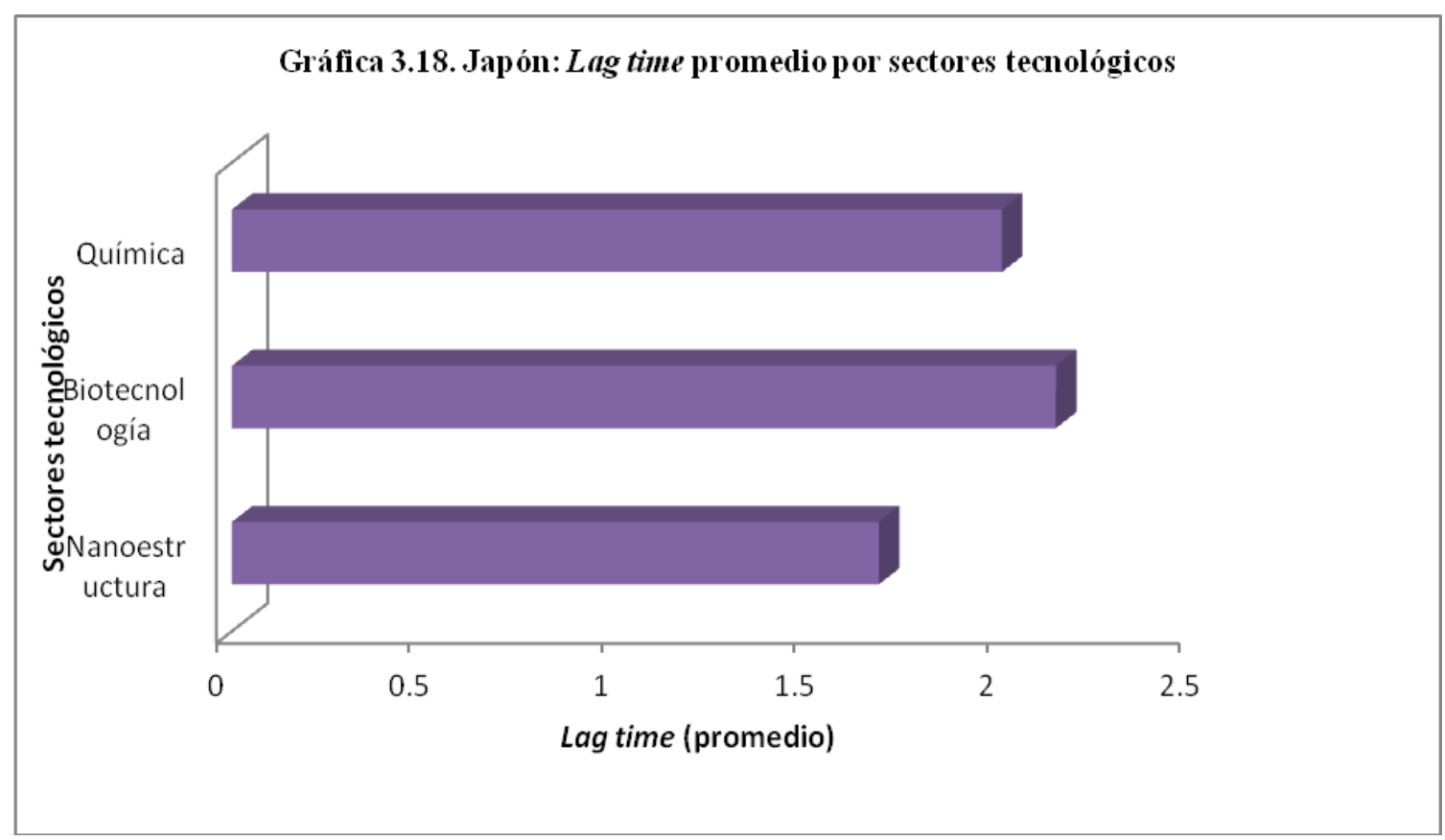

Fuente: elaboración propia con base en muestra de tamaño n=376 patentes, USPTO.

El lag time promedio estimado para las patentes de Corea del Sur resulta sorprendente que el valor sea de 0.92 años; se ubica por debajo del valor promedio estimado para el conjunto de patentes de la muestra y por debajo de las patentes pertenecientes a Estados Unidos. Esto sugiere que un nuevo conocimiento generado en el campo tecnológico de nanotecnología en Corea del Sur se difunde en poco menos de un año, es decir, que su velocidad de difusión es elevada. A su vez, las patentes que se difunden en promedio a mayor velocidad se ubican en el sector tecnológico de biotecnología con un lag time de 0.6 años (véase gráfica 3.19). 


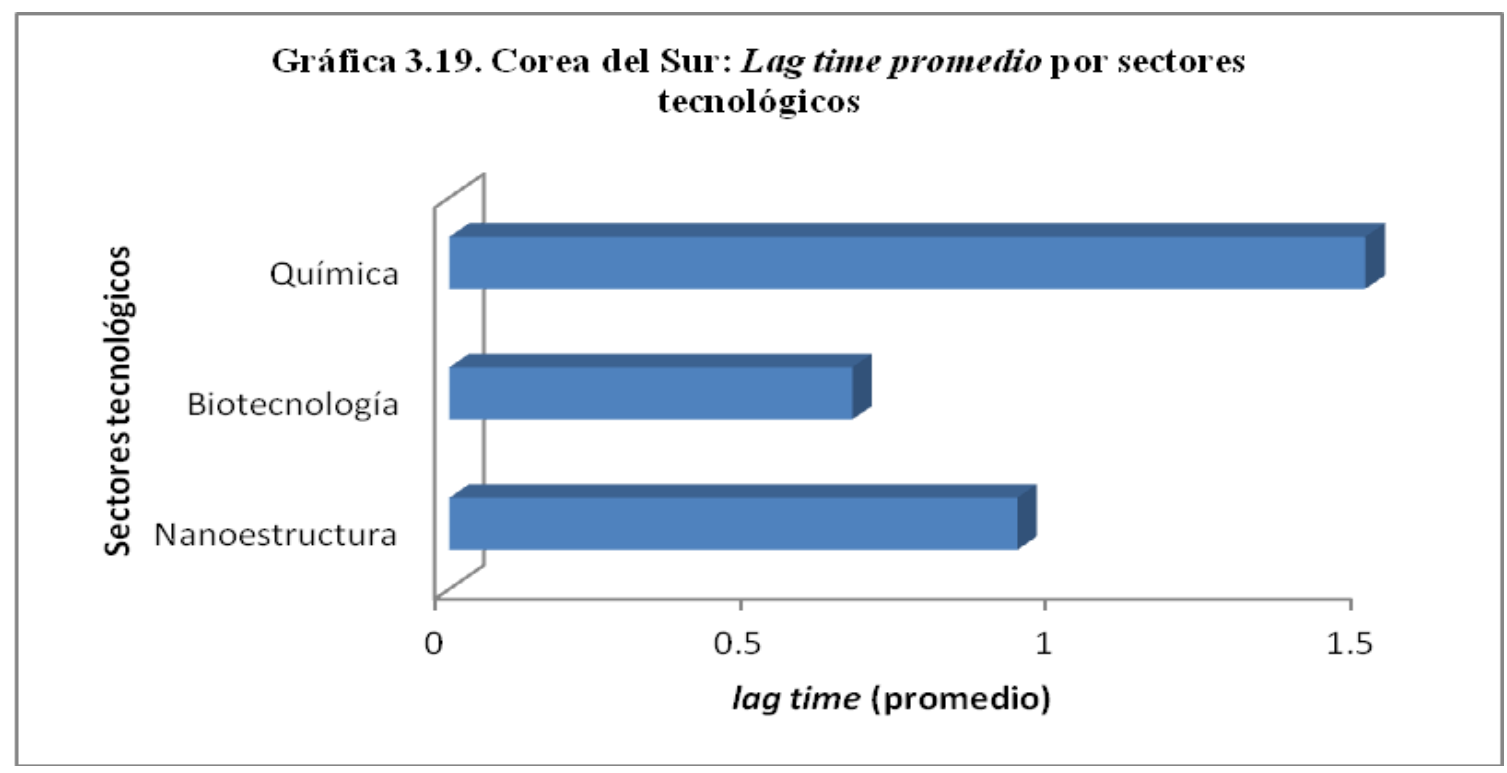

Fuente: elaboración propia con base en muestra de tamaño n=376 patentes, USPTO.

El conocimiento generado en nanotecnología en Alemania se difunde, en promedio, a una velocidad de 2 años, lo cual está por encima del lag time promedio correspondiente a las patentes de la muestra (1.53 años), así como a las patentes que pertenecen a los Estados Unidos (1.5 años). Sin embargo, las patentes pertenecientes a dos sectores tecnológicos (nanoestructura y biotecnología) igualan el valor del lag time promedio estimado para las patentes de Estados Unidos, es decir, con un valor de 1.5 años (véase gráfica 3.20). 


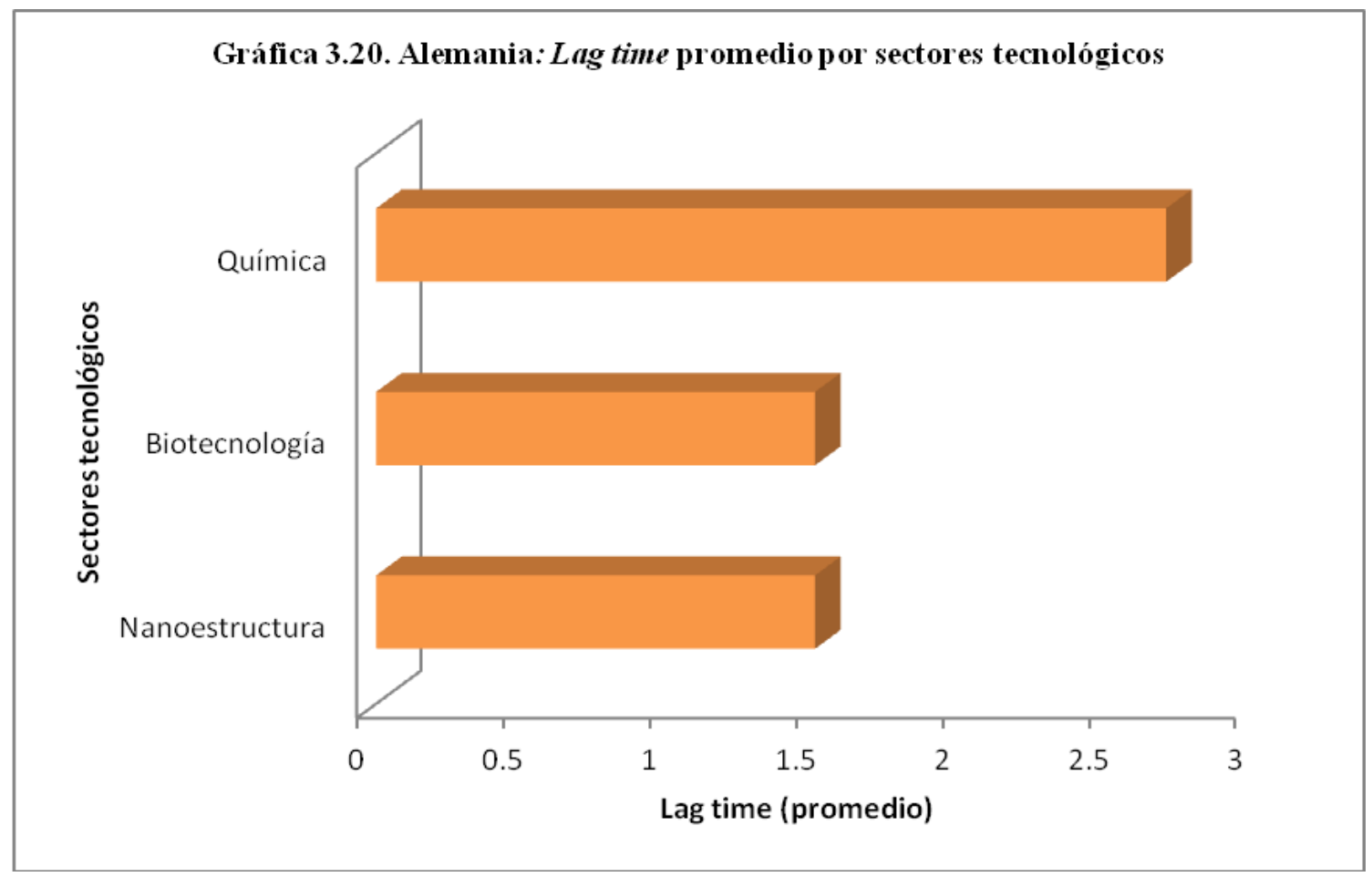

Fuente: elaboración propia con base en muestra de tamaño n=376 patentes, USPTO.

Al considerar el conjunto de países de la muestra (el mundo) y los países industrializados que mayores esfuerzos realizan en nanotecnología (Estados Unidos, Japón, Corea del Sur y Alemania) y al graficar el número de patentes que son citadas contra el rezago de cita medido en años, se observan las brechas en la importancia y difusión tecnológica del conocimiento generado en nanotecnología. La gráfica 3.21 describe este comportamiento. 


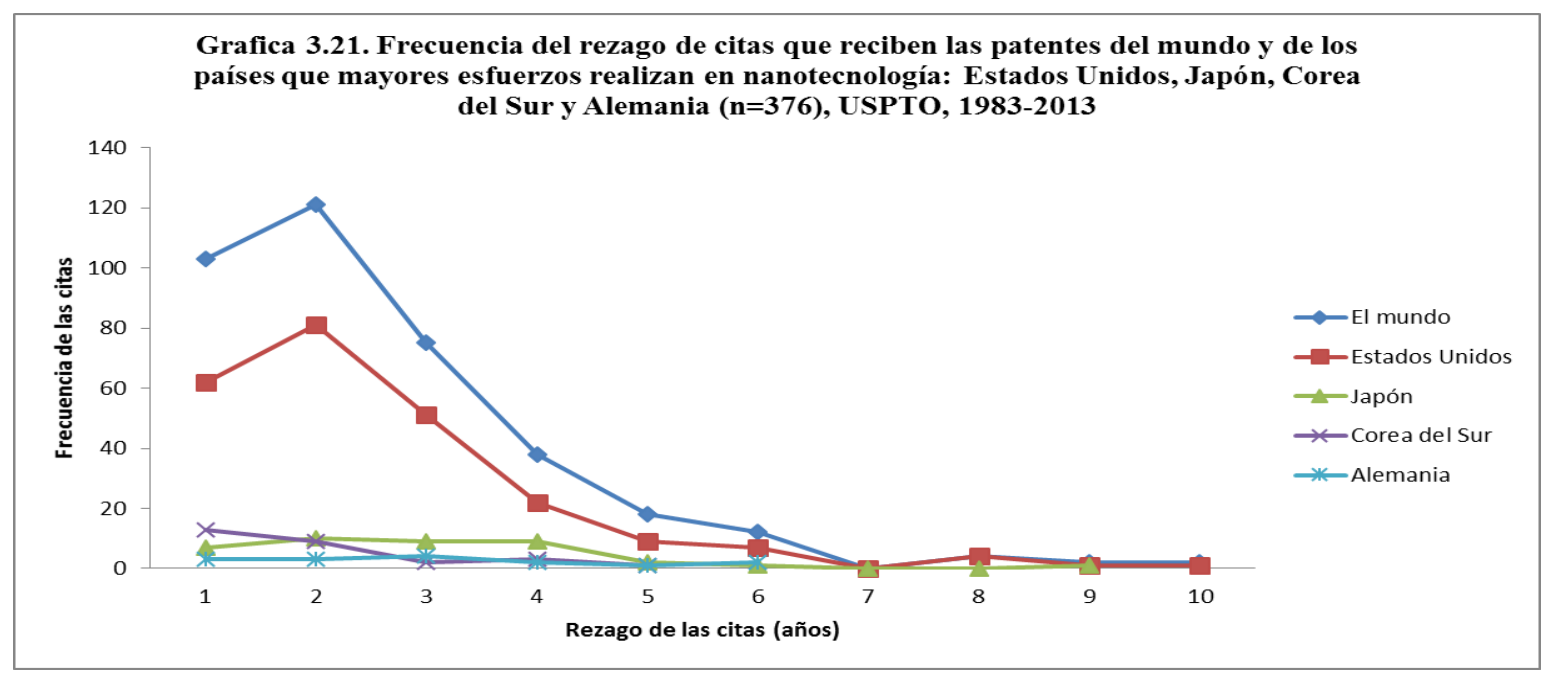

Fuente: elaboración propia con base USPTO.

Se constata que existe una brecha entre Estados Unidos y el resto de los países (Japón, Corea del Sur y Alemania), entre el número de patentes que recibe citas después del primer año de asignación; esta brecha se cierra hasta después del séptimo año de asignación. Esto indica que los conocimientos generados por la actividad inventiva en Estados Unidos se difunden más en los primeros años, después de la fecha de asignación, que los conocimientos generados por la actividad inventiva en los otros países (Japón, Corea del Sur y Alemania); mientras que se difunden igual después del séptimo año posterior a la fecha de asignación. Al mismo tiempo, sugiere que el valor de las patentes de Estados Unidos es mayor que el valor de las patentes del resto de los países en los primeros años posteriores a la fecha de asignación ${ }^{11}$.

Ahora bien, al considerar el análisis descriptivo sobre la velocidad de difusión de este nuevo paradigma tecnológico por países y sectores tecnológicos se observa que el lag time promedio en los sectores tecnológicos de nanoestructura, biotecnología y química en el grupo de países que son los promotores principales (Estados Unidos, Japón, Corea del Sur y Alemania) de la nanotecnología a nivel mundial, es pequeño en los casos de Estados Unidos y Japón en los tres sectores señalados; mientras que en el caso de Corea del Sur es relativamente más pequeño en los tres sectores. Esto sugiere que, en este país, los nuevos conocimientos

\footnotetext{
${ }^{11}$ Estos resultados deben tomarse con cautela, ya que tendrían que contrastarse con el mismo estudio pero tomando como fuente de información otras oficinas de patentes tales como la EPO y la JPO. Queda como posible investigación futura llevar a cabo tal contrastación.
} 
generados en el campo tecnológico de nanotecnología se difunden a mayor velocidad que los nuevos conocimientos generados por Estados Unidos y Japón (ver gráfica 3.22).

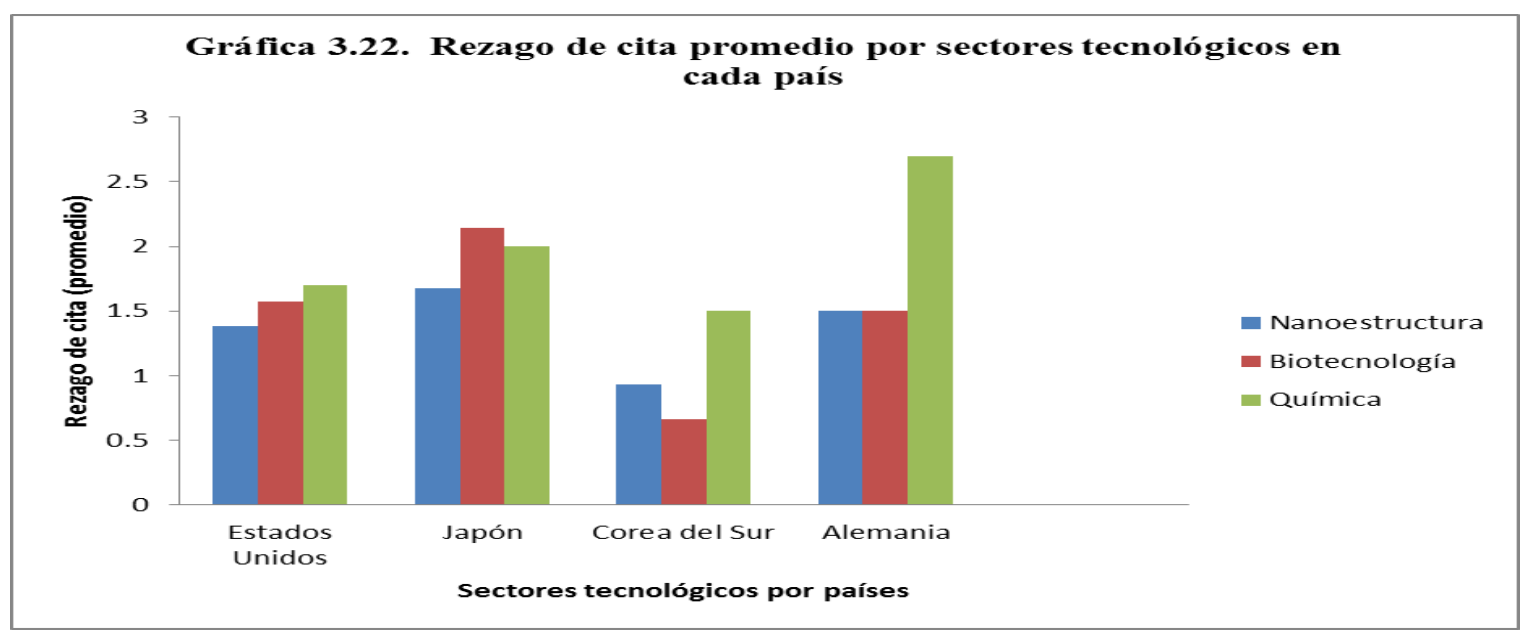

Fuente: elaboración propia con base en USPTO.

En estos países, las políticas dirigidas por el gobierno resulta central para intensificar las interacciones entre los agentes que participan en la actividad inventiva en nanotecnología lo que, posiblemente, haya contribuido a reducir el valor del rezago de cita promedio, tal como ocurrió en los Estados Unidos después de haber sido creada la Iniciativa Nacional de Nanotecnología (NNI, por sus siglas en inglés) en el año 2000 (Mowery, 2011). Así, la NNI se plantea alcanzar cuatro objetivos:

- Mantener un programa de investigación y desarrollo de clase mundial orientado a desarrollar el potencial de la nanotecnología.

- Facilitar la transferencia de nuevas tecnologías a productos para el crecimiento económico.

- Desarrollar recursos educativos, mano de obra especializada e infraestructura de soporte para el avance de la nanotecnología.

- Apoyar el desarrollo responsable de la nanotecnología. (CIMAV, 2008: 26).

Con la NNI crecieron la inversión, las agencias federales y las instituciones que participan en la actividad inventiva en nanotecnología: "Desde la publicación de la NNI, la inversión anual del gobierno en investigación y desarrollo de la nanotecnología se ha duplicado y el número de agencias federales en nanotecnología ha pasado de 6 a 11 y el número total de instituciones que participan creció de 6 a 22. El financiamiento total para la NNI incluyendo lo solicitado para 2006 totaliza más de los 5,000 millones de dólares.” (CIMAV, 2008: 26). 
En el caso de Japón, en su Tercer Plan básico de Ciencia y Tecnología (2006-2010), se afirma que:

Las universidades desempeñan un papel clave en el logro de invenciones, descubrimientos y conocimientos que representan un gran avance. Puesto que los organismos de investigación nacional tienen la misión primordial de promover la investigación orientada a la elaboración de políticas, se espera de ellos que conduzcan el conocimiento emergente y la tecnología clave de importancia nacional al terreno de la innovación. También las universidades desempeñan un papel importante en la transformación del conocimiento en innovación. Será necesario, pues, promover la colaboración y la interacción dinámica entre todas esas organizaciones. (Aizawa et al., 2008: 22)

Y como parte de las áreas prioritarias se destaca la nanotecnología de materiales, la cual: "contribuye a la innovación de la infraestructura tecnológica, creando nuevos y amplios campos como son los de los nanomateriales, nanoelectrónica y nanobiotecnología." (Aizawa et al., 2008: 22).

En el caso de Corea del Sur, las políticas de I+D centran su atención en aquellas ciencias y tecnologías que se consideran estratégicas en el crecimiento económico del país. En particular, se enfoca en el apoyo de las industrias tecnológicamente más avanzadas tales como semiconductores, automóviles, procesos y materiales químicos, biotecnología, robótica y nanotecnología, entre otras (Aizawa et al., 2008).

En cuanto a la nanotecnología, en 2001 el plan del gobierno de Corea del Sur dio a conocer la estrategia y los objetivos a alcanzar durante los próximos años: "establecer la infraestructura y los recursos humanos necesarios para 2005, comercializar nanotecnología a partir de esa fecha, convertirse en uno de los líderes mundiales a partir de 2010 y ser una de las siete naciones más avanzadas tecnológicamente para 2025.” (CIMAV, 2008: 46).

Por último, el caso de Alemania llama la atención porque si bien el valor del rezago de cita correspondiente al sector de química resultó ser el mayor de todos los sectores en los países analizados, el rezago de cita en nanoestructura y biotecnología es menor, incluso menor que el rezago de cita correspondiente a Estados Unidos y Japón en ambos sectores. De esta forma, los esfuerzos en nanotecnología en Alemania se concretizan en su: "infraestructura bien cimentada y un alto nivel de investigación en varios campos de la nanotecnología." (CIMAV, 2008: 33). En el cuadro siguiente (3.9) se presentan algunas tendencias por sectores tecnológicos con base en el rezago de cita por países. 
Cuadro 3.9. Algunas tendencias sobre la velocidad de difusión por países y sectores tecnológicos en el campo tecnológico de nanotecnología, con base en una muestra de 376 patentes, USPTO, 1983-2013

\begin{tabular}{|l|l|l|l|}
\hline País & $\begin{array}{l}\text { Valor promedio rezago } \\
\text { de cita }\end{array}$ & $\begin{array}{l}\text { Sector tecnológico con } \\
\text { mayor velocidad de } \\
\text { difusión }\end{array}$ & $\begin{array}{l}\text { Valor promedio rezago } \\
\text { de cita }\end{array}$ \\
\hline Estados Unidos & 1.5 años & Nanoestructura & 1.38 años \\
\hline Japón & 1.94 años & Nanoestructura & 1.6 años \\
\hline Corea del Sur & 0.92 años & Biotecnología & 0.6 años \\
\hline Alemania & 2 años & $\begin{array}{l}\text { Nanoestructura y } \\
\text { Biotecnología }\end{array}$ & 1.5 años \\
\hline
\end{tabular}

Fuente: elaboración propia con base en muestra de tamaño $n=376$ patentes, USPTO.

A nivel de firmas, las que más difunden el NPN se ubican, a nivel mundial, en los sectores de química, eléctrica y electrónica y medicamentos y medicina, con 56, 32 y 14 patentes asignadas en el campo tecnológico de nanotecnología, lo que representa, en conjunto, el $27.1 \%$ del total de patentes de la muestra de tamaño $\mathrm{n}=376$. Por países que mayores esfuerzos realizan por promover la actividad inventiva en este paradigma tecnológico, el país que reportó en el año 2013 mayor número de firmas en nanotecnología fue Estados Unidos con 10 341, le sigue Alemania con 1110 firmas, Corea del Sur con 504 firmas y Japón con 225 firmas. A su vez, las firmas especializadas o dedicadas en nanotecnología varían en cada uno de estos países. Alemania reportó en ese año 300 firmas, seguido por Corea del Sur con 173 y Estados Unidos con 139. En cuanto al número de firmas pequeñas que difunden el NPN, Estados Unidos reporta 7531 firmas, seguido de Alemania con 800 firmas y Corea del Sur con 132 firmas (ver cuadro 3.10).

Cuadro 3.10. Difusión del NPTN a nivel de firmas en los países promotores

\begin{tabular}{|l|l|l|l|l|}
\hline País & $\begin{array}{l}\text { Gasto en I+D en } \\
\text { nanotecnología*** }\end{array}$ & $\begin{array}{l}\text { Número total de } \\
\text { firmas } \\
\text { nanotecnología }\end{array}$ & $\begin{array}{l}\text { Firmas } \\
\text { especializadas en } \\
\text { nanotecnología }\end{array}$ & $\begin{array}{l}\text { Firmas pequeñas } \\
\text { en } \\
\text { nanotecnología*** }\end{array}$ \\
\hline Estados Unidos & 14054 & 10341 & 139 & 7531 \\
\hline Japón & 1063 & 225 & ND* & ND* \\
\hline Corea del Sur & 7687.1 & 504 & 173 & 312 \\
\hline Alemania & 1549.3 & 1110 & 300 & 800 \\
\hline
\end{tabular}

Fuente: elaboración propia con base en OCDE.

Notas:*el dato de Japón no está disponible. **El gasto en I+D en nanotecnología está en millones de dólares correspondiente al año 2013 . ***Se consideran firmas pequeñas aquellas que tienen menos de 50 empleados. 
Después de analizar la actividad inventiva y difusión del NPN en los países industrializados que mayores esfuerzos realizan en ello, se revisa a continuación la actividad inventiva en este paradigma tecnológico, en un grupo intermedio de países industrializados, de acuerdo con la información arrojada por la muestra: Taiwán, Canadá y Francia.

Actividad inventiva en nanotecnología en países industrializados que realizan medianos esfuerzos (Taiwán, Canadá y Francia)

Según los resultados de la muestra ( $\mathrm{n}=376$ patentes) se identifica otro grupo de países industrializados que marchan detrás del primero. Se trata de Taiwán, Canadá y Francia con 12, 10 y 8 patentes asignadas en nanotecnología (clase 977) en la USPTO. Una primera característica a considerar es que Taiwán y Canadá son países de industrialización más reciente que Francia. Estos países destinan alrededor del 2.3\%, 1.8\% y 2.2\%, respectivamente, del PIB en I+D y presentan importante interés por promover la actividad inventiva en el NPN y aplicar los nuevos conocimientos en ciertos sectores de la industria (Banco Mundial, 2010).

Cabe señalar que Taiwán presenta mayor dinamismo, sobre todo a partir de 2012, que Canadá y Francia y una clara tendencia a formar parte del primer grupo en los próximos años. Por ello, aunque aún se mantiene por debajo de los esfuerzos realizados por Japón y Corea del Sur en cuanto a gastos en I+D (Taiwán (3\% PIB), Japón (3.4\% PIB), Corea del Sur (4.4\% PIB) en 2012 (Banco Mundial, 2012)), se le puede considerar como uno de los países potencia de Asia debido a la importancia que el gobierno le da a la actividad inventiva en nanotecnología: "Los gobiernos de los gigantes asiáticos en nanotecnología como Japón, China, Corea del Sur y Taiwán están invirtiendo de manera importante en investigación y otorgando incentivos para la comercialización de nanotecnologías." (CIMAV, 2008: 41).

Así, en 2011 Taiwán contaba con 2022 maestros graduados y 917 doctores en áreas relacionadas con la nanotecnología (Banco Mundial, 2011). En el mismo año, registra 3165 artículos indexados sobre nanotecnología y 3436 en 2014. Sus principales universidades que dedican esfuerzos en este paradigma tecnológico son la National Tsing Hua University y la National Taipei University of Technology. 
Este potencial de Taiwán en nanotecnología, se halla reflejado en el análisis de citas hacia atrás y hacia adelante ya que, aunque de acuerdo con la muestra reporta menos patentes que los países que mayores esfuerzos realizan en este paradigma tecnológico, sus patentes citan a otras patentes en una proporción ligeramente menor que Japón y mayor que las patentes de Alemania y en promedio se ubican por encima de estos países. De esta forma, las patentes de Taiwán citan a 11 patentes en promedio, mientras que las patentes de Japón, Corea del Sur y Alemania, citan 7.25, 0.6 y 7.4, respectivamente, en promedio.

En cuanto a las citas hacia adelante, nuevamente, el caso de las patentes de Taiwán es sorprendente ya que sus patentes ocupan el tercer lugar en cuanto a citas recibidas (citas hacia adelante), lo que sugiere un potencial importante. Así, en promedio, cada patente de Taiwán recibe 15.7 citas, cifra que está por encima del promedio correspondiente al de las patentes de la muestra (12.3 citas), lo que sugiere que en este país el flujo de conocimiento que permite generar nuevas invenciones en este nuevo paradigma tecnológico es relevante. A su vez, las patentes de Taiwán que reciben mayor número de citas se ubican en el sector tecnológico de química (107 citas hacia adelante), que representa el 56.6\% del número total de citas recibidas por las patentes en nanotecnología pertenecientes a este país (189 citas). Al mismo tiempo, el número promedio de citas que reciben las patentes en el sector de química es de 35.6, es decir, muy por encima del número de citas promedio que reciben las 376 patentes de la muestra (12.3 citas). Esta información sugiere que, en Taiwán, la capacidad de generación de nuevas invenciones, así como la posibilidad de difundir el NPN a nivel mundial, parece residir en el sector tecnológico de química, aunque este análisis debe tomarse con reserva debido al número de patentes (12) analizado.

Cabe señalar que, como parte de este análisis, se propuso una clasificación en alta, media y baja, con base en distintas características obtenidas de las patentes. Así, las patentes de Taiwán presentan un valor de difusión alto (15.7 citas hacia adelante en promedio), velocidad de difusión alta (0.6 años), novedad media (14.8 reivindicaciones promedio), baja movilidad internacional de los inventores (0.08) lo que sugiere que la mayoría de los conocimientos nuevos en nanotecnología son generados por inventores de Taiwán, lo que puede ser considerado como un indicio de la articulación entre los agentes del SNI de este país. Tamaño grande de los equipos de inventores (2.83 inventores en promedio), participación media de firmas y gobierno, índice de generalidad tecnológico (IGT) medio (0.53), lo que sugiere la 
amplitud de los nuevos conocimientos en nanotecnología hacia otros sectores tecnológicos. Estos datos en conjunto sugieren el potencial que muestra Taiwán en el NPN y su posible desarrollo futuro al aprovechar las ventanas de oportunidad que se podrían abrir al difundirse la nanotecnología a nivel mundial.

En cuanto a Canadá, cuenta con 4470 investigadores en I+D por cada millón de personas (dato de 2008), muestra un importante potencial en investigación científica orientada a nanotecnología. Así, en 2011 tenía 2386 artículos publicados en revistas indexadas sobre nanotecnología y para 2014 ya contaba con 3 018. Cabe señalar que, en este corto periodo, Canadá se acercó a los artículos publicados por Taiwán — que en 2014 alcanzó los 3 436—. El papel que juegan las universidades en la generación de conocimientos en nanotecnología es muy importante, ya que universidades como las de Toronto y Waterloo encabezan la lista de las que más artículos publican en este paradigma tecnológico. En cuanto al número de artículos en nanotecnología por cada millón de personas, también muestra una tendencia creciente, ya que en 2010 contaba con 59.02 y para 2014 ya eran 83.98; cifras semejantes a las de Francia. En cuanto al número de patentes asignadas en este campo tecnológico en la USPTO, también muestra una tendencia creciente: de 81 patentes en 2011, pasó a 127 en 2014, lo que sugiere que, aunque su actividad inventiva en el NPN es limitada, es creciente, por lo que Canadá es un país con importante potencial en este paradigma tecnológico. El potencial de Canadá en nanotecnología se confirma al analizar la información contenida en las 10 patentes obtenidas en la muestra de $n=376$ patentes de la USPTO.

El número de citas hacia atrás de las patentes de Canadá en nanotecnología es de 220, ligeramente por debajo de Japón (283) y superior a las de Corea del Sur (19). Este número sugiere que el stock de conocimiento acumulado requerido por la actividad inventiva en nanotecnología de Canadá es más amplio que el de Corea del Sur y muy semejante al de Japón. En promedio, citaron a 22 patentes, valor por encima del promedio de las citas de patentes hechas por las patentes de Estados Unidos (21.7). En cuanto a las citas hacia adelante, las patentes de Canadá recibieron 191 citas de otras patentes, por encima de las citas recibidas por las patentes de Corea del Sur (169) y Alemania (172). En promedio, las patentes de Canadá reciben 19.1 citas, valor por encima de las citas que reciben en promedio las patentes de Estados Unidos (12.9). En cuanto a la velocidad de difusión, el nuevo conocimiento generado por la actividad inventiva en nanotecnología de Canadá se difunde a una velocidad de 2.1 años, 
menor velocidad promedio de difusión que Estados Unidos (1.53 años) y semejante a la velocidad promedio en que se difunden los nuevos conocimientos producidos en Alemania (2.06 años). El conjunto de estos datos confirma el potencial de Canadá en la actividad inventiva y difusión del NPN.

Francia es otro país que muestra importante potencial en el NPN. Así, cuenta con 3751 investigadores en investigación y desarrollo por cada millón de personas (datos de 2009). Un potencial importante en la actividad científica especializada en nanotecnología que se traduce en una gran cantidad de artículos publicados por año. De esta forma, en 2011 Francia publicó 4 554 artículos sobre nanotecnología en revistas indexadas, número superior al de Reino Unido (3 440 artículos) e inferior al de Japón (6 773 artículos) en el mismo año. En 2015 Francia publicó 5618 artículos, lo que muestra una tendencia creciente respecto de 2011. Este potencial se confirma con el número de artículos en nanotecnología por millón de personas, 59.9 en 2010 y 82.3 en 2014. En cuanto a la actividad inventiva en el NPN, en 2011 Francia registró 142 patentes asignadas en la USPTO mientras que en 2014 fueron 347 patentes. Ahora bien, con base en el análisis de la información proporcionada por las patentes obtenidas en la muestra, Francia presenta difusión media (6.1 citas hacia adelante), velocidad media (2 años en promedio), número alto de novedades (18.8 reivindicaciones), baja movilidad internacional de los inventores (0.125), participación media de las firmas en la actividad inventiva en nanotecnología (0.42), alta participación del gobierno en la actividad inventiva en nanotecnología (0.75), valor medio del índice de generalidad tecnológica, 0.44 y tamaño de equipos de inventores grande (3). Estos indicadores, en su conjunto, confirman el potencial de Francia en la actividad inventiva en nanotecnología, aunque en términos relativos, se ubica por debajo de otros países.

En suma, de acuerdo con el número de patentes arrojado por la muestra de estudio así como los datos sobre gastos en I+D, los casos de Taiwán, Canadá y Francia, muestran que si bien se ubican por debajo de los países industrializados que mayores esfuerzos realizan en la actividad inventiva en nanotecnología (Estados Unidos, Japón, Corea del Sur y Alemania), cuentan con un importante potencial en este paradigma tecnológico. Así, el dinamismo que muestra Taiwán lo coloca en posibilidad de cerrar la brecha que lo separa del grupo de países que va a la vanguardia en los próximos años y, por lo tanto, como un país competidor en el mercado mundial. Canadá y Francia también muestran crecimiento en la actividad inventiva en 
nanotecnología, pero los datos sugieren que su dinamismo es menor, por ello, también deben considerarse como competidores potenciales.

No obstante, cabe señalar que algunos estudios (como el de Niosi y Reid, 2007) revelan que existen otros países que, si bien presentan escaso desarrollo en la actividad inventiva en nanotecnología mesurable a través de patentes, sí muestran un importante potencial medible a través de otros indicadores tales como las políticas explícitas de I+D orientadas hacia la nanotecnología, financiamiento dedicado a este sector tecnológico, etcétera; tales son los casos de los países conocidos como los BRIC (Brasil, Rusia, India y China). En el siguiente apartado se presenta un análisis de estos países.

Actividad inventiva en el NPN en los países en vías de desarrollo (China, Rusia, India y Brasil)

Como se explicó en el primer capítulo de la presente investigación, en el marco de la teoría evolucionista, el desarrollo económico y social se entiende como el proceso de acumulación de capacidades tecnológicas y sociales en función del aprovechamiento de ventanas de oportunidad sucesivas y distintas (Pérez, 2001). Las ventanas están dadas por la dinámica económica de los países industrializados y, en particular, por los paradigmas tecnológicos que se originan y se difunden de dichos países hacia los países emergentes. Los nuevos paradigmas pueden constituir grandes sistemas tecnológicos que, a su vez, incluyen a otros sistemas (metasistemas) que originan revoluciones tecnológicas. A su vez, una revolución tecnológica implica cambios radicales o trastornos en los sistemas de producción, en la productividad, en el consumo e, incluso, en la forma de vida de la sociedad. De esta forma, cada revolución tecnológica: "trae consigo cambios profundos y desestabilizadores de la vida de la gente y de sus visiones del mundo" (Pérez, 2004: 78).

De ahí la importancia que tienen los estudios sobre difusión de nuevos paradigmas tecnológicos y, en particular, de la nanotecnología en los países industrializados y emergentes. Si bien este nuevo paradigma tecnológico se promueve y se difunde desde los países industrializados, existen economías emergentes que destinan importantes recursos para su 
generación y difusión que usan distintas estrategias para aprovechar las posibles ventanas de oportunidad generadas por el NPN (Niosi y Reid, 2007).

Estos países realizan cada vez más importantes esfuerzos para impulsar su tecnología, lo que se observa en los gastos de I+D. En el siguiente cuadro, se presenta la evolución del gasto en I+D de estos países a través del tiempo.

Cuadro 3.11. Evolución del gasto en I+D como porcentaje del PIB de China, Rusia, India y Brasil

\begin{tabular}{|l|l|l|l|l|}
\hline Años & China & Rusia & India & Brasil \\
\hline 2000 & 0.9 & 1.05 & 0.74 & 1.02 \\
\hline 2005 & 1.32 & 1.07 & 0.81 & 0.97 \\
\hline 2011 & 1.84 & 1.09 & 0.81 & 1.21 \\
\hline
\end{tabular}

Fuente: elaboración propia con base en Datos en Ciencia y Tecnología del Banco Mundial.

Como se observa en el cuadro 3.11, China, Rusia, India y Brasil, muestran una tendencia creciente en el gasto en I+D como porcentaje del PIB, aunque en el caso de Brasil disminuyó de 2000 a 2005 pasando de 1.02 a 0.97, pero aumentó a 1.21 en 2011, manteniendo una tasa de crecimiento promedio anual de $1.56 \%$, sosteniendo así una tendencia creciente promedio. El caso más claro es el de China, que pasó de 0.9 en 2000 a 1.32 en 2005 y alcanzó el 1.84 en 2011, con lo que mantiene una tasa promedio anual de $6.71 \%$, lo que indica que los esfuerzos que este país está realizando en I+D crecen a gran velocidad. En el caso de Rusia también se observa una tendencia creciente, ya que en 2000 registró un gasto en $\mathrm{I}+\mathrm{D}$ como porcentaje del PIB de 1.05, aumentó a 1.07 en 2005 y en 2011 ya era de 1.09. Lo que también muestra una tendencia clara a incrementar los esfuerzos en investigación y desarrollo. Por último, el caso de la India, aunque presenta un aumento modesto, su tendencia es creciente, pasando de $0.74 \%$ del PIB en el año 2000 a $0.81 \%$ en 2011 , creciendo a una tasa promedio anual de 0.82 . Aunque la tasa es muy baja, muestra una tendencia positiva. En los cuatro países existe una disposición clara por aumentar los esfuerzos en I+D que les permitan incentivar su actividad inventiva y participar en los nuevos paradigmas tecnológicos.

Aunque en la muestra de estudio ( $\mathrm{n}=376$ patentes), Brasil no aparece con patentes en nanotecnología, India solo con una patente, Rusia con dos y China con 7 patentes, sugiere que la actividad inventiva en estos países es relativamente baja, lo cual, no significa que su potencial sea débil. Al revisar el dato sobre el número total de patentes asignadas en este sector 
tecnológico por año en la USPTO, se confirma que en 2011 China registró 180 patentes y pasó a 511 en 2014, es decir, su actividad inventiva en este paradigma tecnológico creció a una tasa de $23.2 \%$ promedio anual. Cabe señalar que el nivel de actividad inventiva de China en nanotecnología en 2014 ya era muy semejante al de Francia (679 patentes). En el caso de Rusia, registró 22 patentes asignadas en 2011 en la USPTO en este paradigma tecnológico y disminuyó un poco su actividad en 2014, ya que registró solo 16 patentes asignadas en nanotecnología. En el caso de la India, en 2011 se registraron 4 patentes asignadas en nanotecnología y pasó a 52 patentes en 2014, es decir, su actividad inventiva en este paradigma tecnológico creció a una tasa promedio anual de 133\%. Por último, Brasil es el país que registra menor actividad inventiva en nanotecnología, ya que en 2011 registró solo 4 patentes en la USPTO pero pasó a 12 patentes en 2014. Así, la tasa de crecimiento promedio anual de Brasil en este breve periodo fue de $44.2 \%$. Además, cabe mencionar que el potencial de Brasil en este paradigma tecnológico es cada vez más importante, pues dedica más recursos en I+D y define políticas para incentivar la actividad inventiva en nanotecnología. Así, en el año 2000, la agencia brasileña de financiamiento de la investigación nacional (ABFIN) creó la Red de Cooperación para la investigación básica en nanotecnología. A su vez, estas redes de cooperación implican: 40 institutos de investigación, 2 empresas (France Telecom y PQSD) y 260 investigadores que han publicado más de 1000 artículos de investigación. Las redes recibieron el primer año \$1 500 000. La mayor parte de la investigación se produce en las universidades. La investigación que se desarrolla en Brasil es, principalmente, en nanomateriales, interfaces, nanotecnología molecular, nanobiotecnología y semiconductores. Cuenta con una buena base científica, pero falta impulsar más la actividad inventiva en este nuevo paradigma tecnológico (Niosi y Reid, 2007).

El caso de China es sorprendente por su rápido crecimiento y el aumento notable en su gasto en I+D. Desde su adhesión a la Organización Mundial de Comercio (OMC) ha producido y difundido los nuevos conocimientos en nanotecnología a través de la atracción de inversión extranjera directa (\$50 000000000 en 2002). Para ello se ha basado en dos estrategias: las políticas fiscales preferenciales y los incentivos a empresas calificadas (que usan alta tecnología). Si bien China ha tenido éxito para atraer inversión extranjera directa, no lo ha tenido para atraer capital de riesgo, por lo que su capacidad para transitar a niveles de desarrollo de alta tecnología, ha quedado rezagada (Niosi y Reid, 2007). 
Rusia muestra un enorme potencial en la actividad inventiva en general, ya que cuenta con 3096 investigadores por cada millón de habitantes dedicados a investigación y desarrollo, cifra relativamente cercana a la de Francia (3 751). De esta forma, en la medida en que la economía de Rusia se estabilice y los cambios institucionales - tales como los derechos de propiedad intelectual — sean favorables a la actividad inventiva en nanotecnología, Rusia irá ganando presencia a nivel mundial. Este país cuenta con distintas organizaciones dedicadas a promover la investigación en nanociencias y nanotecnología, tales como RUSNANO Corporation, que realiza labores para construir una industria competitiva basada en nanotecnología y absorber la transferencia tecnológica proveniente de otros países; la sociedad rusa de microscopía cumple funciones para desarrollar investigaciones aplicadas en el campo de microscopía y nanotecnología; NanoBridge es un consorcio que se centra en la ciencia y desarrollo innovador y pretende reforzar los vínculos entre Rusia y Alemania en estas actividades.

Por último, en el caso de la India, si bien no tiene problemas de escasez de ingenieros y propiedad intelectual, sí carece de laboratorios de calidad y de financiamiento institucional de la magnitud que representa la Iniciativa Nacional en Nanotecnología de Estados Unidos. La India cuenta con el Instituto de Nanotecnología, los niveles para financiar la actividad inventiva en esta actividad son altos. Las organizaciones y grupos de investigación en los departamentos de química de las universidades — por ejemplo, en la universidad de Delhihan desarrollado tecnologías patentables utilizando nanopartículas para la administración de fármacos (cuatro de ellas fueron asignadas en la USPTO de Estados Unidos) (Niosi y Reid, 2007).

Este grupo de países emergentes (China, Rusia, India y Brasil) presentan un potencial importante en nanotecnología y han adoptado, en la fase inicial de difusión de este paradigma tecnológico, distintas estrategias que los orientan a través de distintas trayectorias para cerrar la brecha respecto de los países industrializados. Brasil muestra una base científica sólida en este paradigma tecnológico, sin embargo, presenta baja capacidad inventiva (bajo número de patentes), lo cual sugiere que la actividad científica está poco vinculada con la actividad inventiva. El caso de Rusia es semejante, aunque podría tener mayor potencial científico que Brasil y ha iniciado ya su despegue (aunque algo lento) en la actividad inventiva y comercialización de los productos en nanotecnología. China, ha concentrado sus esfuerzos en 
infraestructura (clusters en $\mathrm{I}+\mathrm{D}$, promoción de start up, atracción de capital de riesgo e incentivos fiscales, entre otros) y la actividad inventiva. Por último, la India muestra un comportamiento semejante a China, pero le falta enfocarse en la actividad inventiva, sobre todo a nivel industrial.

En el primer capítulo se mencionó que una característica de los países emergentes es que tienen sistemas nacionales de innovación desarticulados (Albuquerque, et al.; 2011). Así, los problemas que presentan estos países para aprovechar las ventanas de oportunidad generadas por un nuevo paradigma tecnológico obedecen a tal desarticulación. De esta forma, las ventanas de oportunidad generadas por un nuevo paradigma tecnológico, como el caso de la nanotecnología, si bien pueden ser aprovechadas por países emergentes, no todos logran hacerlo. Solo aquellos que diseñan políticas o estrategias que logran articular las acciones de los distintos actores que participan en el SNI tienen posibilidades de cerrar las brechas con los países industrializados (Pérez, 2004; Niosi y Reid, 2007). En el siguiente apartado se presenta, con base en el análisis previo de los países industrializados y de industrialización reciente, una taxonomía de los patrones de difusión de la nanotecnología.

Taxonomía de los patrones de difusión del NPN en países industrializados y de industrialización reciente

En el cuadro 3.12 se presenta una taxonomía del NPN en países industrializados y de industrialización reciente. Se proponen dos criterios para establecer la tipología de patrones de difusión: i) la capacidad de difundir los nuevos conocimientos tecnológicos, medido a través del número de citas que reciben (citas hacia adelante) las patentes asignadas para países industrializados y emergentes; ii) la velocidad de difusión de los nuevos conocimientos tecnológicos medida a través del rezago temporal de cita (lag time), como una medida proxy de la velocidad. Así, es posible identificar 6 tipos de patrones de difusión: ${ }^{12}$

1) Difusión alta-velocidad media: Estados Unidos, Japón y Alemania;

\footnotetext{
${ }^{12}$ La clasificación se basa en el siguiente criterio: tomar el valor más alto del número de citas promedio y del rezago de cita promedio (lag time) de cada uno de estos países y dividir entre tres. De esta forma, cada subgrupo obtenido representa un tipo de la clasificación: alta, media o baja.
} 
2) Difusión baja-velocidad alta: Corea del Sur;

3) Difusión alta-velocidad alta: Taiwán;

4) Difusión media-velocidad media: Francia;

5) Difusión media-velocidad alta: China;

6) Difusión baja-velocidad baja: Gran Bretaña.

Ahora bien, estos patrones de difusión podrían deberse a la combinación de una serie de factores asociados con distintos grados de articulación de los actores que participan en los sistemas nacionales de innovación de cada uno de estos países. Por ejemplo, el caso de Estados Unidos, ubicado en el patrón de difusión alta-velocidad media, en comparación con Japón, el cual pertenece al mismo patrón. Se observa que, en ambos casos, el número de novedades reconocidas en la patente, podrían ser un factor que incida sobre la difusión de este nuevo paradigma tecnológico. Lo mismo ocurre con las variables: participación de las firmas en las patentes (aunque en el caso de Japón parece tener mayor importancia que en Estados Unidos), amplitud tecnológica de la patente (ya que en ambos países es media) y el tamaño de los equipos de los inventores (ya que en ambos casos, es alta). También coinciden en que la movilidad de los inventores es baja y la participación del gobierno en las patentes no es relevante. Pero difieren en el grado de intensidad tecnológica contenida en la patente, donde en Estados Unidos es alta y en Japón baja. También son semejantes en cuanto a que la actividad inventiva en nanotecnología no depende de la colaboración a través de co-patentes. Cabe señalar que el uso de modelos econométricos puede ayudar a identificar los factores que explican estos patrones de difusión, al identificar correlaciones entre variables.

Cuadro 3.12. Taxonomía de los patrones de difusión del NPN en países industrializados y emergentes, 1983-2013

\begin{tabular}{|l|l|l|l|l|l|l|l|l|}
\hline Variable/País & $\begin{array}{l}\text { Estados } \\
\text { Unidos }\end{array}$ & Japón & $\begin{array}{l}\text { Corea } \\
\text { del Sur }\end{array}$ & Alemania & Taiwán & Francia & China & $\begin{array}{l}\text { Gran } \\
\text { Bretaña }\end{array}$ \\
\hline $\begin{array}{l}\text { Número de citas } \\
\text { hacia adelante, } \\
\text { Difnan }\end{array}$ & $\begin{array}{l}13.2 \\
\text { alta }\end{array}$ & $\begin{array}{l}11.8 \\
\text { alta }\end{array}$ & $\begin{array}{l}4.7 \\
\text { baja }\end{array}$ & $\begin{array}{l}11.4 \\
\text { alta }\end{array}$ & $\begin{array}{l}15.7 \\
\text { alta }\end{array}$ & $\begin{array}{l}6.1 \\
\text { media }\end{array}$ & $\begin{array}{l}9.4 \\
\text { media }\end{array}$ & $\begin{array}{l}5.2 \\
\text { baja }\end{array}$ \\
\hline $\begin{array}{l}\text { Rezago temporal } \\
\text { de cita } \\
\text { (velocidad) }\end{array}$ & $\begin{array}{l}1.53 \\
\text { media }\end{array}$ & $\begin{array}{l}1.94 \\
\text { media }\end{array}$ & $\begin{array}{l}1 \\
\text { alta }\end{array}$ & $\begin{array}{l}2.06 \\
\text { media }\end{array}$ & $\begin{array}{l}0.66 \\
\text { alta }\end{array}$ & $\begin{array}{l}2 \\
\text { media }\end{array}$ & $\begin{array}{l}0.85 \\
\text { alta }\end{array}$ & $\begin{array}{l}3.5 \\
\text { baja }\end{array}$ \\
\hline Número de & 21.7 & 22.1 & 17.9 & 21.2 & 14.8 & 18.8 & 17 & 13.7 \\
\hline
\end{tabular}




\begin{tabular}{|c|c|c|c|c|c|c|c|c|}
\hline $\begin{array}{l}\text { reivindicaciones } \\
\text { o claims. } \mathrm{Cl}\end{array}$ & alta & alta & alta & alta & media & alta & alta & media \\
\hline $\begin{array}{l}\text { Movilidad } \\
\text { internacional de } \\
\text { los inventores, } \\
\text { MobIn }\end{array}$ & $\begin{array}{l}0.11 \\
\text { baja }\end{array}$ & $\begin{array}{l}0.02 \\
\text { baja }\end{array}$ & $\begin{array}{l}0.04 \\
\text { baja }\end{array}$ & $\begin{array}{l}0.2 \\
\text { media }\end{array}$ & $\begin{array}{l}0.08 \\
\text { baja }\end{array}$ & $\begin{array}{l}0.125 \\
\text { baja }\end{array}$ & $\begin{array}{l}0.42 \\
\text { alta }\end{array}$ & $\begin{array}{l}0.25 \\
\text { media }\end{array}$ \\
\hline $\begin{array}{l}\text { Participación de } \\
\text { las firmas en las } \\
\text { patentes, Firminv }\end{array}$ & $\begin{array}{l}0.66 \\
\text { media }\end{array}$ & $\begin{array}{l}0.92 \\
\text { alta }\end{array}$ & $\begin{array}{l}0.96 \\
\text { alta }\end{array}$ & $\begin{array}{l}0.73 \\
\text { alta }\end{array}$ & $\begin{array}{l}0.41 \\
\text { media }\end{array}$ & $\begin{array}{l}0.42 \\
\text { media }\end{array}$ & $\begin{array}{l}1 \\
\text { alta }\end{array}$ & $\begin{array}{l}0.75 \\
\text { alta }\end{array}$ \\
\hline $\begin{array}{l}\text { Participación del } \\
\text { gobierno en las } \\
\text { patentes, Goveff }\end{array}$ & $\begin{array}{l}0.31 \\
\text { baja }\end{array}$ & $\begin{array}{l}0.10 \\
\text { baja }\end{array}$ & $\begin{array}{l}0.12 \\
\text { baja }\end{array}$ & $\begin{array}{l}0.26 \\
\text { baja }\end{array}$ & $\begin{array}{l}0.58 \\
\text { media }\end{array}$ & $\begin{array}{l}0.75 \\
\text { alta }\end{array}$ & $\begin{array}{l}1 \\
\text { alta }\end{array}$ & $\begin{array}{l}0.25 \\
\text { baja }\end{array}$ \\
\hline $\begin{array}{l}\text { Índice de } \\
\text { generalidad } \\
\text { tecnológica, } I G T\end{array}$ & $\begin{array}{l}0.42 \\
\text { media }\end{array}$ & $\begin{array}{l}0.37 \\
\text { media }\end{array}$ & $\begin{array}{l}0.41 \\
\text { media }\end{array}$ & $\begin{array}{l}0.43 \\
\text { media }\end{array}$ & $\begin{array}{l}0.53 \\
\text { media }\end{array}$ & $\begin{array}{l}0.44 \\
\text { media }\end{array}$ & $\begin{array}{l}0.36 \\
\text { media }\end{array}$ & $\begin{array}{l}0 \\
\text { baja }\end{array}$ \\
\hline $\begin{array}{l}\text { Número de citas } \\
\text { hacia atrás, A }\end{array}$ & $\begin{array}{l}21.7 \\
\text { alta }\end{array}$ & $\begin{array}{l}7.2 \\
\text { baja } \\
\end{array}$ & $\begin{array}{l}9.7 \\
\text { media }\end{array}$ & $\begin{array}{l}7.4 \\
\text { media } \\
\end{array}$ & $\begin{array}{l}11 \\
\text { media }\end{array}$ & $\begin{array}{l}5 \\
\text { baja } \\
\end{array}$ & $\begin{array}{l}18.1 \\
\text { alta }\end{array}$ & $\begin{array}{l}7.2 \\
\text { baja }\end{array}$ \\
\hline $\begin{array}{l}\text { Número de citas } \\
\text { de artículos } \\
\text { científicos, } \\
\text { PatBibSc }\end{array}$ & $\begin{array}{l}18.7 \\
\text { alta }\end{array}$ & $\begin{array}{l}4.7 \\
\text { baja }\end{array}$ & $\begin{array}{l}5.9 \\
\text { baja }\end{array}$ & $\begin{array}{l}1.9 \\
\text { baja }\end{array}$ & $\begin{array}{l}4.08 \\
\text { baja }\end{array}$ & $\begin{array}{l}2.3 \\
\text { baja }\end{array}$ & $\begin{array}{l}3.8 \\
\text { baja }\end{array}$ & $\begin{array}{l}8 \\
\text { media }\end{array}$ \\
\hline Co-patentes & $\begin{array}{l}0.04 \\
\text { baja }\end{array}$ & $\begin{array}{l}0.02 \\
\text { baja }\end{array}$ & $\begin{array}{l}0.04 \\
\text { baja }\end{array}$ & $\begin{array}{l}0.06 \\
\text { baja } \\
\end{array}$ & $\begin{array}{l}0.08 \\
\text { baja } \\
\end{array}$ & $\begin{array}{l}0.25 \\
\text { baja }\end{array}$ & $\begin{array}{l}1 \\
\text { alta } \\
\end{array}$ & $\begin{array}{l}0 \\
\text { baja } \\
\end{array}$ \\
\hline $\begin{array}{ll}\text { Tamaño } & \text { del } \\
\text { equipo de } & \text { los } \\
\text { inventores, } & \\
\text { SizeRt } & \\
\end{array}$ & $\begin{array}{l}3.13 \\
\text { alta }\end{array}$ & $\begin{array}{l}3.05 \\
\text { alta }\end{array}$ & $\begin{array}{l}3.28 \\
\text { alta }\end{array}$ & $\begin{array}{l}3.53 \\
\text { alta }\end{array}$ & $\begin{array}{l}2.83 \\
\text { alta }\end{array}$ & $\begin{array}{l}3 \\
\text { alta }\end{array}$ & $\begin{array}{l}3 \\
\text { alta }\end{array}$ & $\begin{array}{l}2 \\
\text { media }\end{array}$ \\
\hline
\end{tabular}

Fuente: elaboración propia con base en USPTO, 1983-2013. Los valores para realizar la clasificación se obtuvieron para cada una de las variables de la siguiente forma: se tomó el valor máximo y se dividió entre tres para establecer tres intervalos que indican la clasificación "baja", "media" y "alta" en sentido ascendente. La información del cuadro se lee por filas.

Si bien la descripción de los datos arroja información relevante sobre los patrones de difusión de este nuevo paradigma tecnológico — principalmente en los países promotores de nanotecnologías-, no es suficiente para confirmar o desechar las hipótesis planteadas en el presente trabajo de investigación. Para ello, se propone un modelo econométrico de conteo que se plantea a continuación. 


\subsection{Propuesta de modelo econométrico}

Los modelos econométricos de conteo, se basan en datos que: "se obtienen cuando se contabiliza el número de veces que ocurre un suceso en un intervalo de amplitud determinada $\mathrm{y}$, en consecuencia, pueden ser considerados como realizaciones de una variable aleatoria que solo toma valores enteros no negativos." (Romero et al., 2003: 456). Algunos ejemplos de datos que son analizados con base en modelos de conteo son: el número de visitas al médico en cierto tiempo, por ejemplo, en un mes; el número de artículos científicos en cierto periodo, por ejemplo, en un año o el número de vuelos en un aeropuerto registrados en cierto tiempo, por ejemplo en una semana, entre otros (Cano y Rodríguez, 2008). Lo común en estos ejemplos es que los eventos aleatorios son independientes y ocurren en un tiempo dado (Canavos, 2008). Debido a estas características peculiares de los eventos, su función de distribución de probabilidad es discreta y se le conoce como la distribución de Poisson, en honor al probabilista francés Simeón Denis Poisson quien fue el primero en describirla (Canavos, 2008).

Los modelos de regresión estándar, como el modelo de regresión lineal, presentan deficiencias a la hora de ser utilizados para analizar este tipo de datos, ya que ignoran la naturaleza de la variable dependiente. Como consecuencia de ello, se han definido nuevas aproximaciones cuyo objetivo es captar convenientemente los rasgos característicos de estos datos. En el presente trabajo se utilizan dos aproximaciones frecuentemente usadas: el modelo de Poisson y el modelo binomial negativo.

\section{El modelo de Poisson}

Suponiendo que la variable dependiente son datos de conteo con función de distribución de probabilidad Poisson, entonces: "el parámetro $\lambda$ del proceso de Poisson depende de un conjunto de variables explicativas." (Romero, et al., 2003: 458). Formalmente, 


$$
\lambda_{i}=E y_{i} / x_{i}=\exp \left(x_{i}, \beta\right)
$$

para

$$
y_{i}=0,1,2, \ldots
$$

donde $\lambda_{\mathrm{i}}$ es el valor esperado de que ocurra el suceso de interés para el individuo $i$, para toda $i=$ $1,2, \ldots, \mathrm{N}$; en un intervalo de amplitud unitaria, dado un conjunto de variables explicativas $x_{i}$. (Romero et al., 2003).

\section{Limitaciones del modelo}

Dado el supuesto anterior, una limitación de este modelo es que la función de distribución de tipo Poisson tiene la propiedad de que sus primeros momentos son iguales, es decir, que la media y la varianza son iguales (equidispersión). Sin embargo, esta propiedad, por lo general, no se cumple, por lo que el ajuste de los datos no es confiable. Otra limitación es la heteroscedasticidad intrínseca, debido a que la naturaleza de los datos es no lineal, entonces la varianza de los errores no es constante. Debido a estas limitaciones que presenta el modelo de Poisson, se proponen otras aproximaciones, tal como el modelo binomial negativo.

\section{El modelo binomial negativo}

Las limitaciones señaladas del modelo de tipo Poisson se resuelven añadiendo una fuente de aleatoriedad en el parámetro $\lambda$ :

$$
\lambda_{i}^{*}=\exp x_{i} \beta+\varepsilon_{i}=\lambda_{i} \exp \left(\varepsilon_{i}\right)
$$

donde $\varepsilon$ i se supone que se distribuye como:

$$
\Gamma(\lambda \mathrm{i}, v \mathrm{i})
$$

Bajo estos supuestos, la variable de conteo tiene una distribución binomial negativa:

$$
\operatorname{Pr}\left(\mathrm{y}_{\mathrm{i}} / \mathrm{x}_{\mathrm{i}}\right)=\frac{\Gamma\left(y_{i}+v_{i}\right)}{\Gamma y_{i}+1 \Gamma\left(v_{i}\right)}{\frac{v_{i}}{v_{i}+\lambda_{i}}}^{v_{i}}{\frac{\lambda_{i}}{v_{i}+\lambda_{i}}}^{y_{i}}
$$

donde: 


$$
\begin{aligned}
& \quad \lambda_{i}=\exp \left(x_{i} \beta\right) \\
& v_{i}=1 / \alpha \lambda_{i}^{t} \\
& \text { Para } t=0,1
\end{aligned}
$$

Modelo binomial negativo 1:

Si $v=(1 / \alpha)$, entonces:

$$
\begin{aligned}
& E y_{i} / x_{i}=\exp \left(x_{i} \beta\right) \\
& \text { Var } y_{i} / x_{i}=1+\alpha \exp \left(x_{i} \beta\right)
\end{aligned}
$$

Modelo binomial negativo 2:

Si $v=(1 / \alpha) \lambda$, entonces,

$$
\begin{aligned}
& E y_{i} / x_{i}=\exp \left(x_{i} \beta\right) \\
& \text { Var } y_{i} / x_{i}=\exp x_{i} \beta\left(1+\alpha \exp x_{i} \beta\right)
\end{aligned}
$$

En estos modelos si $\alpha>0$, entonces hay sobredispersión, es decir, ocurre que:

$$
\text { Var } y_{i} / x_{i} \geq E y_{i} / x_{i}
$$

Tanto el modelo de tipo Poisson como el binomial negativo, se estiman a través del método de máxima verosimilitud (Romero et al., 2008; Cano y Rodríguez, 2008).

\section{Especificación del modelo}

La especificación base es un modelo de tipo Poisson donde el número de sucesos, dado un conjunto de regresores $X$, tiene una distribución de tipo Poisson y la media condicional depende de las características individuales recogidas en los regresores, es decir:

$$
\operatorname{DifNan}_{i}=\lambda_{i}=E y_{i} x_{i}=\exp \left(x_{i}, \beta\right)
$$

Es importante señalar que, en este tipo de modelos, una característica que posee la distribución de la variable aleatoria de Poisson, es que su esperanza es igual a su varianza.

En nuestro caso:

DifNani, representa el número promedio de citas realizadas en patentes sucesivas (como una variable proxy de la difusión del NPN), dado un conjunto de variables independientes $x i$ 
que reflejan las características de la patente citada. El conjunto $X$ se compone de las siguientes variables:

$X=[C l, \operatorname{lagFwCit}, A, I G T$, SizeRT, MobIn, CoopTec , Pat-BibSC, GovEff, FirmsINV, f]

Donde:

$C l$ es el número de reivindicaciones (claims)

lagFwCit, es el rezago temporal (medido en años) en que una patente concedida en el campo de nanotecnología es citada por primera vez por otra patente

$A$ es el número de citas recogidas en la patente (citas backward)

$I G T$ es el índice de generalidad tecnológica

SizeRT representa el tamaño de equipos de inventores

MobIn es la movilidad internacional de los inventores

CoopTec es la colaboración cuando hay co-patentes

Pat-BibSC representa el número de citas de artículos científicos

GovEff representa los esfuerzos del gobierno en la generación de invenciones en nanotecnología

FirmsINV es la participación de las empresas en las patentes

$f$ es una variable de control

Hipótesis de las variables

i) El número de reivindicaciones $(\mathrm{Cl})$ se propone como una variable proxy del número de novedades que incluye la patente.

Hipótesis: se espera que el número de citas que recibe una patente de otra sucesiva sea mayor si el número de reivindicaciones es mayor (Tong y Frame, 1992; Lanjouw y Schankerman, 2000 y 2004).

ii) El rezago temporal (lag time) en que una patente concedida en el campo de nanotecnología es citada por primera vez por otra patente $(\operatorname{lag} F w C i t)$, considera la diferencia temporal (medida en años) entre la fecha de concesión de una patente y la fecha en que la patente es citada por primera vez por otra patente (Gay et al., 2005). Es una variable proxy de velocidad de difusión del paradigma tecnológico. 
Hipótesis: se espera que la propensión de que una patente sea citada por otra, sea mayor si el rezago temporal es menor.

iii) El número de citas realizadas a otras patentes (citas backward), A, como reflejo de la intensidad del conocimiento tecnológico utilizado en la patente supone un acervo inicial de conocimientos tecnológicos que se difunden a partir de que las nuevas patentes los citan, reforzando así la difusión del nuevo paradigma. Se puede considerar una variable proxy de un proceso acumulativo de conocimiento tecnológico.

Hipótesis: se espera que, a mayor número de citas realizadas a otras patentes, la propensión de que una patente sea citada por otra patente sucesiva, sea mayor (Duguet y Macgarvie, 2005; Gay y Le Bas, 2005).

iv) Un índice de generalidad tecnológica propuesto por Trajtenberg y Henderson (1997), IGT, que recoge la amplitud de las posibles aplicaciones de la tecnología patentada en diferentes sectores tecnológicos.

Hipótesis: se espera que la propensión de que una patente reciba cita de otra patente sucesiva sea mayor si la patente pertenece a un amplio rango de campos tecnológicos (Trajtenberg y Henderson, 1997).

El índice de generalidad tecnológica $(I G T)$ propuesto por Trajtenberg se estima a través de la expresión:

$$
I G T=1-{ }_{j}^{n_{1}} S_{i j}^{2}
$$

donde: Sij denota el porcentaje de citas que recibe una patente $i$ que pertenece a la clase $j$, dentro del grupo $n l$ de clases de patentes.

Hipótesis: Una puntuación alta en generalidad sugiere que la patente ha tenido un amplio impacto, puesto que ha influenciado innovaciones subsiguientes en toda una gama de campos (Trajtenberg y Henderson, 1997).

v) SizeRT representa el tamaño de equipos de inventores. Se refiere al número de inventores involucrados en la generación de la patente. Esta característica implica la posibilidad de generar más ideas porque los miembros de los equipos pueden pertenecer a otras redes de equipos que, a su vez, difunden las ideas del nuevo paradigma tecnológico. Se supone que entre mayor sea el equipo mayor número de ideas pueden generarse y difundirse. 
Hipótesis: se espera que la propensión de que una patente sea citada por otra sea mayor si el tamaño de los equipos de los inventores es mayor.

vi) MobIn representa la movilidad internacional de los inventores. Esta es una variable dummy en la cual 1 significa que hay movilidad internacional de los inventores y 0 significa que no la hay. Se supone que la movilidad internacional de los inventores favorece la derrama de conocimientos codificados y tácitos.

Hipótesis: se espera que, si hay movilidad internacional de los inventores en la patente, la propensión de que sea citada sea mayor que en aquellas patentes donde no hay movilidad internacional de los inventores.

vii) CoopTec es la colaboración cuando hay co-patentes y es una variable proxy de la cooperación tecnológica presente en la invención. Es una variable dummy, en la cual 1 significa que si hay colaboración y 0 que no la hay.

Hipótesis: se espera que si hay colaboración en la patente, el número de citas que recibe la patente sea mayor que en aquellas patentes donde no hay colaboración.

viii) Pat-BibSC representa el número de citas de artículos científicos que aparecen en la patente. Indica el vínculo con el sector académico. Es una variable proxy del conocimiento científico en el que se basa la patente.

Hipótesis: se espera que la propensión de que una patente sea citada por otra sucesiva sea mayor si el número de artículos científicos citados en la patente es mayor.

xix) GovEff representa el esfuerzo del gobierno en la generación de invenciones en nanotecnología. Se utiliza el número de patentes de universidades e institutos de investigación como una variable proxy. Supone que una patente indica el resultado en invenciones derivado del esfuerzo invertido en I+D. Es una variable dummy, donde 1 significa que hay esfuerzos del gobierno y 0 que no los hay.

Hipótesis: se espera que, si hay esfuerzos del gobierno en la patente, el número de citas que reciba sea mayor que en aquellas patentes donde no hay esfuerzos del gobierno.

x) FirmsINV es la participación de las empresas en las patentes. Se propone utilizar las patentes cuyas empresas sean los titulares. La participación de las empresas en la generación de patentes sugiere una mayor probabilidad de que éstas se escalen a nivel industrial y se instalen como innovaciones. Es una variable dummy, en la que 1 indica que hay participación de las empresas en las patentes y 0 que no la hay. 
Hipótesis: se espera que, si hay participación de las empresas en las patentes, el número de citas recibidas por la patente sea mayor que en aquellas patentes donde no hay participación de las empresas.

xi) Por último, se agrega una variable de control, $f$, con el propósito de filtrar las variaciones temporales en el número de citas hacia adelante, ya que las patentes más antiguas son generalmente más citadas porque se dispuso de más tiempo para ello. 


\subsection{Estimación del modelo de conteo}

El propósito del presente apartado es presentar los resultados de la estimación del modelo de conteo propuesto en el apartado anterior. Como se mencionó, el propósito del modelo es ubicar algunas variables que podrían explicar la difusión de los conocimientos generados por la actividad inventiva ocurrida bajo el NPN, utilizando una muestra de tamaño $n=376$ patentes asignadas en este campo tecnológico, tomadas de la Oficina de Marcas y Patentes de Estados Unidos (USPTO). Es importante remarcar que las estimaciones realizadas fueron a nivel de muestra. En primer lugar, se estimó el modelo a nivel general, es decir, incluyendo todas las patentes de la muestra pertenecientes a los diferentes países seleccionados. En segundo lugar, se estimó el modelo por países, considerando solo a los países que mayores esfuerzos realizan en el impulso de este nuevo paradigma tecnológico: Estados Unidos, Japón, Corea del Sur y Alemania. Cabe reiterar que la selección de estos países obedece al hecho de que son los países que mayor actividad inventiva realizan en este paradigma tecnológico, como se mostró en el diagnóstico general, también son los países que más conocimientos en nanotecnología difunden a nivel mundial y, por estos motivos, es pertinente estudiar sus patrones de difusión ${ }^{13}$.

A continuación se presentan y analizan los resultados del modelo general (incluye todos los países seleccionados en la muestra de tamaño $n=376$ patentes).

\section{Estimación y resultados del modelo general}

\footnotetext{
${ }^{13}$ Cabe señalar que se hizo el intento de estimar el modelo con los datos de Estados Unidos, Japón, Corea del Sur y Alemania, tomando de la muestra $(n=376$ patentes) las submuestras pertenecientes a cada uno de estos países: 176, 32, 15 y 12, respectivamente. Como se esperaba, dado el tamaño de las submuestras, solo el modelo correspondiente a los datos de Estados Unidos resultó con un buen ajuste, los demás fueron desechados. Se realizó un segundo intento, utilizando un muestreo estratificado obteniendo muestras de 1 257, 296, 110 y 56, respectivamente. Con estos datos las estimaciones del modelo fueron buenas para Estados Unidos y mejoraron ligeramente para Japón pero no para Corea del Sur y Alemania, por lo que, finalmente, se decidió trabajar con los datos poblacionales de estos tres países: Japón (1 602 patentes), Corea del Sur (752 patentes) y Alemania (325 patentes) (número total de patentes asignadas en nanotecnología en la USPTO entre 1974 y 2013) que se extrajeron de la población de estudio (18 414 patentes). Con base en estos datos, las estimaciones del modelo mejoraron notablemente.
} 
En el cuadro 3.13 se presenta la descripción estadística de las variables numéricas del modelo (Difnan, Cl, lagFwcit, A, SizeRt, PatBibSc, IGT). Se observa que en el caso del número de citas hacia adelante, Difnan, presenta una media de 12.5, lo que significa que, en promedio, cada patente asignada en el campo tecnológico de nanotecnología recibe un poco más de 12 citas, lo cual, representa un número considerable como indicador de la difusión y del valor de las patentes en este campo. No obstante, hay patentes que reciben muchas citas y otras que no tienen citas. Así, el máximo de citas recibidas es de 190 y el mínimo es 0 . Al considerar la frecuencia de las citas recibidas se tiene que, de las 376 patentes de la muestra, 103 patentes no recibieron citas, mientras que solo 1 patente recibió 190 citas. Entre ambos extremos se ubican muchas patentes que recibieron citas entre 0 y 190 con una desviación respecto de la media de 21.7 citas. La distribución de esta variable describe el comportamiento típico de las variables de conteo, es decir, cargadas hacia la izquierda de la media y con una larga cola hacia la derecha de la media.

El número de reivindicaciones que reciben las patentes, $C l$, describe una distribución distinta a la de la variable Difnan. En promedio, cada patente asignada en este campo recibe 20.8 reivindicaciones, lo que refleja el grado de novedad contenida en la patente y su potencial uso y aplicaciones. El número de reivindicaciones recibidas por las patentes oscila entre 143 y 1. El valor de la desviación estándar es de 16.9, es decir, menor al valor de la media, lo que describe mayor concentración de los datos alrededor de la media.

En cuanto a la variable que se refiere al rezago temporal de cita (medida en años), lagFwcit, reporta una media de 1.5 años, lo que indica que, en promedio, cada una de las patentes asignadas en el campo tecnológico de nanotecnología reciben su primera cita en un año y medio después de la fecha de asignación. Esto sugiere que los nuevos conocimientos generados en nanotecnología se difunden relativamente rápido. Sin embargo, hay patentes que tardan más tiempo en ser citadas por primera vez, hasta 9 años, y otras que son citadas antes de que pase un año después de la fecha de asignación. La mayoría de las patentes reciben su primera cita alrededor de 1.5 años, después de la fecha de asignación, ya que la desviación estándar es de 1.6 años, es decir, casi igual que el valor medio, lo que describe una distribución casi simétrica. 
La variable que corresponde al número de citas recogidas en la patente (citas hacia atrás), $A$, presenta un valor medio de 17.4 citas lo que indica que, en promedio, cada una de las patentes asignadas en este campo tecnológico cita a 17.4 patentes, lo que sugiere la intensidad tecnológica acumulada y el valor de las patentes en nanotecnología. No obstante, hay pocas patentes que citan a muchas patentes, 311 patentes citadas, y muchas patentes que hacen referencia a pocas o ninguna patente. Su desviación estándar es de 32.3 citas, casi el doble del valor medio. Así, la distribución de esta variable es semejante a la distribución de la variable Difnan, es decir, cargada hacia la izquierda de la media y con una larga cola hacia la derecha de la media.

En cuanto al tamaño de equipo de los inventores que participan en la generación del nuevo conocimiento contenido en las patentes de este paradigma tecnológico, se observa que, en promedio, cada patente registra 3.2 inventores. Esto confirma que la actividad inventiva en nanotecnología se caracteriza por la participación de inventores que trabajen en colaboración. Sin embargo, en los extremos se hallan patentes que registran la participación de hasta 12 inventores, mientras que hay otras patentes que registran solo un inventor. La desviación estándar es de 1.8 inventores, valor que es menor al de la media, lo que sugiere que la mayoría de las patentes registra la participación de equipos de inventores alrededor de 3.2.

En cuanto al número de citas de artículos científicos, PatBibSc, cada patente asignada en nanotecnología registra, en promedio, 14.8 citas de artículos científicos, lo que refleja el grado de vinculación con la actividad científica o académica. Como se argumentó en el capítulo 2 de la presente investigación, un rasgo característico de los nuevos paradigmas tecnológicos (digital y molecular) es que los vínculos con la actividad científica son mayores. Sin embargo, hay patentes que muestran un vínculo mayor con la ciencia que otras. Así, hay pocas patentes que registraron cerca de o 286 citas de artículos científicos y muchas patentes que registraron pocas o ninguna referencia de artículos científicos. La desviación estándar es de 30.6 citas, lo que sugiere que la distribución de esta variable está cargada hacia la izquierda de la media y con una larga cola hacia la derecha de la media, como ocurre con las variables típicas de conteo.

Por último, el índice de generalidad tecnológica, IGT, que mide la amplitud de la patente asignada en nanotecnología. Este índice tiene valores que oscilan entre 0 y 1 , si el valor es próximo o igual a 0 indica que la difusión del nuevo conocimiento registrado en la patente 
está concentrado en pocos o en un solo sector; pero si el valor del índice es cercano o igual a 1 indica que el nuevo conocimiento contenido en la patente se difunde en muchos o todos los sectores tecnológicos. Así, en promedio, cada patente asignada en el campo tecnológico de nanotecnología presenta un valor del $I G T$ de 0.4 , lo que indica que el nuevo conocimiento contenido en cada una de las patentes en nanotecnología se difunde en la mitad de los sectores tecnológicos en promedio. Pero, hay pocas patentes que difunden sus nuevos conocimientos en casi todos los sectores tecnológicos y otras patentes que aún no logran difundir sus nuevos conocimientos en otros sectores. La desviación estándar es de 0.1 , lo que indica que la mayoría de las patentes tienen una amplitud media, es decir, alrededor de 0.4. El resto de las variables son dummy, por lo que no fueron consideradas en este análisis. Estos resultados se observan en el siguiente cuadro.

Cuadro 3.13. Medidas descriptivas de las patentes $(n=376)$

\begin{tabular}{llllllll}
\hline & Difnan & Cl & lagFwcit & A & SizeRt & PatBibSc & IGT \\
\hline Media & 12.5 & 20.8 & 1.5 & 17.4 & 3.2 & 14.8 & 0.4 \\
Desviación estándar & 21.7 & 16.9 & 1.6 & 32.3 & 1.8 & 30.6 & 0.1 \\
Mínimo & 0.0 & 1.0 & 0.0 & 0.0 & 1.0 & 0.0 & 0.0 \\
Máximo & 190.0 & 143.0 & 9.0 & 311.0 & 12.0 & 286.0 & 1.0 \\
\hline
\end{tabular}

Fuente: elaboración propia con base en la muestra de tamaño $n=376$ patentes tomadas de la USPTO. Donde: Difnan, es el número de citas hacia adelante; $\mathrm{Cl}$, es el número de reivindicaciones; lagFwcit, es rezago temporal de cita; SizeRt, es el tamaño de equipo de inventores; PatBibSc, es el número de citas de artículos científicos y $I G T$, es el índice de generalidad tecnológica.

Estimación del modelo y resultados

Se realizaron varias estimaciones del modelo a nivel general y se descartaron los resultados no significativos. Como se explicó arriba, el modelo de conteo original supone que los valores de la variable dependiente Difnan se distribuyan como una función de tipo Poisson, la cual es simétrica y, por ello, supone que la media es igual a la varianza. Sin embargo, en la práctica este tipo de datos no logra cumplir este supuesto y presentan, por lo general, el problema de sobre dispersión. Este problema se corrigió ajustando los datos a otra función de distribución 
conocida como binomial negativa. Por este motivo, en las estimaciones del modelo se utilizó una función de distribución de tipo binomial negativa.

También se mencionó que otro problema que presentan los modelos no lineales, y en particular los de conteo, es la heteroscedasticidad intrínseca, es decir, que la varianza de los errores no es constante. Para corregir este problema se estimó un modelo que incorpora robustez en los errores estándar. Al realizar estos cálculos únicamente los parámetros de las variables $C l$, lagFwcit, MobIn y GovEff resultaron significativos con un p-valeu menor que 0.05. Sin embargo, con el propósito de captar más información relevante de las variables explicativas se propuso dividir los valores del índice de generalidad tecnológica (valores que se ubican entre cero y uno), IGT, en tres intervalos que reflejan distintos grados de amplitud de las patentes asignadas en nanotecnología. En el siguiente cuadro se presenta esta clasificación.

Cuadro 3.14. Grados de difusión tecnológica de la nanotecnología hacia los demás sectores tecnológicos, USPTO, 1983-2013 (para n=376)

\begin{tabular}{|l|l|}
\hline Intervalos de los valores del $\boldsymbol{I G T}$ & Grados de difusión tecnológica \\
\hline $0 \leq \mathrm{IGT} \leq 0.33$ & Baja \\
\hline $0.34 \leq \mathrm{IGT} \leq 0.66$ & Media \\
\hline $0.67 \leq \mathrm{IGT} \leq 1$ & Alta \\
\hline
\end{tabular}

Fuente: elaboración propia con base en los valores del IGT propuesto por Trajtenberg y Henderson (1997).

Con base en esta información se incorporaron tres variables en la estimación del modelo que reflejan el grado de difusión tecnológica de las patentes asignadas en la nanotecnología. Estas variables son: disper, medisp y altdisp, que corresponden a difusión baja, media y alta, respectivamente. Al estimar nuevamente el modelo incorporando estas variables, el único parámetro estimado que resultó no significativo fue el de altdisp, ya que hay pocos valores de la variable $I G T$ que caen dentro de este intervalo. Por último, se estimaron los parámetros de las variables independientes, usando los valores del logaritmo natural de la variable dependiente, es decir, de Difnan, lo que mejoró la significancia de los valores de los parámetros.

En el cuadro 3.15, se observan los resultados del modelo de conteo con una distribución de tipo binomial negativo y con el problema de heteroscedasticidad corregido. Se observa que el p-valeu correspondiente a los valores de cada parámetro es menor que 0.05 , lo que significa que el ajuste de los datos es bueno. 
Cuadro 3.15. Estimación del modelo de conteo $(n=376)$

\begin{tabular}{lll}
\hline Variables & $\begin{array}{l}\text { Binomial Negativo } \\
\text { (Coeficientes) }\end{array}$ & $\mathbf{P}>\mathbf{z}$ \\
\hline Constante & 0.45518 & 0.0000 \\
$\mathrm{Cl}$ & 0.00296 & 0.0160 \\
MobIn & 0.22874 & 0.0080 \\
Goveff & -0.23875 & 0.0040 \\
Medisp & 0.39987 & 0.0000 \\
Disper & 0.49287 & 0.0000 \\
\hline
\end{tabular}

Fuente: elaboración propia con base en la estimación del modelo de conteo.

Ahora bien, la interpretación de los resultados requiere el cálculo de los efectos marginales. En el siguiente apartado se presenta este análisis.

Interpretación de los parámetros estimados

En cuanto a la interpretación de los parámetros, arrojan información relevante sobre el fenómeno de la difusión del NPN. De esta forma, al aumentar en una unidad las reivindicaciones (claims), $\mathrm{Cl}$, el número promedio de citas que recibe una patente asignada en nanotecnología aumenta en $0.6 \%$. Esto indica que una de las variables que explican los patrones de difusión de este nuevo paradigma tecnológico es la novedad del conocimiento tecnológico difundido. Se confirmó la hipótesis establecida sobre esta variable en la especificación del modelo.

La movilidad internacional de los inventores, MobIn, también es una variable que explica la difusión de la nanotecnología ya que se confirma que, si hay movilidad en las patentes, el número promedio de citas recibidas por una patente asignada en este paradigma tecnológico aumenta en $51.3 \%$ más que en aquellas patentes donde no hay movilidad internacional de los inventores. Esto sugiere que los vínculos o redes que se establecen entre los equipos de investigación a nivel internacional representan un canal importante de difusión de los nuevos conocimientos tecnológicos. Se confirmó la hipótesis establecida. 
En cuanto a los esfuerzos del gobierno en la generación de invenciones en nanotecnología, GovEff, si bien es importante en la fase inicial de la difusión de un nuevo paradigma tecnológico, se observa la tendencia de ceder su lugar a otros sectores de la economía, tales como las firmas, individuos o centros de investigación mixtos (gobierno y firmas). Esta tendencia se refleja en el valor del parámetro estimado correspondiente a esta variable explicativa. Así, si hay esfuerzos del gobierno en las patentes para la generación de invenciones en nanotecnología, el número promedio de citas que recibe una patente concedida en este paradigma tecnológico es de $46.6 \%$ menor que en aquellas patentes donde no hay esfuerzos del gobierno. El resultado es coherente con la proporción que ocupa el número de patentes donde hay esfuerzos del gobierno respecto del total de patentes de la muestra (30.8\%). Aunque no se confirmó la hipótesis establecida, los países industrializados confirman, en general, esta tendencia. En la muestra base del presente análisis, los países industrializados que más esfuerzos realizan en nanotecnología (Estados Unidos, Japón, Corea del Sur y Alemania), ocupan el $84.8 \%$ de la muestra total, lo que explica dicho resultado. Por otra parte, si la amplitud hacia otros sectores tecnológicos de las patentes asignadas en nanotecnología es baja $(0 \leq I G T \leq 0.33)$, el número promedio de citas que recibe una patente concedida en este paradigma tecnológico, aumentará en $125.7 \%$, y si la amplitud es media, $(0.34 \leq I G T \leq 0.66)$, entonces aumentará en $83.3 \%$, lo cual sugiere que si el conocimiento generado en el paradigma tecnológico de la nanotecnología se haya concentrado en su mismo campo, tiene mayor probabilidad de generar nuevos conocimientos que el conocimiento difundido en otros campos tecnológicos. Estos resultados, se hallan resumidos en el cuadro 3.16.

\begin{tabular}{|c|c|c|}
\hline Variables & $\begin{array}{l}\text { Binomial Negativo } \\
\text { (Efectos marginales) }\end{array}$ & $\mathbf{P}>\mathbf{z}$ \\
\hline $\mathrm{Cl}$ & 0.00608 & 0.0150 \\
\hline MobIn & 0.51303 & 0.0130 \\
\hline Goveff & -0.46630 & 0.0020 \\
\hline Medisp & 0.83310 & 0.0000 \\
\hline Disper & 1.25712 & 0.0000 \\
\hline
\end{tabular}

Fuente: elaboración propia con base en las estimaciones del modelo.

Los resultados del modelo general complementan el análisis estadístico presentado en el apartado 3.2. De esta forma, el NPN tiene su origen en aquellos países que mayores 
esfuerzos realizan en I+D y, específicamente, en nanotecnología: Estados Unidos, Japón, Corea del Sur y Alemania, principalmente. A partir de este grupo de países se difunde hacia el resto del mundo. Al analizar la difusión de este paradigma tecnológico a nivel de flujos de conocimiento, se confirma que incluye una variedad de sectores tecnológicos: nanoestructura, biotecnología y química, principalmente, pero también eléctrica y electrónica, medicamentos y medicinas, computación y comunicaciones y mecánica. En promedio, el paradigma se difunde a una velocidad relativamente alta, ya que el valor medio del rezago temporal de cita (lag time) fue de 1.53 años entre 1983 y 2013. A su vez, este patrón de difusión del nuevo paradigma tecnológico a nivel de flujos de conocimiento, obedece a varios factores: el carácter novedoso del conocimiento, la movilidad internacional de los inventores, los esfuerzos del gobierno en impulsar el nuevo paradigma tecnológico y del grado de concentración de los nuevos conocimientos en nanotecnología a nivel sectorial (concentración baja y media). Cabe señalar que estos factores reflejan, en su conjunto, la importancia de los agentes que participan en los sistemas nacionales de innovación (SNI): universidades y centros de investigación, firmas, gobierno, así como el marco institucional bajo el cual interactúan estos agentes. Pero las formas específicas de interacción dependen de cada país. En el siguiente apartado se realiza un análisis por países.

Estimación y resultados del modelo por países: Estados Unidos, Japón, Corea del Sur y Alemania

Una vez presentado el análisis de los resultados del modelo de conteo a nivel general con base en la muestra de tamaño n=376 patentes se presenta, en este apartado, un análisis por países, en particular, de los países que mayores esfuerzos realizan en la actividad inventiva de este nuevo paradigma tecnológico: Estados Unidos, Japón, Corea del Sur y Alemania. El propósito del análisis es ubicar los factores que influyen en la difusión de la nanotecnología generadas por la actividad inventiva de estos países. Se suscribe la hipótesis de que, tales factores, tienen que ver con la forma en que los sistemas nacionales de innovación (SNI) de estos países están articulados. 
A partir de una muestra de 1257 patentes asignadas en el campo tecnológico de nanotecnología (clase 977) en la Oficina de Marcas y Patentes de los Estados Unidos (USPTO), se realizó el análisis estadístico de las variables del modelo. Así, en el cuadro 3.17, se presentan las medidas descriptivas de las patentes. Se observa que la variable citas hacia adelante, Difnan, tiene una media de 19.8, lo que indica que, en promedio, cada una de las patentes asignadas en nanotecnología de Estados Unidos recibe 19.8 citas, dato que está por arriba del promedio global, 12.5 citas. Sin embargo, un porcentaje reducido de patentes recibe muchas citas, máximo 335, y un porcentaje alto de patentes no ha recibido citas. La desviación estándar es de 36.22, lo que es superior a la media por 16.42. Esto describe la siguiente distribución. 


\section{Gráfica 3.23. Estados Unidos: distribución de la variable número de citas hacia a delante, Difnan}

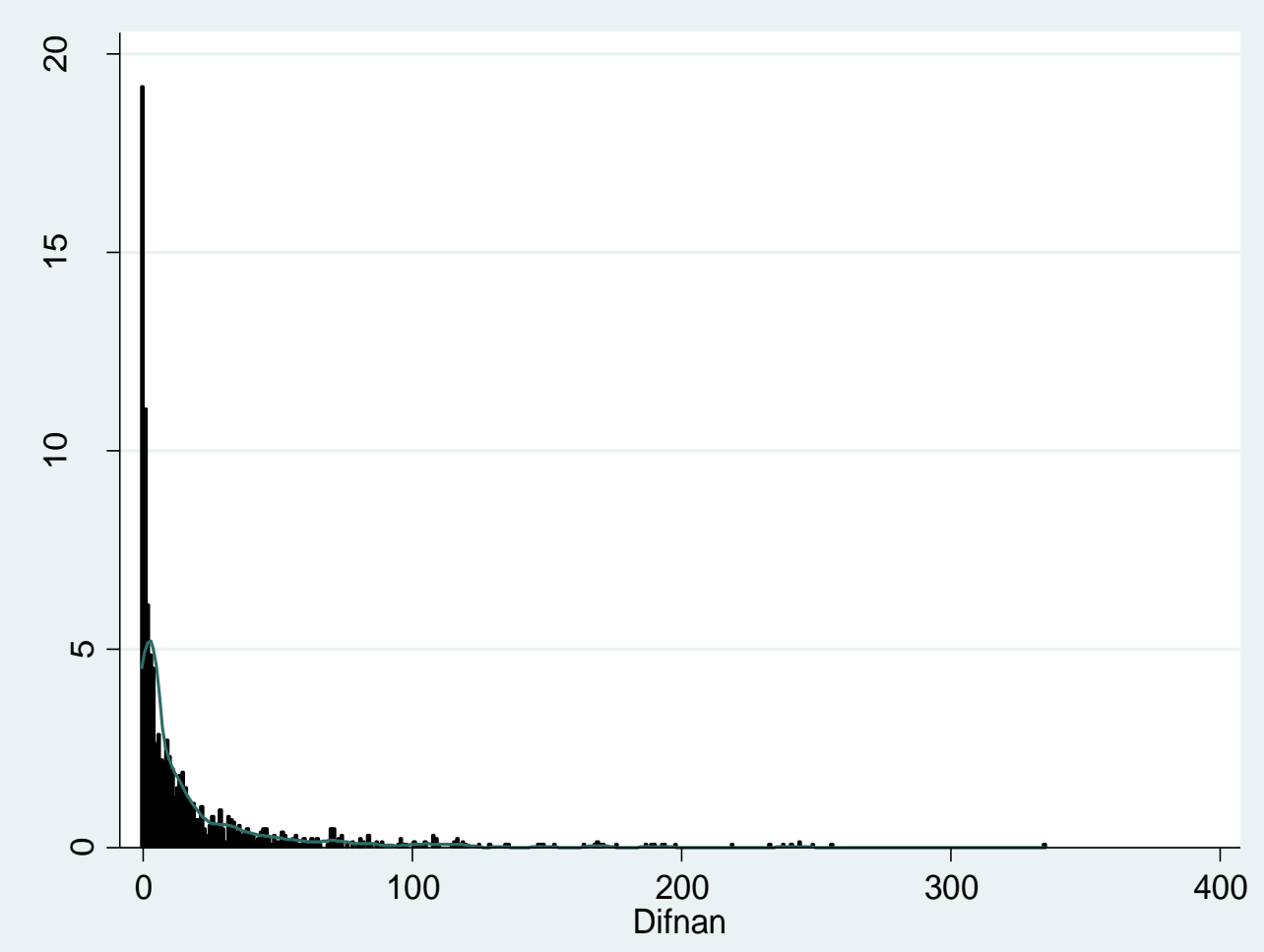

Fuente: elaboración propia con base en USPTO.

En cuanto al número de reivindicaciones, $\mathrm{Cl}$, en promedio, cada patente asignada en nanotecnología recibe 22.6 reivindicaciones, valor por encima del promedio global, 20.8. Hay patentes que reciben muchas reivindicaciones, 240 máximo, y otras que no tienen reivindicaciones. La desviación estándar es de 19.4, es decir, menor que la media, lo que describe una distribución concentrada alrededor de la media. La variable movilidad internacional de los inventores, MobIn, es dummy, y muestra que las patentes que tienen esta característica son pocas, solo 5. Este último dato, sugiere que mientras que a nivel mundial la movilidad internacional es un factor importante en la difusión del NPN, en el caso de Estados Unidos no lo es, lo que supone la forma peculiar en que interactúan los agentes del SNI de este país. La participación de las firmas en la actividad inventiva en nanotecnología, Firminv, es importante, ya que, de las 1257 patentes, 776 registran participación de las firmas, por lo que es una variable significativa para el modelo. Las variables dispersión media, Medisp, y 
dispersión baja, Disper, reflejan grados de amplitud de la patente con base en el índice de generalidad tecnológica propuesto por Trajtenberg et al. (2006) y también son variables relevantes que explican la difusión de la nanotecnología. En el siguiente cuadro se presentan, en forma resumida, estas medidas descriptivas.

\section{Cuadro 3.17. Estados Unidos: Medidas descriptivas de las patentes}

\begin{tabular}{llllll}
\hline Variable & Obs & Mean & Std. Dev. & Min & Max \\
\hline difnan & 1257 & 19.83453 & 36.22826 & 0 & 335 \\
cl & 1257 & 22.65712 & 19.46971 & 0 & 240 \\
mobin & 1257 & 0.09228 & 0.40033 & 0 & 5 \\
firminv & 1254 & 0.61882 & 0.48587 & 0 & 1 \\
medisp & 1257 & 0.32538 & 0.46870 & 0 & 1 \\
disper & 1257 & 0.22832 & 0.41992 & 0 & 1 \\
Fuente: elaboración propia con base en USPTO. & & &
\end{tabular}

Estimación del modelo y resultados

El modelo de conteo supone que los valores de la variable dependiente, en este caso el número de citas hacia adelante, Difnan, se distribuyen como una función de tipo Poisson, la cual se supone que es una función simétrica y, por ello, la media es igual a la varianza. Sin embargo, en la práctica, este tipo de datos no logra cumplir este supuesto y presentan, por lo general, el problema de sobredispersión. Este problema se corrige ajustando los datos a otra función de distribución conocida como binomial negativa. Además, otro problema que presentan los modelos no lineales y, en particular los de conteo, es la heteroscedasticidad, es decir, que la varianza de los errores no es constante. Para corregir este problema se estima un modelo que incorpora robustez en los errores estándar. Al realizar estos cálculos únicamente los parámetros de las variables $\mathrm{Cl}$, Medisp y Disper resultaron significativos con un p-valeu menor que 0.05. Al realizar la estimación del modelo binomial negativo mejoró el ajuste de los datos, ya que los valores de todos los parámetros estimados fueron significativos. En el cuadro 3.18 se presentan los resultados de las estimaciones del modelo Poisson y binomial negativo. 
Cuadro 3.18. Estados Unidos: resultados de los modelos Poisson y binomial negativo

\begin{tabular}{|l|l|l|}
\hline Variables & Poisson & binomial negativo \\
\hline Constante & 2.6 & 2.27 \\
& $(0.000)$ & $(0.000)$ \\
\hline Cl & 0.007 & 0.01 \\
& $(0.000)$ & $(0.000)$ \\
\hline MobIn & -0.22 & -0.24 \\
& $(0.070)$ & $(0.028)$ \\
\hline Firminv & 0.12 & 0.38 \\
& $(0.243)$ & $(0.000)$ \\
\hline Medisp & 0.61 & 0.64 \\
& $(0.000)$ & $(0.000)$ \\
\hline Disper & -0.83 & -0.96 \\
& $(0.003)$ & $(0.000)$ \\
\hline
\end{tabular}

Fuente: elaboración propia con base en las estimaciones de los modelos Poisson y binomial negativo.

Interpretación de los parámetros estimados

La estimación de los efectos marginales permite la interpretación de los parámetros estimados por el modelo. En el cuadro 3.19 se presentan estos resultados. Así, para el caso de Estados Unidos, un aumento en una unidad del número de reivindicaciones que reciben las patentes esto es, de una novedad reconocida en las patentes asignadas en nanotecnología - aumenta el número de citas que reciben, en promedio, en 0.23. Esto sugiere que un factor que explica la difusión de los nuevos conocimientos generados en este paradigma tecnológico es, específicamente, la novedad del conocimiento patentado.

Otro factor es la movilidad internacional de los inventores, MobIn, que representa los vínculos entre inventores a nivel internacional, lo cual también es un canal de difusión de un paradigma tecnológico. Los efectos marginales indican que, en este caso, si hay movilidad internacional de los inventores, el número de citas que reciben las patentes asignadas en nanotecnología es 4.019 menor que en aquellas patentes que no hay movilidad internacional. Este resultado es interesante, porque sugiere que, en Estados Unidos, la movilidad internacional de los inventores no es un factor determinante de la difusión de este nuevo paradigma tecnológico. El valor promedio del rezago temporal de cita de las patentes de este país es de 1.5 años, lo que confirma que este nuevo paradigma tecnológico se difunde, de Estados Unidos hacia el mundo, a gran velocidad. En este sentido, otro factor que incide de forma importante en la difusión de la nanotecnología es la participación de las firmas en la 
actividad inventiva en este campo tecnológico. Así, si hay participación de firmas en las patentes, el número de citas promedio que reciben las patentes asignadas en nanotecnología es 6.18 mayor que en aquellas patentes donde no participan las firmas. En Estados Unidos la innovación en nanotecnología parece guardar mucho interés para las firmas, posiblemente por sus enormes expectativas de aplicación económica y comercial. Por último, la misma amplitud que tienen los nuevos conocimientos generados bajo este paradigma tecnológico parece ser un factor que favorece su difusión, ya que las patentes con amplitud media, Medisp, $(0.34 \leq \mathrm{IGT} \leq 0.66)$ inciden de forma más importante en la difusión de los nuevos conocimientos en nanotecnología que aquellas patentes que tienen amplitud baja, Disp, $(0 \leq \mathrm{IGT} \leq 0.33)$.

Los resultados del modelo confirman que, en el caso de Estados Unidos, la difusión del NPN ocurre en forma amplia, abarcando varios sectores tecnológicos como los de biotecnología, química, farmacéutica, eléctrica y electrónica, computación, entre otros, sectores con enormes posibilidades de uso económico o comercial, de ahí las expectativas que genera para las firmas. También, los resultados confirman la importancia de las políticas promovidas por el gobierno para impulsar el desarrollo de la nanotecnología, tal como la Iniciativa Nacional en Nanotecnología (INN). Lo que supone, a su vez, la articulación de los agentes que participan en el sistema nacional de innovación de este país: gobierno, firmas, universidades y centros de investigación.

Cuadro 3.19. Estados Unidos: estimación del modelo de conteo ( $n=1257)$

\begin{tabular}{lll}
\hline Variables & binomial negativo (efectos marginales) & $\mathbf{P > \mathbf { z }}$ \\
\hline $\mathrm{cl}$ & 0.2320065 & 0.000 \\
mobin & -4.01977 & 0.031 \\
firminv & 6.182374 & 0.001 \\
medisp & 12.13351 & 0.000 \\
disper & -12.68341 & 0.000 \\
\hline
\end{tabular}

Fuente: elaboración propia con base en resultados del modelo. 
Japón

Con base en 1605 patentes asignadas en el campo tecnológico de nanotecnología (clase 977) en la USPTO extraídas de la población de estudio (18 414 patentes), se realizó el análisis descriptivo de las variables del modelo de conteo para el caso de Japón. De esta forma, en el cuadro 3.20 se presentan las medidas descriptivas de la variable número de citas hacia adelante, Difnan. En promedio, cada una de las patentes asignadas en nanotecnología recibe 9.6 citas, valor que está por de debajo del promedio global, 12.5 citas, y del promedio de las patentes de Estados Unidos en nanotecnología, 19.8 citas. No obstante, hay algunas patentes que reciben muchas citas (189 máximo) y patentes que reciben pocas o ninguna cita (0 mínimo). En ambos extremos se hallan patentes que reciben citas. La desviación estándar es de 17.06, lo que describe una distribución “cargada" hacia el lado derecho de la media y con una larga cola hacia la derecha de la media, tal como se observa en la gráfica 3.24. 


\section{Gráfica 3.24. Japón: distribución de la variable número de citas hacia adelante,}

Difnan

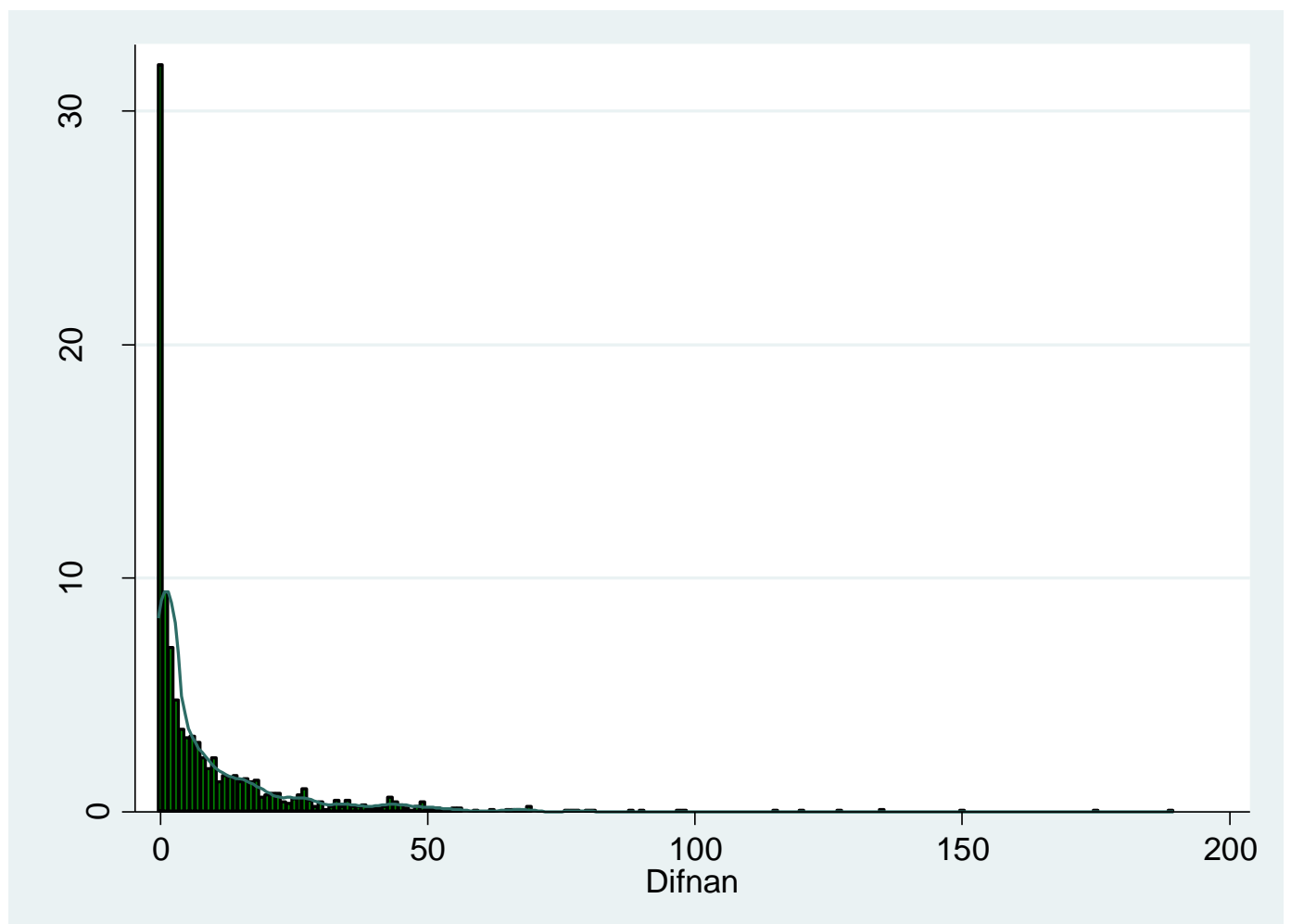

Fuente: elaboración propia con base en USPTO.

En cuanto a la variable número de reivindicaciones (claims) se observa que, en promedio, cada una de las patentes asignadas en el campo tecnológico de nanotecnología recibe 14.3 reivindicaciones, valor por debajo de las reivindicaciones que reciben las patentes a nivel global, 20.8, así como de las reivindicaciones que reciben las patentes de Estados Unidos, 22.6. No obstante, algunas patentes reciben muchas (199 reivindicaciones) y otras no reciben. La desviación estándar es de 12.63, valor por debajo del valor promedio, lo que describe una distribución donde los datos se concentran alrededor de la media.

En cuanto a la movilidad internacional de los inventores, MobIn es una variable dummy, por lo que las medidas descriptivas no permiten observar su distribución. Sin embargo, cabe señalar que solo el $1.4 \%$ de las patentes de Japón registran la presencia de inventores extranjeros. Esto sugiere que la movilidad internacional de los inventores para este país no representa una variable significativa que incida en la actividad inventiva y difusión del 
conocimiento generado en este paradigma tecnológico. La aplicación del modelo de conteo confirmará está hipótesis. Por otro lado, también sugiere que el sistema nacional de innovación de Japón crea los agentes (científicos e inventores) que requiere la actividad inventiva en nanotecnología, por lo que la participación de inventores extranjeros es escasa.

En cuanto a la participación de las firmas en las patentes asignadas en este nuevo paradigma tecnológico, Firminv, de igual forma, las medidas descriptivas no permiten observar su distribución porque se trata de una variable dummy. Sin embargo, es importante señalar que la participación de las firmas en este paradigma tecnológico es fundamental, ya que participan en un $91.6 \%$. Esto sugiere el potencial que tiene el NPN en cuanto a las elevadas expectativas de su uso comercial, por lo que atrae de manera importante a las firmas. Esto último se confirma al analizar la amplitud de las patentes asignadas en nanotecnología a través del índice de generalidad tecnológica (IGT) propuesto por Trajtenberg et al. (2006). En el cuadro 3.21 se presentan dos medidas al respecto: la amplitud media, Medisp, donde se ubican las patentes con un valor del IGT entre 0.34 y 0.66 ; y la amplitud baja, Disper, donde se ubican las patentes con un valor del $I G T$ entre 0 y 0.33 . En cuanto a la primera, se observa que, en promedio, cada una de estas patentes tiene un $I G T$ de 0.21 y una desviación estándar de 0.41 , valores que se hallan dentro de los límites del intervalo definido. La variable Disper registra un promedio de 0.34, pero este valor no pertenece al intervalo definido. Es decir, que en promedio, las patentes que se ubican en el rango de amplitud baja se distribuyen hacia la frontera de la amplitud media (ver cuadro 3.20). La amplitud de la patente refleja otra característica de un nuevo paradigma tecnológico, ya que muestra las posibles aplicaciones y usos de los nuevos conocimientos en diversos sectores tecnológicos.

Cuadro 3.20. Japón: Medidas descriptivas de las patentes

\begin{tabular}{llllll}
\hline Variable & Obs & Mean & Std. Dev. & Min & Max \\
\hline difnan & 1605 & 9.65481 & 17.06306 & 0 & 189 \\
$\mathrm{cl}$ & 1605 & 14.37321 & 12.63198 & 0 & 199 \\
mobin & 1605 & 0.01495 & 0.12643 & 0 & 1 \\
firminv & 1605 & 0.91651 & 0.27671 & 0 & 1 \\
medisp & 1605 & 0.21745 & 0.41264 & 0 & 1 \\
disper & 1605 & 0.34393 & 0.47516 & 0 & 1 \\
\hline \multicolumn{7}{l}{ Fuente: elaboración propia con base en USPTO. }
\end{tabular}


Estimación del modelo y resultados

Los resultados de los modelos Poisson y binomial negativo se presentan en el cuadro 3.22. Se observa que el modelo Poisson presenta problemas de significancia estadística a nivel de los parámetros estimados solo en la variable Firminv, con un valor del parámetro estimado de 0.14 y un $p$-valeu de 0.516 , es decir, mayor que 0.05 , por lo que no es significativo. Los parámetros estimados de las demás variables y la constante son significativos. También se corrigió el problema de heteroscedasticidad intrínseca al calcular un modelo con robustez en los errores. Por ello, los resultados de este modelo son aparentemente adecuados. Sin embargo, presenta problemas de sobredispersión, esto es, no satisface el supuesto de equidispersión implícito en la distribución de tipo Poisson que supone la variable dependiente Difnan. Así, el valor del parámetro alpha es de 1.9, es decir, distinto de 0 , por lo que se confirma que el ajuste del modelo Poisson no es pertinente.

Al estimar el modelo binomial negativo se logró un mejor ajuste de los datos, aunque el valor del parámetro Firminv sigue siendo no significativo con un p-valeu de 0.314, es decir, mayor que 0.05 pero menor que el p-valeu obtenido con el modelo Poisson (0.516). Así, aunque se logró reducir el grado de insignificancia, no es suficiente para que sea significativo. En cuanto al valor estimado de los parámetros de las demás variables del modelo se confirma que son significativos, pero con el ajuste del modelo binomial negativo se obtuvieron otros valores (ver cuadro 3.21).

Cuadro 3.21. Japón: resultados de los modelos Poisson y binomial negativo

\begin{tabular}{|l|l|l|}
\hline Variables & Poisson & binomial negativo \\
\hline Constante & 1.9 & 1.66 \\
& $(0.000)$ & $(0.000)$ \\
\hline Cl & 0.006 & 0.012 \\
& $(0.000)$ & $(0.000)$ \\
\hline MobIn & -0.19 & -1.59 \\
& $(0.000)$ & $(0.000)$ \\
\hline Firminv & 0.14 & 0.35 \\
& $(0.516)$ & $(0.314)$ \\
\hline Medisp & 0.94 & 0.95 \\
& $(0.000)$ & $(0.000)$ \\
\hline Disper & -1.49 & -1.50 \\
& $(0.000)$ & $(0.000)$ \\
\hline
\end{tabular}

Fuente: elaboración propia con base en los resultados de los modelos Poisson y binomial negativo. 
Interpretación de los parámetros estimados

De esta manera, con una muestra de 1605 patentes, los resultados del modelo de difusión del NPN para el caso de Japón se presentan en el cuadro 3.21. Se confirma que los principales factores que determinan la difusión de este nuevo paradigma tecnológico en este país son el número de reivindicaciones que reciben las patentes asignadas en nanotecnología, $\mathrm{Cl}$, la movilidad internacional de los inventores, MobIn, la amplitud media de las patentes asignadas en nanotecnología, Medisp, y la amplitud baja de éstas, Disper.

En el cuadro 3,22 se observan los valores de los efectos marginales. Así, al aumentar el número de reivindicaciones que reciben las patentes asignadas en nanotecnología, $\mathrm{Cl}$, en una unidad, el número de citas promedio que reciben las patentes en nanotecnología aumenta en 0.07, esto sugiere que el conocimiento novedoso contenido en la patente es un factor que incide en la difusión de este nuevo paradigma tecnológico en el caso de Japón. Por otro lado, si hay movilidad internacional de los inventores (MobIn) el número de citas promedio que reciben las patentes asignadas en nanotecnología es 9.98 menor que en aquellas patentes donde no hay movilidad internacional.

En cuanto a la participación de las firmas en las patentes asignadas en nanotecnología (Firminv), no pasó la prueba de significancia estadística. Sin embargo, de acuerdo con la base de datos se confirma que una buena parte de las patentes asignadas en nanotecnología (91\% del total) registran participación de las firmas. La falta de significancia estadística del parámetro estimado puede deberse a problemas de multicolinealidad. Otro factor importante que incide en la difusión de los nuevos conocimientos generados bajo este nuevo paradigma tecnológico es la amplitud de la patente, medida a través del índice de generalidad tecnológica propuesto por Trajtenberg et al (2006). Se observa que si la patente asignada en nanotecnología presenta una amplitud media (Medisp), es decir, un valor del IGT entre 0.34 y 0.66 , el número de citas promedio que reciben las patentes es de 8.15. En cambio, si la amplitud de la patente asignada es baja, es decir, un valor del $I G T$ entre 0 y 0.33 , el número de citas promedio que reciben las patentes asignadas en este campo tecnológico es 8.17 menor que en aquellas patentes que no son de amplitud baja. Este resultado sugiere que la amplitud de la patente es un factor que incide de manera importante en la difusión de los nuevos conocimientos generados en este 
paradigma tecnológico. Se confirma que, a mayor amplitud de la patente, mayor difusión, esto es, que se refuerza el proceso de difusión del nuevo paradigma en el caso de Japón.

Cuadro 3.22. Japón: estimación del modelo de conteo (n=1605)

\begin{tabular}{lll}
\hline Variables & binomial negativo (efectos marginales) & $\mathbf{P}>\mathbf{z}$ \\
\hline $\mathrm{cl}$ & 0.0776406 & 0.004 \\
mobin & -9.984509 & 0.000 \\
firminv & 1.91524 & 0.243 \\
medisp & 8.15049 & 0.000 \\
disper & -8.176256 & 0.000 \\
\hline
\end{tabular}

Fuente: elaboración propia con base en resultados del modelo binomial negativo.

\section{Corea del Sur}

A partir de 752 patentes asignadas en el campo tecnológico de nanotecnología (clase 977) tomadas de la población de estudio (18 414 patentes), se realizó el análisis descriptivo de las variables del modelo de conteo para el caso de Corea del Sur. En el cuadro 3.24 se observa que, en promedio, cada una de las patentes asignadas en el campo tecnológico de nanotecnología pertenecientes a Corea del Sur recibe 3.6 citas, valor muy por debajo del promedio global, 12.5 citas, y de las patentes de Estados Unidos, 19.8 citas y de Japón, 9.6. Pocas patentes reciben muchas citas (199 máximo) y muchas patentes reciben pocas citas o ninguna. La desviación estándar es de 12.9 citas. Este comportamiento se observa en la gráfica 3.25 . 


\section{Gráfica 3.25. Corea del Sur: distribución de la variable número de citas hacia adelante, Difnan}

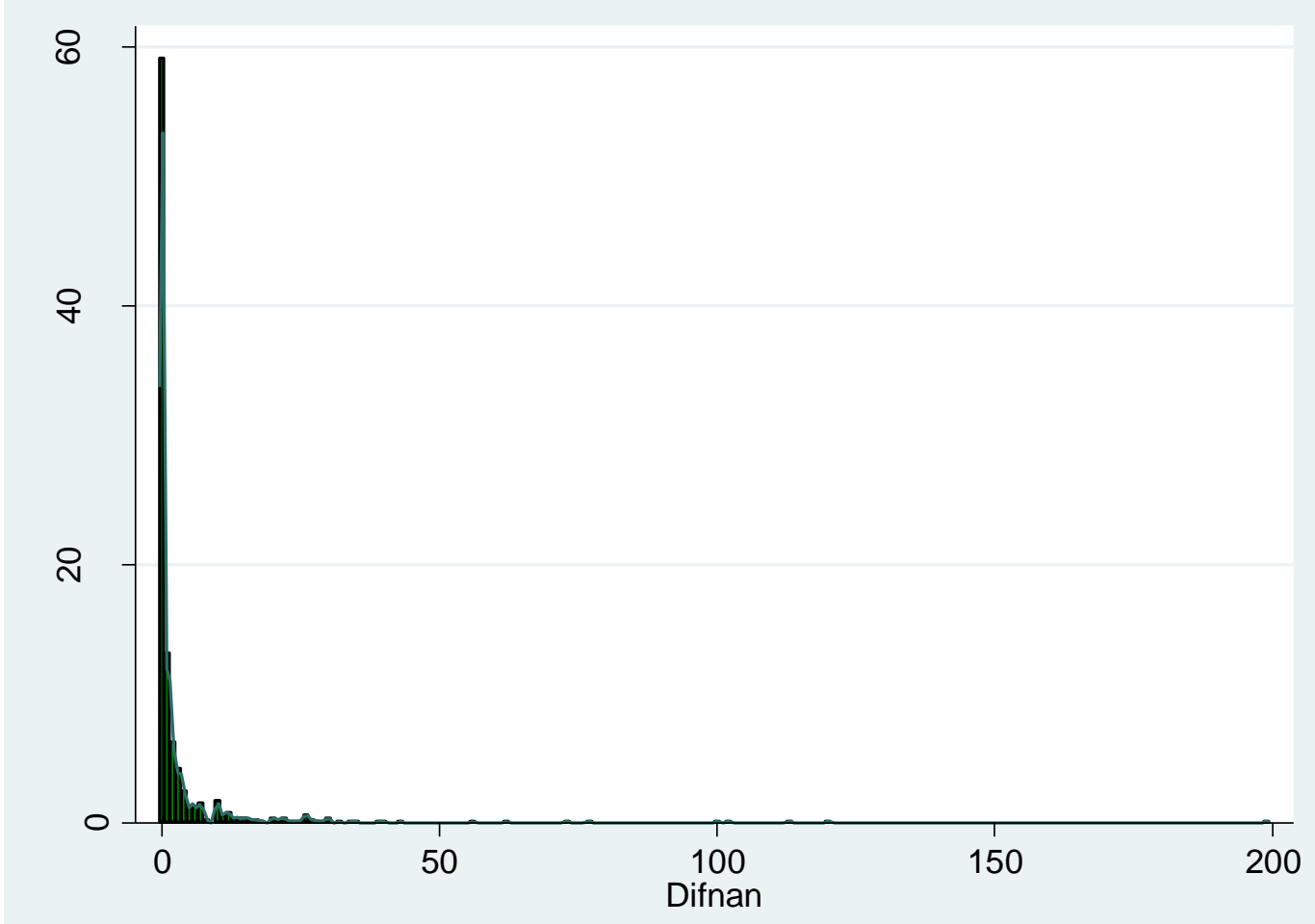

Fuente: elaboración propia con base en USPTO.

En cuanto al número de reivindicaciones o claims, las patentes de Corea del Sur reciben en promedio 13.6, valor por debajo del promedio global, 20.8, y de las patentes de Estados Unidos, 22.6, pero muy cercano al valor promedio de las patentes de Japón, 14.3. Algunas patentes reciben hasta 52 reivindicaciones y otras patentes pocas o ninguna. Su desviación estándar es de 7.5 por debajo del valor promedio, lo que sugiere que la distribución se haya muy concentrada alrededor del valor medio. En cuanto a la movilidad internacional de los inventores, MobIn es una variable dummy por lo que no es posible observar su distribución. Sin embargo, cabe señalar que solo el $1.4 \%$ de las patentes de este país registran movilidad internacional de los inventores, lo que sugiere la importancia del sistema nacional de innovación de Corea del Sur, en particular del sistema educativo, para generar los agentes (científicos e inventores) que se requieren para llevar a cabo la actividad inventiva bajo este nuevo paradigma tecnológico. Por otra parte, la participación de las firmas en las patentes 
asignadas en nanotecnología refleja las expectativas en cuanto a sus posibles aplicaciones y usos comerciales y, por lo tanto, los niveles de rentabilidad esperada. En este país, el $82.9 \%$ de las patentes asignadas en nanotecnologías tuvo participación de las firmas. El análisis de la amplitud de las patentes asignadas en este campo tecnológico confirma el amplio interés de las firmas. Al considerar aquellas patentes que se ubican en un rango del $I G T$ entre 0.34 y 0.66 se observa que, en promedio, cada una de las patentes pertenecientes a este rango presenta un valor del $I G T$ de 0.08 , lo que sugiere que hay muchas patentes que tienen un IGT cercano a 0.34. Mientras que el valor promedio de aquellas patentes que se ubican en el rango de amplitud baja, un valor del IGT entre 0 y 0.33 , presentan un valor promedio de amplitud alto, 0.63 . Esto sugiere que hay muchas patentes que se ubican en este rango y que, además, tienen un valor del $I G T$ cercano a 0.33 (ver cuadro 3.23).

\section{Cuadro 3.23.Corea del Sur: medidas descriptivas de las patentes}

\begin{tabular}{|c|c|c|c|c|c|}
\hline Variable & Obs & Mean & Std. Dev. & Min & Max \\
\hline difnan & 752 & 3.64096 & 12.97355 & 0 & 199 \\
\hline $\mathrm{cl}$ & 752 & 13.66090 & 7.57937 & 0 & 52 \\
\hline mobin & 752 & 0.01463 & 0.12014 & 0 & 1 \\
\hline firminv & 752 & 0.82979 & 0.39675 & 0 & 1 \\
\hline medisp & 752 & 0.08777 & 0.28314 & 0 & 1 \\
\hline disper & 752 & 0.63431 & 0.48194 & 0 & 1 \\
\hline
\end{tabular}

Fuente: elaboración propia con base en USPTO.

Estimación del modelo y resultados

En el caso de Corea del Sur también se estimó primero el modelo Poisson y se corrigió el problema de heteroscedasticidad intrínseca, pero no pasó la prueba de equidispersión, es decir, los datos se hayan sobre dispersos, por lo que el ajuste del modelo a los datos no es adecuado. Después, se estimó el modelo binomial negativo y se corrigió nuevamente el problema de heteroscedasticidad intrínseca y también el problema de sobre dispersión. Los resultados de ambos modelos se presentan en forma comparada en el cuadro 3.25.

Así, se observa que el parámetro estimado correspondiente a la variable número de reivindicaciones, $C l$, en ambos modelos resulto ser no significativo, con un $p$-valeu de 0.967 en 
el caso del modelo Poisson y de 0.819 en el caso del modelo binomial negativo. El parámetro correspondiente a la variable movilidad internacional de los inventores, MobIn, también resultó estadísticamente no significativo en ambos modelos, con un p-valeu de 0.296 y de 0.096, respectivamente. En cuanto al parámetro estimado de la variable Firminv, resulto significativo en el caso del modelo Poisson con un p-valeu de 0.001, pero en el caso del modelo binomial negativo resultó ser no significativo, con un p-valeu de 0.181. El parámetro de la variable amplitud media, Medisp, que considera un valor del IGT entre 0.34 y 0.66, resultó significativo en ambos modelos. Por último, el parámetro estimado de la amplitud baja de la patente, Disper, que considera un valor del $I G T$ entre 0 y 0.33 , también resultó significativo en ambos casos.

\section{Cuadro 3.24. Corea del Sur: resultados de los modelos Poisson y binomial negativo}

\begin{tabular}{|l|l|l|}
\hline Variables & Poisson & binomial negativo \\
\hline Constante & 1.16 & 1.03 \\
& $(0.000)$ & $(0.009)$ \\
\hline$C l$ & -0.0005 & 0.005 \\
& $(0.967)$ & $(0.819)$ \\
\hline MobIn & -0.55 & -1.82 \\
& $(0.296)$ & $(0.096)$ \\
\hline Firminv & 0.66 & 0.71 \\
& $(0.001)$ & $(0.181)$ \\
\hline Medisp & 1.001 & 0.99 \\
& $(0.000)$ & $(0.000)$ \\
\hline Disper & -1.74 & -1.72 \\
& $(0.000)$ & $(0.000)$ \\
\hline
\end{tabular}

Fuente: elaboración propia con base en los resultados de los modelos Poisson y binomial negativo.

Interpretación de los parámetros estimados

En el cuadro 3.25 se presentan los resultados de los efectos marginales. De esta forma, si hay movilidad internacional de los inventores en las patentes asignadas en nanotecnología, MobIn, el número promedio de citas que reciben las patentes asignadas en este campo tecnológico es 1.12 menor que en aquellas patentes donde no hay movilidad internacional. Este resultado sugiere que, al igual que en los casos de Estados Unidos y de Japón, si bien la movilidad internacional de los inventores es importante en la generación del nuevo conocimiento en este paradigma tecnológico, los agentes que participan de forma articulada en el SNI de Corea del Sur son el principal factor que genera el nuevo conocimiento en nanotecnología. Otro factor 
que incide de forma importante en la difusión de este nuevo paradigma tecnológico es la amplitud de la patente. Así, las patentes que tienen amplitud media, Medisp, con un valor del $I G T$ entre 0.34 y 0.66 , inciden en el número de citas promedio que reciben las patentes asignadas en este campo tecnológico en 3.07 más que aquellas patentes que no tienen amplitud media. Sin embargo, si la amplitud de las patentes es baja, Disper, es decir, con un IGT entre 0 y 0.33 , el número de citas promedio que reciben las patentes asignadas en nanotecnologías es 4.8 menor que en aquellas patentes que no tienen amplitud baja. Los parámetros de las variables número de reivindicaciones, $C l$, y participación de las firmas en las patentes asignadas en nanotecnologías, Firminv, resultaron no significativas al calcular los efectos marginales.

\begin{tabular}{lll}
\multicolumn{2}{l}{ Cuadro 3.25. Corea del Sur: estimación del modelo de conteo $(\mathbf{n}=\mathbf{7 5 2})$} \\
\hline Variables & binomial negativo (efectos marginales) & $\mathbf{P}>\mathbf{z}$ \\
\hline $\mathrm{cl}$ & 0.0103648 & 0.813 \\
mobin & -1.125021 & 0.048 \\
firminv & 1.408679 & 0.258 \\
medisp & 3.076602 & 0.014 \\
disper & -4.849662 & 0.000 \\
\hline
\end{tabular}

Fuente: elaboración propia con base en resultados del modelo binomial negativo.

\section{Alemania}

A partir de 325 patentes asignadas en el campo tecnológico de nanotecnología en la USPTO extraídas de la población de estudio (18 414 patentes) se observa que, en el caso de Alemania, cada patente recibe en promedio 7.12 citas (ver cuadro 3.27), valor que se ubica por debajo del promedio global (12.5), de Estados Unidos (19.8 citas) y de Japón (9.6 citas), pero por encima del de Corea del Sur (3.6). No obstante, hay patentes que reciben muchas citas (máximo 50) y patentes que reciben pocas o ninguna. La desviación estándar es de 11.5, lo que sugiere que la distribución de las citas hacia adelante presenta una larga cola hacia la derecha, tal como se observa en la siguiente gráfica. 


\section{Gráfica 3.26. Alemania: distribución de la variable número de citas hacia adelante, Difnan}

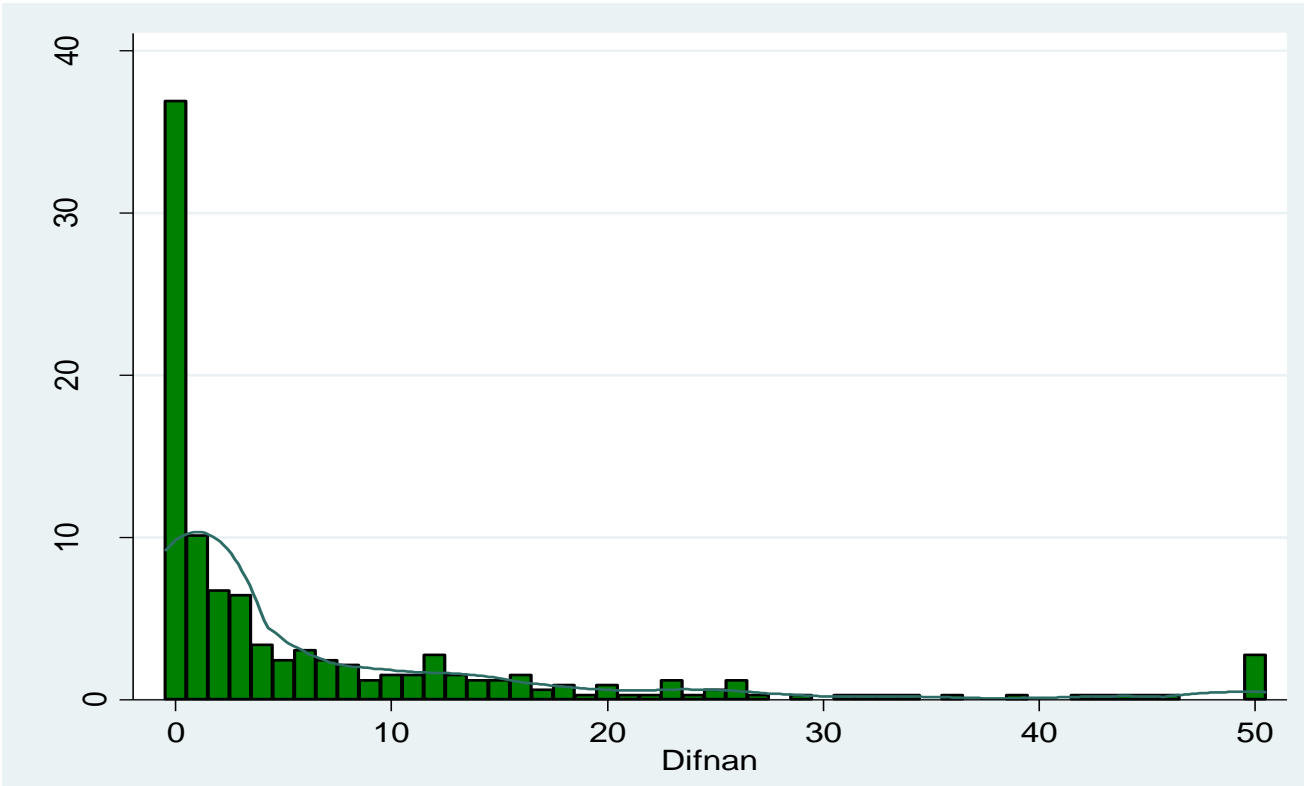

Fuente: elaboración propia con base en USPTO.

En cuanto al número de reivindicaciones se observa que, en promedio, cada patente de este país recibe 19.4. Pero hay patentes que aportan muchas novedades y reciben muchos claims (máximo 305) y otras que reciben pocas o al menos una. La desviación estándar es de 19.2, valor muy semejante al de la media. La variable movilidad internacional de los inventores es dummy y representa el $18.7 \%$ de la muestra, por lo que podría ser una variable significativa para explicar el patrón de difusión en el caso de Alemania. Algo semejante ocurre con la variable que se refiere a la participación de las firmas en las patentes asignadas en nanotecnología, donde el $95.3 \%$ de las patentes registran participación de firmas. Las amplitudes media y baja también podrían ser significativas (ver cuadro 3.26). 
Cuadro 3.26.Alemania: Medidas descriptivas de las patentes

\begin{tabular}{llllll}
\hline Variable & Obs & Mean & Std. Dev. & Min & Max \\
\hline difnan & 325 & 7.12923 & 11.57245 & 0 & 50 \\
cl & 325 & 19.45846 & 19.26622 & 1 & 305 \\
mobin & 325 & 0.18769 & 0.39107 & 0 & 1 \\
firminv & 325 & 0.95385 & 0.21014 & 0 & 1 \\
medisp & 325 & 0.16308 & 0.37001 & 0 & 1 \\
disper & 325 & 0.42769 & 0.49551 & 0 & 1 \\
\hline
\end{tabular}

Fuente: elaboración propia con base en USPTO.

Al realizar las estimaciones del modelo de conteo para el caso de Alemania, se eliminaron las variables no significativas y se corrigió el problema de heteroscedasticidad en el modelo Poisson. Sin embargo, como ocurrió en el caso de los otros países, el ajuste de los datos no es adecuado porque presenta problemas de sobredispersión, ya que el valor del parámetro alpha fue diferente de cero (2.6). Este problema se corrigió usando el modelo binonial negativo, lo que mejoró el ajuste de los datos, pero la significancia estadística de los parámetros estimados de las variables $C l$, MobIn, Firminv y Medisp, no tuvo mejoría, como lo indica el valor del $p$-valeu mayor que 0.05 , tal como se observa en el cuadro 3.27. Solo el valor del parámetro Disper resultó estadísticamente significativo. Aunque se amplió la muestra, los resultados no tuvieron mejoría. Esto puede deberse a varios motivos: i) existencia de muchos ceros en la variable explicada: ii) presencia de autocorrelación en las variables explicativas; iii) muchas variables explicativas definidas como dummys; iv) pocas observaciones. Se espera que las estimaciones mejoren al ampliar nuevamente la muestra y usando otro modelo de ajuste que considere el problema de la abundancia de ceros.

Cuadro 3.27. Alemania: resultados de los modelos Poisson y binomial negativo

\begin{tabular}{|l|l|l|}
\hline Variables & Poisson & binomial negativo \\
\hline Constante & 2.26 & 2.20 \\
& $(0.000)$ & $(0.001)$ \\
\hline Cl & 0.003 & 0.014 \\
& $(0.253)$ & $(0.293)$ \\
\hline MobIn & 0.23 & 0.13 \\
& $(0.512)$ & $(0.669)$ \\
\hline Firminv & -0.06 & -0.19 \\
& $(0.870)$ & $(0.762)$ \\
\hline Medisp & 0.08 & 0.08 \\
& $(0.638)$ & $(0.644)$ \\
\hline
\end{tabular}




\begin{tabular}{|l|l|l|}
\hline Disper & -1.20 & -1.26 \\
& $(0.000)$ & $(0.000)$ \\
\hline
\end{tabular}

Fuente: elaboración propia con base en los resultados de los modelos Poisson y binomial negativo.

Interpretación de los parámetros estimados

En el cuadro 3.28 se presentan los efectos marginales de las variables del modelo binomial negativo en el caso de Alemania. Así, el único valor que tiene sentido interpretar es el de la variable Disper, ya que fue el único estadísticamente significativo. El valor de este parámetro indica que, si la amplitud de las patentes asignadas en nanotecnología es baja, el número promedio de citas recibidas será de 7.3 menos que en aquellas patentes que no tienen amplitud baja. Esto sugiere que, a mayor amplitud de la patente, mayor posibilidad tendrá de difundirse.

Cuadro 3.28. Alemania: estimación del modelo de conteo $(n=325)$

\begin{tabular}{lll}
\hline Variables & binimial negativo (efectos marginales) & $\mathbf{P}>\mathbf{z}$ \\
\hline $\mathrm{cl}$ & 0.0840772 & 0.301 \\
mobin & 0.8383985 & 0.683 \\
firminv & -1.284812 & 0.782 \\
medisp & 0.5232008 & 0.653 \\
disper & -7.36966 & 0.000 \\
\hline Fuente: elaboración propia con base en estimaciones del modelo binomial negativo.
\end{tabular}

Fuente: elaboración propia con base en estimaciones del modelo binomial negativo.

A continuación se presenta un análisis comparativo de los resultados obtenidos con el modelo binomial negativo por país.

Análisis comparativo de la difusión de la nanotecnología en los países que mayores esfuerzos realizan en la actividad inventiva de este nuevo paradigma tecnológico (Estados Unidos, Japón, Corea del Sur y Alemania)

El cuadro 3.29 concentra los resultados del modelo de conteo binomial negativo de los países que mayores esfuerzos realizan en generar nuevos conocimientos en el paradigma tecnológico de nanotecnología. Los factores que inciden en la difusión de este paradigma tecnológico en cada uno de estos países son distintos. Esto define distintos patrones de difusión. De esta 
forma, la novedad reconocida en las patentes asignadas en este campo tecnológico, medida a través del número de reivindicaciones (claims), $\mathrm{Cl}$, tiene incidencia importante en Estados Unidos y Japón, pero no en Corea del Sur. En el caso de la movilidad internacional de los inventores, MobIn, incide en estos países, pero en forma menor que en aquellas patentes que no registran movilidad internacional de los inventores. Esto sugiere que los sistemas nacionales de innovación de cada uno de estos países generan los agentes que llevan a cabo la actividad inventiva y la difusión de este nuevo paradigma tecnológico. Cabe señalar que estos países se caracterizan por contar con sistemas nacionales de innovación articulados, donde los agentes que participan en ellos tales como las firmas, el gobierno, los centros de investigación (tanto públicos como privados) y las universidades trabajan de manera articulada, a diferencia de los sistemas nacionales de innovación de los países emergentes, los cuales se caracterizan por ser desarticulados (Albuquerque et al., 2011).

Otro elemento que caracteriza la difusión del NPN es que, en estos países, la participación de las firmas en la generación de los nuevos conocimientos en nanotecnología es fundamental. Aunque los resultados del modelo muestran que en los casos de Japón y de Corea del Sur los parámetros estimados correspondientes a esta variable fueron no significativos, lo cual puede deberse a problemas de multicolinealidad, la variable Firminv representa, en el caso de Japón, el 91\% del total de patentes de la muestra (1 605 patentes), mientras que, para el caso de Corea del Sur, representa el 82.9\% del total de la muestra (752 patentes). En el caso de Estados Unidos, donde el parámetro estimado correspondiente a esta variable sí es significativo, representa el $61.7 \%$ del total de la muestra (1 257 patentes). Claramente, la participación de las firmas en la generación y difusión de la nanotecnología es más importante en Japón que en Estados Unidos y Corea del Sur, pero en los tres países se mantiene esta tendencia. Por último, se observa que la amplitud de las patentes asignadas en este campo tecnológico incide de forma importante en la difusión de este nuevo paradigma tecnológico. En particular, la amplitud media, Medisp, definida como el valor del índice de generalidad tecnológica $(I G T)$ con valores entre 0.034 y 0.66 . A su vez, es claro que incide más en el caso de las patentes de Estados Unidos que en los de Japón y Corea del Sur. Igualmente, la incidencia de la amplitud baja, definido para las patentes con un IGT con valores entre 0 y 0.33, es menos importante para Estados Unidos que para Japón, Corea del Sur y Alemania. A su vez, es menos importante en Alemania que en Corea del Sur. 
Cuadro 3.29. Resultados del modelo de conteo: comparativo por países

\begin{tabular}{lllllllll}
\hline & \multicolumn{3}{l}{ Estados Unidos } & Japón & \multicolumn{3}{c}{ Corea del Sur } & \multicolumn{2}{c}{ Alemania } \\
\hline Variables & E.M. & $\mathbf{P}>\mathbf{z}$ & E.M. & P> $\mathbf{z}$ & E.M. & P> $\mathbf{z}$ & E.M. & P> z \\
\hline cl & 0.2320065 & 0.000 & 0.0776406 & 0.004 & 0.0103648 & 0.813 & 0.084077 & 0.301 \\
mobin & -4.01977 & 0.031 & -9.984509 & 0.000 & -1.125021 & 0.048 & 0.838399 & 0.683 \\
firminv & 6.182374 & 0.001 & 1.91524 & 0.243 & 1.408679 & 0.258 & 1.284812 & 0.782 \\
medisp & 12.13351 & 0.000 & 8.15049 & 0.000 & 3.076602 & 0.014 & 0.523201 & 0.653 \\
disper & -12.68341 & 0.000 & -8.176256 & 0.000 & -4.849662 & 0.000 & -7.36966 & 0.000 \\
\hline
\end{tabular}

Fuente: elaboración propia con base en los resultados del modelo binomial negativo por países.

El análisis presentado en el presente capítulo se puede resumir señalando los principales resultados obtenidos a nivel mundial (con base en la muestra de tamaño $n=376$ patentes) y a nivel de los países que mayores esfuerzos realizan en la actividad inventiva de este nuevo paradigma tecnológico. En cuanto al análisis a nivel mundial, uno de los resultados importantes es que este nuevo paradigma tecnológico se difunde a una velocidad promedio de 1.53 años. Es decir, que cada patente que se asigna en el campo tecnológico de nanotecnología es citada por otra patente, en promedio, después de año y medio.

En cuanto a su propagación por clases tecnológicas, se difunde en orden de magnitud en nanoestructura, biotecnología y química, a una velocidad promedio de 1.36, 1.57 y 1.8 años, respectivamente. Es decir, que nanoestructura es la que reporta mayor actividad inventiva y donde, al mismo tiempo, el nuevo conocimiento generado se difunde a mayor velocidad a nivel mundial. En cuanto a su propagación a nivel sectorial se confirma que las aplicaciones y uso de los nuevos conocimientos en nanotecnología es amplia, y ocurre en diversos sectores tecnológicos: química, biotecnología, mecánica, eléctrica y electrónica, computación y comunicaciones y medicamentos y medicinas, y otros. A su vez, la principal actividad inventiva se concentra en química, eléctrica y electrónica y medicamentos y medicinas con una participación de $36 \%, 32 \%$ y $15 \%$, respectivamente. De éstos, el sector que se difunde a mayor velocidad es química, con un lag time promedio de 1.33 años, mientras que medicamentos y medicinas se difunde a menor velocidad promedio de todos los sectores, 2.54 años. En contraste, el sector que reporta mayor velocidad de difusión de todos los sectores es computación y comunicaciones, ya que reporta un lag time promedio de 0.94 años. En cuanto a la propagación por países, los países que mayores esfuerzos realizan en la actividad inventiva 
en este nuevo paradigma tecnológico son aquellos que realizan mayores esfuerzos en $\mathrm{I}+\mathrm{D}$ a nivel mundial como porcentaje del PIB, es decir, Japón (3.5\%), Corea del Sur (3.4\%), Alemania (2.9\%) y Estados Unidos (2.7\%); le siguen otro grupo de países entre los que se encuentran Taiwán, Francia y Canadá, los cuales, si bien reportan menor actividad inventiva en este paradigma tecnológico, cuentan con un importante potencial basado en el conocimiento científico desarrollado por las universidades y, detrás de éstos, se ubican países como los BRIC, que muestran importante potencial en su capacidad científica, aunque aún se mantienen rezagados en la actividad inventiva en nanotecnología.

Por último, el modelo econométrico de conteo aplicado a nivel mundial indica que los principales factores que influyen en la difusión de este nuevo paradigma tecnológico a nivel de actividad inventiva son: el número de reivindicaciones (claims), la movilidad internacional de los inventores, la amplitud tecnológica medida a través del índice de generalidad tecnológica (IGT) y la participación del gobierno y de las firmas. Un resultado importante es que la participación de las firmas es más importante que la participación del gobierno en la difusión de la nanotecnología. En el cuadro 3.30 se presenta el resumen de este análisis.

\section{Cuadro 3.30. Patrones de difusión del NPTN a nivel mundial, 1983-2013}

\begin{tabular}{|c|c|c|c|c|c|}
\hline $\begin{array}{l}\text { Nivel de } \\
\text { estudio }\end{array}$ & $\begin{array}{l}\text { Velocida } \\
\text { d de } \\
\text { difusión }\end{array}$ & $\begin{array}{lr}\begin{array}{l}\text { Propagación } \\
\text { clases }\end{array} & \text { en } \\
\text { tecnológicas } & \text { y } \\
\text { velocidad } & \text { de } \\
\text { difusión } & \end{array}$ & $\begin{array}{lr}\begin{array}{l}\text { Propagación } \\
\text { sectores }\end{array} & \text { en } \\
\text { tecnológicos } & \text { y } \\
\text { velocidad } & \text { de } \\
\text { difusión } & \end{array}$ & $\begin{array}{l}\text { Propagación } \\
\text { espacial (países } \\
\text { con mayor } \\
\text { actividad } \\
\text { inventiva } \\
\text { difusión) }\end{array}$ & $\begin{array}{lll}\begin{array}{l}\text { Factores de la } \\
\text { difusión }\end{array} & & \end{array}$ \\
\hline Mundial & 1.53 años & $\begin{array}{l}\text { Nanoestructura } \\
(1.36) \\
\text { Biotecnología } \\
(1.57) \\
\text { Química (1.8) }\end{array}$ & $\begin{array}{l}\text { Química (1.33) } \\
\text { Biotecnología } \\
(1.64) \\
\text { Mecánica (1.33) } \\
\text { Eléctrica y } \\
\text { electrónica (1.41) } \\
\text { Computación y } \\
\text { comunicaciones } \\
(0.94) \\
\text { Medicamentos y } \\
\text { medicinas (2.45) } \\
\text { Otros (1.77) }\end{array}$ & $\begin{array}{l}\text { Estados Unidos } \\
\text { Japón } \\
\text { Corea del Sur } \\
\text { Alemania } \\
\text { Taiwán } \\
\text { Canadá } \\
\text { Francia } \\
\text { China } \\
\text { Gran Bretaña }\end{array}$ & $\begin{array}{l}\text { Reivindicaciones } \\
\text { (claims), } \\
\text { Mobilidad } \\
\text { internacional de } \\
\text { los inventores, } \\
\text { Amplitud } \\
\text { tecnológica (IGT) } \\
\text { Participación de } \\
\text { las firmas. } \\
\text { Participación del } \\
\text { gobierno. }\end{array}$ \\
\hline
\end{tabular}

Fuente: elaboración propia con base en resultados del modelo y USPTO.

A nivel de los países que mayores esfuerzos realizan en la actividad inventiva en nanotecnología a nivel mundial, se observa que este nuevo paradigma tecnológico se difunde a 
distintas velocidades: Estados Unidos (1.53 años), Japón (1.94 años), Corea del Sur (1 año) y Alemania (2.06 años). A su vez, el país que reportó mayor gasto total en $\mathrm{I}+\mathrm{D}$ en nanotecnología en 2013 fue Estados Unidos con \$1 405000 000, le siguieron Corea del Sur con \$7 687100 000, Alemania con \$1 549300000 y Japón con \$1 063000000 (ver cuadro 3.32).

A su vez, en cada uno de estos países las clases tecnológicas que difunden a mayor velocidad los nuevos conocimientos generados en este nuevo paradigma tecnológico son: nanoestructura (1.38 años) en Estados Unidos, nanoestructura (1.6 años) en Japón, biotecnología (0.6 años) en Corea del Sur y biotecnología y nanoestructura (1.5 años) en Alemania. Esto sugiere tendencias de especialización de estos países y, por lo tanto, características que dotan a estos países de distintas ventajas tecnológicas.

Sin embargo, cuando se analizan las clases que más difunden los nuevos conocimientos generados en este nuevo paradigma tecnológico en cada uno de estos países, medido a través del número de citas promedio que reciben las patentes asignadas en estas clases, la configuración cambia: Estados Unidos (nanoestructura), Japón (biotecnología), Corea del Sur (biotecnología y química) y Alemania (biotecnología). Solo en Estados Unidos y en Japón, las clases que más difunden son, al mismo tiempo, las que lo hacen a mayor velocidad (ver cuadro 3.31). Por sectores tecnológicos, los que más difunden son, para el caso de Estados Unidos: química, eléctrica y electrónica; en Japón: eléctrica y electrónica y química; en Corea del Sur: química; en Alemania: medicamentos y medicinas y eléctrica y electrónica (ver cuadro 3.31).

Con base en el análisis de la difusión (número de citas recibidas en promedio) y de la velocidad de difusión (lag time), se propuso una taxonomía de los patrones de difusión por países. Así, se distinguen los siguientes tipos de difusión: i) difusión alta-velocidad media (Estados Unidos, Japón y Alemania); ii) difusión baja-velocidad alta (Corea del Sur); iii) difusión alta-velocidad alta (Taiwán); iv) difusión media-velocidad media (Francia); v) difusión media-velocidad alta (China); y vi) difusión baja-velocidad baja (Gran Bretaña).

Ahora bien, para analizar los factores que determinan estos patrones de difusión, se propuso un modelo econométrico de conteo y se aplicó al grupo de países que mayores esfuerzos realizan en la generación de los nuevos conocimientos bajo el paradigma tecnológico de la nanotecnología. Así, se encontró que, para los casos de Estados Unidos, Japón y Corea del Sur, las principales variables que explican su patrón de difusión son: el número de 
reivindicaciones (claims), $\mathrm{Cl}$; aunque con incidencia baja, la movilidad internacional de los inventores, MobIn; la participación de las firmas en las patentes, Firminv; la amplitud media (Medisp) y baja (Disper) de la patente. Cabe señalar que, en el caso de Alemania, solo la variable Disper resultó estadísticamente significativa, lo que podría deberse al tamaño de la muestra, por lo que se podría corregir aumentando el tamaño de la muestra y aplicando otro modelo que considere el problema de exceso de ceros (ver cuadro 3.31).

Cuadro 3.31. Patrones de difusión del nuevo paradigma tecnológico, nanotecnologías, a nivel de países que mayores esfuerzos realizan en su promoción

\begin{tabular}{|c|c|c|c|c|}
\hline Nivel de estudio & $\begin{array}{l}\text { Velocidad } \\
\text { promedio } \\
\text { (años) }\end{array}$ & $\begin{array}{l}\text { Clases tecnológicas } \\
\text { que difunden a mayor } \\
\text { velocidad (años) }\end{array}$ & $\begin{array}{l}\text { Sectores } \\
\text { tecnológicos } \\
\text { que más } \\
\text { difunden }\end{array}$ & $\begin{array}{l}\text { Factores que más influyen } \\
\text { en la difusión }\end{array}$ \\
\hline Estados Unidos & 1.53 & Nanoestructura (1.38) & $\begin{array}{l}\text { Química } \\
\text { Eléctrica } \\
\text { electrónica }\end{array}$ & $\begin{array}{l}\text { Número de reivindicaciones } \\
\text { (claims) } \\
\text { Movilidad internacional de } \\
\text { los inventores } \\
\text { Participación de las firmas } \\
\text { Amplitud tecnológica (IGT) }\end{array}$ \\
\hline Japón & 1.94 & Nanoestructura (1.6) & $\begin{array}{l}\text { Eléctrica y } \\
\text { electrónica } \\
\text { Química }\end{array}$ & $\begin{array}{l}\text { Número de reivindicaciones } \\
\text { (claims) } \\
\text { Movilidad internacional de } \\
\text { los inventores } \\
\text { Participación de las firmas } \\
\text { Amplitud tecnológica (IGT) }\end{array}$ \\
\hline Corea del Sur & 1 & Biotecnología (0.6) & Química & $\begin{array}{l}\text { Número de reivindicaciones } \\
\text { (claims) } \\
\text { Movilidad internacional de } \\
\text { los inventores } \\
\text { Participación de las firmas } \\
\text { Amplitud tecnológica (IGT) }\end{array}$ \\
\hline Alemania & 2.06 & $\begin{array}{ll}\text { Nanoestructura } & \text { y } \\
\text { Biotecnología (1.5) } & \end{array}$ & $\begin{array}{l}\text { Medicamentos } \\
\text { y medicinas } \\
\text { Eléctrica y } \\
\text { electrónica }\end{array}$ & Amplitud tecnológica (IGT) \\
\hline
\end{tabular}

Fuente: elaboración propia con base en resultados del modelo de conteo y USPTO.

A nivel de firmas, las que más difunden este nuevo paradigma tecnológico se ubican, a nivel mundial, en los sectores de química, eléctrica y electrónica y medicamentos y medicina, con 56, 32 y 14 patentes asignadas en el campo tecnológico de nanotecnología, lo que representa, en conjunto, el $27.1 \%$ del total de patentes de la muestra de tamaño $n=376$. A nivel de países que mayores esfuerzos llevan a cabo en la actividad inventiva en nanotecnología, el 
país que reportó en el año 2013 mayor número de firmas fue Estados Unidos con 10 341, le sigue Alemania con 1 110, Corea del Sur con 504 y Japón con 225 firmas.

Cuadro 3.32. Difusión del NPTN a nivel de firmas en los países promotores

\begin{tabular}{|l|l|l|l|l|}
\hline País & $\begin{array}{l}\text { Gasto en I\&D en } \\
\text { nanotecnología** }\end{array}$ & $\begin{array}{l}\text { Número total de } \\
\text { firmas } \\
\text { nanotecnología }\end{array}$ & $\begin{array}{l}\text { Firmas } \\
\text { especializadas en } \\
\text { nanotecnología }\end{array}$ & $\begin{array}{l}\text { Firmas pequeñas } \\
\text { en } \\
\text { nanotecnología*** }\end{array}$ \\
\hline Estados Unidos & 14054 & 10341 & 139 & 7531 \\
\hline Japón & 1063 & 225 & ND* & ND* \\
\hline Corea del Sur & 7687.1 & 504 & 173 & 312 \\
\hline Alemania & 1549.3 & 1110 & 300 & 800 \\
\hline
\end{tabular}

Fuente: elaboración propia con base en OCDE.

Notas:*el dato de Japón no está disponible. **El gasto en I\&D en nanotecnología está en millones de dólares correspondiente al año 2013. ***Se consideran firmas pequeñas aquellas que tienen menos de 50 empleados.

Por último, se presenta una descripción esquemática de la difusión del NPN a nivel mundial.

Trayectoria de la difusión del NPN a nivel de actividad inventiva

En la gráfica 3.27 se describe, en forma esquemática, la trayectoria de la difusión de la nanotecnología. Se observan tres grupos de países ubicados en distintas fases de la trayectoria de difusión. En la parte superior, se ubica el primer grupo liderado por Estados Unidos y seguido de Japón, Corea del Sur y Alemania. Este grupo se ubica en una fase en la que, si bien la actividad inventiva en nanotecnología mantiene una tendencia creciente, el ritmo de crecimiento de la difusión de los nuevos conocimientos generados en este paradigma tecnológico comienza a disminuir, al mismo tiempo en que se da la convergencia con otros paradigmas, lo cual, se expresa a través de los nuevos productos y procesos. En esta fase, el reto es mantener, por un lado, la tendencia creciente en la actividad inventiva y, por otro lado, promover la comercialización de los productos. Esto último, sugiere la atracción de la inversión privada en aquellos sectores lucrativos al mismo tiempo en que la participación del gobierno va cediendo su lugar a las firmas. En esta fase de la difusión, también pueden empezar a vislumbrarse las posibles ventanas de oportunidad para los países seguidores inmediatos. 
El segundo grupo se halla liderado por Taiwán, país que incrementa sus esfuerzos en I+D dedicados a nanotecnología, así como su potencial en investigación científica y tecnológica en este paradigma tecnológico. Esto se traduce en un crecimiento acelerado de la actividad inventiva en nanotecnología así como en la difusión de los nuevos conocimientos generados. Estas condiciones, lo colocan como un potencial competidor del primer grupo de países y tiende a unirse con ellos en los próximos años. A Taiwán lo siguen países como Francia y Canadá que, aunque también mantienen una tendencia creciente en los esfuerzos dedicados a la investigación y desarrollo en nanotecnología, lo hacen a menor ritmo que Taiwán. Si bien estos países muestran un importante potencial en la actividad inventiva en nanotecnología, falta incrementar la actividad inventiva. Esto se expresa en el número de patentes relativamente bajo, aunque con tendencia creciente. La difusión de los nuevos conocimientos generados en Francia y Canadá en este paradigma es media, así como su velocidad.

En el último grupo de países se ubican los BRIC (Brasil, Rusia, India y China). De acuerdo con nuestro análisis, China se ubica como líder de este grupo ya que los esfuerzos realizados en investigación y desarrollo son notablemente mayores que en los demás países. Esto se ve reflejado en una mayor actividad inventiva en nanotecnología y un ritmo creciente en el número de patentes. Además, sus esfuerzos en otros aspectos lo favorecen: cambios institucionales y en los derechos de propiedad intelectual, acuerdos comerciales, movilidad internacional de los inventores, acuerdos de colaboración con otros países, entre otros. Por estas condiciones, China tiende a ubicarse en el segundo grupo en los próximos años y tal vez se ubique rápidamente en el primer grupo. Sin embargo, aún requieren mejorar las condiciones que potencien y hagan crecer la actividad inventiva en nanotecnología. Su difusión es media, pero su velocidad de difusión es alta. Los demás países: Brasil, Rusia e india, también muestran un incremento en sus esfuerzos en investigación y desarrollo dedicado a nanotecnología, pero menor que China, lo que se expresa en su baja actividad inventiva en este paradigma, pero creciente potencial en investigación científica en nanotecnología. No obstante, estos países se caracterizan por tener sistemas nacionales de innovación desarticulados, por lo que requieren mayores esfuerzos no solo en el impulso a la investigación y desarrollo en nanotecnología sino, también, en los cambios institucionales pertinentes para articular los agentes que participan en la actividad inventiva en nanotecnología (ver gráfica 3.27). 


\section{Gráfica 3.27. Trayectoria de la difusión de la nanotecnología}

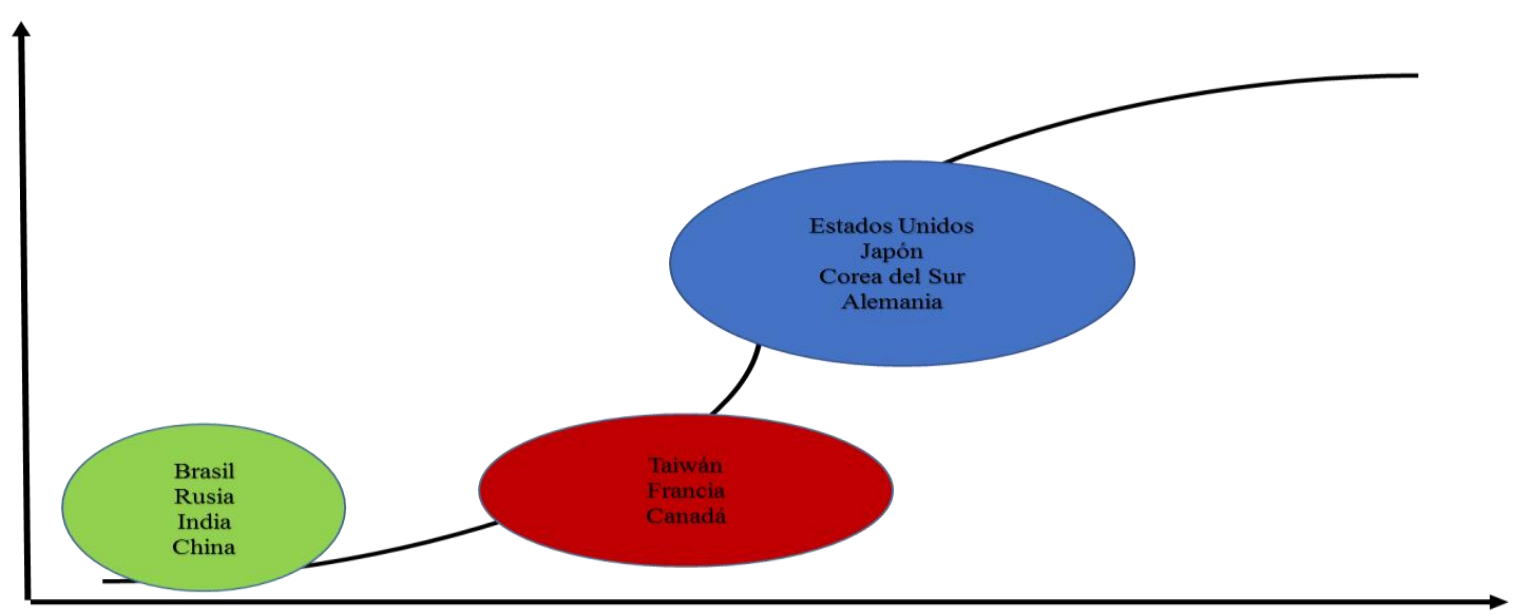

Fuente: elaboración propia.

Ahora bien, es plausible preguntarse si estos países podrán cerrar la brecha que los separa del liderazgo que mantiene Estados Unidos en la actividad inventiva en nanotecnología y, si es posible, bajo qué condiciones. En el siguiente capítulo se presenta este análisis. 


\section{Capítulo 4}

\section{¿Es posible la convergencia tecnológica y de innovación entre países en el nuevo paradigma de nanotecnología?}

En el tercer capítulo se identificaron tres grupos de países que se caracterizan por la actividad inventiva y difusión del nuevo paradigma de nanotecnología (NPN). En el primer grupo se ubican Estados Unidos, Japón, Corea del Sur y Alemania, países que dedican mayores esfuerzos a la actividad inventiva en nanotecnología (medido por el gasto en I+D destinado a este sector y por el número de patentes asignadas en la clase 977 de la USPTO) así como en la difusión de los nuevos conocimientos tecnológicos generados en nanotecnología (medido por el número de citas que reciben sus patentes). Se estimó y analizó su velocidad de difusión, así como su difusión sectorial y hacia el resto del mundo. En un segundo grupo de países se ubican Taiwán, Francia y Canadá, los cuales, si bien presentan menores esfuerzos en I+D dedicados a la actividad inventiva en nanotecnología (lo que se expresa en menor número de patentes asignadas en este sector que los países del primer grupo), tienen un importante potencial a nivel de conocimiento científico generado por la universidades, ubicándose en condiciones de aprovechar las posibles ventanas de oportunidad abiertas por la evolución de este paradigma tecnológico. Por último, se hizo un análisis de un grupo de países emergentes: Brasil, Rusia, India y China (BRIC) que se caracterizan por sus elevadas tasas de crecimiento económico, por lo menos en los últimos diez años, así como por su creciente gasto en I+D a nivel nacional y su impulso a las nanociencias y nanotecnologías a través de iniciativas de política que tienen como propósito explícito incentivar la actividad inventiva en este sector. Cabe señalar que estos países presentan limitada actividad inventiva (medida en número de patentes asignadas en nanotecnología), pero sus iniciativas y mejoras en el funcionamiento de sus sistemas nacionales de innovación, cambios institucionales y mayor financiamiento para incentivar la actividad inventiva en este nuevo paradigma los coloca con un importante potencial para aprovechar las posibles ventanas de oportunidad abiertas por la evolución de este paradigma en el contexto de los países menos desarrollados (Niosi y Reid, 2007).

Es importante señalar, que el estudio de los factores que determinan la difusión hacia el resto del mundo se realizó con base en un modelo econométrico de conteo que solo se aplicó al 
primer grupo de países debido a dos motivos: i) porque estos países dedican mayores esfuerzos en la actividad inventiva en nanotecnología; ii) porque, aunado a lo anterior, cuentan con mayor número de patentes asignadas en este sector y, por lo tanto, cuentan con mayor información disponible para identificar y estudiar los posibles factores que determinan los patrones de difusión. Con base en esta información, se propuso una taxonomía de los patrones de difusión ubicando en ella a los diferentes países.

Las diferencias entre estos grupos de países en cuanto a la actividad inventiva en nanotecnología y su difusión da pie a complementar el análisis de los patrones de difusión desde la perspectiva de brechas tecnológicas y de innovación entre países. De esta forma, es pertinente la siguiente pregunta: ¿es posible la convergencia tecnológica y de innovación entre países en el nuevo paradigma de nanotecnología? La respuesta a esta pregunta complementaría la información y el análisis acerca de los patrones de difusión presentados en el tercer capítulo. Con el propósito de responder esta pregunta se propone un modelo de convergencia, pero, antes de especificar el modelo, se realiza un diagnóstico de las brechas de innovación en nanotecnología entre países. En el siguiente apartado se presenta este diagnóstico. 


\subsection{Brechas de innovación entre países en nanotecnología}

El análisis de brechas en cuanto a la actividad inventiva en nanotecnología entre países se realizó con base en una muestra de 2000 patentes obtenidas de la USPTO en el periodo 19832013. Con base en la muestra, se seleccionaron la mayor cantidad de países que registraron actividad inventiva en nanotecnología en un mismo periodo. Así, solo 17 países registraron patentes en la clase 977 durante el periodo 2000-2010. Con base en esta información se construyó la base de datos para realizar el presente análisis. Cabe señalar que en este grupo de países se consideran todos los países estudiados en el capítulo tres, excepto Brasil. Esto se debe al hecho de que este país no registra actividad inventiva continua en nanotecnología durante el periodo de estudio sino de manera dispersa, por lo cual no fue considerado en el análisis. Al mismo tiempo, la falta de información de Brasil confirma la escasa actividad inventiva en nanotecnología, aunque con un importante potencial en este paradigma tecnológico. De esta forma, los países que se estudian en este apartado son: Estados Unidos, Japón, Corea del Sur, Alemania, Taiwán, Francia, Gran Bretaña, Canadá, China, Israel, España, Holanda, Irlanda, Italia, Suecia, India y Rusia.

Considerando el número de patentes solicitadas en nanotecnología como un indicador de la actividad inventiva en este sector en la USPTO en el periodo 2000-2010, se identifica una brecha importante entre los Estados Unidos y el resto de los países (ver gráfica 4.1). Así, se puede considerar, desde esta perspectiva, que el país líder en la actividad inventiva en este paradigma tecnológico es Estados Unidos, mientras que el resto de los países son seguidores. Sin embargo, al interior de los países seguidores, destacan algunos porque muestran una tendencia a reducir la brecha que los separa del país líder.

De esta manera, se observa que el país menos distante de Estados Unidos es Japón, ya que en este periodo muestra una tendencia a reducir la brecha. De esta forma, en el año 2000, la actividad inventiva en el NPN de Japón representaba el 16.4\% de la actividad inventiva de Estados Unidos, pero en 2009 ya representaba el 27.7\%, lo que sugiere que Japón logró disminuir la brecha en $11.3 \%$ en este periodo. La gráfica de Japón se puede dividir en dos periodos con base en su comportamiento. Entre 2000 y 2003, su actividad inventiva en nanotecnología creció notablemente, lo que le permitió cerrar la brecha con Estados Unidos a 
una tasa de 16\%. Sin embargo, entre 2004 y 2009 la tasa fue de 5.8\%, lo que sugiere que, aunque Japón mantuvo la tendencia de cerrar la brecha con el país líder, lo hizo a menor ritmo.

Una tendencia semejante muestran: Corea del Sur, Gran Bretaña, Canadá, Israel, España, Holanda, Irlanda e Italia. La tendencia de Alemania es contraria a la de estos países en este periodo, es decir, la proporción de la actividad inventiva de este país en nanotecnología con respecto a la actividad inventiva realizada en Estados Unidos no aumentó sino disminuyó, ya que en 2000 representaba el $11.3 \%$ y en 2010 el 3.5\%, lo que sugiere que la brecha con respecto a Estados Unidos se amplió.

Los casos de Francia e India son semejantes, ya que entre 2000 y 2003 la brecha en relación con Estados Unidos se amplió a una tasa de crecimiento promedio anual de $13.7 \%$ y 8.7\%, respectivamente. No obstante, a partir de 2004 muestran una importante recuperación, ya que entre 2004 y 2010 ambos lograron cerrar la brecha a una tasa de crecimiento promedio anual de 3.4\%. El caso de Taiwán es sorprendente, ya que se mantiene cerrando la brecha con respecto a Estados Unidos a una tasa de crecimiento promedio anual de $29 \%$ en ambos periodos. A ese ritmo, podría cerrar la brecha en poco tiempo con Japón, que es el país más cercano a Estados Unidos.

Otro país que sorprende por su ritmo de crecimiento en la actividad inventiva en nanotecnología es China: entre 2002 y 2010, la proporción de la actividad inventiva en el NPN con respecto a Estados Unidos pasó de representar el 1.5\% al 10.7\%, lo que significa una tasa de crecimiento promedio anual de $24.4 \%$. No obstante, en términos absolutos la brecha es enorme. Suecia mantuvo un ritmo de crecimiento modesto en el cierre de la brecha con los Estados Unidos, $3 \%$ entre 2000 y 2003, y 4\% entre 2004 y 2009.

Por último, Rusia mantiene un comportamiento desfavorable al cierre de la brecha con Estados Unidos, ya que muestra bajo nivel de actividad inventiva y la brecha crece a una tasa de 7\%. Como se mencionó, Rusia muestra un potencial importante en nanotecnología pero todavía no se traduce de manera notable en su actividad inventiva (ver gráfica 4.1). En suma, desde la perspectiva de brechas en la innovación en el NPN, se observa que del grupo de países que mayores esfuerzos realizan en la actividad inventiva y difusión de la nanotecnología, Estados Unidos destaca como país líder, mientras que Japón es el país que presenta una brecha de menor magnitud con respecto al líder. A su vez, a Japón le sigue Corea del Sur, mientras que Alemania muestra cierta estabilidad durante este periodo. Abajo se ubican otros países 
como Taiwán, Canadá, Francia, Gran Bretaña y China. Desde la perspectiva de brechas, destaca la posición de China, que se ubica a una distancia semejante a la de Francia y Gran Bretaña. Los casos de India y Rusia presentan la mayor distancia de la brecha con respecto al país líder (ver gráfica 4.1).

\section{Gráfica 4.1. Brechas en la actividad inventiva en nanotecnología entre países,}

2000-2010

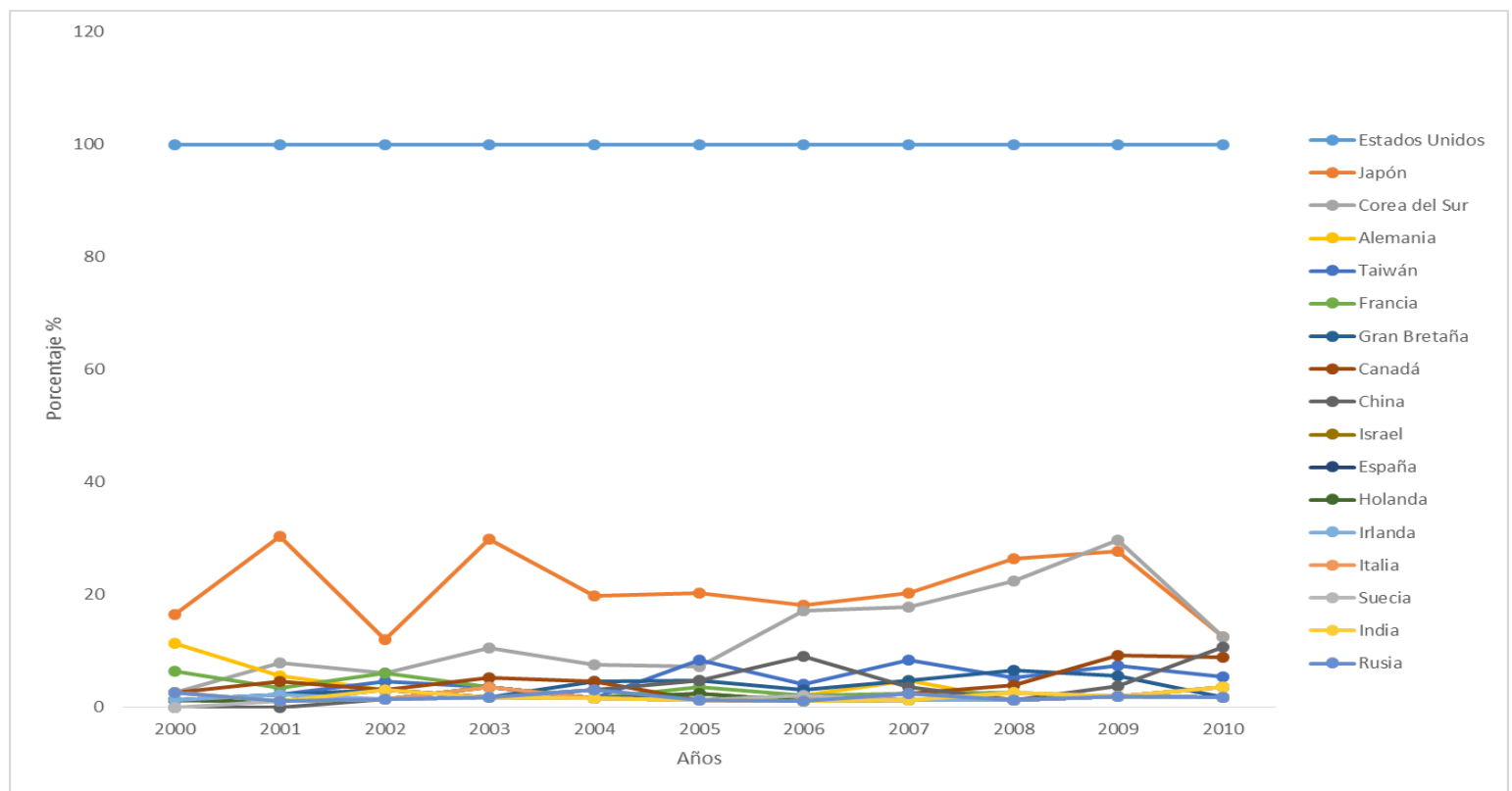

Fuente: elaboración propia con base en USPTO. 


\subsection{Convergencia y alcance en el NPN entre países}

Con el propósito de analizar la posible convergencia de innovación entre países y de actividad inventiva en el NPN se retoma la discusión, a nivel empírico, de los trabajos sobre crecimiento económico y catch-up tecnológico entre países, y se propone un modelo empírico para probar la hipótesis de convergencia tecnológica y de innovación en nanotecnología. Adicionalmente, a las variables tecnológicas se incorporaron otras variables institucionales asociadas al proceso de invención, tales como las capacidades de absorción tecnológica y las capacidades sociales. Factores que dan cuenta del desempeño de los sistemas nacionales de innovación de los países.

\section{Antecedentes teóricos}

En la discusión sobre el tema de crecimiento económico de los países, destaca la hipótesis de convergencia, la cual establece que las economías de los países pobres tienden a crecer, en términos per cápita, igual que las economías de los países ricos. Esta idea se sustenta, a su vez, en la hipótesis del catch-up tecnológico, la cual establece que los países más rezagados del mundo pueden reducir su brecha respecto de la frontera tecnológica, simplemente imitando los descubrimientos tecnológicos hechos en los países líderes. La idea originalmente fue

presentada por Gerschenkron (1962) y formalizada por Nelson y Phelps (1966). Posteriormente, Barro y Sala-i-Martin (1997) argumentaron que esto es posible porque los costos de imitación en el país seguidor son usualmente menores que la innovación que se lleva a cabo en la frontera tecnológica (Manca, 2009). Esto se explica, usualmente, por la amplitud de la brecha tecnológica, la adopción de las tecnologías de mayor alcance y, por ello, la más alta, y por las tasas de crecimiento del país seguidor. Los procesos de catch-up no son inmediatos, ya que los países seguidores carecen de las condiciones suficientes para asegurar su crecimiento y cerrar la brecha (Manca, 2009).

Nelson y Phelps y, posteriormente, Abramovitz (1986) reorganizaron la hipótesis del catching-up de Greschenkron y sugirieron que la tasa de velocidad bajo la cual la brecha tecnológica es cerrada, debería estar vinculada con la habilidad de los seguidores de recibir las derramas de la tecnología de la frontera y que esto depende, en particular, del stock de capital 
humano de los países (Manca, 2009). En este sentido, el trabajo de Benhabib y Spiegel (1994 y 2005), sustentado en las hipótesis de Nelson y Phelps, muestra que empíricamente las diferencias en los stocks de capital humano podrían ayudar a explicar las diferencias observadas en la dispersión del catch-up de tecnología entre países (Manca, 2009). No obstante, otros trabajos como el de Manca muestran que existen otras variables que podrían ser importantes, junto con el capital humano, en la promoción del crecimiento del PIB y el catch-up entre los países. En particular, considera variables tales como la calidad en las instituciones, los esfuerzos a favor de los derechos de propiedad intelectual (DPIs) y el libre comercio.

Así, se consideran en general dos enfoques para estudiar empíricamente la hipótesis del catch-up tecnológico: i) análisis $\sigma$-convergencia; ii) análisis $\beta$-convergencia. El primero se caracteriza por ser un análisis descriptivo, mientras que el segundo busca las posibles causas de la convergencia (Rogers, 2003).

A su vez, dentro del análisis $\beta$-convergencia se distinguen dos tipos: i) $\beta$-convergencia absoluta; ii) $\beta$-convergencia condicional. La primera sostiene la hipótesis de que las economías crecen bajo el mismo estado estacionario, por lo que siempre ocurre que las naciones pobres crecen más rápido que las ricas y, por ello, siempre ocurre la convergencia. En cambio, el análisis $\beta$-convergencia condicional omite dicho supuesto, por lo que las distintas economías no podrán alcanzar los mismos niveles del PIB per cápita en el largo plazo. Este análisis se complementa con la hipótesis de catch-up tecnológico, la cual establece que los países pobres pueden cerrar la brecha con los países más avanzados al aprovechar las derramas del conocimiento tecnológico generado en los países ricos. Sin embargo, esta hipótesis reconoce que la difusión internacional de tecnología no ocurre de forma instantánea o gratuita, sino que se difunde de manera distinta a través de las diferentes economías, debido a que en éstas se han desarrollado distintas capacidades tecnológicas (Fagerberg et al., 2012) y de absorción tecnológica (Rogers, 2003).

Por otra parte, los estudios empíricos sobre paradigmas tecnológicos, muestran que un nuevo paradigma tecnológico (NPT) emerge y se difunde primero en los países industrializados (Pérez, 2004) debido a que éstos han desarrollado mayores capacidades tecnológicas. Pero al difundirse se pueden abrir ventanas de oportunidad para los países menos desarrollados, por lo que promueven y difunden el NPT tiempo después que los países 
industrializados, produciéndose así una brecha en la difusión del NPT entre países. De esta forma se pueden identificar países líderes y seguidores en la difusión del nuevo paradigma. En este contexto, cabe preguntarse si los países menos desarrollados en el NPT (seguidores) cerrarán la brecha con los países más desarrollados en el NPT (líderes).

Así, para dar respuesta a esta pregunta de investigación, se propone un modelo de convergencia entre países en cuanto a la actividad inventiva en nanotecnología, inspirado en el análisis $\beta$-convergencia condicional y en la hipótesis del catch-up tecnológico. A continuación se presenta esta propuesta.

\section{Modelo de convergencia}

La estimación del modelo de convergencia propuesto se realizó utilizando una base de datos de tipo corte transversal que contiene la información de 17 países. Cada uno de éstos ocupa una fila; ocupan columnas las variables que se refieren a: las capacidades tecnológicas y de innovación del país en nanotecnología, las capacidades de absorción tecnológica a nivel nacional y las capacidades sociales del país, ocupan las columnas. Cabe señalar que, debido a la escasez en la información respecto de este tema, la base de datos se construyó con base en la información proporcionada por distintas fuentes.

Así, se consideró la información contenida en las patentes asignadas en nanotecnología de inventores residentes y no residentes en la USPTO para obtener la información que se refiere a las variables de las capacidades de innovación en nanotecnología de cada país. Se tomó como base la información proporcionada por los 17 países analizados en el apartado anterior, dedicado a las brechas en la actividad inventiva en nanotecnología. Los países son: Estados Unidos, Japón, Corea del Sur, Alemania, Taiwán, Francia, Gran Bretaña, Canadá, China, Israel, España, Holanda, Irlanda, Italia, Suecia, India y Rusia. Nuevamente, no se considera a Brasil por las razones ya señaladas. Además, se consideraron otros indicadores y fuentes de información para las variables que se refieren a las capacidades de absorción tecnológica a nivel nacional y para las capacidades sociales de los países.

Se consideró el capital humano por país, medido con base en el número de investigadores en investigación y desarrollo (I+D) por millón de habitantes; el gasto en 
investigación y desarrollo por país como porcentaje del PIB, obtenido de los Indicadores del Banco Mundial ${ }^{14}$; el índice de desarrollo humano por país, proporcionado por el Programa de las Naciones Unidas para el Desarrollo $(P N U D) ;{ }^{15}$ el índice de competitividad global por país; ${ }^{16}$ el grado de tecnología disponible por país; ${ }^{17}$ el grado de eficiencia de las instituciones públicas por país; ${ }^{18}$ el grado de absorción tecnológica de las firmas por país; ${ }^{19}$ el grado de estabilidad macroeconómica por país $;^{20}$ y el grado de corrupción por país $;^{21}$ proporcionados en Global Competitiveness Report, del World Economic Forum, en el periodo de estudio 2000-

\footnotetext{
${ }^{14}$ Indicadores del Banco Mundial. Ciencia y Tecnología. En página web: datos.bancomundial.org/tema/ciencia-y-
} tecnologia?view=chat.

${ }^{15}$ El índice de desarrollo humano (IDH) es una medida, en términos promedio, del desarrollo humano de los países. Toma en cuenta aspectos tales como la esperanza de vida al nacer y el nivel educativo de la población. (United Nations Development Programme).

${ }^{16}$ Es un índice propuesto y calculado por el World Economic Forum con el propósito de evaluar el grado de competitividad de los países. A su vez, se compone de varios subíndices que evalúan distintos aspectos de la economía de un país, tales como requerimientos básicos, eficiencia de los potenciadores y factores de innovación. A su vez, estos subíndices se componen de otros rubros. Así, los requerimientos básicos se componen de instituciones, infraestructura, estabilidad macroeconómica, salud y educación primaria; la eficiencia de los potenciadores consideran educación superior y capacitación, eficiencia de los bienes de mercado, eficiencia del mercado laboral, sofisticación del mercado financiero, preparación o disponibilidad tecnológica y tamaño del mercado; por último, los factores de innovación consideran la sofisticación de los negocios e innovación. El índice de competitividad global se obtiene al calcular el promedio de los tres subíndices y se evalúa en una escala del 1 al 7, el 1 indica menor eficiencia y el 7 mayor eficiencia (World Economic Forum, Global Competitiveness Report 2009/2010, 2009).

${ }^{17}$ Es un rubro que se refiere a la disponibilidad tecnológica del país que, a su vez, forma parte del subíndice de los requerimientos básicos que forman parte del índice de competitividad global estimado por el World Economic Forum. Se estima como un índice que mide el grado de disponibilidad tecnológica de cada país, en una escala del 1 al 7, donde el 1 representa menor disponibilidad y el 7 mayor disponibilidad tecnológica (World Economic Forum, Global Competitiveness Report 2009/2010, 2009).

${ }^{18}$ Forma parte del subíndice instituciones que es un componente, a su vez, del índice de competitividad global que calcula el World Economic Forum. A su vez, el grado de eficiencia de las instituciones públicas, se calcula como un índice que mide este grado en una escala del 1 al 7, donde el 1 significa menor grado de eficiencia y el 7 máximo grado de eficiencia (World Economic Forum, Global Competitiveness Report 2009/2010, 2009).

${ }^{19}$ Es un índice que, a su vez, forma parte del rubro disponibilidad tecnológica del país, el cual, forma parte del índice de competitividad global calculado por el World Economic Forum. Se estima como un índice que mide el grado de absorción tecnológica de las firmas en cada país, en una escala del 1 al 7, donde el 1 representa menor absorción y el 7 mayor absorción tecnológica (World Economic Forum, Global Competitiveness Report 2009/2010, 2009).

${ }^{20}$ Es un rubro que forma parte del subíndice requerimientos básicos que forma parte del índice de competitividad global del World Economic Forum. La estabilidad macroeconómica contempla el déficit (o superávit) del gobierno, la tasa de inflación, la tasa de ahorro y la deuda del gobierno. Se calcula como un índice que mide el grado de estabilidad macroeconómica en cada país, en una escala del 1 al 7, donde el 1 representa menor estabilidad y el 7 mayor estabilidad macroeconómica (World Economic Forum, Global Competitiveness Report 2009/2010, 2009).

${ }^{21}$ Forma parte del rubro instituciones que, a su vez, es un componente del índice de competitividad global del Banco Mundial. Mide el grado de corrupción de las instituciones públicas a través de un índice en una escala del 1 al 7, donde el 1 representa mayor corrupción y el 7 menor corrupción (World Economic Forum, Global Competitiveness Report 2009/2010, 2009). 
2010. Cabe señalar que, con el propósito de realizar las estimaciones del modelo de convergencia, se calcularon tasas de crecimiento promedio anual en cada una de las variables en el periodo de estudio, considerando los problemas de información y de homogeneidad de los datos.

Debido a estos motivos, se construyó una base de datos de corte transversal. Si bien existen estudios de convergencia que usan información de datos panel (Calderón y Tykhonenko, 2006; Díaz, Sánchez y Mendoza, 2009; Montero y Del Río, 2013; Rodríguez, Mendoza y Perrotini, 2015) en este caso se optó por una base de datos corte transversal, dadas las restricciones ya mencionadas de la información. No obstante, el modelo arroja información relevante acerca de las posibles tendencias de la convergencia entre países en el NPN. Una vez hechas estas observaciones, se presenta a continuación el modelo propuesto de convergencia.

\section{Especificación del modelo de convergencia condicional}

Se suscribe como hipótesis central del modelo la siguiente: se espera que la convergencia tecnológica y de innovación en las nanotecnologías entre países, en el largo plazo, esté condicionada por: la existencia de capacidades tecnológicas y de innovación en el sector, las capacidades de absorción tecnológica a nivel nacional y por las capacidades sociales del país.

A fin de verificar tal hipótesis se propone un modelo de regresión lineal (OLS), el cual se especifica formalmente como sigue:

$$
\text { PatNano }_{i, 2000-2010}=\beta \operatorname{lnPatNano} 2000, i+\alpha_{1} X_{1, i}+\alpha_{2} X_{2, i}+\alpha_{3} X_{3, i}+\varepsilon_{i}
$$

Donde:

PatNanoi,2000-2010, es la tasa de crecimiento promedio anual del número de patentes solicitadas en nanotecnología del país; $i$ es una variable proxy de la actividad inventiva en este nuevo paradigma tecnológico. Se considera el periodo 2000-2010.

InPatNano2000,i, es el logaritmo natural del número de patentes del año inicial (2000) solicitadas en nanotecnología del país $i$.

$\beta$, es el coeficiente estimado de estudio, es decir, el parámetro que proporciona información acerca de la convergencia en la actividad inventiva en nanotecnología entre países. 
$X_{1, i}, X_{2, i}$ y $X_{3, i}$ son matrices que contienen variables de control asociadas al fenómeno de la actividad inventiva en tres ámbitos: capacidades tecnológicas y de innovación en el sector estudiado, capacidades de absorción tecnológica a nivel nacional y capacidades sociales, respectivamente. A continuación se desglosan las variables contenidas en cada una de estas matrices.

$X 1, i$ representa las capacidades tecnológicas y de innovación en nanotecnología del país $i$, incluye las siguientes variables:

AtechNano $_{i 2000-2010}$ es la tasa de crecimiento promedio anual (TCPA) de la acumulación de conocimiento tecnológico en este sector del país $i$. Se considera variable proxy a la TCPA del número de citas hacia atrás de las patentes solicitadas en nanotecnología del país $i(2000-2010)$.

ScTecLinkNano $2000-2010$ es la TCPA de los vínculos entre la actividad científica y la actividad inventiva en este sector tecnológico del país $i$. Se considera variable proxy a la TCPA del número de citas de artículos científicos que realizan las patentes solicitadas en nanotecnología del país $i$ (2000-2010) (Guzmán et al. 2016).

SizeRTNanoi $2000-2010$ es la TCPA de las capacidades inventivas de los investigadores en este sector tecnológico del país $i$. La variable proxy es la TCPA del tamaño de equipos de inventores en nanotecnología del país $i$ (2000-2010).

ClNanoi $_{2000-2010}$ es la TCPA de las novedades generadas en este sector tecnológico en el país $i$. La variable proxy es la TCPA del número de reivindicaciones (claims) de las patentes solicitadas en nanotecnologías del país $i$ (2000-2010).

$X 2, i$ es otro grupo de variables que representa las capacidades de absorción tecnológica, a nivel nacional, y se compone de las siguientes variables:

$R \& D / G D P i_{2000-2010}$ es la TCPA de la capacidad inventiva del país $i$. La variable proxy es la TCPA del gasto en I+D/ PIB del país $i$ (2000-2010).

$H k i_{2000-2010}$ es la TCPA del capital humano del país $i$. La variable proxy es la TCPA del número de investigadores en I+D /millón de habitantes del país $i$ (2000-2010).

ProdCompi $_{2000-2010}$ es la TCPA de la capacidad productiva y competitiva del país $i$. La variable proxy es la TCPA del índice de competitividad global del país $i$ (2000-2010). TechHeighti $i_{2000-2010}$ es la TCPA del nivel relativo de tecnología del país $i$. La variable proxy es la TCPA del índice de tecnología del país $i$ (2000-2010). 
TechAbsCapFi $i_{2000-2010}$ es la TCPA de la capacidad de absorción tecnológica de las firmas del país $i(2000-2010)$.

$X 3, i$, es un grupo de variables que representa las capacidades sociales del país $i$. Se compone de las siguientes variables:

DHI $i_{2000-2010}$ es la TCPA del índice de desarrollo humano del país $i$ (2000-2010). Es un indicador sintético de los logros medios obtenidos en las dimensiones fundamentales del desarrollo humano, a saber, tener una vida larga y saludable, adquirir conocimientos $\mathrm{y}$ disfrutar de un nivel de vida digno.

IPEi $i_{2000-2010}$ es la TCPA del grado de eficiencia de las instituciones públicas del país $i$ (2000-2010).

MacStrengthi $i_{2000-2010}$ es la TCPA del grado de estabilidad macroeconómica del país $i$ (2000-2010).

InstWeaki $2005-2010$ es la TCPA de la debilidad institucional. La variable proxy es el grado de corrupción en el país $i$ (2000-2010).

$\alpha 1, \alpha 2$ y $\alpha 3$ son los coeficientes estimados de estas variables.

ci es el factor de error.

\section{Resultados esperados}

Aunque la difusión de los paradigmas tecnológicos presenta distintos patrones temporales y espaciales, como se mostró en el tercer capítulo de la presente investigación, todos comparten la misma pauta en cuanto a su dinámica (Pérez, 2004): generalmente, se inicia en un país industrializado con experiencia acumulada en la innovación, consecuencia, a su vez, de la eficiencia de su sistema nacional de innovación (SNI) y de otros factores de carácter institucional y social que son favorables a la actividad inventiva y, de ahí, se difunden hacia otros sectores y países con la posibilidad de que, al madurar y vincularse con otros paradigmas tecnológicos y dar origen a sistemas tecnológicos más grandes, den lugar a revoluciones tecnológicas, las cuales tendrán un impacto mayor en la economía y en la sociedad (Pérez, 2004 y 2009). Esta pauta sugiere dos aspectos importantes: i) un paradigma tecnológico no se inicia al mismo tiempo en todos los países; ii) su difusión tiende a agotarse a través del tiempo. 
La actividad inventiva en el marco de un paradigma tecnológico ocurre en diferentes momentos en los países y a distinta velocidad de tal forma que pueden formarse brechas entre ellos, es decir, los países que iniciaron primero la actividad inventiva en un paradigma tecnológico llevan ventaja sobre aquellos que iniciaron su actividad inventiva después. Pero al considerar su agotamiento, cabe la posibilidad de que los países seguidores cierren la brecha con respecto a los países líderes, debido a que pueden traslaparse los distintos ritmos de crecimiento de la actividad inventiva de estos países. En otras palabras, es posible que en algún momento las tasas de crecimiento de la actividad inventiva en un paradigma tecnológico sean mayores en los países seguidores que en los países líderes aunque, en términos absolutos, el stock acumulado de invenciones sigue siendo mayor en éstos que en los seguidores. De manera semejante a lo que se espera que ocurra en los modelos de crecimiento de tipo $\beta$-convergencia (Barro y Sala-i-Martin, 1997), es posible esperar que, si la tendencia de la tasa de crecimiento de la actividad inventiva en nanotecnología de los países guarda una relación negativa con el nivel de actividad inventiva inicial y si esta tendencia se mantiene en el tiempo, entonces los países seguidores cerrarán la brecha con los líderes, ya que significaría que la actividad inventiva en nanotecnología crece a una tasa mayor en los países seguidores que en los líderes, lo que haría posible que la tendencia cerrara la brecha. Esta información está contenida en el parámetro $\beta$, el cual, es el parámetro de estudio.

\section{Parámetro de convergencia}

De esta forma, se espera que:

Si $\beta<0$, los países seguidores tenderán a alcanzar a los líderes. Es decir, hay convergencia.

Si $\beta=0$, no hay convergencia ya que, en este caso, la tasa de crecimiento de la actividad inventiva de los países seguidores es la misma que la de los líderes, por lo que la diferencia en la actividad inventiva inicial se mantendría. La brecha se conserva. 
Si $\beta>0$, hay divergencia, ya que los países líderes mantendrían tasas de crecimiento elevadas de la actividad inventiva, asociadas positivamente con sus niveles altos de su actividad inventiva inicial. Por el contrario, los países seguidores mantendrían tasas de crecimiento bajas de la actividad inventiva, asociadas positivamente con sus bajos niveles de actividad inventiva inicial. A través del tiempo, la brecha se haría más grande.

Sin embargo, de acuerdo con diversos trabajos teóricos y empíricos sobre la convergencia tecnológica (Abramovitz, 1986; Rogers, 2003; Manca, 2009 y Fagerberg et al., 2012) se reconoce que este proceso es un fenómeno complejo, el cual no solo depende de la relación entre los cambios porcentuales de la actividad inventiva inicial y las tasas de crecimiento promedio anual de la actividad inventiva sino, además, está condicionado por variables del entorno que inciden favorablemente no solo en el ritmo de crecimiento de la actividad inventiva sino, por ende también, en el proceso de convergencia estudiado a través del parámetro $\beta$. Por lo tanto, estas variables de control condicionan el proceso de convergencia.

\section{Variables de control}

Se suscribe con base en estudios teóricos y empíricos (Nelson y Phelps, 1966; Abramovitz, 1986; Benhabib y Spiegel, 1994 y 2005; Rogers, 2003; Manca, 2009 y Fagerberg et al., 2012) que tales variables están asociadas a tres entornos: i) las capacidades tecnológicas y de innovación en nanotecnología del país $i\left(X_{1, i}\right)$. Diferentes estudios teóricos y empíricos ponen énfasis en variables asociadas directamente con la actividad inventiva, a nivel sectorial, con el propósito de resaltar las diferencias en las capacidades de innovación tales como el stock de conocimiento tecnológico acumulado en el sector, los vínculos entre la actividad científica y la actividad inventiva en ese sector, el tamaño de equipos de inventores y el número de reivindicaciones (claims) de las patentes solicitadas, entre otras, como indicadores de la fortaleza del sector tecnológico donde se lleva a cabo la actividad inventiva (OCDE y OEPM, 2009); ii) otro grupo de variables pone énfasis en el entorno de las capacidades de absorción tecnológica a nivel nacional del país $i\left(X_{2, i}\right)$. En particular, Nelson y Phelps (1966), Benhabib y Spiegel (1994 y 2005) y Manca (2009), ponen énfasis en las habilidades y conocimientos del 
capital humano de los países como una condicionante importante en el proceso de convergencia.

En la presente investigación se proponen otras variables que hacen referencia a las capacidades de absorción tecnológica de los países tales como el gasto en I+D como porcentaje del PIB, la capacidad productiva y competitiva del país medida a través del índice de competitividad global, el grado de tecnología del país medido a través del índice de tecnología del país y la capacidad de absorción tecnológica de las firmas. Por último, otro grupo de variables referidas al entorno de las capacidades sociales del país $i\left(X_{3, i}\right)$. Autores como Rogers y Fagerberg señalan que el entorno social condiciona de manera importante el proceso de innovación tecnológica. En la presente investigación se consideran variables sociales tales como el índice de desarrollo humano, el grado de eficiencia de las instituciones públicas, el grado de estabilidad macroeconómica y la debilidad institucional medida a través del índice de corrupción. Todas estas variables de control en tasas de crecimiento promedio anual. Se espera que, en el análisis de convergencia, los parámetros estimados de estas variables incidan favorablemente (excepto el parámetro de la variable referida a la debilidad institucional) en el ritmo de crecimiento de la actividad inventiva y, por ende, en el proceso de convergencia que se analiza con base en el valor del parámetro $\beta$. A continuación, se presentan las hipótesis asociadas a cada una de las variables de control.

Hipótesis de las variables del modelo

Las hipótesis de cada una de estas variables de control se presentan en el siguiente cuadro:

Cuadro 4.1. Significado e hipótesis de las variables independientes del modelo

\begin{tabular}{|l|l|l|}
\hline Variable & Significado & $\begin{array}{l}\text { Hipótesis. } \\
\text { Se espera que: }\end{array}$ \\
\hline InPatNano2000, $i$, & $\begin{array}{l}\text { Es el logaritmo natural del número de } \\
\text { patentes del año inicial (2000) asignadas en }\end{array}$ & $\begin{array}{l}\text { Al aumentar el número de patentes } \\
\text { asignadas en nanotecnología del país } i\end{array}$ \\
\hline
\end{tabular}




\begin{tabular}{|c|c|c|}
\hline & nanotecnología del país $i$; & $\begin{array}{l}\text { en el año inicial, } 2000 \text {, la convergencia } \\
\text { ocurra, es decir, que el valor de } \beta \text { sea } \\
\text { negativo. }\end{array}$ \\
\hline AtechNano $_{i 2000-2010}$ & $\begin{array}{l}\text { Es la tasa de crecimiento promedio anual } \\
\text { (TCPA) de la acumulación de } \\
\text { conocimiento tecnológico en este sector del } \\
\text { país } i \text {. Se considera variable proxy a la } \\
\text { TCPA del número de citas hacia atrás de } \\
\text { las patentes solicitadas en nanotecnología } \\
\text { del país } i(2000-2010) \text {. }\end{array}$ & $\begin{array}{l}\text { Un incremento en la tasa de } \\
\text { crecimiento promedio anual de la } \\
\text { acumulación de conocimiento } \\
\text { tecnológico en el sector de } \\
\text { nanotecnología del país } i \text {, en el periodo } \\
\text { 2000-2010, favorezca la propensión a } \\
\text { la actividad inventiva en este sector y, } \\
\text { además, que refuerce la convergencia. }\end{array}$ \\
\hline $\begin{array}{l}\text { ScTecLinkNano } 2000- \\
2010\end{array}$ & $\begin{array}{l}\text { Es la TCPA de los vínculos entre la } \\
\text { actividad científica y la actividad inventiva } \\
\text { en este sector tecnológico del país } i \text {. Se } \\
\text { considera variable proxy a la TCPA del } \\
\text { número de citas de artículos científicos que } \\
\text { realizan las patentes solicitadas en } \\
\text { nanotecnología del país } i \text { (2000-2010) } \\
\text { (Guzmán et al 2016). }\end{array}$ & $\begin{array}{l}\text { Al aumentar la tasa de crecimiento } \\
\text { promedio anual de los vínculos entre la } \\
\text { actividad científica y la actividad } \\
\text { inventiva en el periodo 2000-2010, } \\
\text { aumente también la tasa de } \\
\text { crecimiento promedio anual de la } \\
\text { actividad inventiva en nanotecnologías } \\
\text { del país } i \text { y, además, que favorezca a la } \\
\text { convergencia. }\end{array}$ \\
\hline $\begin{array}{l}\text { SizeRTNanoi } 2000- \\
2010\end{array}$ & $\begin{array}{l}\text { Es la TCPA de las capacidades inventivas } \\
\text { de los investigadores en este sector } \\
\text { tecnológico del país } i \text {. La variable proxy es } \\
\text { la TCPA del tamaño de equipos de } \\
\text { inventores en nanotecnología del país } i \\
(2000-2010) \text {. }\end{array}$ & $\begin{array}{l}\text { Al aumentar la tasa de crecimiento } \\
\text { promedio anual de las capacidades } \\
\text { inventivas en el sector de } \\
\text { nanotecnología en el sector } i \text { en el } \\
\text { periodo 2000-2010, aumente la tasa de } \\
\text { crecimiento promedio anual de la } \\
\text { actividad inventiva en este sector y, } \\
\text { además, que refuerce la convergencia. }\end{array}$ \\
\hline ClNanoi $_{2000-2010}$ & $\begin{array}{l}\text { Es la TCPA de las novedades generadas en } \\
\text { este sector tecnológico en el país } i \text {. La } \\
\text { variable proxy es la TCPA del número de } \\
\text { reivindicaciones (claims) de las patentes } \\
\text { solicitadas en nanotecnologías del país } i \\
(2000-2010) \text {. }\end{array}$ & $\begin{array}{l}\text { Al aumentar la tasa de crecimiento } \\
\text { promedio anual de las novedades } \\
\text { generadas en el sector de } \\
\text { nanotecnología del país } i \text { en el periodo } \\
\text { 2000-2010, aumente también la tasa de } \\
\text { crecimiento promedio anual de la } \\
\text { actividad inventiva en este sector y, } \\
\text { además, que favorezca la } \\
\text { convergencia. }\end{array}$ \\
\hline$R \& D / G D P i_{2000-2010}$ & $\begin{array}{l}\text { Es la TCPA de la capacidad inventiva del } \\
\text { país } i \text {. La variable proxy es la TCPA del } \\
\text { gasto en I+D/ PIB del país } i(2000-2010) \text {. }\end{array}$ & $\begin{array}{l}\text { Al aumentar la tasa de crecimiento } \\
\text { promedio anual del gasto en I+D como } \\
\text { porcentaje del PIB del país } i \text { en el } \\
\text { periodo 2000-2010, aumente la tasa de } \\
\text { crecimiento promedio anual de la } \\
\text { actividad inventiva en nanotecnología } \\
\text { del país } i \text { y, además, que la } \\
\text { convergencia se refuerce. }\end{array}$ \\
\hline$H k i_{2000-2010}$ & $\begin{array}{l}\text { Es la TCPA del capital humano del país } i \text {. } \\
\text { La variable proxy es la TCPA del número } \\
\text { de investigadores en I+D /millón de } \\
\text { habitantes del país } i(2000-2010) \text {. }\end{array}$ & $\begin{array}{l}\text { Al aumentar la tasa de crecimiento } \\
\text { promedio anual del capital humano en } \\
\text { el país } i \text { en el periodo 2000-2010, } \\
\text { aumente la tasa de crecimiento } \\
\text { promedio anual de la actividad } \\
\text { inventiva en nanotecnología en el país } \\
i \text { y, además, que la convergencia se } \\
\text { refuerce. }\end{array}$ \\
\hline ProdCompi $2000-2010$ & $\begin{array}{l}\text { Es la TCPA de la capacidad productiva y } \\
\text { competitiva del país } i \text {. La variable proxy es }\end{array}$ & $\begin{array}{l}\text { Al aumentar la tasa de crecimiento } \\
\text { promedio anual de la capacidad }\end{array}$ \\
\hline
\end{tabular}




\begin{tabular}{|c|c|c|}
\hline & $\begin{array}{l}\text { la TCPA del índice de competitividad } \\
\text { global del país } i(2000-2010) \text {. }\end{array}$ & $\begin{array}{l}\text { productiva y competitiva del país } i \text { en } \\
\text { el periodo 2000-2010, aumente la tasa } \\
\text { de crecimiento promedio anual de la } \\
\text { actividad inventiva en nanotecnología } \\
\text { del país } i \text { y, además, que refuerce la } \\
\text { convergencia. }\end{array}$ \\
\hline $\begin{array}{l}\text { TechHeighti } 2000- \\
2010,\end{array}$ & $\begin{array}{l}\text { Es la TCPA del nivel relativo de tecnología } \\
\text { del país } i \text {. La variable proxy es la TCPA } \\
\text { del índice de tecnología del país } i \text { (2000- } \\
2010) \text {. }\end{array}$ & $\begin{array}{l}\text { Al aumentar la tasa de crecimiento } \\
\text { promedio anual del nivel relativo de } \\
\text { tecnología del país } i \text {, aumente la tasa } \\
\text { de crecimiento promedio anual de la } \\
\text { actividad inventiva en nanotecnología } \\
\text { del país } i \text { y, además, que la } \\
\text { convergencia se refuerce. }\end{array}$ \\
\hline $\begin{array}{l}\text { TechAbsCapFi } i_{2000-} \\
\text { 2010, }\end{array}$ & $\begin{array}{l}\text { Es la TCPA de la capacidad de absorción } \\
\text { tecnológica de las firmas del país } i \text { (2000- } \\
2010) \text {. }\end{array}$ & $\begin{array}{l}\text { Al aumentar la tasa de crecimiento } \\
\text { promedio anual de la capacidad de } \\
\text { absorción tecnológica de las firmas del } \\
\text { país } i \text { en el periodo 2000-2010, } \\
\text { aumente la tasa de crecimiento } \\
\text { promedio anual de la actividad } \\
\text { inventiva en nanotecnología del país } i \\
\text { y, además, que refuerce la } \\
\text { convergencia. }\end{array}$ \\
\hline DHIi $_{2000-2010}$, & $\begin{array}{l}\text { Es la TCPA del índice de desarrollo } \\
\text { humano del país } i \text { (2000-2010). Es un } \\
\text { indicador sintético de los logros medios } \\
\text { obtenidos en las dimensiones } \\
\text { fundamentales del desarrollo humano, a } \\
\text { saber, tener una vida larga y saludable, } \\
\text { adquirir conocimientos y disfrutar de un } \\
\text { nivel de vida digno. }\end{array}$ & $\begin{array}{l}\text { Al aumentar la tasa de crecimiento } \\
\text { promedio anual del índice de } \\
\text { desarrollo humano del país } i \text { en el } \\
\text { periodo 2000-2010, aumente la tasa de } \\
\text { crecimiento de la actividad inventiva } \\
\text { en nanotecnología del país } i \text { y, además, } \\
\text { que refuerce la convergencia. }\end{array}$ \\
\hline$I P E i_{2000-2010}$ & $\begin{array}{l}\text { Es la TCPA del grado de eficiencia de las } \\
\text { instituciones públicas del país } i \text { (2000- } \\
\text { 2010). }\end{array}$ & $\begin{array}{l}\text { Al aumentar la tasa de crecimiento } \\
\text { promedio anual del grado de eficiencia } \\
\text { de las instituciones públicas del país } i \\
\text { en el periodo 2000-2010, aumente la } \\
\text { tasa de crecimiento promedio anual de } \\
\text { la actividad inventiva en } \\
\text { nanotecnología en el país } i \text { y, además, } \\
\text { que refuerce la convergencia. }\end{array}$ \\
\hline $\begin{array}{l}\text { MacStrengthi } 2000- \\
\text { 2010, }\end{array}$ & $\begin{array}{l}\text { Es la TCPA del grado de estabilidad } \\
\text { macroeconómica del país } i(2000-2010) \text {. }\end{array}$ & $\begin{array}{l}\text { Al aumentar la tasa de crecimiento } \\
\text { promedio anual del grado de } \\
\text { estabilidad macroeconómica del país } i \\
\text { en el periodo 2000-2010, aumente la } \\
\text { tasa de crecimiento promedio anual de } \\
\text { la actividad inventiva en } \\
\text { nanotecnología del país } i \text { y, además, } \\
\text { que refuerce la convergencia. }\end{array}$ \\
\hline InstWeaki $2005-2010$ & $\begin{array}{l}\text { Es la TCPA de la debilidad institucional. } \\
\text { La variable proxy es el grado de corrupción } \\
\text { en el país } i \text { (2005-2010). }\end{array}$ & $\begin{array}{l}\text { Al aumentar la tasa de crecimiento } \\
\text { promedio anual de la debilidad } \\
\text { institucional (grado de corrupción) en } \\
\text { el país } i \text { en el periodo 2005-2010, } \\
\text { disminuya la tasa de crecimiento } \\
\text { promedio anual de la actividad } \\
\text { inventiva en nanotecnología del país } i \\
\text { y, además, que la convergencia se }\end{array}$ \\
\hline
\end{tabular}




\section{Estadística descriptiva de las variables del modelo}

En este apartado se analiza el comportamiento de cada variable en el conjunto de los países del estudio con base en la media, la varianza y la desviación estándar, con la finalidad de analizar la distribución de los datos y hacer una exploración inicial del comportamiento estadístico de las variables.

Una variable que no presenta problemas de dispersión es el logaritmo natural del número de patentes del año inicial (2000) asignadas en nanotecnología del país $i$. El valor máximo es de 4.4 donde se ubica el país líder en la actividad inventiva en nanotecnología, Estados Unidos, seguido de países que se ubican por encima del promedio tales como Japón y Alemania. Estos países, a su vez, guardan una brecha con los países que se ubican en el valor promedio (1), tales como Israel y Francia. Por debajo de la media se ubican Corea del Sur, Gran Bretaña, Canadá, China, Irlanda, Italia, India y Rusia, mientras que en el valor mínimo (0) se ubican España, Holanda, Suecia y Taiwán. Cabe señalar que, aunque la distancia entre Estados Unidos y los demás países es grande, en conjunto, los datos no están muy dispersos.

En cuanto a la variable TCPA de las novedades generadas en nanotecnología en el país i, ClNanoi2000-2010, el país líder es Suecia con un valor máximo de 10.2, muy por encima del promedio (-2.7) donde se ubica Holanda, mientras que en el mínimo se ubica Taiwán (-10.8). En este rubro Estados Unidos tiene un valor de -4.3. El comportamiento de los datos sugiere que, aunque Estados Unidos mantiene el mayor ritmo de crecimiento en cuanto a la actividad inventiva en nanotecnología, en cuanto a las novedades generadas en este sector mantiene un ritmo por debajo del promedio.

Respecto de la variable TCPA del gasto en I+D/ PIB del país $i$ (2000-2010), $R \& D / G D P i 2000-2010$, el país que alcanzó el máximo en este periodo fue China (6.6), muy por encima del valor promedio (1.7), mientras que en el mínimo se ubica Rusia (-0.7), Estados Unidos se ubica con 1.02, es decir, por debajo del promedio. Nuevamente, los datos revelan 
que Estados Unidos no es país líder en cuanto al ritmo de crecimiento en el gasto en I+D como porcentaje del PIB, variable proxy de la capacidad inventiva del país.

Respecto de la variable TCPA del nivel relativo de tecnología del país $i$, TechHeighti2000-2010, el país que se ubica en el máximo es Japón (0.5), en el promedio (-1.6) se ubican Corea del Sur, Taiwán y Holanda, y en el valor mínimo (-4.3) se ubican Italia y España; Estados Unidos se ubican por debajo del promedio con un valor de -1.1.

En cuanto a la variable TCPA del grado de eficiencia de las instituciones públicas del país $i$, IPEi2000-2010, el país líder es nuevamente China (0.8), en el valor mínimo se ubica Italia (-4.2) y en el valor promedio (-1.4) se ubica Rusia; mientras que Estados Unidos se ubica por debajo del promedio con un valor de -2.4. Esto sugiere que, mientras que China mejora en la eficiencia de sus instituciones públicas a un ritmo creciente, Estados Unidos lo hace a un ritmo decreciente.

La variable TCPA del capital humano del país $i, H k i 2000-2010$, donde el país líder es Corea del Sur con un máximo de 8.7, en el valor promedio (2.9) se ubica Francia y en el mínimo (-1.1) se encuentra Rusia; mientras que Estados Unidos se ubica por debajo del promedio con 1.07 (ver cuadro 4.2).

Por otra parte, la variable que tiende a una mayor dispersión es la tasa de crecimiento promedio anual de la acumulación de conocimiento tecnológico en nanotecnología del país $i$, AtechNanoi2000-2010, con valor máximo de 26.5 donde se ubica Holanda, en el mínimo (100) está Rusia y en el valor promedio (-2.7) se encuentra India, Estados Unidos se ubica por arriba del promedio (12.8) pero muy por debajo del ritmo de crecimiento de Holanda (ver cuadro 4.2).

Esta breve descripción del comportamiento estadístico de estas variables revela algunas fortalezas y debilidades que muestran los países de estudio. Si bien Estados Unidos es el país líder en cuanto al ritmo de crecimiento en la actividad inventiva en nanotecnología, desde esta perspectiva dinámica, otros países como China revelan fortalezas en otros rubros tales como el gasto en I+D o en la mejora de la eficiencia de las instituciones públicas, pero también confirma las debilidades que exhiben otros países como Rusia. 
Cuadro 4.2. Estadística descriptiva de las variables del modelo

\begin{tabular}{|l|c|c|c|c|}
\hline Variables & Media & Desviación & Mínimo & Máximo \\
\hline PatNanoi, 2000-2010 & 3.0 & 12.3 & -16.4 & 24.1 \\
\hline InPatNano 2000,i & 1.0 & 1.1 & 0.0 & 4.4 \\
\hline AtechNano i,2000-2010 & -2.7 & 28.2 & -100.0 & 26.5 \\
\hline ScTecLinkNano i,2000-2010 & -0.4 & 19.3 & -28.3 & 59.4 \\
\hline SizeRTNano i,2000-2010 & -0.9 & 7.0 & -11.5 & 10.2 \\
\hline CINano i,2000-2010 & -2.7 & 5.7 & -10.8 & 10.2 \\
\hline RdD/GDP i,2000-2010 & 1.7 & 2.3 & -0.7 & 6.6 \\
\hline Hki2000-2010 & 2.9 & 2.4 & -1.1 & 8.7 \\
\hline ProdComp i2000-2010 & -0.3 & 0.8 & -1.5 & 1.3 \\
\hline TechHeight i,2000-2010 & -1.6 & 1.3 & -4.3 & 0.5 \\
\hline TechAbsCapF i2000-2010 & 1.2 & 3.8 & -6.3 & 9.9 \\
\hline DHI i2000-2010 & 0.0 & 0.3 & -0.7 & 0.7 \\
\hline IPE i2000-2010 & -1.4 & 1.2 & -4.2 & 0.8 \\
\hline MacStrength i2000-2010 & 0.5 & 1.6 & -2.1 & 3.0 \\
\hline InstWeaki2005-2010 & -1.0 & 1.4 & -4.6 & 1.5 \\
\hline
\end{tabular}

Fuente: elaboración propia con base en USPTO, 1974-2013, indicadores del Banco Mundial, 2000-2010, Plan para el Desarrollo de las Naciones Unidas (PNUD), 2000-2010 y The Global Competitiveness Report, del Banco Mundial, 2001, 2005 y 2010.

Por último, al graficar el logaritmo natural del número de patentes solicitadas en nanotecnología del país $i$ en el año inicial, 2000, versus la tasa de crecimiento promedio anual del número de patentes solicitadas en este sector del país $i$ en el periodo 2000-2010, se confirma que Estados Unidos, Japón y Alemania presentan una condición inicial alta, es decir, un nivel de actividad inventiva inicial en nanotecnología elevada, por lo que se puede afirmar que son los países líderes en este paradigma tecnológico. Sin embargo, presentan tasas de crecimiento promedio anual negativas en este periodo. Por otro lado, países como Suecia, Corea del Sur, Italia, Taiwán, Gran Bretaña, Canadá e Irlanda si bien presentan niveles de actividad inventiva bajos en comparación con Estados Unidos, Japón y Alemania, tienen tasas de crecimiento promedio anual elevadas, por lo que se espera que tiendan a cerrar la brecha con los países líderes, especialmente, con Estados Unidos (ver gráfica 4.2). 


\section{Gráfica 4.2. Logaritmo natural del número de patentes solicitadas en}

nanotecnologías del país $i$ en el año inicial, 2000, vs la tasa de crecimiento promedio anual del número de patentes solicitas en nanotecnologías del país $i, 2000-2010$.

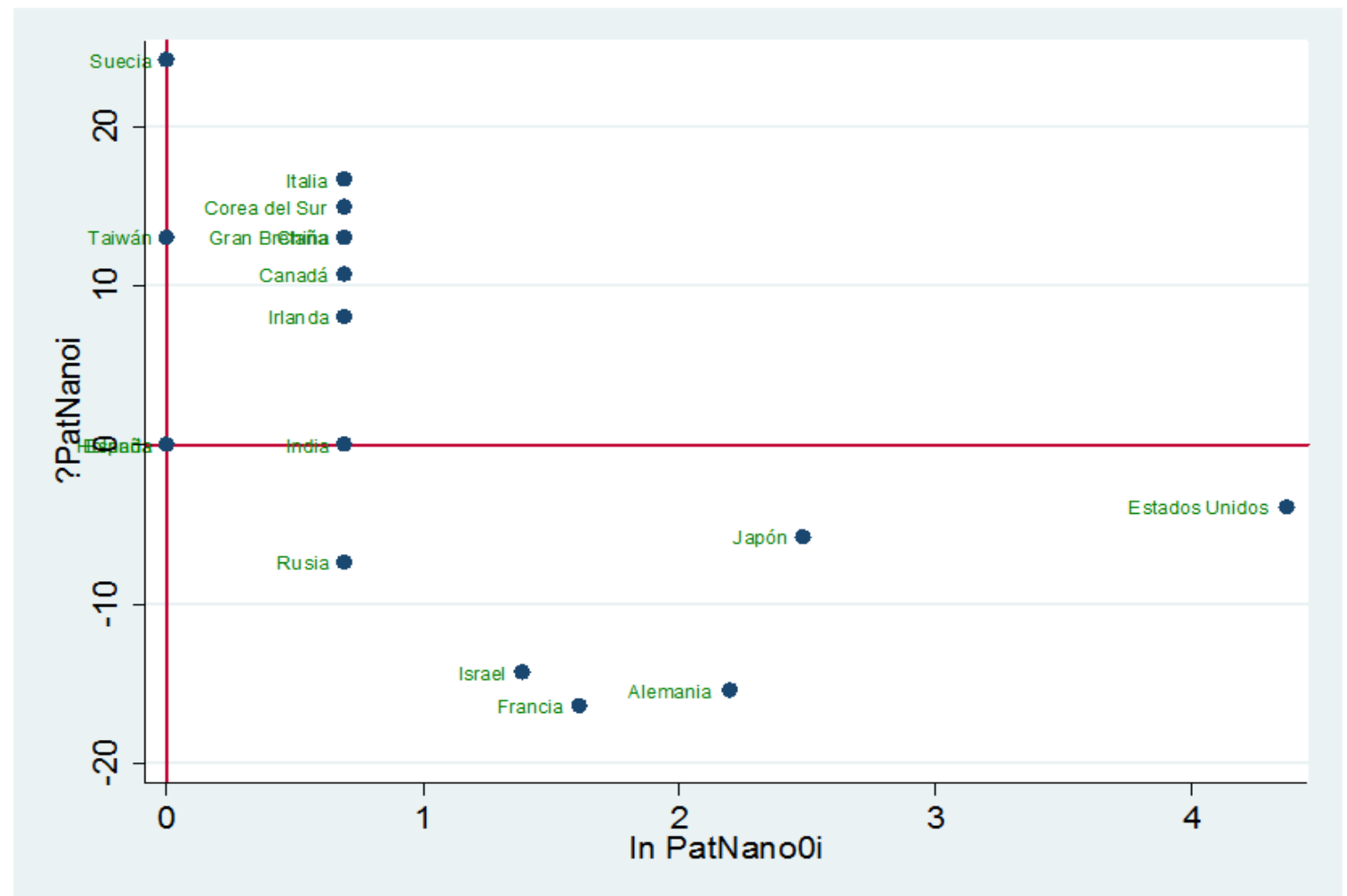

Fuente: elaboración propia con base en USPTO.

Para verificar la hipótesis de convergencia se estima el modelo econométrico propuesto. Los resultados se presentan a continuación.

\section{Estimación del modelo}

En la búsqueda de la mejor estimación del modelo, es decir, en la que los estimadores son MELI (mejores estimadores linealmente insesgados), se utilizaron dos procedimientos. El primero consistió en estimar el modelo con todas las variables propuestas. Se calculó un modelo robusto para corregir el problema de heteroscedasticidad. Los resultados arrojaron estimadores estadísticamente no significativos con $p$-valeu mayores que 0.05 . Además, el valor 
del parámetro de convergencia $(\beta)$ fue negativo, pero relativamente bajo (-3.30). Ante estos resultados se estimó el modelo considerando el análisis descriptivo de correlación en función de su comportamiento tanto con respecto a la variable independiente como con respecto a las demás variables. ${ }^{22}$ Aunque hubo mejoría en el valor de $\beta$, los parámetros estimados de las demás variables continuaron siendo no significativos. Después, se usó el segundo procedimiento. Éste se apoya en la propuesta de Rogers, quien para estimar el parámetro $\beta$ en un modelo de convergencia sobre crecimiento económico entre países, estimó un conjunto de regresiones en las que, mediante prueba y error, estimó la variable del parámetro $\beta$ más otra variable independiente en cada una de las regresiones con el propósito de observar el efecto condicionado sobre el valor de $\beta$ (Rogers, 2003). Al usar este procedimiento, las estimaciones mejoraron notablemente.

En la primera regresión se estimó el modelo robusto de la variable dependiente tasa de crecimiento promedio anual del número de patentes asignadas en nanotecnología del país $i$, PatNanoi,2000-2010 en función de la variable logaritmo natural del número de patentes del año inicial (2000) asignadas en nanotecnología del país $i$, InPatNano2000, $i$, con el propósito de calcular solo el valor del parámetro $\beta$, el cual fue de -5.72 y estadísticamente significativo con un $p$-valeu de 0.032 (dato entre paréntesis en el cuadro 4.3). Siguiendo el procedimiento de Rogers, se calculó una regresión robusta para cada una de las variables independientes propuestas, con el propósito de observar el efecto condicionado sobre el valor de $\beta$, es decir, sobre el parámetro de convergencia. Los resultados muestran que variables tales como la tasa de crecimiento promedio anual del número de citas hacia atrás de las patentes solicitadas en nanotecnología del país $i$, AtechNano ${ }_{i 2000-2010}$; la tasa de crecimiento promedio anual del índice de desarrollo humano del país $i$, DHIi $2000-2010$, la tasa de crecimiento promedio anual del tamaño de equipos de inventores en nanotecnología del país $i$, SizeRTNanoi ${ }_{2000-2010}$, la tasa de

\footnotetext{
${ }^{22}$ El análisis de dispersión de las variables de control se complementó con un análisis de correlación: con respecto a la variable dependiente y entre ellas. Con respecto al primero, se identificaron cuatro variables que comparten una baja dispersión y una elevada correlación con respecto a la variable dependiente: InPatNano0, i; ClNanoi20002010; R\&D/GDPi2000-2010 y TechHeighti2000-2010. Este comportamiento estadístico sugiere que estas variables podrían incidir favorablemente en la variable dependiente, PatNanoi2000-2010.

En cuanto a la correlación entre las variables independientes, se identificaron seis combinaciones que presentaron correlación elevada: i) AtechNanoi2000-2010 y TechAbsCapFi2000-2010; ii) AtechNanoi2000-2010 y Hki20002010; iii) AtechNanoi2000-2010 y InstWeaki2005-2010; iv) ScTecLinkNano2000-2010 y TechAbsCapFi20002010; v) Hki2000-20 y ScTecLinkNano2000-2010 y vi) TechAbsCapFi2000-2010 y InstWeaki2005-2010. La consideración de estas combinaciones entre variables ayudó a encontrar la mejor especificación del modelo.
} 
crecimiento promedio anual del grado de estabilidad macroeconómica del país $i$, MacStrengthi $i_{2000-2010}$ y la tasa de crecimiento promedio anual del índice de corrupción en el país $i$, InstWeaki $i_{2005-2010,}$ muestran un efecto condicionado favorable en el valor de $\beta$. Sin embargo, solo en combinación, de manera separada, con AtechNano ${ }_{i 2000-2010}$ e InstWeaki $2005-2010$ el valor del parámetro $\beta$ es estadísticamente significativo (ver cuadro 4.3).

Hay otro grupo de variables, tales como la tasa de crecimiento promedio anual del número de citas de artículos científicos que realizan las patentes solicitadas en nanotecnología del país $i$, ScTecLinkNano $2000-2010$, la tasa de crecimiento promedio anual del índice de competitividad global del país $i$, ProdCompi $2000-2010$, y la tasa de crecimiento promedio anual de la capacidad de absorción tecnológica de las firmas del país $i$, TechAbsCapFi 2000-2010, que en combinación con InPatNano2000,i, se obtuvo un valor del parámetro $\beta$ estadísticamente significativo, pero menor; lo que sugiere que estas variables no condicionan favorablemente a la convergencia. Por último, se ubica otro grupo de variables tales como la tasa de crecimiento promedio anual del número de reivindicaciones (claims) de las patentes asignadas en nanotecnología del país $i$, ClNanoi $2000-2010$, la tasa de crecimiento promedio anual del gasto en investigación y desarrollo como porcentaje del PIB del país $i, R \& D / G D P i_{2000-2010}$, la tasa de crecimiento promedio anual del grado de tecnología disponible del país $i$, TechHeighti $2000-2010$, la tasa de crecimiento promedio anual del grado de eficiencia de las instituciones públicas del

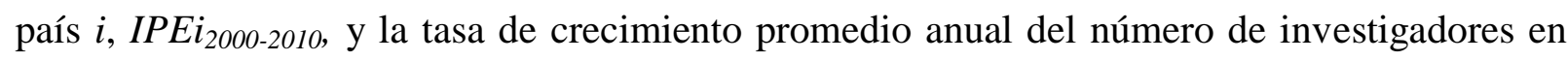
investigación y desarrollo por cada millón de habitantes del país $i, H k i_{2000-2010}$, que no inciden en la variable dependiente (PatNanoi,2000-2010) y, por ende, no condicionan favorablemente al proceso de convergencia (ver cuadro 4.3). 


\section{Cuadro 4.3. Regresiones (método de Rogers). Valores de $\beta$}

\begin{tabular}{|c|c|c|c|c|c|c|c|c|c|c|c|c|c|c|}
\hline Variables/Regresiones & 1 & 2 & 3 & 4 & 5 & 6 & 7 & 8 & 9 & 10 & 11 & 12 & 13 & 14 \\
\hline \multirow{2}{*}{ lnPatNano2000,i } & -5.7220 & -5.2567 & -5.4264 & -5.1491 & -6.1144 & -5.4131 & -5.7584 & -6.1098 & -5.497716 & -4.642984 & -5.580504 & -5.702473 & -5.731043 & -5.751022 \\
\hline & {$[0.032]$} & {$[0.067]$} & {$[0.07]$} & {$[0.092]$} & {$[0.029]$} & {$[0.042]$} & {$[0.06]$} & {$[0.06]$} & {$[0.069]$} & {$[0.135]$} & {$[0.044]$} & {$[0.044]$} & {$[0.067]$} & {$[0.051]$} \\
\hline \multirow[t]{2}{*}{ AtechNanoi,2000-2010 } & & 0.4759 & & & & & & & & & & & & \\
\hline & & {$[0.3]$} & & & & & & & & & & & & \\
\hline \multicolumn{2}{|l|}{ ScTecLinkNanoi,2000-2010 } & & 1.1730 & & & & & & & & & & & \\
\hline & & & {$[0.238]$} & & & & & & & & & & & \\
\hline \multirow[t]{2}{*}{ SizeRTNanoi,2000-2010 } & & & & -1.4342 & & & & & & & & & & \\
\hline & & & & {$[0.509]$} & & & & & & & & & & \\
\hline \multirow[t]{2}{*}{ ClNanoi,2000-2010 } & & & & & 0.1638 & & & & & & & & & \\
\hline & & & & & {$[0.012]$} & & & & & & & & & \\
\hline \multirow[t]{2}{*}{ R\&D/GDPi,2000-2010 } & & & & & & 0.1556 & & & & & & & & \\
\hline & & & & & & {$[0.2]$} & & & & & & & & \\
\hline \multirow[t]{2}{*}{ Hki2000-2010 } & & & & & & & -3.2080 & & & & & & & \\
\hline & & & & & & & {$[0.743]$} & & & & & & & \\
\hline \multirow[t]{2}{*}{ ProdCompi2000-2010 } & & & & & & & & 0.2194 & & & & & & \\
\hline & & & & & & & & {$[0.56]$} & & & & & & \\
\hline \multirow[t]{2}{*}{ TechHeighti,2000-2010 } & & & & & & & & & 0.8555458 & & & & & \\
\hline & & & & & & & & & {$[0.75]$} & & & & & \\
\hline \multirow[t]{2}{*}{ TechAbsCapFi2000-2010 } & & & & & & & & & & 1.15817 & & & & \\
\hline & & & & & & & & & & {$[0.328]$} & & & & \\
\hline \multirow[t]{2}{*}{ DHII2000-2010 } & & & & & & & & & & & -3.04961 & & & \\
\hline & & & & & & & & & & & {$[0.225]$} & & & \\
\hline \multirow[t]{2}{*}{ IPE22000-2010 } & & & & & & & & & & & & -0.8815083 & & \\
\hline & & & & & & & & & & & & {$[0.16]$} & & \\
\hline \multirow[t]{2}{*}{ MacStrengthi2000-2010 } & & & & & & & & & & & & & -0.0202632 & \\
\hline & & & & & & & & & & & & & {$[0.993]$} & \\
\hline \multirow[t]{2}{*}{ InstWeaki2005-2010 } & & & & & & & & & & & & & & -0.2862377 \\
\hline & & & & & & & & & & & & & & {$[0.889]$} \\
\hline
\end{tabular}

Fuente: elaboración propia con base en estimaciones del modelo.

Ahora bien, con base en la información obtenida usando el procedimiento de Rogers y considerando el análisis previo de la estadística descriptiva de las variables del modelo, se realizaron intentos por estimar un modelo que considere simultáneamente a un conjunto de variables. Finalmente, se llegó a la siguiente especificación particular:

$$
\begin{aligned}
\text { PatNano }_{i, 2000} & -2010 \\
& =\beta \text { PlnPatNano } \\
& +\alpha_{2000, i} \text { ScTecLinkNano }_{i, 2000-2010}+\alpha_{1} \text { AtechNano }_{i, 2000-2010} \text { SizeRTNano }_{i, 2000-2010} \\
& +\alpha_{4} \text { InstWeak }_{i, 2005-2010}+\varepsilon_{i}
\end{aligned}
$$

Se estimó una regresión robusta. Los resultados muestran una R-cuadrada de 0.5 , un valor estimado de $\beta$ de -6.31 , con un $p$-valeu de 0.038 lo que indica que este parámetro es estadísticamente significativo. Los resultados sugieren que la convergencia en la actividad inventiva en nanotecnología entre países en el largo plazo está condicionada por variables del entorno que se refieren a las capacidades tecnológicas y de innovación en nanotecnología, en particular: la tasa de crecimiento promedio anual de la acumulación de conocimiento tecnológico en el sector de nanotecnología del país $i$ (AtechNanoi,2000-2010); la tasa de crecimiento promedio anual de los vínculos entre la actividad científica y la actividad inventiva en este sector tecnológico del país $i$ (ScTechLinkNanoi,2000-2010); la tasa de crecimiento 
promedio anual de las capacidades inventivas de los investigadores en nanotecnología del país $i$ (SizeRTNanoi, 2000-2010); las capacidades sociales de los países considerados en el estudio, en particular, la tasa de crecimiento promedio anual de la debilidad institucional (InstWeaki, 2005-2010). No obstante, solo una de las variables de control tiene incidencia directa sobre la tasa de crecimiento promedio anual de la actividad inventiva en nanotecnología: la variable tasa de crecimiento promedio anual del número de citas hacia atrás de las patentes solicitadas en nanotecnología del país $i$, AtechNanoi, 2000-2010, con un p-valeu de 0.009 y valor del parámetro estimado de 0.1786 , es decir, un valor positivo, lo que sugiere que su incidencia sobre la variable dependiente es positiva, tal como se esperaba en la hipótesis correspondiente a esta variable. Las demás variables no tienen incidencia directa sobre la variable dependiente ya que presentan p-valeus mayores que 0.05 , pero sí condicionan el proceso de convergencia (ver cuadro 4.4).

Cuadro 4.4. Regresión. Coeficientes estimados del modelo de convergencia

\begin{tabular}{|l|r|r|}
\hline Variable independiente & Coeficiente & \multicolumn{1}{|c|}{ p-valeu } \\
\hline InPatNano 2000,i & -6.312414 & 0.038 \\
\hline AtechNano i,2000-2010 & 0.1786479 & 0.009 \\
\hline ScTecLinkNano $\boldsymbol{i , 2 0 0 0 - 2 0}$ & 0.146622 & 0.25 \\
\hline SizeRTNano i,2000-2010 & 0.1662029 & 0.63 \\
\hline Inst Weak i2005-2010 & -1.571873 & 0.276 \\
\hline Robusto, r & & \\
\hline 17 observaciones & & \\
\hline R-cuadrada: 0.4954 & & \\
\hline
\end{tabular}

Fuente: elaboración propia, con base en las estimaciones del modelo.

Se realizaron otras pruebas estadísticas para verificar la fortaleza de la regresión en su conjunto. En primer lugar, se realizó la prueba de White y se confirmó que los estimadores son homoscedásticos (p-valeu de H0, 0.3856). 
También se verificó si la regresión del modelo presenta problemas de multicolinealidad, es decir, si las variables independientes están correlacionadas entre ellas. Para probar esto, se aplicó la prueba VIF (factor de inflación de la varianza) (ver cuadro 4.5 ). ${ }^{23}$

\section{Cuadro 4.5. Prueba VIF}

\begin{tabular}{|l|c|c|}
\hline Multicolinealidad: Prueba VIF & & \\
\hline Variable & VIF & 1/VIF \\
\hline AtechNano i,2000-2010 & 1.14 & 0.875715 \\
\hline InstWeak i2005-2010 & 1.13 & 0.884724 \\
\hline InPatNano 2000,i & 1.11 & 0.89687 \\
\hline SizeRTNano i,2000-2010 & 1.1 & 0.909468 \\
\hline ScTecLinkNano i,2000-2010 & 1.02 & 0.977862 \\
\hline Media VIF & 1.1 & \\
\hline
\end{tabular}

Fuente: elaboración propia con base en estimación del modelo.

Otro supuesto que debe cumplir una buena regresión es el de normalidad de los errores. Los coeficientes que definen la normalidad de una distribución son el coeficiente de asimetría y el coeficiente de kurtosis, los que deben tomar valores de 0 y 3 , respectivamente. En este caso, el primero fue de -0.36 y el segundo de 1.98. La probabilidad de las diferencias en los valores de estos coeficientes muestra que, de manera individual, no se rechaza la hipótesis nula, H0, de que el coeficiente de asimetría es igual a cero, ya que la probabilidad es de 0.4492 . La hipótesis nula de que el coeficiente de kurtosis es igual a 3 tampoco se rechaza, ya que la probabilidad es de 0.3157 . La prueba conjunta arroja una probabilidad de 0.454 , por lo que se concluye que los errores se distribuyen en forma normal.

Por último, la prueba de Ramsey RESET muestra que la especificación del modelo es adecuada ( $p$-valeu, 0.1705) en el sentido de no haber omitido variables independientes en la especificación del modelo.

\footnotetext{
${ }^{23}$ La regla sobre este factor indica que existe multicolinealidad si el promedio de todos los VIF calculados es mayor que 10 o si el mayor de ellos es mayor que 10. En este caso, se confirmó que la regresión estimada no presenta problemas de multicolinealidad, ya que el promedio de todos los VIF es menor que $10 \mathrm{y}$ el mayor de ellos es también menor que 10 .
} 


\section{Interpretación de resultados}

Con la intención de interpretar los resultados se calcularon las elasticidades. ${ }^{24}$ La elasticidad asociada con InPatNanoi,2000-2010 es de -2.139801. Este valor sugiere que, si aumenta en $1 \%$ la productividad en la actividad inventiva en nanotecnología del conjunto de países estudiado, la tasa de crecimiento de las patentes solicitadas en el periodo 2000-2010 cae en 2.13\%. El resultado sugiere que el conjunto de países de estudio convergirá en el largo plazo, es decir, conforme se vaya agotando la actividad inventiva en nanotecnología, lo cual, ocurrirá al mismo tiempo en que se agote la difusión de este nuevo paradigma tecnológico. Además, el resultado muestra que la convergencia está condicionada al crecimiento de otras variables de carácter no solo tecnológico sino también de tipo social tal como la variable que se refiere a la debilidad institucional, InstWeaki, 2005-2010. Los resultados de los cálculos de las elasticidades muestran que al incrementarse en $1 \%$ el stock de conocimiento tecnológico acumulado en nanotecnología de los países de estudio en el periodo 2000-2010, AtechNanoi, 2000-2010, la tasa de crecimiento promedio anual de la actividad inventiva en este campo tecnológico, aumenta en $0.17 \%$ en el mismo periodo.

De esta forma, se puede afirmar que, si un país seguidor en nanotecnología tiene como propósito aprovechar las ventanas de oportunidad abiertas por la difusión de este nuevo paradigma tecnológico, debe incrementar su stock acumulado de conocimiento tecnológico en este sector, es decir, poner atención el aprendizaje y experiencia acumulada en la actividad inventiva en nanotecnología. A su vez, esto puede ser reforzado por políticas que incentiven la actividad inventiva en el sector.

Además, los resultados del modelo sugieren que otras variables tales como los vínculos entre el sector académico o científico, el apoyo a los equipos de investigación en nanotecnología y el combate a la corrupción son condicionantes que favorecen la convergencia en la actividad inventiva en nanotecnología en el largo plazo entre países y, en este sentido,

\footnotetext{
${ }^{24}$ El valor del coeficiente $\beta$ estimado en la regresión no puede ser interpretado de acuerdo con el fenómeno estudiado, ya que la variable dependiente PatNanoi,2000-2010 representa una tasa de crecimiento, mientras que la variable independiente InPatNano2000, $i$ se halla en logaritmo natural. Con este propósito, se calcula la elasticidad dividiendo el valor de $\beta$ entre la media de PatNanoi,2000-2010. De esta forma, si el valor de la elasticidad es mayor que 1 , entonces es elástica y si es menor que 1 es inelástica.
} 
pueden ser considerados en el diseño de políticas económicas orientadas a favorecer el crecimiento de este nuevo paradigma tecnológico (ver cuadro 4.6).

Por último, cabe señalar que los resultados del modelo confirman la hipótesis de autores como Greschenkron (1962), Nelson y Phelps (1966) y Abramovitz (1986), quienes sugirieron que la tasa de velocidad bajo la cual la brecha tecnológica es cerrada, debería estar vinculada con la habilidad de los seguidores de recibir las derramas de la tecnología de la frontera y que esto depende, en particular, no solo de factores tecnológicos sino, además, de factores económicos y sociales.

\section{Cuadro 4.6. Elasticidades de las variables explicativas del modelo}

\begin{tabular}{|l|r|}
\hline Variable independiente & Elasticidad \\
\hline InPatNano $2000, \boldsymbol{i}$ & -2.139801356 \\
\hline AtechNano $\boldsymbol{i}, 2000-2010$ & 0.1786479 \\
\hline
\end{tabular}

Fuente: elaboración propia con base en resultados del modelo.

Una vez presentado el análisis de los patrones de difusión de la nanotecnología en los países industrializados y emergentes, así como el estudio acerca de su posible convergencia, se concluye este capítulo con algunas sugerencias de política para los países industrializados y emergentes. 


\subsection{Algunas sugerencias generales para los países industrializados y emergentes}

\section{Países industrializados}

El análisis de los patrones de difusión del nuevo paradigma tecnológico de nanotecnología permitió identificar algunas tendencias en los países que mayores esfuerzos realizan en su generación y difusión a nivel de flujos de conocimiento: Estados Unidos, Japón, Corea del Sur y Alemania ${ }^{25}$. Así, de acuerdo con nuestro estudio, de este grupo de países Estados Unidos se ubica en la vanguardia: mayor actividad inventiva (de acuerdo con nuestra muestra, 63\% del total de patentes generadas a nivel mundial), patentes con mayor valor tecnológico y económico, mayor velocidad de difusión (rezago de cita promedio de 1.5 años) después de Corea del Sur (rezago de cita promedio de 0.92 años). A su vez, el sector tecnológico que genera la mayor parte de los nuevos conocimientos tecnológicos, y lo hace a mayor velocidad, es el sector de nanoestructura, el cual se halla vinculado con la industria de microelectrónica. De esta forma, el sector más desarrollado en términos de su aplicación comercial y, por ello más lucrativo, es el de nanomateriales (CIMAV, 2008). Aunque la actividad inventiva en nanotecnología no se restringe solo a este sector sino que se haya diversificada en otros tales como biotecnología, química, computación, medicamentos y medicinas, entre otros, falta mayor desarrollo comercial de los productos y procesos generados en estos sectores. Es ahí donde la iniciativa nacional de nanotecnología (NNI) de Estados Unidos tendrá que dirigir sus esfuerzos para lograr el objetivo de mantenerse a la vanguardia en nanotecnología (CIMAV, 2008). De hecho, los datos confirman que estos esfuerzos son crecientes: de 5000 millones de dólares destinados a la NNI en 2006 (CIMAV, 2008) ha pasado a 1.8 billones de dólares anuales (OCDE, 2013). Por otro lado, los esfuerzos dirigidos hacia la comercialización de productos y procesos generados en otros sectores, lo confirma la evaluación del impacto económico de la nanotecnología hecha en el simposio sobre nanotecnología organizado por la

\footnotetext{
${ }^{25}$ Cabe señalar que los resultados y tendencias del presente estudio, tendrían que contrastarse utilizando datos de patentes pertenecientes a otras oficinas tales como la EPO o la JPO, lo que implicaría repetir el estudio bajo el mismo periodo pero usando los datos de patentes de dichas oficinas, lo cual, podría realizarse en estudios futuros. Por este motivo, las tendencias halladas en el presente estudio deben considerarse como resultados parciales, por lo que no son suficientes para proponer políticas públicas dirigidas a los países industrializados o emergentes. Además, para alcanzar este propósito, se requieren estudios más profundos y exhaustivos en cada caso. No obstante, se pueden emitir algunas sugerencias generales para estos países.
} 
OCDE (2013). Se afirma que los esfuerzos en nanotecnología en Estados Unidos deberán orientarse hacia cuatro sectores en los próximos años: medio ambiente, salud, seguridad (EHS, por sus siglas en inglés) y en nanomanufactura. La tendencia que muestra este país, es un tránsito de la difusión amplia e intensa de los nuevos conocimientos generados en nanotecnología a través de los diferentes sectores tecnológicos, tal como lo muestra el índice de generalidad tecnológica (IGT), hacia la amplia difusión de los productos y procesos para su consumo a través del mercado. Así, al mismo tiempo en que Estados Unidos tendrá que sostener su liderazgo en la actividad inventiva y difusión de nuevos conocimientos tecnológicos en nanotecnología, tendrá que desarrollar la comercialización de los productos y procesos generados en este paradigma tecnológico para sostener su competitividad y potencial económico a nivel mundial. Pero el gran mercado tecnológico de Estados Unidos, así como la articulación de los agentes que participan en el sistema nacional de innovación de este país (universidades, firmas, centros de investigación y gobierno), a través de la NNI, favorecen las expectativas de liderazgo económico futuro de Estados Unidos (OCDE; 2013).

Los países seguidores más próximos (Japón, Corea del Sur y Alemania, principalmente) podrían aprovechar los nuevos conocimientos generados y difundidos en sectores estratégicos: biotecnología (Japón), química y biotecnología (Corea del Sur) y biotecnología y química (Alemania) y competir con Estados Unidos en las industrias relacionadas con estos sectores. La distancia que estos países mantengan respecto del país líder dependerá de la medida en que los sistemas nacionales de innovación de cada uno de estos países se mantengan articulados y funcionen eficientemente, así como de la capacidad del gobierno para generar incentivos para las inversiones.

De esta forma, los resultados de las elasticidades presentados en el cuadro 3.25 permiten realizar algunas sugerencias generales para este grupo de países. Tanto Japón como Corea del Sur tendrán que mejorar considerablemente en cuanto al número de reivindicaciones (claims), variable que mide los conocimientos novedosos contenidos en la patente, para ampliar su difusión. Para ello, su actividad inventiva tendría que aprovechar áreas poco exploradas en nanotecnología por Estados Unidos. La evaluación del impacto económico de la nanotecnología llevada a cabo en el simposio organizado por la OCDE (2013), muestra que la tendencia de Japón se dirige hacia generación, transmisión, almacenamiento y ahorro de energía, medio ambiente, medicina generativa y la aplicación de sistemas biológicos en otros 
campos (OCDE, 2013). Como se observa, se trata de sectores estratégicos que podrían mejorar la competitividad y el potencial económico de Japón. En el caso de Corea del Sur, tendrá que mejorar su capacidad de innovación en nanotecnología y, sobre todo, en aquellos sectores donde tiene oportunidades de competir comercialmente con Estados Unidos y Japón. Siendo Corea del Sur un país de industrialización relativamente reciente, tendrá que acelerar no solo en la generación de nuevos conocimientos en nanotecnología sino, al mismo tiempo, en la comercialización de los productos y procesos para no quedarse rezagado en este aspecto frente a Japón y Estados Unidos (CIMAV, 2008). El gobierno de Corea del Sur parece tener claros los objetivos a alcanzar en nanotecnología. En su iniciativa sobre nanotecnología, puesta en marcha un año después de que Estados Unidos pusiera en marcha su NNI, se plantean como objetivos: "establecer la infraestructura y los recursos humanos para 2005, comercializar nanotecnología a partir de esa fecha, convertirse en uno de los líderes mundiales a partir de 2010 y ser una de las siete naciones más avanzadas tecnológicamente para 2025." (CIMAV, 2008: 46).

En cuanto a la movilidad internacional de los inventores, el modelo muestra que si bien es importante en la difusión de este paradigma tecnológico, incide menos en la difusión que la no movilidad. A su vez, en las patentes de Corea del Sur incide más que en Estados Unidos y Japón. Tal vez la incidencia aumentaría si se amplían los acuerdos de cooperación entre las universidades y centros de investigación de estos países. Cabe señalar, que este resultado no considera la movilidad informal de los inventores, la cual, podría ser intensa y un factor importante en la actividad inventiva en nanotecnología. No obstante esta limitación presente en la metodología de patentes, el resultado del modelo sugiere que los gobiernos pueden promover o incentivar más la movilidad formal de inventores entre países, lo cual, potenciaría la difusión de este paradigma tecnológico.

Por otra parte, aunque la participación de las firmas en la actividad inventiva en nanotecnología es fundamental en Estados Unidos, Japón y Corea del Sur, lo es más en el primero. Esto sugiere que los gobiernos de Japón y Corea del Sur podrían cerrar la brecha en este punto al generar mayores incentivos para atraer inversión y, con ello, mayor participación de las firmas sobre todo en aquellas áreas donde podrían tener ventaja o competir con los Estados Unidos. 
Otra brecha donde Estados Unidos aventaja a Japón y Corea del Sur es en la incidencia que tiene la amplitud de las patentes. Así, se espera que una patente asignada en nanotecnología tenga mayor posibilidad de aplicación y uso comercial si presenta mayor amplitud. Nuevamente, Japón y Corea del Sur podrían incentivar la actividad inventiva en nanotecnología en áreas menos exploradas, por ejemplo nanobiotecnología, y orientadas a resolver problemas específicos de salud y medio ambiente. De hecho, el gobierno de Japón se plantea impulsar estas áreas como parte del tema "Nanotecnología y Materiales" en su plan básico de ciencia y tecnología (CIMAV, 2008).

En cuanto a Alemania, los resultados del modelo mostraron que solo el efecto marginal de la variable que denota la amplitud baja de las patentes en nanotecnología resultó significativo, por lo que solo se pueden hacer sugerencias en este aspecto. Así, las patentes de Alemania tendrán que aumentar su amplitud, igualmente, hacia sectores poco explorados. De acuerdo con este análisis, el potencial de Alemania se ubica en biotecnología y química. Como se mostró en los primeros apartados del capítulo 3, Alemania tiene un importante potencial en gasto en I+D dedicado a nanotecnología, en infraestructura e investigación, lo que se refleja en una tendencia creciente en la actividad inventiva en este paradigma tecnológico. Sin embargo: “comparado con Estados Unidos y el sureste asiático, Alemania tiene el reto de reducir el tiempo que le toma el llevar el resultado de las investigaciones a productos listos para el consumidor. Esto significa que debe llevar a cabo cambios que conduzcan a intensificar los esfuerzos para utilizar los resultados de las investigaciones y establecer los procedimientos regulatorios y de estandarización que sean necesarios.” (CIMAV, 2008: 33).

Otro grupo de países industrializados compuesto por Taiwán, Canadá y Francia se identificó y caracterizó en el presente estudio como seguidor del primer grupo. Aunque el modelo de difusión no se aplicó a este grupo, la información proporcionada por datos de patentes y otras fuentes de datos, proporcionan información para realizar algunas sugerencias generales. Así, estos datos sugieren que estos países muestran una tendencia creciente en cuanto a los esfuerzos realizados en I+D destinado a nanotecnología, así como en el potencial de la actividad inventiva en este paradigma tecnológico. Taiwán se ubica a la vanguardia de este grupo y más cercano al primer grupo. Así, de acuerdo con el análisis presentado en el presente estudio, el sector tecnológico más dinámico de Taiwán es el de química, la amplitud de las patentes asignadas en nanotecnología es media y la participación de las firmas y el 
gobierno en la actividad inventiva en este paradigma tecnológico también es media. Aunque presenta un importante potencial en investigación y desarrollo en nanotecnología, lo que se muestra a través del número de maestros y doctores graduados en áreas relacionadas con la nanotecnología (2 939 en total, datos de 2011 del Banco Mundial) y, en promedio, tamaño de investigadores grande (aproximadamente 3 investigadores), el gobierno de Taiwán tendrá que seguir impulsando no solo la infraestructura que se requiere para aumentar la capacidad en investigación y desarrollo en este paradigma tecnológico sino, al mismo tiempo, dirigir los esfuerzos para impulsar la actividad inventiva en nanotecnología en más sectores tecnológicos, es decir, aumentar la amplitud de las patentes. Esto último, requiere el destino de inversión pública en tales sectores y la atracción de la inversión privada. En este sentido, la tarea del gobierno de Taiwán se esclarece: impulsar la nanotecnología en una variedad más amplia de sectores tecnológicos a través dela inversión pública y atraer la inversión privada.

En el caso de Canadá, también presenta una tendencia creciente en el potencial de la investigación científica en nanotecnología: universidades que aumentan su actividad de investigación en este paradigma, número de artículos científicos a velocidad creciente, mayor número de investigadores dedicados a nanotecnología, principalmente. Sin embargo, su capacidad inventiva es relativamente limitada: de 81 patentes asignadas en la USPTO en 2011 pasó a 127 en 2014. Esto sugiere que el gobierno de Canadá tiene la tarea no solo de continuar promoviendo la actividad de investigación en nanotecnología sino, además, de impulsar la actividad inventiva en este paradigma tecnológico.

La situación de Francia muestra, igualmente, potencial creciente en investigación dedicada a nanotecnología: gran cantidad de artículos publicados por año (4 554 artículos en 2011 y 5618 artículos en 2015), impulso de redes de investigadores en nanociencia y nanotecnología y equipos grandes de inventores (3) en promedio. La actividad inventiva de Francia medida a través del número de patentes asignadas en nanotecnología, muestra una tendencia creciente pero aún es limitada: 142 patentes en 2011 y 347 patentes en 2014. La participación del gobierno en la actividad inventiva es significativa (0.75) y la amplitud de sus patentes es media (valor del IGT de 0.44). Estos datos sugieren que el gobierno de Francia tendrá que mantener la tendencia creciente en investigación dedicada a nanotecnología y, también, tendrá que impulsar la inversión privada en una diversidad de sectores menos 
explorados por la nanotecnología. Al mismo tiempo, aumentará la amplitud promedio de las patentes y la participación del sector privado.

Los resultados del modelo de convergencia complementan estas sugerencias generales, ya que muestran que la convergencia entre el país líder en nanotecnología (Estados Unidos) y los países seguidores, entre los que se encuentran países industrializados y emergentes, pueden cerrar la brecha respecto del país líder si aumentan su stock de conocimientos en este sector, si aumentan las novedades reconocidas en las patentes asignadas en nanotecnología, si aumenta el potencial de los equipos de investigación, es decir, si el entorno en donde se lleva a cabo la actividad inventiva en nanotecnología es mejorado, pero también si mejora el entorno social del país donde se lleva a cabo ésta, tal como lo indica la variable que se refiere al funcionamiento de las instituciones públicas. Aunque, de acuerdo con los resultados del modelo, solamente la variable que se refiere a la acumulación de conocimientos en nanotecnología tiene incidencia directamente sobre la actividad inventiva en este sector, la combinación con las otras variables es importante porque refuerza el proceso de convergencia. En este sentido, los países industrializados seguidores de Estados Unidos en nanotecnología no solo pueden aprovechar su fortaleza en ciertas subclases tecnológicas de la nanotecnología, sino también mejorar el entorno social donde se lleva a cabo la actividad inventiva.

A continuación se exponen algunas sugerencias para un grupo de países emergentes.

\section{Países emergentes}

En cuanto a los países emergentes, los estudios empíricos sobre la difusión de los nuevos paradigmas tecnológicos y una mejor comprensión de este fenómeno podría ayudar para que los gobiernos de estos países diseñen estrategias para aprovechar las posibles ventanas de oportunidad abiertas por la difusión, en este caso, de la nanotecnología y, cerrar así, las brechas de crecimiento y desarrollo que los separan de los países industrializados. De acuerdo con Carlota Pérez, la fase inicial de una revolución tecnológica puede ser aprovechada por los países emergentes para tomar una posible ruta de crecimiento y desarrollo: "Aparte de la fase de madurez, el otro momento cuando los actores débiles enfrentan obstáculos superables no es en la segunda ni en la tercera fase, sino en la primera [...] Son grandes las posibles ganancias, 
se presentan amplias posibilidades de crecimiento del mercado y la productividad y los costos de inversión son realmente bajos. Incluso la inversión en actividades de I\&D puede ser menor que la del innovador original" (Pérez; 2001: 118-119).

En este sentido, países como China, Rusia, India y Brasil, han tomado la iniciativa de aprovechar las ventanas de oportunidad abiertas por este nuevo paradigma tecnológico. Un obstáculo que presentan estos países para lograrlo es la desarticulación de los agentes que participan en sus sistemas nacionales de innovación (universidades, firmas, gobierno y centros de investigación). Sin embargo, hay algunos países como China, India y Brasil, que presentan una buena base científica y, por lo tanto, el capital humano requerido para el impulso del nuevo paradigma tecnológico, aunque faltan los incentivos para atraer las inversiones de las firmas y establecer los vínculos con el sector académico. Ante esta situación, se proponen dos estrategias básicas para estos países:

i) Impulsar la actividad inventiva en áreas con potencial para atraer capital de riesgo extranjero;

ii) Promover clusters y alianzas estratégicas entre los sectores gobiernouniversidad-industria. Por cluster se entiende una concentración geográfica de compañías que compiten y cooperan, productores e instituciones asociadas. Un ejemplo es Silicon Valley.

Estas sugerencias se complementan, nuevamente, con otras que se derivan de los resultados del modelo de convergencia. Los resultados confirman la hipótesis de que la convergencia de los países seguidores depende del desarrollo de capacidades tecnológicas en el sector de nanotecnología, tales como el conocimiento tecnológico acumulado, el desarrollo y reforzamiento de los vínculos entre los sectores inventivo y académico, el apoyo a los equipos de inventores en nanotecnologías, así como el desarrollo de capacidades sociales, por ejemplo, disminuyendo los niveles de corrupción. Los resultados del modelo también sugieren que el desarrollo de las capacidades de absorción tecnológica a nivel nacional es importante, ya que sin éstas no se pueden incentivar las capacidades tecnológicas a nivel de sector tecnológico. En este sentido, el reto para los países emergentes seguidores es mucho mayor que para los países industrializados seguidores: por un lado, aumentar los esfuerzos en investigación y desarrollo 
al mismo tiempo que articular a los actores que participan en el SNI y, por otro lado, mejorar las condiciones del entorno institucional y social.

Con base en estos resultados se plantean las siguientes sugerencias generales para los países emergentes: mejorar las capacidades tecnológicas en nanotecnología a través de un mayor gasto en I+D orientado hacia ese sector, acompañado de políticas orientadas al desarrollo de las capacidades de absorción tecnológica del país en su conjunto, a través de políticas orientadas a establecer o reforzar los vínculos entre los agentes que forman parte del sistema nacional de innovación (SNI), cambios institucionales que permitan mayor eficiencia de éste, así como los incentivos que requiere la actividad inventiva a través de los derechos de propiedad intelectual (DPIs) o a través del comercio. Mejorar las condiciones sociales donde se lleva a cabo la actividad inventiva, elevando los niveles de desarrollo humano, mejorando la estabilidad macroeconómica, así como disminuyendo los niveles de corrupción. 


\section{Conclusión}

Con el propósito de explicar los patrones de difusión en países industrializados y emergentes de un nuevo paradigma tecnológico, en particular, el caso de la nanotecnología (NPN), la presente investigación se llevó a cabo con base en tres preguntas de trabajo planteadas en el marco de la teoría evolucionista. La primera, interroga acerca de las características e importancia económica de la difusión de este nuevo paradigma en países industrializados y emergentes: ¿hacia qué sectores económicos y clases tecnológicas se difunde el NPN y cuál es su importancia económica en países industrializados y emergentes? Como hipótesis, se esperó mostrar que el ámbito de la difusión de la nanotecnología es amplio y va desde los sectores tecnológicos maduros hasta los recientemente considerados nuevos paradigmas tecnológicos (TIC y biotecnología). De acuerdo con la metodología propuesta para el estudio de este fenómeno se confirmó que, en efecto, en cuanto al análisis a nivel mundial, el NPN se difunde en orden de magnitud en las siguientes clases tecnológicas: nanoestructura, biotecnología y química; y lo hace a una velocidad promedio de 1.36, 1.57 y 1.8 años, respectivamente. Los datos sugieren que en nanoestructura, donde tuvo su origen este nuevo paradigma asociado con la microelectrónica, se lleva a cabo la mayor actividad inventiva (37.8 $\%$ del total de patentes) y, al mismo tiempo, el nuevo conocimiento generado ahí se difunde a mayor velocidad hacia otras clases y sectores tecnológicos a nivel mundial. En cuanto a su propagación a nivel sectorial y, de acuerdo con la clasificación de Jaffe y Trajtenberg (2002), se confirmó que las aplicaciones y usos de los nuevos conocimientos en nanotecnología son amplios, y ocurren en diversos sectores tecnológicos: química, biotecnología, mecánica, eléctrica y electrónica, computación y comunicaciones, medicamentos y medicinas, y otros. A su vez, la principal actividad inventiva se concentra en química, eléctrica y electrónica y medicamentos y medicinas con una participación de 36\%, 32\% y 15\%, respectivamente. De éstos, el sector que difunde el nuevo conocimiento a mayor velocidad es química, con un rezago temporal de cita (lag time) promedio de 1.33 años, mientras que medicamentos y medicinas difunde los conocimientos nuevos a menor velocidad promedio (2.54 años) que los demás sectores. En contraste, computación y comunicaciones, el cual se halla asociado con la revolución tecnológica de las TIC, es el sector que reporta la más alta velocidad de difusión de 
las invenciones de todos los sectores, ya que reporta un lag time promedio de 0.94 años. Estos resultados se complementan con la estimación del índice de generalidad tecnológica (IGT) propuesto por Trajtenberg et al. (1997), el cual, mide la amplitud de las patentes asignadas en un sector tecnológico hacia otros sectores. El valor del IGT se ubica entre 0 y 1, siendo 1 (o cercano) un alto impacto en otros sectores y, 0 (o cercano), nulo o bajo impacto. Se confirmó que el valor promedio del IGT de las patentes asignadas en nanotecnología es de 0.37 , que se ubicó como una amplitud media. En particular, el sector que presenta un valor del IGT más elevado es biotecnología (0.4), lo que sugiere que los nuevos conocimientos generados por la actividad inventiva en nanotecnología que tienen mayor amplitud, se ubican en el sector de biotecnología, seguidos por los generados en nanoestructura (0.39).

En cuanto al análisis por países, la importancia económica de este nuevo paradigma tecnológico, se ve reflejada en los gastos en I+D que los países dedican a la actividad inventiva en nanotecnología. De esta forma, se identificaron cuatro países industrializados que mayores esfuerzos realizan. Considerando información de 2013, los montos asignados por estos países son: Estados Unidos (\$14 054000000 dólares), Corea del Sur (\$7 687100000 dólares), Alemania (\$1 549300000 dólares) y Japón (\$1 063000000 dólares). En estos países, las clases que más difunden los nuevos conocimientos generados en nanotecnología, medido a través del número de citas promedio que reciben las patentes asignadas en las clases, son: Estados Unidos (nanoestructura), Japón (biotecnología), Corea del Sur (biotecnología y química) y Alemania (biotecnología). Por sectores tecnológicos, los que más difunden en orden de importancia son para el caso de Estados Unidos: química, eléctrica y electrónica; en Japón: eléctrica y electrónica y química; en Corea del Sur: química y en Alemania: medicamentos y medicinas y eléctrica y electrónica.

Detrás de este grupo de países, se ubican otros tales como Taiwán, Canadá y Francia, los cuales, aunque dedican menores esfuerzos en la actividad inventiva en nanotecnología que los primeros, muestran un importante potencial en investigación científica orientada a este paradigma, la cual, se expresa en una actividad relativamente menor que en los países del primer grupo pero creciente, sobre todo a partir de 2011. Así, en 2011 Taiwán contaba con 2 022 maestros graduados y 917 doctores en áreas relacionadas con la nanotecnología (Banco Mundial, 2011). En ese año, registró 3165 artículos indexados sobre este tema y 308 patentes solicitadas en USPTO en comparación con las 551 solicitadas en 2014 en esta oficina. En el 
caso de Canadá, en 2008 registró 4470 investigadores en I+D por cada millón de personas. En 2011, reportó 2386 artículos publicados sobre nanotecnología en revistas indexadas, es decir, 779 artículos por debajo de Taiwán y solamente 81 patentes solicitadas en USPTO, aunque en 2014 el dato aumentó a 127 patentes. En el caso de Francia, en 2009 registró 3751 investigadores en I+D por cada millón de personas (Banco Mundial, 2009). En 2011 publicó 4 554 artículos sobre nanotecnología en revistas indexadas, es decir, dato superior al de Taiwán y Canadá. En cuanto al número de patentes en nanotecnología, en 2011 solicitó 142 patentes en USPTO y 347 en 2014.

Por último, cabe señalar que dentro de los países emergentes destacan cuatro países por su potencial, aunque limitado pero creciente en nanotecnología: Brasil, Rusia, India y China (BRIC), que podrían incorporarse en los próximos años a la competencia por tecnología y aprovechar las posibles ventanas de oportunidad dadas por la difusión de la nanotecnología. Aunque estos países muestran potencial en nanociencia cobijado por políticas y programas orientados a promover la actividad inventiva en nanotecnología, su nivel de actividad inventiva sigue siendo relativamente escaso. Solamente China destaca en este rubro. De esta forma, en 2011 registró 180 patentes en USPTO y pasó a 511 en 2014. Estos países se encuentran en proceso de reformas institucionales que podrían favorecer a la limitada actividad inventiva en nanotecnología los próximos años.

Sobre la segunda pregunta de trabajo: ¿cuál es la probabilidad de que los países difundan y a mayor velocidad el NPN y qué factores son determinantes? Se propuso la siguiente hipótesis a verificar: se espera que la mayor probabilidad de difusión y velocidad del nuevo paradigma tecnológico, nanotecnología, se halle asociado con: investigación y desarrollo (I+D); redes internacionales de investigación; tamaño de equipos de investigación; extensión de campos tecnológicos; stock de conocimientos científicos y tecnológicos; colaboración entre universidades-firmas y especialización tecnológica del país.

Esta segunda hipótesis también se confirmó. En efecto, la mayor difusión y velocidad de la nanotecnología ocurre en aquellos países que invierten más en $\mathrm{I}+\mathrm{D}$, que cuentan con un mayor número de investigadores, más redes de investigación, equipos más grandes de investigación y mayor colaboración entre universidades, institutos y empresas. Así, los resultados que arrojó nuestro análisis son los siguientes: en cuanto a la propagación por países, los países que mayores esfuerzos realizan (mayor número de patentes asignadas en 
nanotecnología) para promover el NPN son los que realizan mayores esfuerzos en I+D a nivel mundial como porcentaje del PIB, es decir, Estados Unidos (2.7\%), Japón (3.5\%), Corea del Sur (3.4\%) y Alemania (2.9\%). Estos países, al mismo tiempo son los que destinan mayores gastos en I+D en nanotecnología, como ya se mostró en el análisis de la primera hipótesis.

Acerca de la velocidad de difusión (lag time), el NPN se difunde en estos países a distintos ritmos en promedio: Estados Unidos (1.53 años), Japón (1.94 años), Corea del Sur (1 año) y Alemania (2.06 años). A su vez, en cada uno de estos países las clases tecnológicas que difunden a mayor velocidad los nuevos conocimientos generados en este nuevo paradigma son: nanoestructura (1.38 años) en Estados Unidos, nanoestructura (1.6 años) en Japón, biotecnología (0.6 años) en Corea del Sur y biotecnología y nanoestructura (1.5 años) en Alemania. Estos datos podrían sugerir tendencias de especialización sectorial de estos países. Al contrastar las clases que más difunden con la velocidad de difusión, se encontró que, solo en los casos de Estados Unidos y Japón, las clases que más difunden son, al mismo tiempo, las que lo hacen a mayor velocidad.

Ahora bien, con base en el análisis de la difusión (número de citas recibidas en promedio) y de la velocidad de difusión (lag time), se propuso una taxonomía de los patrones de difusión por países. Así, se distinguen los siguientes tipos de difusión: i) difusión altavelocidad media (Estados Unidos, Japón y Alemania); ii) difusión baja-velocidad alta (Corea del Sur); iii) difusión alta-velocidad alta (Taiwán); iv) difusión media-velocidad media (Francia); v) difusión media-velocidad alta (China).

Sobre los factores que determinan la difusión, los resultados del modelo econométrico de conteo aplicado a nivel mundial (incluyendo a todos los países de la muestra de n=376 patentes), confirman que las principales variables que influyen en la difusión de este nuevo paradigma tecnológico a nivel de actividad inventiva son: el número de reivindicaciones (claims), la movilidad internacional de los inventores, la amplitud tecnológica medida a través del índice de generalidad tecnológica $(I G T)$ y la participación del gobierno y de las firmas. Un resultado relevante es que, a su vez, la participación de las firmas es más importante que la participación del gobierno en la difusión de la nanotecnología.

Al estimar el modelo de conteo en los casos de Estados Unidos, Japón y Corea del Sur, las principales variables que explican su patrón de difusión son: el número de reivindicaciones o claims, $\mathrm{Cl}$, la movilidad internacional de los inventores, MobIn, la participación de las firmas 
en las patentes, Firminv, y la amplitud media (Medisp) y baja (Disper) de la patente. Cabe señalar que, en el caso de Alemania, solo la variable Disper resultó estadísticamente significativa, lo que podría deberse al tamaño de la muestra o el exceso de ceros, por lo que se podría corregir aumentando el tamaño de la muestra y aplicando otro modelo que considere el problema de exceso de ceros.

En cuanto a la participación de las firmas, las que más difunden el NPN se ubican, a nivel mundial, en los sectores de química, eléctrica y electrónica y medicamentos y medicina, con 56, 32 y 14 patentes asignadas en este campo tecnológico lo que representa, en conjunto, el $27.1 \%$ del total de patentes de la muestra de tamaño $n=376$. Por países que mayores esfuerzos realizan por promover la actividad inventiva en este paradigma tecnológico, el país que reportó en el año 2013 mayor número de firmas en nanotecnología fue Estados Unidos con 10 341, le siguen Alemania con 1110 firmas, Corea del Sur con 504 firmas y Japón con 225 firmas. A su vez, las firmas especializadas o dedicadas en nanotecnología varían en cada uno de estos países. Alemania reportó en ese año 300 firmas, seguido por Corea del Sur con 173 y Estados Unidos con 139. En cuanto al número de firmas pequeñas que difunden el NPN, Estados Unidos reporta 7531 firmas, seguido de Alemania con 800 firmas y Corea del Sur con 132 firmas.

Si bien, como lo muestran los resultados del modelo en estos países, la importancia de las firmas es mayor que la del gobierno en la difusión de los nuevos conocimientos generados en nanotecnología, estos países industrializados se caracterizan por contar con sistemas nacionales de innovación articulados, en los que la coordinación de los agentes que participan en la actividad inventiva de nanotecnología (universidades, firmas y centros públicos y privados de investigación) se halla dirigida por iniciativas, programas y políticas gubernamentales tales como la Iniciativa Nacional de Nanotecnología (NNI, por sus siglas en inglés) de Estados Unidos encargada de financiar y coordinar a los agentes que llevan a cabo la actividad inventiva en este paradigma tecnológico a partir de 2001. En general, la NNI tiene como propósito desarrollar recursos educativos, mano de obra especializada e infraestructura para el avance de la nanotecnología así como facilitar la transferencia de estas nuevas tecnologías para el crecimiento económico (CIMAV, 2008). Tal como lo muestran los resultados del presente estudio el sector más importante, por el lado de la oferta, en nanotecnología en Estados Unidos es nanoestructura (mayor actividad inventiva, difusión y 
velocidad de difusión), y también lo es por el lado de la demanda, ya que es el sector más rentable (CIMAV, 2008). Sin embargo, la NNI tiene como propósito no solo continuar impulsando al sector de nanoestructura sino, además, al sector de biotecnología y orientar su desarrollo hacia la comercialización de sus productos. En el caso de Japón, las agencias gubernamentales y grandes corporaciones son la base del apoyo que recibe la actividad inventiva en nanotecnología. En este caso, se trata de una iniciativa combinada entre gobierno y firmas. Como se mostró, el sector más dinámico en Japón es nanoestructura, asociado con el desarrollo de materiales y electrónica. Sin embargo, también tienen como propósito el apoyo a nanobiotecnología, relacionado con medicamentos y medicina. En el caso de Corea del Sur, el gobierno se encarga del financiamiento y dirección de la actividad inventiva en nanotecnología desde 2001 a través de la iniciativa nacional NT Master Plan, con el propósito de contar con la infraestructura y los recursos humanos necesarios para el impulso a la nanotecnología. También tiene como propósito la comercialización de los productos, sobre todo de biotecnología que es el sector más dinámico. En el caso de Alemania, la actividad inventiva en este paradigma también es impulsada por el gobierno a través de su Nano-Iniciativa, como parte de sus planes. El gobierno de este país, tiene claro impulsar la comercialización de los productos en nanotecnología asociados con biotecnología y materiales. Para ello, se ha propuesto realizar los cambios institucionales y formales requeridos para su comercialización. En todos estos casos, el papel protagonista del gobierno es central en el financiamiento, orientación y coordinación de los agentes que participan en la actividad inventiva en nanotecnología. En estos países, los sistemas nacionales de innovación son articulados por el gobierno a través de distintas estrategias de colaboración entre los agentes que participan en la actividad inventiva en este nuevo paradigma tecnológico.

Ahora bien, considerando el análisis de la evidencia empírica así como los resultados del modelo de conteo, es posible identificar un país líder a nivel de actividad inventiva en nanotecnología: Estados Unidos, y países industrializados seguidores inmediatos, Japón, Corea del Sur y Alemania y, detrás de estos, se ubican otros países como Taiwán, Canadá, Francia y a su vez, detrás de éstos, países emergentes como China, Rusia, India y Brasil que muestran una intención de aprovechar las posibles ventanas de oportunidad abiertas por la difusión de la nanotecnología. Ante estas diferencias entre países resulta plausible la tercera pregunta de investigación. Si existen brechas a nivel de actividad inventiva en este paradigma tecnológico 
¿los países seguidores podrán alcanzar en algún momento a los países líderes y qué condiciones requieren para lograrlo? La hipótesis planteada para esta pregunta fue: se espera que la convergencia tecnológica y de innovación en la nanotecnología entre países, en el largo plazo, esté condicionada por la existencia de tres conjuntos de factores reconocidos por algunos autores en las discusiones sobre crecimiento económico y convergencia entre países (Abramovitz, 1986; Rogers, 2003; Manca, 2009; Fagerberg et al., 2012): capacidades tecnológicas y de innovación en el sector, las capacidades de absorción tecnológica a nivel nacional y por las capacidades sociales del país.

Para verificar esta hipótesis, se propuso un modelo econométrico de tipo OLS (mínimos cuadrados ordinarios) usando datos de corte transversal. Los resultados del modelo para verificar convergencia confirmaron parcialmente la hipótesis de trabajo planteada. En efecto, se confirmó que la convergencia en la actividad inventiva en el NPN entre países está condicionada, en el largo plazo, a la existencia de capacidades tecnológicas y de innovación en el sector y las capacidades sociales del país. Cabe señalar, que las variables seleccionadas referidas a las capacidades de absorción tecnológica a nivel nacional, no resultaron significativas. Así, la convergencia en la actividad inventiva en nanotecnología entre países en el largo plazo está condicionada por variables del entorno que se refieren a las capacidades tecnológicas y de innovación en nanotecnología, en particular, la tasa de crecimiento promedio anual de la acumulación de conocimiento tecnológico en el sector de nanotecnología del país $i$ (AtechNanoi,2000-2010); la tasa de crecimiento promedio anual de los vínculos entre la actividad científica y la actividad inventiva en este sector tecnológico del país $i$ (ScTechLinkNanoi,2000-2010); la tasa de crecimiento promedio anual de las capacidades inventivas de los investigadores en nanotecnología del país $i$ (SizeRTNanoi, 2000-2010); y a las capacidades sociales de los países considerados en el estudio, en particular, la tasa de crecimiento promedio anual de la debilidad institucional (InstWeaki, 2005-2010). No obstante, solo una de estas variables tiene incidencia directa sobre la tasa de crecimiento promedio anual de la actividad inventiva en nanotecnología: la variable tasa de crecimiento promedio anual del número de citas hacia atrás de las patentes solicitadas en nanotecnología del país $i$, AtechNanoi, 2000-2010, lo que sugiere la importancia de los procesos de aprendizaje acumulados en el sector. 
Con base en estos resultados, se plantearon algunas sugerencias generales para los países seguidores: mejorar las capacidades tecnológicas en nanotecnología, a través no solo de un mayor gasto en I+D orientado hacia ese sector sino, además, acompañado de políticas orientadas al desarrollo de las capacidades de absorción tecnológica del país en su conjunto, a través de políticas orientadas a establecer o reforzar los vínculos entre los agentes que forman parte del sistema nacional de innovación (SNI) y mejorar las condiciones sociales en el entorno donde se lleva a cabo la actividad inventiva, mejorando la eficiencia de las instituciones públicas de tal forma que disminuyan los niveles de corrupción.

Estas sugerencias, se pueden complementar con otras que se derivan del análisis de los patrones de difusión de los países, tales como: generar mayores incentivos para atraer inversión y, con ello, mayor participación de las firmas. Orientar la actividad inventiva en nanotecnología hacia áreas poco exploradas y aumentar así la amplitud de las patentes. También esta medida puede servir para atraer capital de riesgo extranjero; promover clusters y alianzas estratégicas entre los sectores gobierno-universidad-industria. En otras palabras, se sugiere que, para que estos países logren aprovechar sus propios recursos y posicionarse en la difusión de un nuevo paradigma tecnológico, se requieren medidas que contribuyan a articular e incentivar a los agentes que participan en el sistema nacional de innovación. Esto podría lograrse a través de políticas gubernamentales que incentiven la actividad inventiva en nanotecnología en el marco de políticas de crecimiento.

Finalmente, cabe mencionar algunas preguntas que dio pie esta investigación y que podrían abordarse en futuras investigaciones: ¿cuáles son los patrones de difusión de los productos y procesos generados por la nanotecnología en el mercado? ¿Qué sectores de la producción utilizan innovaciones en nanotecnología para competir y cómo se están beneficiando? ¿Cómo los países emergentes podrían aprovechar los recursos naturales y el potencial en investigación científica en la configuración de la futura revolución tecnológica basada en el paradigma molecular? ¿Cuál será la situación de los países que logren aprovechar sus recursos y potencial científico? Y ¿cuál será la situación de aquellos países emergentes que no lo hagan? ¿En qué sentido cambiarán las instituciones, organizaciones y estilo de vida de la población al difundirse la próxima revolución tecnológica basada en la nanotecnología? ¿Qué nuevos problemas económicos, sociales y del medio ambiente se gestarán ante la difusión y consumo de los productos basados en la nanotecnología? La incertidumbre que existe ante la 
difusión de un nuevo paradigma tecnológico abre nuevas interrogantes y, al mismo tiempo, posibilidades de evolución no solo de un paradigma tecnológico sino, también, de desarrollo de la sociedad. Pero depende de cómo los agentes que participan en los sistemas nacionales de innovación logran visualizar las posibles tendencias de la difusión del nuevo paradigma y de cómo logren aprovechar las posibles ventanas de oportunidad abiertas en el proceso de difusión. 


\section{Bibliografía}

Abramovitz, M. (1986). "Catching Up, Forging Ahead, and Falling Behind”. The Journal of Economic History, vol. 46, número 2, pp. 385-406.

. (1989). Thinking about growth. And other essays on economic growth and welfare. Cambridge: Cambridge University Press.

Abramovitz, M. y David, P. A. (1996). "Technological change and the rise of intangible investments: the US Economy's growth-path in the twentieth century" en D. Foray y B. A. Lundvall (editores), Employment and Growth in the Knowledge-based Economy. París: OCDE.

Acosta, M.; Coronado, D. y A. M. Fernández. (2008). Pautas de difusión de la tecnología española. Una identificación a través de la información contenida en las patentes [versión electrónica]. Consultado en www. minetur.gob.es el 20 de octubre de 2014.

Albuquerque, E.; Britto, G.; Silva, O., y Kruss, G. (2011). “Global Interactions Between Firms and Universities: Global Innovation Networks as first steps towards a Global Innovation System". CEDEPLAR, Texto para discussao número 419. Belo Horizonte: UFMG/CEDEPLAR, 2011.

Aldana, M. (2006). "Redes Complejas". [Versión electrónica]. Consultado en www.fis. unam.mx/ max/English/notasredes.pdf el 8 de enero de 2014.

Alonso, J.; Carrillo, J. y O. Contreras. (2000). "Trayectorias tecnológicas en empresas maquiladoras asiáticas y americanas en México". Santiago de Chile. Red de Reestructuración y competitividad. División de desarrollo productivo y empresarial. Agosto de 2000. CEPAL-Naciones Unidas.

Anderson, D. R.; Sweeney, D. J. y Williams, T. A. (2008). Estadística para administración y economía. México: Cengage Learning.

Archibugi, D. y A. Filippetti. (2010). "The Global of Intellectual Property Rights: Four Learned Lessons and Four Theses”. Global Policy, 1 (2), pp. 137-149.

Archibugi, D. y M. Pianta. (1996). "Measuring technological through patents and innovation surveys". Technovation, 16 (9), pp. 451-468.

Arrow, K. J. (1974). The Limits of Organization. New York-London. W. W. Norton and Company.

Ashton, T. S. (1948). The Industrial Revolution. Oxford: Oxford University Press.

Banco Mundial, Indicadores. "Ciencia y Tecnología". Consultado en www.datos.bancomundial.org/tema/ciencia-y-tecnologia?view=chat. 
Barro, R., y X. Sala-i-Martin, X. (1997). Economic Growth. Cambridge: The MIT Press.

Bass, F. M. (1969). “A New Product Growth for Model Consumer Durables”. Management Science, Vol. 15, No. 5, January, 215-227.

Basberg, B. L. (1987). "Patents and the measurement of technological change: A survey of the literature". Research Policy, 16, pp. 131-141.

Baumol, W. (1986). "Productivity Growth Convergence, and Welfare: What the Long-Run Data Show”. The American Economic Review, vol. 76, número 5, pp. 1072-1085.

Benhabib, J. y M. Spiegel. (1994). "The Role of Human Capital in Economic Development: Evidence from Aggregate Cross-Country Data". Journal of Monetary Economics, 34, pp. 143-173.

. (2005). "Human capital and technology diffusion" en P. Aghion y S. N. Durlauf (editores), Handbook of economic growth. Amsterdam y San Diego: North-Holland/ Elsevier (Handbook economics, 22), pp. 935-966.

Benhabib, J.; Perla, J. y Tonetti, C. (2012). "Catch-Up and fall-back through innovation and imitation”. Cambridge, NBER Working Paper número 18091. [Versión electrónica]. Consultado en http://www.nber.org/papers/w18091 el 18 de febrero de 2013.

Bertalanffy, K. V. (1968). General System Theory. Foundations, development, applications. New York: George Braziller.

Booker, R. E. y Boysen, E. (2005). Nanotechnology for Dummies. New Jersey: Hoboken.

Bramuglia, C. (2000). "La tecnología y la teoría económica de la innovación”. Buenos Aires, Instituto de Investigaciones Gino Germani, Facultad de Ciencias Sociales, Universidad de Buenos Aires, Documento de trabajo número 15. CLACSO.

Calderón-Martínez, G. (2014). "Patentes en Instituciones de Educación Superior en México". Revista de la Educación Superior, vol. XLIII (2), número 170, abril-junio, pp. 37-56.

Calderón, C. y A. Tykhonenko, A. (2006). "La liberalización económica y la convergencia regional en México". Comercio Exterior, Vol. 56, número 5, México, Banco de Comercio Exterior, mayo, pp. 374-381.

Canavos, G. C. (1988). Probabilidad y Estadística. México: McGraw-Hill.

Cano, V. (2008). "Modelos para datos de recuento". Universidad de la Laguna. [Versión electrónica]. Consultado en www.vcano.web.ull.es el 25 de marzo de 2014. 
CEPAL. (2012). Cambio estructural para la igualdad. Una visión integrada del desarrollo. Santiago de Chile: CEPAL.

CIMAV (2008). Diagnóstico y Prospectiva de la Nanotecnología en México. México: FUNTEC y Secretaría de Economía.

Cimoli, M. y G. Porcile. (2014). "Technology, structural change and BOP-constrained growth: a structuralist toolbox". Cambridge Journal of Economics, vol. 38, número 1, pp. 215237.

Comin, D. y B. Hobijn. (2005). "Lobbies and Technology Diffusion". Cambridge, NBER Working Paper Series número 11022. [Versión electronica]. Consultado en http://www.nber.org/papers/w11022 el 18 de enero de 2013.

Comin, D. y M. Mestieri. (2013). "Technology Diffusion: Measurement, Causes and Consequences". [Versión electronica]. Consultado en www.dartmouth.edu el 21 de enero de 2013.

Corona, L. (2010). "Disciplinas y enfoques de la innovación ante la sociedad del conocimiento" en L. Corona, Innovación ante la sociedad del conocimiento. México: UNAM / Plaza y Valdés.

Cranck, J. (1964). The Mathematics of Diffusion. Oxford: Clarendon Press.

Davies, S. (1979). The Diffusion of Process Innovations. Cambridge: Cambridge University Press.

Delgado, G. (2007). "Nanotecnología, paradigma tecnológico de vanguardia". Contribuciones a la Economía, febrero 2007. [Versión electrónica]. Consultado en http://www.eumed.net/cel/ el 26 de julio de 2015.

. (2011). "Nanotecnología, Economía y Sociedad: Retos y Paradigmas desde una perspectiva del caso mexicano". En N. Takeuchi (editor), Nanociencia y nanotecnología. México: UNAM, pp. 221-250.

Derry, T. K. y W. Trevor. (2000). Historia de la tecnología. Vols. 4 y 5. México: Siglo XXI.

Díaz, J.; Sánchez, A. y M. A. Mendoza. (2009). "Convergencia hacia la economía líder en México: un análisis de cointegración con datos de panel”. El Trimestre Económico, vol. 76, pp. 1-25.

Dorogovtsev, S. N. y J. F. F. Mendes. (2002). "Evolution of Networks". Advances in Physics, 51 (4), pp. 1079-1187. 
Dosi G. (1982). "Technological Paradigms and Technological Trajectories: A Suggested Interpretation of the Determinants and Directions of Technical Change". Research Policy, 11, pp. 174-162.

(1984). Technical Change and Industrial Transformation. The Theory and Aplication to the Semiconductor Industry. London: Macmillan Press.

. (1988). "Sources, Procedures and Microeconomic Effects of Innovation". Journal of Economic Literature, Vol. XXVI. Sept., pp. 1120-117.

. (2009). "La interpretación evolucionista de las dinámicas socio-económicas". En Viale, R. (compilador). Las nuevas economías. México: FLACSO, pp. 33-47.

Duguet, E. y M. MacGarvie. (2005). "How Well do Patent Citations Measure Flows of Technology? Evidence from French Innovation Surveys". Economics of Innovation \& New Technology, 14 (5), pp. 375-393.

Fagerberg, J.; Feldman, M. P. y Srholec, M. (2013). "Technological Dynamics and Social Capability: Comparing U.S. States and European Nations". Journal of Economic Geography Advance Access Published, September 2, 2013, pp. 1-25.

Farr, W. (1840). "Progress of epidemics". Second Report of the Registrar General of England and Wales, London, 91-98.

Finardi, U. (2013). "The technological paradigm of Nanosciences and Technologies: a study of science-technology time and space relations". Economía, Teoría y Práctica, número 39, pp. 11-29.

Fischer, M.; Scherngell, T., y E. Jansenberger. (2009). "Geographic localization of knowledge spillovers: evidence from high-tech patent citations in Europe”. December, 2009. Springer-Verlag. 43:839.

Flax, J. (2012). "Patentes: un conflicto entre el derecho a la propiedad y el derecho al conocimiento". En Agora Philosophica. Revista Marplatense de Filosofía, ISSNN18533612. No. 25/26, Vol. XIII.

Freeman, C. (1987). Output measurement in science and technology. Amsterdam: NorthHolland. . (2008). Systems of Innovation. USA: Northampton, MA.

Freeman, C. y F. Louça. (2001). As times goes by. From the Industrial Revolutions to the Information Revolution. Oxford: Oxford University Press. 
Freeman, C. y C. Pérez. (1988). "Structural crises of adjustment: business cycles and investment behavior" en G. Dosi et al. (editores), Technical Change and Economic Theory. London/ New York: Pinter/ Columbia University Press.

García-Colín, L. (2000). De la máquina de vapor al cero absoluto (calor y entropía). México: Fondo de Cultura Económica.

Gay, C. y Bas, C. Le. (2005). "Uses Without too Many Abuses of Patent Citations or the Simple Economics of Patent Citations as a Measure of Value and Flows of Knowledge". Economics of Innovation and New Technology, 14 (5), pp. 333-338.

Gay, C.; Bas, C. Le; Patel, P. y K. Touach. (2005). "The Determinants of Patent Citations: an Empirical Analysis of French and British Patents in the US". Economics of Innovation \& New Technology, 14 (5), pp. 339-350.

Geschenkron, A. (1962). Economic Backwardness in Historical Perspective. A book of Essays. Cambridge: Harvard University Press.

Gibbons, M. y R. Johnston. (1974). "The Roles of Science in Technological Innovation". Research Policy, 1974, Vol. 3, pp. 220-242.

Globerman, S.; Kokko, A. y Sjöholm, F. (2000). "International Technology Diffusion: Evidence from Swedish Patent Data". Kyklos, 53, pp. 17-38.

Griliches, Z. (1957). "Hybrid corn: an exploration in the economics of technological change". Econometrica, No. 25, pp. 501-22.

. (1960). "Hybrid corn and the economics of innovation", Science, New Series, Vol. 132, No. 3422, pp. 275-280.

. (1998). "Patent Statistics as Economic Indicators: A Survey" en Z. Griliches, $R \& D$ and Productivity: The Econometric Evidence. Chicago: University of Chicago Press, pp. 287-343.

Gomulka, S. (1971). "Inventive Activity, Diffusion and Stages of Economic Growth". Skrifter fra Aarhus universitets okonomiske institut nr. 24, Aarhus.

(1990). The theory of technological change and economic growth. London: Routledge.

Guzmán, A. y A. Toledo. (2009). "Las nanotecnologías: un paradigma tecnológico emergente. Dinámica y especialización de la innovación en las nanotecnologías". Razón y Palabra, Vol. 14, número 68, mayo-junio, 2009, pp. 1-32. 
Guzmán, A.; Acatitla, E. y Vázquez, T. (2016). "Propensity toward industry-science links across Mexico's technological sectors: An analysis of patents, 1980-2013". EconoQuantum, vol. 13, núm. 1, pp. 125-157.

Hall, B.; Jaffe, A. B. y M. Trajtenberg. (2001). "The NBER Patent Citations Data File: Lessons, Insights and Methodological Tools". Cambridge, MA. NBER Working Paper 8498.

Harhoff, D.; Scherer, F. M. y Vopel, K. (2003). "Citations, family size, opposition and the value of patent rights". Research Policy, 1596, pp. 1-21.

Hilbert, M. (2008). "El Paradigma digital” en M. Hilbert y O. Cairó (editores), ¿Quo vadis, tecnología de la información y de las comunicaciones? Colombia: CEPAL-Naciones Unidas, pp. 1-56.

(2008). "Trayectorias Tecnológicas de las TIC". En M. Hilbert y O. Cairó (editores), ¿Quo vadis, tecnología de la información y de las comunicaciones? Colombia: CEPAL-Naciones Unidas, pp. 57-114.

Hobsbawm, E. J. (1997). "La Revolución Industrial”. En Industria e Imperio: Una historia económica de Gran Bretaña desde 1750. Capítulo 3. Madrid: Editorial Ariel, pp. 55-76.

Hu, A. G. y A. B. Jafee. (2003). "Patent Citations and International Knowledge flow: the cases of Korea and Taiwan". International Journal of Industrial Organization, número 21, pp. 849-880.

Huang, Z.; Chen, H.; Yip, A.; Ng, G.; Chen, Z. y M. Rocco. (2003), "Longitudinal patent analysis for nanoscale science and engineering: Country, institution, and technology field”. Journal of Nanoparticle Research, número 5, pp. 333-363.

Jaffe, A. y M. Trajtenberg. (1999). "International Knowledge Flows: Evidence from Patent Citations". Economics of Innovation and New Technology, número 8, pp. 105-136.

(1996). "Flows of Knowledge from Universities and Federal Labs: Modelling the Flow of Patent Citations Over Time and Across Institutional and Geographic Boundaries". Cambridge, MA. NBER Working Paper número 5712. Consultar en www.core.ac.uk.

(2002). Patents, Citations and Innovations: A window on the knowledge Economy. Cambridge: MIT Press.

Jaffe, A.; Trajtenberg, M. y R. Henderson. (1993). "Geographic Localization of Knowledge Spillovers as Evidenced by Patent Citations". Quarterly Journal of Economics, 79 (3), pp. 577-598. 
Jasso, J. (2004). "Trayectorias tecnológicas y ciclo de vida de las empresas: una interpretación metodológica acerca del rumbo de la innovación". [Versión electronica]. Consultado en www.ejournal.unam.mx/rca/214/RCA21404.pdf el 16 de febrero de 2013.

Keller, W. (2001). "Knowledge Spillovers at the World's Technology Frontier". CEPR Working Paper 2815. [Versión electronica]. Consultado en http://www.cepr.org/active/publications/discussion_papers/dp.php?dpno=2815 el 2 de marzo de 2013.

Kermack, W. y A. McKendrick. (1927). "Contributions to the mathematical theory of epidemics”. Proc. Roy. Soc., número A 115, pp. 700-721.

Kuhn, T. S. (1962). The Structure of Scientific Revolutions. Chicago: University of Chicago Press.

Langrish, J., et. al. (1972). "Wealth from Knowledge: A Study of Innovation in Industry" en J. Langrish, M. Gibbons, W.G. Evans y F. R. Jevons (cargo).

Lanjouw, J. O. y M. Schankerman. (2000). "Patent Suits: Do They Distort Research Incentives?" Center for Economic Policy Research, London, CEPR Working Papers Series, No. 2042.

. (2004), "Patent Quality and Research Productivity: Measuring innovation with Multiple Indicators". The Economic Journal, 114 (495), pp. 441-465.

Laursen, K. y V. Meliciani. (2002). "The relative importance of international vis-à-vis national technological spillovers for market share dynamics". Industrial and Corporate Change, vol. 11, No. 4, pp. 875-894.

Lundvall, B. (1992). National Systems of Innovation: Towards a theory of innovation and interactive learning. London: Printer.

(2004). "National Innovation Systems-Analytical Concept and Development Tool". Copenague, Dinamarca, Conferencia presentada en DRUID Tenth Anniversary Summer Conference, June, 27-29.

Lundvall, B.; Joseph, K. J.; Chaminade, C. y Vang, J. (2009). Handbook of Innovation Systems and Developing Countries. Massachusetts, USA: Edward Elgar.

MacGarvie, M. (2005). "The Determinants of International Knowledge Diffusion as Measured by Patent Citations". Economics Letters, 87 (1), pp. 121-126.

. (2006). "Do Firms Learn from International Trade?". The Review of Economics and Statistics, 88 (1), pp. 46-60. 
Manca, F. (2009). “Technology Catching-up and the Role of Institutions”. Barcelona: Research Institute of Applied Economics, Working Papper, 2009/12, 40 páginas. Consultar en www.ub.edu.

Mansfield, E. (1961). “Technical change and the rate of imitation”. Econometrica, 29, pp. 741766.

Marco, A. C. (2006). "The dynamics of patent citations". New York: Vassar College Economics, Working Paper, No. 124. Consultar en www.economics.vassar.edu/docs/working-papers/VCEWP84.pdf.

Martínez, A.; García, A. y J. Murguía. (2009). "Trayectoria productiva y tecnológica de General Motors en México: el caso del Complejo de Silao, Guanajuato". Ciencia@UAQ, 2 (2), pp.79-93.

Maurseth, P. B. (2005). "Lovely but Dangerous: the impact of Patent Citations on Patent Renewa". Economics of Innovation \& New Technology, 14 (5), pp. 351-374.

Metcalfe, S. (1995). "The Economic Foundations of Technology Policy: Equilibrium and Evolutionary Perspectives" en P. Stoneman (editor), Handbook of the Economics of Innovation and Technological Change. Cambridge: Blackwell Publishers.

Mijáilov, V. P. (1978). Ecuaciones diferenciales en derivadas parciales. Moscú: Editorial MIR.

Montero, C. M. y M. A. del Río. (2013). "Convergencia en Bolivia: un enfoque especial con datos de panel dinámicos”. Revista de Economía del Rosario, vol. 16, número 2, juliodiciembre, pp. 233-256.

Montobbio, F. y V. Sterzi. (2010). "Inventing together: exploring the nature of international knowledge spillovers in Latin America". CESPRI, Working Paper, No. 225.

Moreno, M. (2009). "Propiedad intellectual y conflict de valores en la sociedad del conocimiento". En Gazeta de Antropología, 2009, No. 25 (1), artículo 30. ISSN 02147564.

Mowery, D. (2011). "Federal Policy and the Development of Semiconductors, Computer Hardware, and Computer Software: A Policy Model for Climate-Change-Change R\&D?" en Henderson, R. y Newell (editores), Accelerating Energy Innovation: Insights from Multiple Sectors. Chicago: University of Chicago Press, pp. 159-88.

Mowery, D. y N. Rosenberg. (1979). "The influence of market demand upon innovation: a critical review of some recent empirical studies". Research Policy, 8, pp. 102-153. (1998). Paths of Innovation. Cambridge: Cambridge University Press. 
Myres, S. y D. G. Marquis. (1969). Successful Industrial Innovation: A study of factors underlying innovation in selected firms, 69-71. National Science Foundation.

Nelson, R. y E. Phelps. (1966). "Investment in Humans, Technological Diffusion, and Economic Growth”. The American Economic Review, vol. 56, número 1/2, pp. 69-75.

Nelson, R. y S. Winter. (1982). An Evolutionary Theory of Economic Change. Cambridge/ London: Harvard University Press.

Nelson, R. (1992). "National Innovation Systems: A Retrospective on a Study". Oxford: Oxford University Press.

Newman, M. (2003). "The Structure and Function of Complex Networks". SIAM, 45 (2), pp. 167-256.

Niosi, J. y S. Reid. (2007). "Biotechnology and Nanotechnology: Science-based Enabling Technologies as Windows of Opportunity for LDCS?”. World Development, 35 (3), pp. 426-438.

OCDE (1992). "Technology and the economy. The Key relationships". The Technology/ Economy Programme (TEP). Traducido del inglés por Raquel Albornoz. Buenos Aires, Argentina: Redes, Vol. III, número 8, diciembre, 1996, pp. 119-161.

OCDE. (2002). "Reviewing the ICT sector definition: Issues for discussion". En Working Party on Indicators for the Information Society. Stockholmo, 25-26, April 2002. DSTI/ICCP/IIS(2002)2. Consultar en www.oecd.org/internet/ieconomy/20627293.pdf.

(2005). Oslo Manual. París: OCDE y Eurostat. Consultar en www.ec.europa.edu/eurostat/documents/3859598/OSLO-EN.PDF.

(2013). "Symposium on Assessing the Economic Impact of Nanotechnology". Synthesis Report. Consultar en www.oecd.org/sti/nano/Washington\%20Symposium\%20Report_final.pdf.

OCDE y OEPM. (2009). Manual de Estadísticas de Patentes de la OCDE. París: OCDE, Ministerio de Industria, Turismo y Comercio, Oficina Española de Patentes y Marcas.

OMPI. Año. ¿Qué es la propiedad intelectual?, número 450 (S).

Patel, P. y K. Pavitt, K. (1994). "National Innovation Systems: Why they are important, and how they might be Measured and Compared". Economics of Innovation and New Technology, 3, pp. 77-95.

Pavitt, K. (1984). "Sectoral patterns of technical change”. Research Policy, 13, pp. 343-373. 
Pérez, C. (1989). "Technical Change, Comparative Restructuring and Institutional Reform in Developing Countries". Washington D. C., World Bank, Discussion Paper número 4.

. (2001). "Cambio tecnológico y oportunidades de desarrollo como blanco móvil". Revista de la CEPAL, número 75, diciembre, pp. 115-136.

XXI.

(2004). Revoluciones tecnológicas y capital financiero. México: Editorial Siglo

(2009). "The doublé bubble at the turn of the century: technological roots and structural implications". Cambridge Journal of Economics, 33, pp. 779-805.

(2010). "Revoluciones tecnológicas y paradigmas tecno-económicos". Del original: "Technological revolutions and techno-economic paradigms". Cambridge Journal of Economics, Vol. 34. No. 1, pp. 185-202.

. (2011). "Finance and Technical Change: A Long-term View" en African Journal of Science, Technology, Innovation and Development. Vol. 3, No. 1, 2011, pp. 10-35.

PNUD. (2010), Informe sobre desarrollo humano 2010. Programa de las Naciones Unidas para el Desarrollo, PNUD. Madrid: Ediciones Mundi-Prensa.

Poole, C. P. y F. J. Owens. (2003), Introduction to Nanotechnology. New Jersey: John Wiley \& Sons.

Prebisch, R. (1949). "El desarrollo económico de América Latina y algunos de sus principales problemas". UN E/CN. 12/89, Rev. 1. Santiago: CEPAL. Consultar en www.prebisch.cepal.org.

Réka, A. y A. Barabási. (2002). "Statistical Mechanics of Complex Networks". Reviews of Modern Physics, 74 (1), pp. 47-97.

Roco, M. C. (2005). "International perspective on government nanotechnology funding in 2005”. Journal of Nanopart Res, 7, pp. 707-712.

Roco, M. C. y W. S. Bainbridge. (2013). "The new world of discovery, invention, and innovation: convergence of knowledge, technology, and society". En Perspectives, J Nanopart Res (2013) 15: 1946.

Rodríguez, D.; Mendoza, M.A., e I. Perrotini. (2015). "Análisis no lineal de la convergencia regional en América Latina, 1950-2010: un modelo panel TAR". Problemas del Desarrollo, 182 (46), julio-septiembre, pp. 119-142.

Romero, M. E.; Los Arcos, E.; Cano, V. y Sánchez, M. (2003). “Análisis de citas de patentes a través de modelos de regresión para datos de recuento". Estadística Española, vol. 45, número 154, pp. 455-478. 
Rogers, M. (2003). Knowledge, Technological Catch-up and Economic Growth. Harris Manchester College, University of Oxford. Edward Elgar.

Salomon, J. J. y Sachs, C. (1996). Una búsqueda incierta. Ciencia, tecnología y desarrollo. Editorial de la Universidad de las Naciones Unidas, Tokio-Nueva York-París. México: Centro de Investigación y Docencia Económicas y Fondo de Cultura Económica,

Schmookler, J. (1952). "The changing efficiency of the American economy, 1869-1938". Review of Economics and Statistics, 34 (3), pp. 214-31.

. (1962). "Economic sources of inventive activity". Journal of Economic History, No. 22, marzo, pp. 1-120.

Schumpeter, J. A. (1939). Business Cycles. A Theoretical Historical, and Statistical of the Capitalist Process. New York/ London: Mc Graw-Hill.

Skiba, Y. N. (2009). Introducción a la dinámica de fluidos. México: UNAM.

Solari, A. y S. Padilla. (2006). “Trayectorias Tecnológicas y Análisis Local”. Economía y Sociedad, vol. XI, número 17, enero-junio, pp. 33-50.

Spolaore, E. y R. Wacziarg. (2011). "Long-Term Barriers to the International Diffusion of Innovations". NBER International Seminar on Macroeconomics 2011, edited by Jeffrey Frankel and Christopher Pissarides, 11-46. Chicago and London: University of Chicago Press. Consultar en www.anderson.ucla.edu/faculty_pages/romain.wacziarg/downloats/adoption.pdf.

Thompson, P. (2006). "Patent Citations and the Geography of Knowledge Spillovers: Evidence from Inventor and Examiner added Citations". The Review of Economics and Statistics, 88 (2), pp. 383-388.

Takeuchi, N. (2011). Nanociencia y nanotecnología. México: Fondo de Cultura Económica.

Takeuchi, N.; Falkenberg, G. y Johnson, R. L. (2001). "Scanning Tunneling Microscopy and ab initio Calculations: c (4x8) Reconstructions of $\mathrm{Pb}$ on $\mathrm{Si}$ and Ge (001)". Physical Review B, vol. 64 .

Taniguchi, N. (1974). "On the Basic Concept of 'Nano-Technology"'. Proc. Intl. Conf. Prod. Eng. Tokyo, Part II, Japan Society of Precision Engineering. Consultar en www.who.int.

Tong, X. y J. D. Frame. (1992). "Measuring National Technological Performance with Patent Claims Data". Research Policy, 23, pp. 19-50.

Trajtenberg, M.; Jaffe, A. y R. Henderson. (1997). "University versus Corporate Patents: A Window of the Basicness of invention". Economics of Innovation \& New Technology, 5 (1), pp. 19-50. 
Trajtenberg, M.; Shiff, G. y R. Melamed. (2006). "The 'Names Game'. Harnessing Inventors: Patent data for economic research". Cambridge, MA: NBER Working paper, número 12479. Consultar en www.primage.tau.ac.il/libraries/brender/booksf/2086129.pdf.

Tutor, J. D. y Serena, P. A. (2011). "La divulgación y la formación de la nanociencia y la nanotecnología en España: un largo camino por delante". Mundo Nano, vol. 4, número 2, pp. 48-58.

Vence, X. (1995). Economía de la innovación y del cambio tecnológico. Madrid: Siglo XXI.

Verspagen, B. (2000). "The Role of Large Multinationals in the Dutch Technology Infrastructure. A patent Citation Analysis”. Scientometrics, 47 (2), pp. 427-448.

Viso, E. (2008). Introducción a la teoría de la computación. México: UNAM.

World Economic Forum (2001). The Global Competitiveness Report 2001-2002. Switzerland, 2001.

Weissmann, V. (2008). “Difusión de nuevas tecnologías y estimación de la demanda de nuevos productos: un análisis comparativo entre Argentina y EE.UU.”. Palermo Business Review, número 1, pp. 5-18. 